\title{
A Theory of Atmospheric Oxygen
}

\section{Citation}

Laakso, Thomas. 2015. A Theory of Atmospheric Oxygen. Doctoral dissertation, Harvard University, Graduate School of Arts \& Sciences.

\section{Permanent link}

http://nrs.harvard.edu/urn-3:HUL.InstRepos:17467352

\section{Terms of Use}

This article was downloaded from Harvard University's DASH repository, and is made available under the terms and conditions applicable to Other Posted Material, as set forth at http:// nrs.harvard.edu/urn-3:HUL.InstRepos:dash.current.terms-of-use\#LAA

\section{Share Your Story}

The Harvard community has made this article openly available.

Please share how this access benefits you. Submit a story.

Accessibility 


\title{
A Theory of Atmospheric Oxygen
}

\author{
A dissertation presented
}

by

Thomas Andrew Laakso

to

The Department of Earth and Planetary Sciences

in partial fulfillment of the requirements

for the degree of

Doctor of Philosophy

in the subject of

Earth and Planetary Sciences

Harvard University

Cambridge, Massachusetts

April, 2015 
(c) 2015 Thomas Andrew Laakso All rights reserved. 


\title{
A Theory of Atmospheric Oxygen
}

\begin{abstract}
There is no direct geologic record of the level of free oxygen in the atmosphere over Earth history. Indirect proxy records have led to a canonical view of atmospheric $\mathrm{pO}_{2}$, according to which the atmosphere has passed through three stages. During the first of these periods, corresponding roughly to the Archean eon, $\mathrm{pO}_{2}$ was less than $0.001 \%$ present atmospheric levels (PAL). Oxygen levels rose abruptly around 2.4 billion years ago, a transition referred to as the "Great Oxidation Event" (GOE). This event marks the beginning of the second phase in the history of oxygen, corresponding roughly to the Proterozoic eon, during which $\mathrm{pO}_{2}$ was in the range of $1 \%$ to $10 \%$ PAL. Between the latest Neoproterozoic and the early Phanerozoic eon, oxygen rose again, beginning the final stage in the history of oxygen, characterized by essentially modern levels of $\mathrm{pO}_{2}$.
\end{abstract}

The processes governing this evolution of the atmosphere are poorly understood. The biogeochemical cycles of redox-sensitive species in the ocean and atmosphere, including oxygen, carbon, iron, and sulfur, must somehow stabilize $\mathrm{pO}_{2}$ on billion-year time scales, much longer than the residence time of the individual species, and yet also allow $\mathrm{pO}_{2}$ to achieve equilibrium at widely divergent levels at different points in time. Only with a clear understanding of these steady-state processes can we understand how $\mathrm{pO}_{2}$ will respond to the changes in biogeochemical cycling that may have driven the two major oxidation events.

In this thesis we use a model of biogeochemical cycling and laboratory experiments to ex- 
plore the processes that stabilize $\mathrm{pO}_{2}$ at different levels over Earth history. We find that a suite of negative feedbacks, including the oxygen-sensitivity of organic carbon burial, allow the stability of oxygen at modern levels. These feedbacks leave $\mathrm{pO}_{2}$ very insensitive to most aspects of the biogeochemical system, such that stable, Proterozoic levels of $\mathrm{pO}_{2}$ can only be explained by a smaller supply of phosphorus to the biosphere at that time. Experimental results show that inorganic scavenging processes, which compete with biology for phosphorus, may be more effective in low-oxygen environments due to differences in iron-redox cycling.

We explore redox dynamics in the Archean by coupling our biogeochemical model to a hydrogen escape calculation that incorporates the effects of changing oxygen levels on thermosphere composition and temperature. We find that the Archean was characterized by several different steady states of oxygen, each corresponding to a different stage in the evolution of life. Furthermore, interactions between the cycles of carbon, oxygen, iron and calcium give rise to a previously unrecognized positive feedback. Our model results show that this feedback allows Archean $\mathrm{pO}_{2}$ to increase rapidly to a new steady state at Proterozoic levels, given a large enough perturbation. The high levels of atmospheric carbon dioxide following a Snowball Earth glacial event do act as such a trigger in our simulations, providing a hypothesis for the apparent synchronicity between the GOE and the Paleoproterozoic Snowball glacials. 


\section{Contents}

1 Introduction 1

2 Regulation of atmospheric oxygen during the Proterozoic

3 Atmospheric oxygen as a constraint on Proterozoic carbon isotope systematics 


\section{Acknowledgments}

To begin, I would like to thank my advisor, Dan Schrag. There is no doubt that this work could not have happened without his scientific insight. I thank him not only for teaching me carbonate chemistry and isotope systematics, but also for teaching me how to distill simplicity from complexity. His particular brand of guidance and patience have driven me to think and inquire, rather than frittering away the days in trivial troubleshooting and mechanical mathematics.

I'd also like to thank all the members of my qualifying and dissertation committees - Jim Anderson, Eli Tziperman, Dave Johnston, Andy Knoll, and Dimitar Sasselov. In particular, thanks to Andy Knoll for generously introducing me to a larger world of paleontology and geology. I thank Dimitar Sasselov for his assistance with the intricacies of hydrogen escape; and Dave Johnston for many helpful conversations, for use of his laboratory, and for patience during my education in experiment. I am also indebted to Greg Eischeid, Erin Beirne, and Andy Masterson for their help in the lab, and to JC Creveling for instructing me in phosphorus and iron speciation methods.

Many other students have contributed to my education (and my enjoyment of graduate school). I of course thank my fellow residents in the Geochemical Oceanography lab over the years - Kurt House, John Higgins, Julie Shoemaker, Itay Halevy, Kate Dennis, Sierra Peterson, Katie Dagon and Lauren Kuntz - as co-workers and comrades. All the students of the EPS department contribute to the greater society I've enjoyed over my $\mathrm{PhD}$. In the interest of brevity I can mention only a few; thanks to Wil Leavitt, Ethan Butler, Andy Rhines, Kristian Bergen, Erik Chan and Ben Kotrc for scientific insight and a sauna or two. 
Beyond the boundaries of the department, I would like to thank the Legends for keeping me on my toes; Philip Kreycik for many good miles; the White Horses for great Wednesdays; the Chiefs for wisdom; and the Original Four for friendship.

Ten thousand thanks to my family, in its entirety. Summer days at Vinton are an inspiration for working in the earth sciences, and also a source of serenity. Thanks to my mother and father for their support, care, and interest in my work over the years, even when I traded phone calls for late night programming sessions a few times. And thanks too for inspiring me to work unpretentiously and conscientiously with others in mind.

Finally, thank you to my wife, Alex. You've done so much for me since we came to Cambridge; sacrificed, supported, and frankly just made me happy. The course of this dissertation has followed the course of our romance: we met the month I applied to graduate school, and celebrated our first wedding anniversary in the week between my private and public defenses. I am tremendously happy that these two threads have separated: the $\mathrm{PhD}$ draws to a close, but our time together shows stretches ahead. Much love. 


\section{Chapter 1}

\section{Introduction}

The level of free oxygen in the atmosphere has varied greatly over Earth history. Though no direct record of atmospheric $\mathrm{pO}_{2}$ exists in the geologic record, a large array of proxy data has led to a canonical history for $\mathrm{pO}_{2}$ which is divided into three stages. The most recent corresponds roughly to the Phanerozoic eon (540 Ma to present), and is characterized by essentially modern levels of $\mathrm{pO}_{2}$. The second stage reaches from $2400 \mathrm{Ma}$ to the beginning of the Phanerozoic, and is approximately equivalent to the Proterozoic eon. Oxygen in this stage is thought to have been between $1 \%$ and $10 \%$ of present atmospheric levels (PAL), though the bounds on this stage are weak. The third stage ends at $2400 \mathrm{Ma}$; it has no firm starting date, but begins before the origin of life. $\mathrm{pO}_{2}$ in this earliest period was less than $10^{-5}$ PAL.

The bounds on Phanerozoic $\mathrm{pO}_{2}$ are derived from the existence of a continous charcoal record since the Silurian (Scott \& Glasspool 2006), which is interpreted to represent wild-

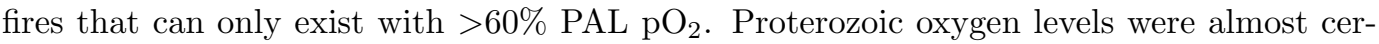
tainly lower than in the Phanerozoic, given systematic differences in many redox-sensitive elements and isotope systems on either side of the Precambrian boundary, including iron speciation (Poulton \& Canfield 2011), $\delta^{34}$ S (Canfield \& Teske 1996), and sediment molybdenum content (Scott et al. 2008). Quantitative bounds have been difficult to derive, but models of iron cycling in paleosols (Rye \& Holland 1998) and pyrite and uraninite oxidation rates (Johnson et al. 2014a) point to a loose range of $1 \%$ to $10 \%$ PAL, with a hard lower bound of $0.001 \%$ PAL derived from modeling of mass independent fractionation (MIF) in 
sulfur isotopes (Pavlov \& Kasting 2002). The disappearance of the sulfur MIF record after $2.4 \mathrm{Ga}$ represents the onset of oxidative sulfur cycling rapid enough to homogenize the mass-independent isotopic signals generated during photolysis of S-bearing compounds in the atmosphere (Farquhar et al. 2000, 2001). The threshold at which this occurs, $0.001 \%$ PAL, therefore also serves as the upper bound on oxygen during the Archean.

This simple picture of three plateaus in atmospheric $\mathrm{pO}_{2}$ has become more complicated with the recent development of many qualitative trace-metal redox proxies (see Lyons et al. 2014 for a summary). This data has led to debate over whether $\mathrm{pO}_{2}$ began rising or oscillating toward higher values in the hundred million years leading up to the Great Oxidation Event (Anbar et al. 2007), and whether oxygen fell transiently back to Archean levels after the GOE (Partin et al. 2013). Nevertheless, it remains true that most redox proxies show distinctly different behavior in the Archean, Proterozoic, and Phanerozoic eons, on time scales far longer than the residence time of any redox-sensitive species. This suggests that the canonical view of $\mathrm{pO}_{2}$, with three approximate steady state conditions, is fundamentally correct.

Major questions remain regarding even this simplest view of atmospheric $\mathrm{pO}_{2}$. Thes include understanding what processes set the value of $\mathrm{pO}_{2}$ during each period, how oxygen is stabilized at those values, and what drives the rapid transitions between those stable conditions.

The source of oxygen is burial of organic carbon (roughly $\mathrm{CH}_{2} \mathrm{O}$ ) produced during photosynthesis:

$$
\mathrm{H}_{2} \mathrm{O}+\mathrm{CO}_{2} \rightarrow \mathrm{CH}_{2} \mathrm{O}+\mathrm{O}_{2}
$$


but the actual stable level of $\mathrm{pO}_{2}$ in the atmosphere results from balancing this source against a myriad of sinks, which include reaction with pyrite and organic carbon on the continents, oxidation of oceanic crust, and reaction with reducing fluids released from the mantle by hydrothermal systems and volcanoes. Stability at this levels requires negative feedbacks, by which a change in $\mathrm{pO}_{2}$ drives a compensating change in either its source or its sink. Dynamical models of biogeochemical cycling in the present-day suggest that several negative feedbacks work to maintain oxygen at its modern level. These include the oxygen-dependence of organic carbon burial efficiency (Kump \& Garrells 1986, Berner \& Canfield 1989, Lasaga \& Ohmoto 2002, Bergman et al. 2004), and oxygen-dependent rates of organic carbon weathering (Chang \& Berner 1999). Other models have explored the stability of oxygen at very low levels, maintained by oxygen-dependent reaction rates with either the crust or volcanic gases (Goldblatt et al. 2006, Claire et al. 2006). However, no model has shown how these stabilization processes allow $\mathrm{pO}_{2}$ to be stable at two or three different levels, as required by the proxy record.

Many theories exist to explain the large changes in $\mathrm{pO}_{2}$ during the Great Oxidation Event and at the end of the Proterzoic. Though some of these theories have been tested in dynamical biogeochemistry models, none has been examined in the context of all the negative feedbacks believed to be important over Earth history.

The goal of the work presented here is to establish a coherent dynamical model of oxygen cycling in the ocean and atmosphere. Such a model can be used to examine, in a consistent manner over geolgic history, what processes set the value of $\mathrm{pO}_{2}$ at a given moment, and how that level is stabilized for hundreds of millions of years. Only in the context of a dynamical theory for $\mathrm{pO}_{2}$ is it possible to rigorously test theories for the oxidation events. These must explain both how two different equilibrium $\mathrm{pO}_{2}$ values can exist on relatively 
short time scales, and how the atmosphere moves between these states despite the existence of stabilizing feedbacks.

Chapter 2 describes a steady-state model of biogeochemical cycling in the Phanerozoic ocean and atmosphere. Due to the negative feedbacks that make the modern atmosphere stable, this model is not able to maintain $\mathrm{pO}_{2}$ at levels less than $50 \%$ PAL. This is problematic, given that the proxy record suggests that $\mathrm{pO}_{2}$ was $\sim 1 \%$ PAL for 2 billion years of Proterozoic time. Sensitivity tests demonstrate that phosphrous, as the globally limiting nutrient on long times scales (Tyrrell 1999), sets a lower bound on organic carbon burial. A minimum burial rates prevents $\mathrm{pO}_{2}$ from falling by orders of magnitude, even if other aspects of the surface redox cycle are greatly changed. Therefore, the only physically plausible explanation for Proterozoic $\mathrm{pO}_{2}$ is a large reduction in the supply of phosphorus to the biosphere under low oxygen conditions.

An oxygen-sensitive phosphorus supply could be explained by the adsorption of $\mathrm{P}$ onto iron oxide particles. Adsorbed P is not accessible to organisms, i.e. it is not "bioavailable". This process is known to be less effective when a mature crystalline oxide interacts with dissolved $\mathrm{P}$; additional adsorption occurs when the iron is oxidized in solution with phosphate (Mayer \& Jarrell 2000). Today, iron is oxidized almost instantly after dissolution of the parent mineral. However, in a low-oxygen environment, soluble reduced iron is flushed into river systems (Holland 1984), where it can oxidize gradually, resulting in more efficient immobilization of phosphorus. Atmospheric $\mathrm{pO}_{2}$ is stable at both Phanerozoic and Proterozoic levels of $\mathrm{pO}_{2}$ when an oxygen-sensitive flux of bioavailable $\mathrm{P}$ is included in the model. This result depends on the functional form of the $\mathrm{O}_{2}-\mathrm{P}$ relationship, providing specific constraints on any hypothetical mechanism. 
Chapter 3 explores the consequences of a Proterozoic ocean characterized by low bioavailability of phosphorus. Such an ocean must have very low primary production and organic carbon burial. This contradicts the traditional reading of the carbon isotope record, which calls on constant or even rising levels of organic burial back through time. This paradox can be resolved by calling on additional pathways of carbon burial, such as authigenic calcite precipitation (Schrag et al. 2013). Simple constraints on the size of this flux can be found by simultaneously reproducing the $\mathrm{pO}_{2}$ and $\delta^{13} \mathrm{C}$ records in the biogeochemical model, modified to include carbon isotope systemtics. These results predict abundances and isotopic compositions for authigenic carbonate during the Proterozoic and Phanerozoic.

Chapter 4 presents experimental results demonstrating how phosphorus adsorption depends on the redox state of iron introduced to solution. Scavenging is found to be most effective when the iron is initially present in its reduced or ferrous form, $\mathrm{Fe}^{2+}$, similar to the results of Mayer \& Jarrell (2000). Further experiments describe how phosphate adsorption varies continuously with the average redox state of the bulk iron introduced to solution. This data is applied to two very simple models of riverine $\mathrm{P}$ under different redox conditions. These calculations are not conclusive, but are consistent with the possibility of a large change in bioavailability given modest changes in iron delivery. This work highlights a number of further experiments which could be used to further explore the $\mathrm{O}_{2}-\mathrm{P}$ feedback proposed in Chapter 2.

Moving further back in time, Chapter 5 presents a calculation of hydrogen escape rates relevant to the Archean. Hydrogen escape, though slow today (Hunten et al. 1973), may have been an important part of the surface redox budget in the past, when low oxygen and rapid outgassing could have led to very high levels of hydrogen-bearing reductants in the atmosphere (e.g., Kasting 1993). However, existing models of the Archean atmosphere have 
typically used an escape parameterization based on the maximum possible rate of escape (e.g. Catling et al. 2001). Other authors (Tian et al. 2005) have pointed out that this may be an overestimate, given inefficient escape from a cold, low-oxygen thermosphere. In order to properly represent escape rates in the biogeochemical model, this chapter presents a detailed escape calculation, driven by temperatures derived from an energy balance model that includes both heating (UV absorption) and cooling (stimulation of the $\mathrm{CO}_{2} 15 \mu \mathrm{m}$ band) effects related to oxygen.

Chapter 6 examines how $\mathrm{pO}_{2}$ evolved over the course of the Archean, using an updated form of the biogeochemical model that includes the hydrogen escape calculations. $\mathrm{pO}_{2}$ and $\mathrm{pH}_{2}$ are found to have taken several equilibrium levels as new metabolisms evolved, passing from a hydrogen-rich prebiotic atmosphere to a low-hydrogen, low-oxygen atmosphere after the appearance of autotrophy. Finally, there is a transition to a more oxygenated state after the evolution of oxygenic photosynthesis, though this stable "oxygenated" level can be well below $10^{-5} \mathrm{PAL}$. Low $\mathrm{pO}_{2}$ is maintained by suppression of the bioavailable phosphorus flux, and by large fluxes of reducing gases from the mantle (Claire et al. 2006). Therefore, the evolution of oxygenic photosynthesis need not lead to an immediate GOE.

A novel feedback in the oxygen system is also described in Chapter 6 . Increases in oxygen will suppress ferrous iron concentrations in the ocean, particularly if the system is initially very reducing. The removal of iron represents a loss of alkalinity, which will drive down calcite and siderite precipitation. Loss of these carbon sinks results in rising $\mathrm{pCO}_{2}$. Temperatures will also rise until silicate weathering becomes fast enough to restore alkalinity levels, via the silicate weathering "thermostat" described by Walker et al. (1981) and Berner et al. (1983). However, the accelerated weathering also releases more apatitic phosphorus, leading to increased organic carbon burial and oxygen production, closing a positive feedback loop. 
This feedback results in multiple equilibria in the oxygen model, at levels corresponding to Archean and Proterozoic $\mathrm{pO}_{2}$.

The existence of multiple equilibria allows a new theory for the Great Oxidation Event. Under this hypothesis, the atmosphere is stable at less than $10^{-5}$ in the late Archean, as demonstrated by the model. A large pertubation in $\mathrm{CO}_{2}$ leads to a burst of apatite weathering and a transient rise in $\mathrm{pO}_{2}$. The alkalinty feedback leads to further oxygen production, ultimately stabilizing the atmosphere at its high oxygen state, $10^{-3}-10^{-2} \mathrm{PAL}$. This hypothesis allows the GOE to be triggered by the high $\mathrm{pCO}_{2}$ levels following one of the Paleoproterozoic Snowball Earth events, explaining their apparent synchronicity (Hoffman 2013). An explicit simulation of this event is provided in Chapter 6 .

Together, this work constitutes progress toward a coherent theory of atmospheric oxygen over the Archean, Proterozoic and Phanerozoic. The modeling results presented here can explain stable oxygen levels at many different values, with specific predictions for the geological record. The model will be valuable in future studies: of the trigger for the late Proterozoic oxidation event; of an MIF-record of the evolution of life and oxygenic photosynthesis; and of biological signatures in exoplanet atmospheres. 
Chapter 2 - Proterozoic / Phanerozoic dynamics

\title{
Chapter 2
}

\section{Regulation of Atmospheric Oxygen During the Proterozoic}

\begin{abstract}
Many studies suggest that oxygen has remained near modern levels throughout the Phanerozoic, but was much less abundant from the Great Oxygenation Event around 2.4 Ga until the late Neoproterozoic around 600 Ma (Kump 2008). Using a simple model, we show that the maintenance of atmospheric $p \mathrm{O}_{2}$ at $\sim 1 \%$ of present atmospheric levels (PAL) is inconsistent with modern biogeochemical cycling of carbon, sulfur and iron unless new feedbacks are included. Low oxygen conditions are stable in our model if the flux of phosphorus to the oceans was greatly reduced during the Proterozoic. We propose a mechanism to reduce this flux through the scavenging of phosphate ions with an iron trap driven by greater surface mobility of ferrous iron in a low $p \mathrm{O}_{2}$ world. Incorporating this feedback leads to two stable equilibria for atmospheric oxygen, the first quantitative hypothesis to explain both Proterozoic and Phanerozoic O2 concentrations.
\end{abstract}


Chapter 2 - Proterozoic / Phanerozoic dynamics

\subsection{Introduction}

Atmospheric oxygen has passed through three broad plateaus in earth history (Kump 2008). Mass-independent sulfur isotopes show that it was negligibly low during the Archean, rising abruptly around 2.4 Ga (Pavlov and Kasting 2000). Paleosols (Rye \& Holland 1998), pyrite and uraninite grains (Holland 1984), sulfur isotopes (Canfield and Teske 1996), and widespread ferrous and euxinic basins (Poulton and Canfield 2011) point to a moderately oxygenated Proterozoic, likely 1-10\% PAL (Kump 2008). Though $p \mathrm{O}_{2}$ may have varied between these bounds through the Proterozoic, the appearance of large multicellular animals and large colonial algae supports a second rise in O2 near the end of the Neoproterozoic (Anbar \& Knoll 2002), and the charcoal record requires at least 60\% PAL since the Silurian (Scott \& Glasspool 2006). The two major oxidation events may have been complex oscillations in $p \mathrm{O}_{2}$ (e.g. Anbar et al. 2007, Dahl et al. 2010), but the associated changes in the proxy record are abrupt compared to the length of the intervening periods. At hundreds of millions of years, this stability time scale is much greater than the residence times of redox-sensitive species, so the oxygen system must have been in several different steady states over geological history.

Much research has been devoted to the Great Oxidation Event of $2.4 \mathrm{Ga}$ and the second oxidation in the terminal Proterozoic. These events have been attributed to any number of drivers. For the late Archean, these include abrupt overturning of a redox-stratified mantle (Kump et al. 2001), rapid hydrogen escape (Catling et al. 2001), or a change from more reducing submarine volcanism to more oxidized subaerial outgassing (Kump \& Barley 2007); for the late Proterozoic, the evolution of biological ballast (Logan et al. 1995), more active clay formation (Kennedy et al. 2006), or a perturbation related to the Snowball glaciation (Hoffman \& Schrag 2002). 
Chapter 2 - Proterozoic / Phanerozoic dynamics

Unfortunately, it is difficult to evaluate these hypotheses given our incomplete understanding of redox dynamics. The result of a perturbation or a change in geochemical cycling is only meaningful in the context of a dynamical system, which dictates the steady state values of $p \mathrm{O}_{2}$ and the feedbacks that maintain them. To understand the oxygenation events and any transient oscillations, it is therefore necessary to understand the mechanisms underlying the long periods of stability in the Archean, Proterozoic and Phanerozoic. Goldblatt et al. (2006), for example, have suggested a model for bistability around the Great Oxidation Event, based on Archean photochemistry. In this study we use a simple model of oceanatmosphere electron cycling to explore the feedbacks that can produce a two-state redox system corresponding to the Proterozoic and Phanerozoic.

Previous work on redox dynamics has mostly focused on the stability of the Phanerozoic atmosphere. Some models for past $\mathrm{O}_{2}$ levels avoid the need for explicit feedbacks by using constraints from carbon isotope variations in marine carbonate, assumed to represent fluctuations in the burial of organic carbon relative to calcium carbonate (Berner 2006). Other studies have explored the dynamical stability of the Phanerozoic using different negative feedbacks, particularly an oxygen-dependent weathering rate for reduced minerals (Kump \& Garrels 1986, Berner \& Canfield 1989, Lasaga \& Ohmoto 2002, Bergman et al 2004). Oxygen-dependent burial efficiencies for organic carbon and sulfide have also been proposed (Kump \& Garrels 1986, Berner \& Canfield 1989, Lasaga \& Ohmoto 2002). One study has investigated the stability of low-oxygen Proterozoic conditions (Fennel et al. 2005), but their model explicitly excluded the negative feedbacks known from the Phanerozoic work.

The series of feedbacks referenced above, when taken together, make it impossible to maintain very low $p \mathrm{O}_{2}$, as low $\mathrm{O}_{2}$ leads to higher organic carbon burial and the inevitable build-up 
Chapter 2 - Proterozoic / Phanerozoic dynamics

of oxygen. Stabilizing $\mathrm{O}_{2}$ at both high Phanerozoic levels and low Proterozoic levels requires either a slowly evolving external forcing, or a new feedback, previously undescribed. Rather than proposing a particular hypothesis, we build a model tuned to present-day conditions, and explore the sensitivity of its stable $p \mathrm{O}_{2}$ level to different changes in the model parameters. By identifying those changes that can produce stable, Proterozoic-like conditions, we aim to narrow the list of geochemical processes that might host the forcing or feedbacks that allow for a two-state system.

\subsection{Model}

Our model couples the carbon, iron and sulfur cycles through first-order chemical reactions in a two-layer, phosphorus-limited (Tyrrell 1999) ocean. The time-dependent equations are given Table 2.1, and the flux parameterizations discussed below are summarized in Table 2.2. Values used for the modern run of the model are given in Table 2.3 (rate constants), Table 2.4 (reservoir sizes, hydrothermal / weathering fluxes) and Table 2.5 (other parameters).

The Phanerozoic equilibrium model is shown in Figure 1. This state was tuned to reproduce major electron fluxes, resulting in equilibrium $p \mathrm{O}_{2}$ at 1.1 PAL. The Proterozoic simulation is shown in Figure 2. It is defined by a 5 -fold reduction in both terms in the riverine phosphorus flux ( $W_{p}$, Table 3 ), and no sulfate weathering, though total sulfur weathering is held fixed (i.e., $W_{S}=0, W_{p y r}=3.7$, compare with Table 5). Solar luminosity is set to $90 \%$ of modern, corresponding to $1.3 \mathrm{Ga}$ (Gough 1981). The mean surface temperature at 280 ppm $\mathrm{pCO}_{2}$ is therefore adjusted to $\left(0.91^{1 / 4}\right) * 288 \mathrm{~K}$, based on rudimentary energy balance. 


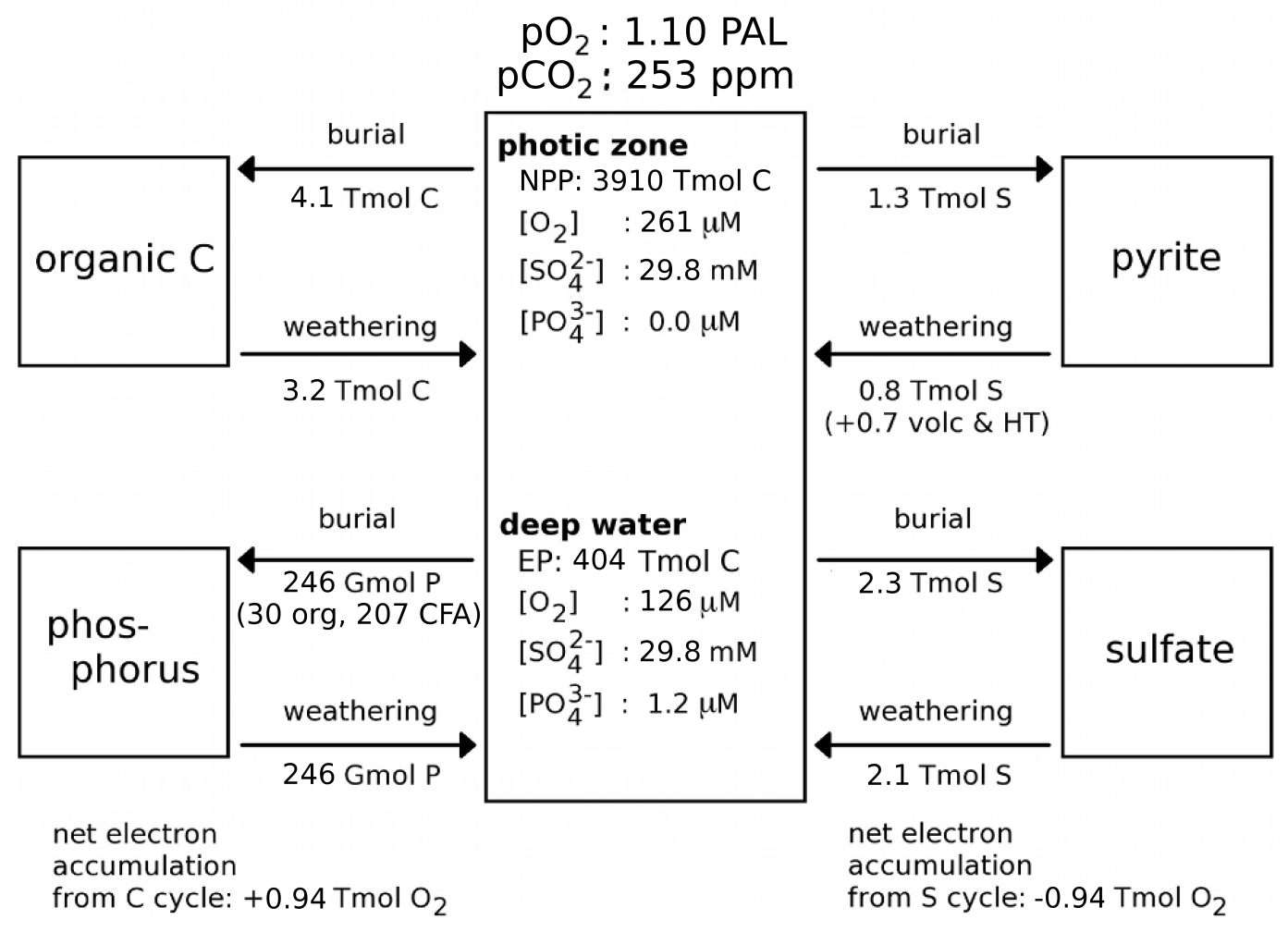

Figure 2.1: Phanerozoic simulation. Steady state reservoirs and fluxes for the modern run of the model.

\subsubsection{Primary Production and Export}

Primary production (NPP) and all subsequent organic cycling occurs at a fixed C:P Redfield ratio $(r)$ of 106:1. Production proceeds to quantitative uptake (Sarmiento \& Gruber 2006) of phosphorus in the upper ocean layer during each time step. Production remaining after respiration, adsorption, and burial in shallow water sediments is exported to deep waters (EP). 


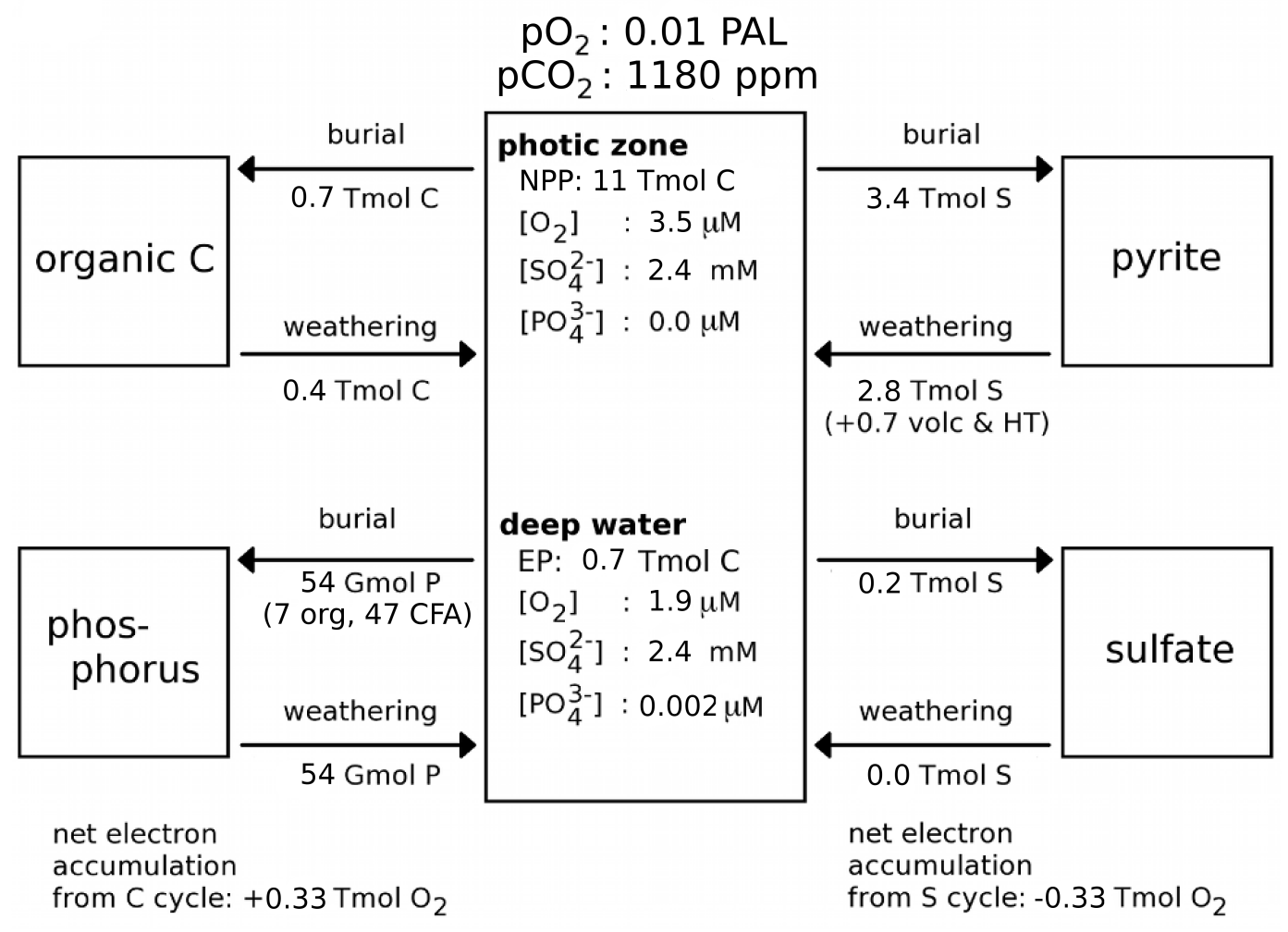

Figure 2.2: Proterozoic simulation. Steady state reservoirs and fluxes for the Proterozoic run of the model, with 5-fold reduction in the riverine phosphorus flux, 1.3 Ga solar luminosity, and no evaporite weathering.

\subsubsection{Water-column remineralization}

Remineralization in the water column is modeled as oxic respiration $\left(R_{w c}\right)$ in the presence of oxygen, and sulfate reduction $\left(S_{w c}\right)$ otherwise. Sulfate reduction rates are observed to follow Michaelis-Menten kinetics (e.g. Ingvorsen et al. 1984); our model uses a linear approximation. This results in a mineralization rate that is somewhat over-sensitive to sulfate levels above the Michaelis constant of $\sim 200 \mu \mathrm{M} \mathrm{SO}_{4}^{2-}$ (Ingvorsen et al. 1984), though linearized behavior is a good approximation far from this value. We repeated our analysis 
Chapter 2 - Proterozoic / Phanerozoic dynamics

using a Michaelis-Menten parameterization, and the basic results are not affected. Both modes of respiration are therefore modeled as linear in the concentration of the appropriate electron acceptor, $\left[\mathrm{O}_{2}\right]$ or $\left[\mathrm{SO}_{4}^{2-}\right]$, and in $\left[\mathrm{C}_{\text {org }}\right]$.

\subsubsection{Organic Carbon Deposition}

Organic carbon is deposited on the seafloor by two processes: ballasting (Armstrong et al. $2002)$ and unassisted sinking. The ballasted flux $\left(B_{a}\right)$ is proportional to bulk sediment delivery $\left(W_{a}\right)$ assuming a monolayer organic coat (Hedges \& Keil 1995), and to the availability of fresh organic material, represented by NPP. Organic ballast may be inappropriate for modeling the Proterozoic (Logan et al. 1995); sensitivity to this term is explored in Section 2.4.3.1. Unballasted sinking $\left(B_{C}\right)$ is proportional to the unadsorbed, unrespired organic carbon concentration. This burial also scales with riverine nutrient inputs, such that when river delivery accounts for a larger fraction of new production, deposition under shallow waters increases at the expense of export. Details are given in Tables 2 and S1.

\subsubsection{Sedimentary Remineralization}

Remineralization of organic carbon in the sediment includes oxic respiration $\left(R_{s d}\right)$ and sulfate reduction $\left(S_{s d}\right)$. Both processes are modeled as first order with oxidant concentration in the overlying water. The existence of such an oxygen effect has been controversial (Cowie et al. 1995, Hedges et al. 1999); detailed analysis of this parameterization is presented below.

The rate constant for sulfate reduction is modulated by a factor $\beta$, which scales linearly with the "lability" of carbon reaching the sulfate reduction zone, defined here as $\left(R_{s d}+\right.$ $\left.R_{w c}+S_{w c}\right) / N P P$. This increases the reduction rate when sulfate reducers have access to less degraded organic matter (Westrich \& Berner 1984). 
Chapter 2 - Proterozoic / Phanerozoic dynamics

\subsubsection{Remineralization by Other Electron Acceptors}

Other electron acceptors are not included in the model as they are quantitatively much less important than oxygen and sulfur. Denitrification today is only a few percent of $\mathrm{O}_{2}$ consumption (Canfield 1993, DeVries 2012). Iron and manganese are the dominant electron acceptors in some sedimentary environments, but in these cases the flux of metals to the sediment is an order of magnitude smaller than the reduction of those metals, requiring continuous reoxidation by more abundant species such as oxygen and sulfate (e.g. Wang \& Van Cappellen 1996). Globally, the modern fluxes of sulfate and highly reactive iron to the oceans are $\sim 4 \mathrm{Tmol} \mathrm{yr}^{-1}$ (Elderfield \& Schultz 1996, Poulton \& Raiswell 2002), meaning sulfate can potentially oxidize eight times more organic carbon than iron. Even total titration of sulfur as $\mathrm{FeS}_{2}$ in an anoxic ocean (Poulton \& Canfield 2011) requires only one electron out of every fifteen to be donated to iron.

Methanogenesis remineralizes about ten times less carbon globally than does sulfate reduction (Canfield 1993). Some have argued methanogenesis is more important in the absence of other electron acceptors (Wang \& Van Cappellen 1996), an idea that has been invoked to model the Archean with burial efficiencies identical to today (Habicht et al. 2002). However, in Black Sea sediment cores only $0.3 \%$ of NPP is degraded via methanogenesis, compared to $4 \%$ via sulfate reduction (Jorgensen et al. 2001, Arthur et al. 1994), a ratio typical of oxic marine sediments despite burial efficiencies far above the global average (Arthur et al. 1994 Muller-Karger 2005). In the sulfate-limited sediments of Cape Lookout Bight, methanogenesis accounts for a larger portion of anaerobic metabolism (Capone \& Kiene 1984), but still degrades less than ten percent of organic carbon reaching the sediment (Martens \& Klump 1988). At these scales, methanogenesis is negligible: our results are not affected if we include methane formation at a constant $1.3 \mathrm{Tmol} \mathrm{C} \mathrm{yr}^{-1}, 10 \%$ of modern sulfate reduction. 
Chapter 2 - Proterozoic / Phanerozoic dynamics

Recently Crowe et al. (2011) reported that $\sim 85 \%$ of primary production in ferruginous Lake Matano is degraded via methanogenesis, based on a methane flux through the pycnocline calculated from an assumed value for a diffusion coefficient. If exported organic matter is consumed primarily by methanogens, the $\mathrm{CO}_{2}$ produced at depth should be enriched in ${ }^{13} \mathrm{C}$ to balance the production of methane. However, Crowe et al. report deep water $\Sigma \mathrm{CO}_{2} \delta^{13} \mathrm{C}$ that is $1 \%$ depleted relative to surface waters, implying that methane production account for a much smaller fraction of organic matter degradation.

\subsubsection{Sulfide Burial and Oxidation}

Sulfide produced during sulfate reduction is either oxidized or buried as pyrite $\left(B_{\text {pyr }}\right)$. Pyrite burial is set to an oxygen-dependent fraction () of the sulfide generated during sulfate reduction (Berner \& Westrich 1985). Iron limitation may be an important control, but we cannot include this effect without explicitly incorporating the iron cycle. The remaining sulfide diffuses from the sediment. For simplicity, the same pyritization fraction is applied to sulfate reduction in the water column. Aqueous sulfide can be oxidized to sulfate by $\mathrm{O}_{2}$, with the flux $(Q)$ first order in both species (Millero et al. 1987a).

\subsubsection{Sulfate Burial}

Burial of sulfate minerals (gypsum, anhydrite, CAS) is lumped into one term $\left(B_{\text {Sox }}\right)$ proportional to sulfate concentration. Actual deposition likely occurs during large evaporative events (e.g. Halevy et al. 2012). Our parameterization represents an average over many such events, with the assumption that total sulfate in an average evaporative basin must vary with ocean sulfate concentration. This smoothed burial flux is tuned to produce the 2:3 ratio of pyrite:sulfate burial required by isotopic mass balance (Canfield 2004). 
Chapter 2 - Proterozoic / Phanerozoic dynamics

\subsubsection{Sedimentary Phosphorus Cycling}

Phosphorus released to pore waters during organic matter oxidation $\left(R_{s d}, S_{s d}\right)$ can diffuse back into the water column. The diffusive flux $(Y)$ is influenced by adsorption onto iron oxides (Shaffer 1986, Sundby et al. 1992), which depresses phosphate concentrations above the iron redox front. Because the depth of this front depends on oxygen penetration depth, $\mathrm{P}$ diffusion should fall with rising oxygen. Therefore, we allow an oxygen-dependent fraction $(\delta)$ of remineralized $\mathrm{P}$ to diffuse from the sediment. Alternative parameterizations, such as preferential remineralization of organic P (Van Cappellen \& Ingall 1994), are considered in section 2.4.4.2.

\subsubsection{Weathering, Volcanic, and Hydrothermal Fluxes}

Weathering of bulk sediment $\left(W_{a}\right)$, carbonates $\left(W_{C O 3}\right)$, total calcium $\left(W_{C a}\right)$, and apatite $\left(W_{a p}\right)$ all scale with a factor $(\omega)$ calculated from $p \mathrm{CO}_{2}$ and temperature according to Walker et al. (1981). Temperature is calculated from $p \mathrm{CO}_{2}$ by assuming a climate sensitivity of $3 \mathrm{~K}$ per doubling around $288 \mathrm{~K}$ at $280 \mathrm{ppm}$.

Phosphorus weathering $\left(W_{P}\right)$ is the sum of apatite $\left(W_{a p}\right)$ and organic phosphorus $\left(W_{C}\right)$ weathering. Only a fraction $\left(f_{b}\right)$ of remineralized organic $\mathrm{P}$ is considered to be non-detrital and thus biologically available (Froelich 1988). Organic carbon weathering scales with the square root of $p \mathrm{O}_{2}$ (Chang \& Berner 1999). Weathering of pyrite is a constant, reflecting exposure limited oxidation as inferred from the disappearance of detrital $\mathrm{FeS}_{2}$ after the Archean (Holland 1984).

Hydrothermal and volcanic fluxes are constants in the model. These include hydrothermal sulfate uptake and sulfide release, and volcanic carbon outgassing. 
Chapter 2 - Proterozoic / Phanerozoic dynamics

\subsubsection{Calcite Precipitation and Dissolution}

To represent the precipitation and dissolution of calcite, the model maintains a fixed saturation state in the ocean, requiring computation of carbonate ion concentration from total carbon and alkalinity. Alkalinity varies from its modern day value of $2200 \mu \mathrm{M}$ based on variations in calcium around the modern mean ocean average of $10.3 \mathrm{mM}$ (Sarmiento \& Gruber 2006).

Based on the alkalinity and total carbon values, temperature-specific carbonate speciation is calculated for each box using the equilibrium constants from Zeebe \& Wolf-Gladrow (2000) with a salinity of $35,10 \%$ over saturation of the surface ocean with carbon dioxide, and a deep-water calcite saturation constant $\left(k_{s p}\right)$ corresponding to $3800 \mathrm{~m}$ depth. Given the solution for $\left[\mathrm{CO}_{3}^{2-}\right]$, the total precipitation/dissolution of calcite $p$ is chosen such that:

$$
\left(\left[\mathrm{Ca}^{2+}\right]-[p]\right)\left(\left[\mathrm{CO}_{3}^{2-}\right]-[p]\right)=k_{s p} \Omega
$$

where $\Omega$ is a fixed saturation state in each ocean box. Total carbon, alkalinity and carbonate speciation are re-calculated, yielding the $\mathrm{pCO}_{2}$ values fed to the next step.

\subsubsection{Mixing and Ocean-Atmosphere Equilibrium}

The mixing flux $\left(F_{X}\right)$ for species $y$ over a discrete time step is $X\left([y]_{s}-[y]_{d}\right)$, with a fixed rate of water exchange $X$ (value from Hotinski et al. 2000). However, this discrete form is problematic for large time steps, so we compute the flux by integrating the differential form over a single time step $\tau$ : 


$$
\begin{aligned}
d\left([y]_{s} M_{s}\right) & =X\left([y]_{d}-[y]_{s}\right) d t \\
& \Rightarrow F_{X}=\frac{M_{s} M_{d}}{M_{s}+M_{d}}\left([y]_{d}-[y]_{s}\right)\left(\exp \left(-\frac{M_{s}+M_{d}}{M_{s} M_{d}} X \tau\right)-1\right)
\end{aligned}
$$

Surface oxygen is distributed between the atmosphere and shallow ocean boxes according to a fixed partitioning constant $\eta$. Given the total moles $n$ of oxygen in the atmosphere (a) and shallow ocean $(s)$, we can solve the following equilibrium equation assuming ideal behavior for oxygen.

$$
\begin{aligned}
\frac{n_{a}}{n_{s k y}} K_{H} & =\frac{n_{s}}{M_{s}} \\
& \Rightarrow \eta \equiv \frac{n_{a}}{n_{s}}=\frac{n_{s k y}}{K_{H} M_{s}}
\end{aligned}
$$

where $n_{x}$ is the number of moles of oxygen in a given reservoir, $K_{H}$ is Henrys constant, and $n_{s k y}$ is the number of molecules of air in the atmosphere. We assume a fixed Henrys constant of $1.2^{*} 10^{-3} \mathrm{M} / \mathrm{atm}\left(15^{\circ} \mathrm{C}\right)$, and $n_{\text {sky }}$ of $1.8^{*} 10^{17} \mathrm{~mol}$, from an atmosphere of mass $5.3^{*} 10^{18} \mathrm{~kg}$ and effective molar mass of $29.0 \mathrm{~g} / \mathrm{mol}$.

\subsubsection{Integration}

The time-dependent equations are integrated via Eulers method with a time step $\tau$ of 10 years. First, mixing is calculated and used to update the reservoirs of each species. Oxygen and carbonate equilibrium are applied. Primary production is calculated from the new phosphate levels in the surface and used to update surface organic carbon concentrations. Next, adsorption of organic carbon, sulfide oxidation, water column oxic respiration, water column sulfate reduction, organic carbon deposition and export production are calculated, 
in that order; this sequence matters during simulations in which a particular reservoir is depleted. The order is chosen to prioritize processes that are more favorable thermodynamically or biologically. For example, sulfate reduction can occur in the water column, but is inhibited in the presence of oxygen. By calculating oxic respiration first, the model ensures that if oxygen is exhausted by the organic carbon flux, anaerobic respiration can take place. This would not be the case if sulfate reduction was calculated first.

Sulfate burial, oxidation of the seafloor and phosphorus scavenging follow. Oxic respiration and sulfate reduction in the sediment are computed based on gross organic deposition, and phosphorus regeneration follows from the remineralization terms. These fluxes are applied to the reservoirs, and oxygen and carbonate equilibrium are again enforced to end the time step.

\subsubsection{Oxygen-sensitive P Flux Models}

The oxygen-sensitive $\mathrm{P}$ fluxes used to create Figure 6 are calculated by applying a correction factor $\psi$ to $W_{P}$ after it is computed from $\mathrm{pCO}_{2}$ and $W_{C}$ as in Table 2 . The four different models are:

$$
\begin{aligned}
& \psi_{1}=\rho_{1}\left(p O_{2}\right)+\rho_{2} \\
& \psi_{2}=\rho_{3}+\rho_{4} \exp \left(-\rho_{5}\left(p O_{2}\right)\right) \\
& \psi_{3}=\rho_{6} \arctan \left(\rho_{7}\left(p O_{2}\right)-\rho_{8}\right)+\rho_{9} \\
& \psi_{4}=\rho_{10}\left(p O_{2}\right)^{2}+\rho_{11}\left(p O_{2}\right)+\rho_{12}
\end{aligned}
$$

where $\mathrm{pO}_{2}$ is in PAL, and the values of the $\rho$ parameters are given in Table 6 . 
Chapter 2 - Proterozoic / Phanerozoic dynamics

\subsubsection{Black Sea Model}

The Black Sea model variant has smaller ocean boxes, fixed $\mathrm{pO}_{2}$ and $\mathrm{pCO}_{2}$, no hydrothermal inputs and no oxidation of ocean crust. The only fundamental changes to the model are in the handling of mixing and river inputs, which follow the conceptual model of Murray et al. (1991).

The mixing model includes an inflow of subsurface Mediterranean water over the Bosporus sill $\left(X_{M}\right)$, which is assumed to mix into the deep waters. The shallow box receives a water mass from rivers $\left(X_{r}\right)$ and via net transfer from the deep box ( $X_{M}$, by mass balance), and sends a compensating outflow $\left(X_{o}\right)$ over the sill. The outflow is not exactly equal to $X_{M}+X_{r}$ due to net evaporation. The two boxes also exchange with each other via normal mixing $(X)$. The values of the mixing parameters and box sizes are given in Table 7, adapted from Murray et al. (1991).

The mixing terms are large relative to the basin size, and so Eulers method does not give reliable results. Alternatively, the change in water composition assuming no chemistry can be expressed exactly for species $y$ as:

$$
\frac{d}{d t}\left(\begin{array}{c}
{[y]_{d} M_{d}} \\
{[y]_{s} M_{s}}
\end{array}\right)=\left(\begin{array}{cc}
-\left(X+X_{M}\right) & X \\
X+X_{M} & \left(X+X_{o}\right)
\end{array}\right)\left(\begin{array}{c}
{[y]_{d}} \\
{[y]_{s}}
\end{array}\right)+\left(\begin{array}{c}
{[y]_{M} X_{M}} \\
{[y]_{r} X_{r}}
\end{array}\right)
$$

where $[y]_{M}$ and $[y]_{r}$ are the concentrations of species $\mathrm{y}$ in Mediterranean and river water, respectively, given in Table 8 . This can be solved explicitly. The resulting fluxes are used in place of the mixing parameterization described above. This scheme requires that the weathering fluxes in Table 5 are set to zero. 
Chapter 2 - Proterozoic / Phanerozoic dynamics

\subsection{Results}

\subsection{1 $p \mathrm{O}_{2}$ equilibria}

There is only one equilibrium $\mathrm{O}_{2}$ concentration in the model. For initial oxygen levels between zero and two times PAL, and with a range of initial sulfate (1-100 $\mathrm{mM})$, organic carbon, and phosphate $(0-3 \mu \mathrm{M})$ concentrations, the simulations return to modern $\mathrm{pO}_{2}$ levels within 50 million years (Figure 3).

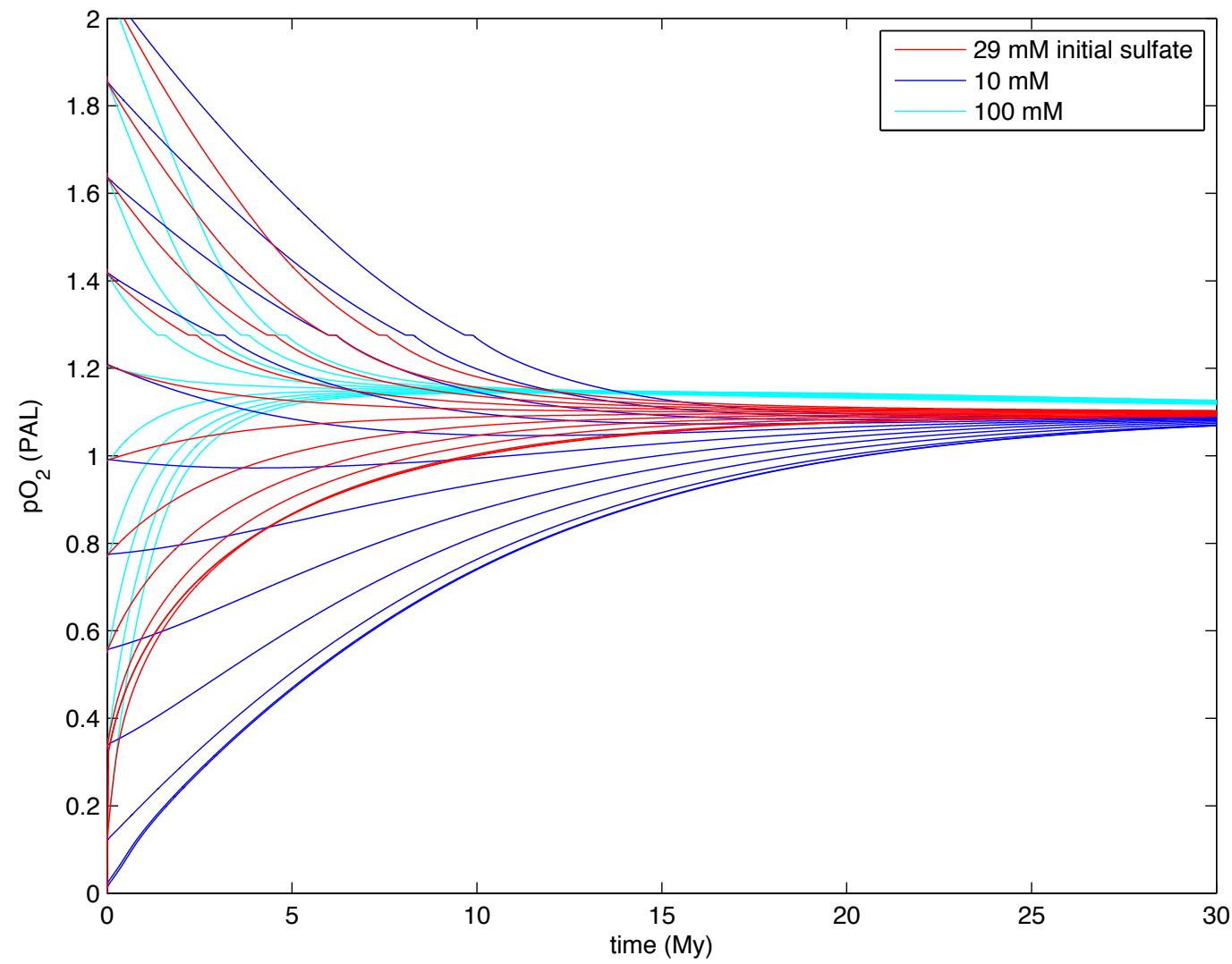

Figure 2.3: Evolution of $\mathrm{pO}_{2}$ after initializing the model with oxygen between 0 and $2 \mathrm{PAL}$, and sulfate between 10 and $100 \mathrm{mM}$. 
Chapter 2 - Proterozoic / Phanerozoic dynamics

\subsubsection{Sensitivity of the $\mathrm{pO}_{2}$ equilibrium}

The value of this sole equilibrium is remarkably insensitive to the model parameters (Figure 4). We ran a sensitivity test over two orders of magnitude variation in each of the major model parameters. For each parameter, we describe in detail only the simulation that produces the largest reduction in $\mathrm{pO}_{2}$. The full sensitivity results are shown in Figure 4 . Within the range tested, only a reduction in the phosphorus input flux can drive $\mathrm{pO} 2$ to less than $0.1 \mathrm{PAL}$.

\section{Sensitivity to water column carbon cycling}

Deposition of organic carbon on the seafloor is modeled as proportional to organic carbon concentrations in the water column. Variations in the rate constant, representing changes in the sinking rate of particles, have no impact on oxygen: equilibrium $\mathrm{pO}_{2}$ is $1.1 \mathrm{PAL}$ after a ten-fold increase in the rate constant. The acceleration in carbon deposition strips average $\mathrm{P}$ concentrations to $10 \mathrm{nM}$. Primary productivity falls in response, from $\sim 3000 \mathrm{Tmol} \mathrm{C}$ $\mathrm{yr}^{-} 1$ to 300 , such that the downward organic flux of $\mathrm{P}$ once again balances inputs. Total organic flux to the sediment, and hence the oxygen budget and $\mathrm{pO}_{2}$, are unchanged.

Water column respiration rate is first-order in both oxygen and organic carbon concentration. $\mathrm{pO}_{2}$ remains at 1.1 PAL for two orders-of-magnitude variation in the rate constant. A ten-fold decrease, representing much less labile organic carbon, reduces the efficiency of water-column remineralization from over $99 \%$ to about $70 \%$. Phosphate concentrations plunge as the unremineralized organic $\mathrm{P}$ is buried. Production falls to $150 \mathrm{Tmol} \mathrm{C} \mathrm{yr}^{-1}$, such that the efficient export of a small, recalcitrant organic pool balances nutrient inputs. Again, balancing nutrient fluxes in a phosphorus-limited ocean guarantees that the organic flux to the sediment, and hence the oxygen budget, does not change. 


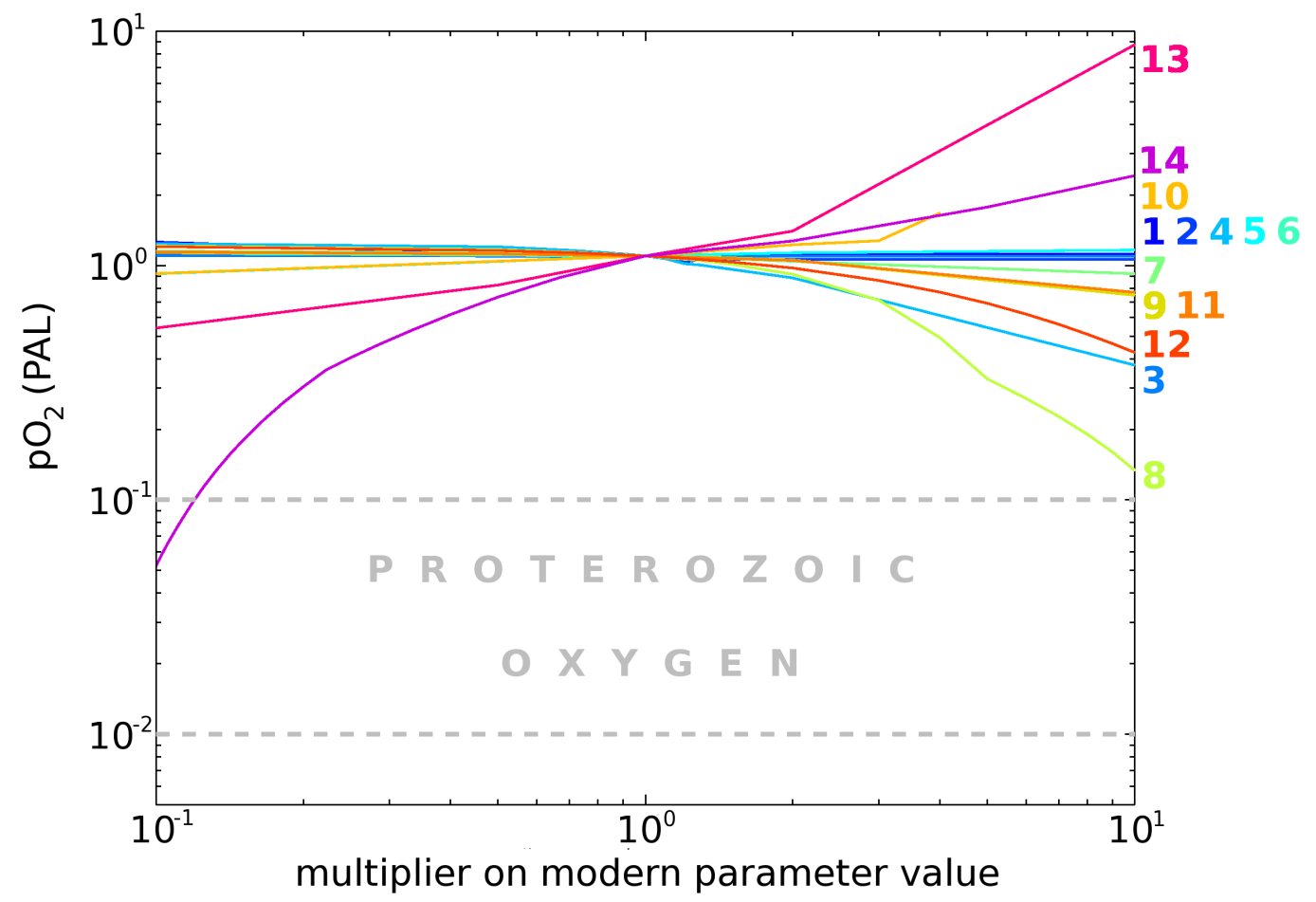

Figure 2.4: Sensitivity of steady-state $\mathrm{pO}_{2}$ to various model parameters. Each curve shows the sensitivity to a given parameter. 1: rate constant (RC) for organic carbon deposition $\left(k_{3}\right), 2$ : water-column oxic respiration $\mathrm{RC}\left(k_{0}\right), 3$ : ballasting $\mathrm{RC}\left(k_{4}\right)$, 4: inorganic $\mathrm{P}$ deposition $\mathrm{RC}\left(k_{8}\right), 5$ : sediment sulfate reduction $\mathrm{RC}\left(k_{6}\right), 6$ : pyrite burial fraction intercept $\left(\gamma\right.$ at $\left.\left[\mathrm{O}_{2}\right]=0\right)$, 7: sulfate burial $\mathrm{RC}\left(k_{7}\right), 8$ : pyrite weathering $\left(W_{p y r}\right), 9$ : organic carbon weathering $\mathrm{RC}\left(k_{9}\right), 10$ : $\mathrm{P}$ regeneration fraction (fixed $\delta$ for all $\left[\mathrm{O}_{2}\right]$ ), 11: oxidation of ocean crust RC $\left(k_{10}\right)$, 12: hydrothermal sulfide flux $\left(H_{S_{r d}}\right)$, 13: volcanic outgassing $\left(V_{C}\right), 14$ : riverine phosphorus flux $\left(W_{P}\right), 15$ : sediment oxic respiration $\mathrm{RC}\left(k_{5}\right)$.

\section{Sensitivity to inorganic nutrient scavenging}

We model the small inorganic deposition of phosphorus as first-order in phosphate concentrations. $\mathrm{pO}_{2}$ falls to $0.7 \mathrm{PAL}$ if the rate constant is increased by a factor of 104 . The additional scavenging draws down $\mathrm{P}$ concentrations, slowing adsorption such that inorganic deposition itself grows by only a factor of 103 , to $40 \%$ of the total shuttle. The reduction in 
Chapter 2 - Proterozoic / Phanerozoic dynamics

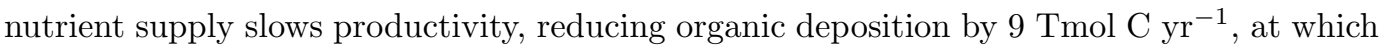
point the combined $\mathrm{P}$ sink again balances inputs. $\mathrm{pO}_{2}$ falls in response, slowing sedimentary respiration until the fraction of organic carbon surviving diagenesis becomes large enough to compensate for the smaller gross flux, re-establishing redox equilibrium.

\section{Sensitivity to sedimentary oxic respiration}

Oxic respiration in the sediments is modeled as first order in the oxygen concentration of the overlying water column. A ten-fold increase in this rate constant drives $\mathrm{pO}_{2}$ to 0.4 PAL. The increased rate of respiration means less efficient organic burial at a given oxygen level, i.e. a smaller fraction of gross organic deposition is ultimately buried. The oxygen source is thus reduced and $\mathrm{pO}_{2}$ falls, slowing respiration and raising burial efficiency until the oxygen source again balances oxygen sinks. The models linear dynamics suggest a ten-fold increase in the rate constant should be balanced by oxygen at $0.1 \mathrm{PAL}$; however, the response is damped to 0.4 PAL by three negative feedbacks.

First, pyrite burial efficiency scales with oxygen concentration. Decreases in $\mathrm{O}_{2}$ therefore drive larger changes in the oxygen source than expected from the dynamics of organic carbon alone: after the ten-fold increase in the oxic respiration rate constant, pyrite burial increases by $60 \%$.

Second, the fraction of pore water P regenerated to the water column falls off with the overlying oxygen concentration. In the simulation with high respiration rate constant, retention of pore water $\mathrm{P}$ decreases from $75 \%$ to $50 \%$, driving up primary production and organic deposition to the sediment. The additional organic flux is effectively an increase in burial efficiency, further accelerating the rate at which the oxygen source responds to decreases in $\mathrm{pO}_{2}$. 
Chapter 2 - Proterozoic / Phanerozoic dynamics

Finally, the weathering of organic carbon increases with $\mathrm{pO}_{2}$. As oxygen decreases in the rapid-respiration scenario, organic weathering falls by $40 \%$ even as pyrite and organic carbon burial increase, allowing redox balance to be achieved with less overall change in $\mathrm{pO}_{2}$ than would be expected for a fixed sink.

\section{Sensitivity to sulfate reduction}

Sulfate reduction in the sediment is linear in the overlying $\mathrm{SO}_{4}^{2-}$ concentration. A ten-fold increase in the rate constant results in $\mathrm{pO}_{2}$ of $1.1 \mathrm{PAL}$, compared to 0.4 PAL for a similar increase in the rate constant for aerobic respiration. Along with the feedbacks discussed above, several additional effects weaken the impact of sulfate reduction on the oxygen source, particularly as compared to aerobic respiration. First, elevated sulfide production results in additional pyrite burial, driving oceanic sulfate to $13 \mathrm{mM}$. This slows respiration such that $\mathrm{S}$ equilibrium is achieved with just a doubling of sulfate reduction, despite the tenfold change in rate constant. Furthermore, pyrite formation is a transfer of electrons from one sedimentary sink to another, so the pyritized fraction of sulfide production (15\%) is unimportant from a redox perspective.

\section{Sensitivity to pyrite burial}

Pyrite burial is modeled as an O2-dependent fraction of the sulfide produced during sedimentary sulfate reduction. $\mathrm{pO}_{2}$ stabilizes at 0.4 PAL if this fraction decreases from $20 \%$ at modern oxygen to a fixed $2 \%$. Pyrite burial falls from 1.3 to $0.3 \mathrm{Tmol} \mathrm{S} \mathrm{yr}^{-1}$, limited to a five-fold decrease by the accumulation of sulfate $(39 \mathrm{mM})$ and the subsequent acceleration of sulfide production. Oxygen decreases in response to this loss of source, raising organic carbon burial and reducing organic carbon weathering until equilibrium is re-achieved. 
Chapter 2 - Proterozoic / Phanerozoic dynamics

\section{Sensitivity to sulfate burial}

Direct burial of sulfate minerals is first order in sulfate concentration. A ten-fold increase in the rate constant reduces $\mathrm{pO}_{2}$ to $0.9 \mathrm{PAL}$. More rapid burial draws sulfate down to $4 \mathrm{mM}$, resulting in equilibrium sulfate burial of $3.3 \mathrm{Tmol} \mathrm{S} \mathrm{yr}^{-1}$, increased from 2.3. This large $\mathrm{S}$ sink is balanced by slower sulfate reduction and pyrite burial, which induces a net decrease in oxygen source of $3.6 \mathrm{Tmol} \mathrm{C} \mathrm{yr}^{-1} \cdot \mathrm{pO}_{2}$ rises in compensation, raising burial efficiency and slowing weathering.

\section{Sensitivity to pyrite weathering}

The weathering of pyrite is a fixed flux in our model. To isolate the effect of this flux on $\mathrm{pO}_{2}$, increases in pyrite oxidation are offset by decreases in sulfate weathering, such that the total flux of $\mathrm{S}$ to the ocean is unchanged. The entire sulfur flux is sourced from pyrite for a quadrupling of the weathering flux, which drives $\mathrm{pO}_{2}$ to 0.5 PAL. This large electron source is partially offset by additional pyrite burial, which grows from $35 \%$ to $70 \%$ of sulfur burial in the low-oxygen ocean. 1.1 Tmol sulfate are still buried each year, however, so the exposure of purely pyritic S minerals is inconsistent on sufficiently long time scales. This should eventually reduce the size of the pyrite sink for oxygen, but we are unable to test this effect without a model for uplift and emplacement of sediments on the continents. 0.13 PAL oxygen is possible for a ten-fold increase in pyrite weathering, though this requires the total surface sulfur reservoir to increase by a factor of $\sim 3$.

\section{Sensitivity to organic carbon weathering}

Organic carbon weathering scales with the square root of $\mathrm{pO}_{2}$ in our model. A ten-fold increase in the rate constant reaches equilibrium at $0.75 \mathrm{PAL} \mathrm{pO}_{2}$. Rapid weathering increases the size of the oxygen sink, but organic burial efficiency and hence the oxygen source rise in response as well, balancing at an 8-fold increase in weathering and an additional 
Chapter 2 - Proterozoic / Phanerozoic dynamics

21 Tmol organic C and 0.9 Tmol pyrite S buried annually.

\section{Sensitivity to sedimentary phosphorus cycling}

In our model, an oxygen-sensitive fraction of the $\mathrm{P}$ remineralized in the sedimentary is regenerated to the water column. At steady state, this loss must be exactly balanced by additional gross burial of organic P. Therefore, any recycled $\mathrm{P}$ represents additional deposition and an effective increase in burial efficiency. As an extreme example, we can set the regenerated fraction to zero at all oxygen levels. This model stabilizes at 0.92 PAL, slowing respiration such that net organic burial remains $60 \%$ of gross deposition, despite a $5 \mathrm{Tmol} \mathrm{C} \mathrm{yr}^{-1}$ reduction in the latter.

\section{Sensitivity to mantle fluxes}

Mantle electrons enter the ocean-atmosphere system as hydrothermal fluids, volcanic gases, and minerals along ridge flanks.

Oxidation of new crust is parameterized as an oxygen-sensitive weathering of ferrous iron. A ten-fold increase in the rate constant reduces $\mathrm{pO}_{2}$ to $0.77 \mathrm{PAL}$. The large iron sink draws down oxygen until redox balance is achieved through rising organic burial, falling organic weathering, and a decrease in iron oxidation itself. As an alternative parameterization we can model crustal oxidation as independent of $\mathrm{O}_{2}$, i.e. as fast enough to oxidize to completion at any oxygen level. In this case, a ten-fold increase in the exposure rate reduces $\mathrm{pO}_{2}$ to 0.56 PAL.

A ten-fold increase in the flux of hydrothermal sulfide drives equilibrium $\mathrm{pO}_{2}$ to 0.43 PAL. Though the sulfide is a large sink for oxygen, it also triples sulfur inputs to the ocean, which are balanced by an additional $6.5 \mathrm{Tmol}$ pyrite $\mathrm{S}$ buried every year. This large additional source prevents oxygen from plunging to zero. 
Chapter 2 - Proterozoic / Phanerozoic dynamics

Volcanic outgassing releases many redox-sensitive species to the atmosphere; we represent changes in this flux simply as a scaling of $\mathrm{CO}_{2}$ and sulfide inputs. Surprisingly, a tenfold decrease in outgassing brings $\mathrm{pO}_{2}$ down to $0.5 \mathrm{PAL}$, despite the smaller sulfide flux. $\mathrm{pCO}_{2}$ stabilizes at $150 \mathrm{ppm}$ due to the small carbon supply, halving the rate of phosphorus weathering. This loss of $\mathrm{P}$ input is a powerful lever on $\mathrm{pO}_{2}$, as discussed below, resulting in lower oxygen.

\section{Sensitivity to phosphorus input}

The primary source of phosphorus is weathering of apatites. A ten-fold decrease in this term stabilizes $\mathrm{pO}_{2}$ at 0.05 PAL. The small phosphorus supply supports less production, reducing organic deposition by a factor of five, such that the shuttle of $\mathrm{P}$ to the sediment can balance the smaller input, after allowing for $\mathrm{P}$ regeneration. The small gross organic flux reduces the oxygen source, and $\mathrm{pO}_{2}$ falls; net burial efficiency rises by $40 \%$ in response, restoring equilibrium. The suboxic ocean exports organic particles very efficiently, and so only $10 \mathrm{Tmol} \mathrm{C} \mathrm{yr}^{-1}$ primary production is needed to maintain the necessary burial.

\subsubsection{Multiple steady states models for $\mathrm{pO}_{2}$}

When an arbitrary oxygen-sensitive $\mathrm{P}$ flux is included in the model, atmospheric $\mathrm{O}_{2}$ is able to stabilize at two levels, converging to either a high or a low concentration depending on its initial state (Figure 6); low $\mathrm{pO}_{2}$ is achieved for sufficiently low initial concentrations of oxygen and sulfate. Existence of this behavior depends on the precise oxygen sensitivity of the $\mathrm{P}$ flux: a wide class of simple, smooth relationships produces two stable $\mathrm{pO}_{2}$ levels. In particular, multiple steady states are possible when the positive feedback between $\mathrm{P}$ and oxygen becomes weak near the expected equilibrium pO2 values (Kump et al. 2009). Weak variation is defined relative to the rate at which equilibrium pO2 increases with an imposed 
Chapter 2 - Proterozoic / Phanerozoic dynamics

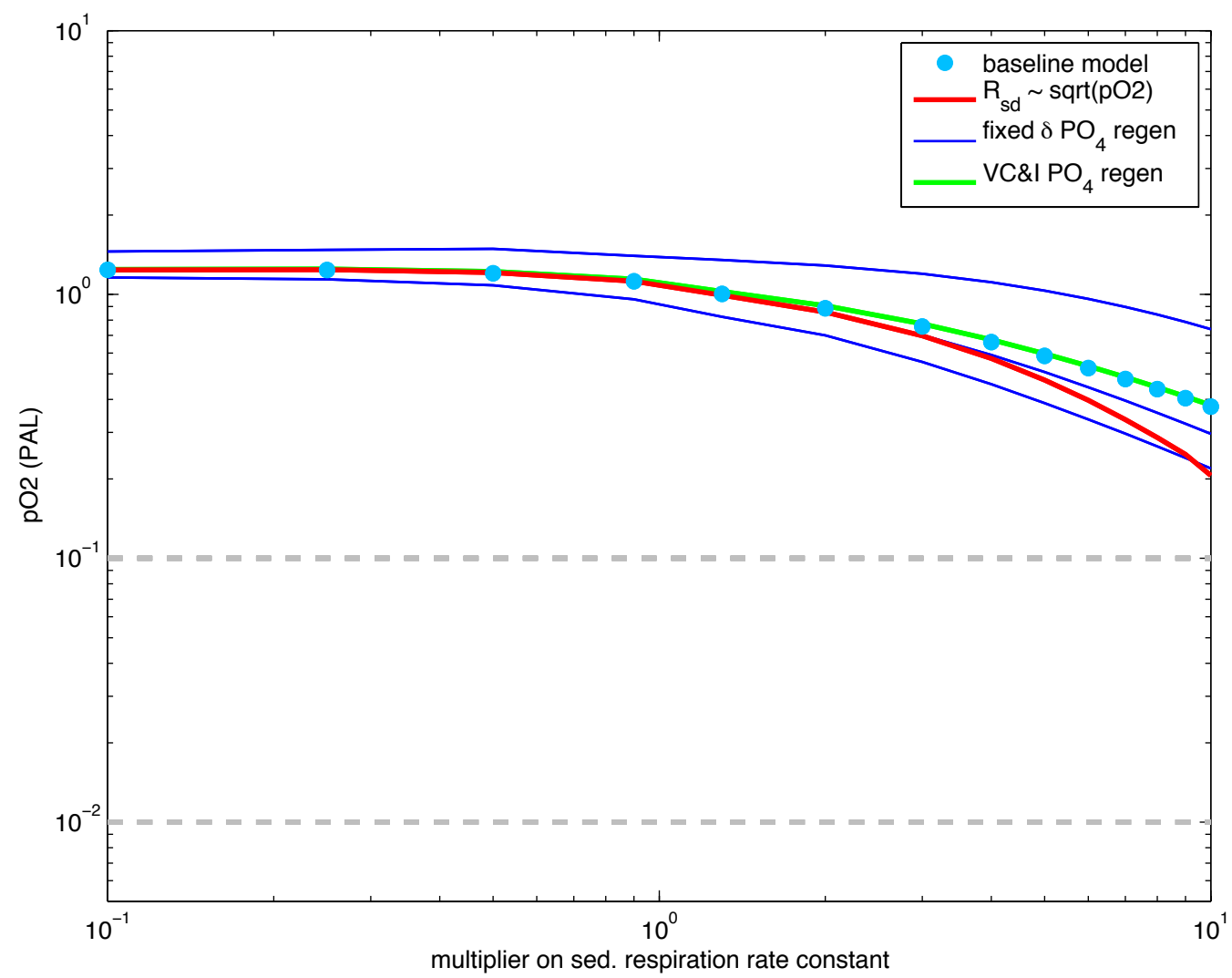

Figure 2.5: Sensitivity of steady-state $\mathrm{pO}_{2}$ to the rate constant on sedimentary respiration under different model configurations. Blue dots: baseline model with respiration rate linear in oxygen and $\mathrm{O}_{2}$-sensitive diffusion of remineralized $\mathrm{P}$ (compare to curve 15 in Figure 2.4). Red curve: respiration rates scale with square root of oxygen. Blue curves: diffusion of $\mathrm{P}$ is a fixed fraction of remineralization. Green curve: diffusion of $\mathrm{P}$ is an $\mathrm{O}_{2}$-sensitive fraction of gross deposition.

P flux (Figure 6, dotted line). 
Chapter 2 - Proterozoic / Phanerozoic dynamics

\subsection{Discussion}

\subsubsection{The instability of a low oxygen atmosphere}

Our Phanerozoic-tuned model always converges to a modern, high-oxygen state, even when it is initially anoxic and stripped of sulfate and phosphorus. This stability is driven by more efficient organic carbon and pyrite burial under low oxygen conditions (see also section 2.4.4.1). For example, when this model is initialized with zero oxygen, the total annual $\mathrm{O}_{2}$ source is $21 \mathrm{Tmol}$, three times the modern value and seven times the oxygen sink. The imbalance rapidly pumps oxygen into the system. As in earlier models (Berner and Canfield 1989, Lasaga and Ohmoto 2002, Bergman et al. 2004), this simple feedback is sufficient to explain the stability of Phanerozoic redox conditions. However, the feedback also prevents Proterozoic-like conditions from prevailing for more than a few million years. To achieve stability, a low-oxygen world must somehow limit growth in the oxygen source, despite slowed respiration and a P-driven lower-limit on the organic flux to the sediment.

\subsubsection{Is the Black Sea an analog for the Proterozoic Ocean?}

By providing a floor on organic carbon deposition, larger phosphorus inputs actually maintain higher levels of $\mathrm{pO}_{2}$ (Figure 4). This is a fundamental limitation in stabilizing a lowoxygen world, but may seem counter-intuitive in the context of modern eutrophic basins. The Black Sea, for example, is totally anoxic at depth precisely because phosphorus inputs through the Danube are large enough to support vigorous export production, which consumes all the oxygen in the poorly ventilated deep waters (Konolov \& Murray 2001).

Anoxic basins such as the Black Sea are poor models for global anoxia. They are coupled to a much larger well-oxygenated atmosphere/ocean, forming a highly oxidizing boundary condition. Therefore, these basins can bury organic carbon without significantly impacting 
$\mathrm{pO}_{2}$, despite their high burial efficiencies (Arthur et al. 1994). Once decoupled from this essentially infinite reservoir, efficient burial would drive up $\mathrm{pO}_{2}$, exacerbated by a slowdown in mineralization due to a loss of sulfate-rich Mediterranean water over the Bosporus sill (Ozsoy \& Unluata 1997). Ultimately $\mathrm{pO}_{2}$ would rise until the slow Black Sea mixing oxygenated the deep and restored $\mathrm{O}_{2}$ equilibrium.

To demonstrate this, we fix $\mathrm{pO}_{2}$ in our model and add flows of oxygenated ocean water into the deep basin, and phosphorus-rich river water into the surface. Methanogenesis is included (following Section 2.2.2.5). Sure enough, this results in an anoxic deep basin (0 $\mathrm{M}[\mathrm{O} 2])$, high phosphorus $\left(20 \mu \mathrm{M}\left[\mathrm{PO}_{4}^{3-}\right]\right)$ and vigorous primary production (4000 Tmol C

$\mathrm{yr}^{-1}$, scaled to the surface area of the global ocean). When the sill overflow is shut off and the atmosphere is driven by the basin alone, the steady-state looks just like a smaller version of the modern global ocean with substantially higher $\mathrm{P}$ inputs and increased stratification: well oxygenated $(80 \mu \mathrm{M})$, with moderate levels of deep water phosphorus $(1.7 \mu \mathrm{M})$. The nutrient-rich, anoxic basin is possible specifically because it exchanges with an effectively infinite oxidized reservoir. High phosphorus levels therefore do not imply low oxygen in a global ocean. This distinction is critical in understanding how the modern phosphorus flux limits the sensitivity of $\mathrm{pO}_{2}$ to changes in the redox system.

\subsubsection{Mechanisms for a stable low oxygen atmosphere}

As noted above, a low-oxygen world must limit growth in the oxygen source, despite more efficient burial of an organic flux maintained by phosphorus cycling. Coupled with a number of secondary negative feedbacks, this leaves $\mathrm{pO}_{2}$ insensitive to most aspects of geochemical cycling. The sensitivity tests show that a reduction in the riverine phosphorus flux is by far the most powerful lever on $\mathrm{pO}_{2}$, ruling out other mechanisms for a stable low-oxygen world. 
Chapter 2 - Proterozoic / Phanerozoic dynamics

\section{Ballasting and burial mechanisms}

Balance of the phosphorus budget leaves water-column carbon cycling irrelevant to $\mathrm{pO}_{2}$, demonstrated by the insensitivity to settling rate and water column respiration. Any alteration to gross organic deposition perturbs the phosphorus budget, driving compensating changes in primary productivity to ensure the organic $\mathrm{P}$ sink balances inputs. This discounts the hypothesis of Logan et al. (1995), which proposes lower pre-Cambrian oxygen due to less efficient export of organic particles before the advent of ballasting fecal pellets.

\section{Respiration-related mechanisms}

One way to maintain modern burial efficiency at low oxygen is to invoke a compensating increase in the efficiency of respiration, such that remineralization rates themselves remain unchanged. The sensitivity of $\mathrm{pO}_{2}$ to the rate constants for aerobic and anaerobic respiration show this can be successful in reducing oxygen levels. However, secondary negative feedbacks weaken the response, such that more than ten-fold changes to rate constants are required to stabilize oxygen at 0.1 PAL: an increase in the efficiency of pyrite burial at low oxygen (Berner \& Westrich 1985), a drop in organic carbon weathering (Chang \& Berner 1999), and a greater fraction of regenerated pore water P (Shaffer 1986, Anderson et al. 2001), all conspire to limit the drop in $\mathrm{pO} 2$. Changes of this scale cannot be justified by invoking, for example, the hypothesis of Kennedy et al. (2006). They argue that a difference in weathering products before the advent of land plants drove a seven-fold decrease in protective sorption relative today much too small to achieve Proterozoic levels of oxygen.

\section{Sink mechanisms}

The simplest explanation for low $\mathrm{pO}_{2}$ is a sufficiently large Proterozoic sink for oxygen. Fixed fluxes are the most powerful levers, but it is difficult to justify the order-of-magnitude

changes required to explain Proterozoic oxygen. A doubling of present-day hydrothermal 
Chapter 2 - Proterozoic / Phanerozoic dynamics

fluxes is possible for the Mesoproterozoic (Canfield 2004, Kump \& Barley 2007). Pyrite weathering could have been 3-4 times greater if the Proterozoic surface sulfur reservoir were almost $100 \%$ pyrite, consistent with the thin distribution of Proterozoic evaporites (Grotzinger \& Kasting 1993), but this could only be maintained with increased pyrite burial.

\section{Phosphorus-based mechanisms}

Though organic carbon is efficiently buried in a low oxygen ocean, the net $\mathrm{O}_{2}$ source need not grow if there is a compensating reduction in the gross flux of organic material to the seafloor. However, as the dominant P shuttle (Delaney 1998), this flux must be large enough to balance $\mathrm{P}$ inputs.

This limitation would be lifted if mineral shuttling of phosphorus were much larger than today. Bjerrum \& Canfield (2002) have proposed adsorption onto banded iron formations (BIFs) as a mechanism for suppressing phosphate. However, the lack of BIFs between 1.8 and 0.7 Ga (Holland 1984) makes this an unlikely candidate for Proterozoic P control. Furthermore, adsorption is proportional to $\mathrm{P}$ concentration, so iron has a limited ability to remove phosphate from an anoxic ocean in which efficient organic export would limit deepwater nutrients. As shown in the sensitivity tests, even if the equivalent of the entire modern reactive iron flux is oxidized in open water, $\mathrm{pO}_{2}$ cannot be maintained at less than $50 \%$ PAL.

Alternatively, the P budget would require less gross organic deposition if phosphorus inputs were smaller. Oxygen would decrease, maintaining net burial with a compensating increase in the burial efficiency of organic carbon and pyrite. As shown in Figure 2, a ten-fold reduction in the riverine $\mathrm{P}$ flux stabilizes $\mathrm{pO}_{2}$ at 0.1 PAL.

A relationship between $\mathrm{pO}_{2}$ and phosphorus input was identified in some earlier models 
Chapter 2 - Proterozoic / Phanerozoic dynamics

(Lenton \& Watson 2004, Fennel et al. 2005), though these either did not include the burial efficiency feedback, or allowed it only near modern levels of oxygen. Relaxing this feedback makes it much less difficult to stabilize low oxygen. However, we find a relationship between $\mathrm{pO}_{2}$ and phosphorus flux even when this stabilizing feedback is included. Of all the changes tested, a reduction in the riverine flux of bioavailable phosphorus requires the smallest change to drive the atmosphere to Proterozoic oxygen levels.

\subsubsection{Sensitivity to Model Assumptions}

The sensitivity tests discussed above assume the structure of our model is essentially correct, but it does include two controversial negative feedbacks: oxygen-dependent organic burial efficiency, and oxygen-dependent $\mathrm{P}$ regeneration. Here we consider the validity and importance of these assumptions.

\section{Oxygen and organic carbon burial efficiency}

Organic carbon burial efficiency has been shown to vary with oxygen in many environments. Along the Washington margin, Hedges et al. (1999) observe an increase in organic carbon content with decreasing oxygen penetration depth, which depends on bottom water $\mathrm{O}_{2}(\mathrm{Cai}$ \& Sayles 1996). This environment also has lower organic carbon content than the less oxic Mexican margin (Hartnett and Devol 2003). Canfield (1993) finds a negative correlation between burial efficiency and bottom-water oxygen in a wide compilation of sediments, particularly at low sedimentation rates. Cowie at al. (1995) show that organic carbon contents are much higher below the oxygen penetration depth in the 100,000 year-old Madeira abyssal plain turbidite, allowing for integration over a very long period of alteration.

Though there is convincing evidence for an oxygen effect on organic burial efficiency, the exact relationship is unknown. Here we test an alternative parameterization in which rem- 
Chapter 2 - Proterozoic / Phanerozoic dynamics

ineralization scales with the square root of oxygen in the overlying water column. In this case, $\mathrm{pO}_{2}$ is more sensitive to variations in the remineralization rate constant (Figure 5). If Proterozoic remineralization were somehow ten times more efficient than today (Section 2.4.3.2), then the square root model predicts a 0.2 PAL atmosphere, while the linear model gives 0.4 PAL. For a more modest doubling of the rate constant, both models stabilize at 0.85 PAL. Therefore, we believe that our basic finding, of a weak relationship between $\mathrm{pO}_{2}$ and the remineralization rate constant, is robust.

It should be stressed that our model couples $\mathrm{pO}_{2}$ to oxic respiration, not to burial efficiency itself. This results in a weaker-than-linear scaling between oxygen levels and burial efficiency: even at zero oxygen, sulfate reduction ensures burial efficiency is not $100 \%$. Indeed, we allow sulfate reduction to become more vigorous at lower oxygen levels, due to the possibility that sulfate reduction is limited in modern environments by the availability of the most labile carbon (Westrich \& Berner 1984).

\section{Oxygen and phosphorus regeneration}

Oxygen-dependent loss of pore water $\mathrm{P}$ has been documented in a compilation of sedimentary profiles (Colman \& Holland 2000), suggesting enhanced diffusion from sediments underlying low-oxygen waters. This could be due to shoaling of the iron redox boundary, where P can accumulate due to iron cycling (e.g. Sundby et al. 1992), as proposed by Shaffer (1986) for the Black Sea. There are few quantitative bounds on this relationship beyond a handful of observations by Filippelli (2002).

We can eliminate this oxygen-dependence by setting diffusive loss to a fixed fraction of remineralization. In the extreme case with no diffusive loss, $\mathrm{pO}_{2}$ does become more responsive to changes in respiration rate constants (Figure 5), stabilizing at 0.2 PAL for an implausi- 
Chapter 2 - Proterozoic / Phanerozoic dynamics

ble ten-fold increase. As the fixed fraction of $\mathrm{P}$ loss rises, the stable $\mathrm{pO}_{2}$ value increases. Therefore, we believe our conclusion is robust: changes to sedimentary processes alone cannot explain Proterozoic oxygen levels.

Van Cappellen \& Ingall (1994) have influentially argued that P is preferentially remineralized at low oxygen. Though their estimates for P loss have been revised downward by Anderson et al. (2001) after accounting for authigenic P minerals, we can test this model by setting $\mathrm{P}$ release to scale with organic deposition, rather than with remineralization. Most organic $\mathrm{P}$ is remineralized today, so this distinction makes almost no difference in our results (Figure 5).

\subsubsection{Biogeochemistry of the Proterozoic Ocean}

A low oxygen atmosphere is only possible in our model if primary production is maintained at low levels through a reduction in inputs of the limiting nutrient. Independent of the mechanism for reducing nutrient fluxes, the Proterozoic must have been a period of limited productivity relative to today, with implications for the sulfur cycle, carbon isotopes and marine ecosystems.

We simulate a low-oxygen world by applying a 5 -fold reduction in phosphorus inputs to the model with a Mesoproterozoic solar luminosity and no evaporite weathering (Figure 2). In this simulation primary production is several hundred times less than today, about 10 Tmol

$\mathrm{C}^{-1}$, but is exported and buried more than ten times more efficiently. The net result is a ratio of organic to total carbon burial around 0.05 . This is significantly less than the carbon isotopic record suggests (Canfield 2004), though traditional C isotope mass balance models may be inadequate (Schrag et al. 2013). Without extensive water column respiration, 
Chapter 2 - Proterozoic / Phanerozoic dynamics

deep-water P concentration falls to $0.02 \mu \mathrm{M}$. Phosphate-poor upwelling and efficient export starves the photic zone of nutrients, maintaining low productivity. River-borne P accounts for nearly a third of primary production, compared to a few percent today (Dunne et al. 2007). Therefore, it is possible Proterozoic productivity was redistributed primarily along coastal environments and particularly near estuaries. Unfortunately we cannot explore this hypothesis in a 1-D ocean model.

With so little production, global nitrogen demand would have been hundreds of times lower than today, largely met by inorganic sources of fixed nitrogen such as lightning strikes, which make up $2 \%$ of modern total nitrogen fixation (Galloway et al. 2004). This conclusion depends only on the need for low productivity to compensate for the increased burial efficiency of anoxic sediments, rather than on the particular simulation discussed here. Therefore, limitation by nitrogen itself (Fennel et al. 2005) or by trace metal stress on nitrogen fixers (Planavsky et al. 2010) is unlikely at a global scale, consistent with our assumption of phosphorus limitation.

Seawater sulfate is reduced to $3 \mathrm{mM}$ in our low-oxygen simulation, in agreement with evidence from a number of Mesoproterozoic basins (Poulton \& Canfield 2011). Sulfate is drawn down by more than a doubling of pyrite burial, driven by increased sulfate reduction and inefficient reoxidation of sulfide. A predominantly pyritic sink for sulfur is consistent with the sulfur isotopic record (Canfield 2004) and the scarcity of Proterozoic evaporites (Grotzinger \& Kasting 1993). Without sulfate burial, pyrite would make up the bulk of exposed sulfur minerals; for simplicity we assume $100 \%$ of weathered sulfur was pyrite. This is an extreme end member: at smaller fractions the net sulfur cycle is a smaller source of electrons, and a larger reduction in phosphorus is necessary to maintain low oxygen. 
Chapter 2 - Proterozoic / Phanerozoic dynamics

\subsubsection{Multiple steady states: an oxygen-dependent iron trap for phosphorus}

Any mechanism that limits phosphorus inputs and primary production during the Proterozoic is sufficient to explain the low-oxygen atmosphere. This mechanism could take several forms: oxidation of the atmosphere could be due to an external nutrient forcing that evolves through discrete stages. Alternatively, $\mathrm{pO}_{2}$ may be a truly multiple steady state system, which will remain it its initial low oxygen state until forced into the high oxygen regime by a sufficiently large perturbation. Here we pursue one possible multiple equilibrium solution, motivated by the existence of a major perturbation in the Neoproterozoic Snowball Earth events.

Our sensitivity tests show that a multiple state model requires a feedback that maintains lower phosphorus in lower-oxygen rivers. Apatite dissolution, the primary source of fluvial P (Filippelli 2002), is not an oxidative process, so the feedback cannot involve phosphorus weathering itself. The geochemistry of iron, however, will be greatly affected by lower $\mathrm{O}_{2}$ in the atmosphere. This change may have played an important part in limiting $\mathrm{P}$ delivery to rivers through scavenging by iron oxides.

Phosphate is commonly found sorbed to iron oxides in river colloids. Adsorption is greatest when ferrous iron oxidizes in solution with dissolved anions, as in anoxic groundwater outflows (Mayer \& Jarrell 1995). In laboratory experiments (Mayer \& Jarrell 2000), such coprecipitation raises the particulate P:Fe ratio by a factor of 10 compared to direct addition of ferric iron to solution. This may be due to the high surface area of the colloidal oxides before particle aggregation (Fuller et al. 1993), or to the high surface area of ferrihydrite before crystallization (Mayer \& Jarrell 2000). Today, iron liberated during weathering is typically 
oxidized immediately, before eroding into groundwaters. In the weathering environment of a 0.1 PAL atmosphere, the kinetics of iron oxidation would be 10 times slower than today (Millero et al. 1987b), resulting in significant transport of ferrous iron out of soils, and subsequent oxidation in rivers and estuaries. The efficiency of $\mathrm{P}$ scavenging would greatly increase, limiting bioavailable P. There is evidence for this effect in modern environments: while iron particles in rivers have P:Fe ratios well below 0.1 (Fox 1990,1991), precipitates in eutrophic lakes (Buffle et al. 1989) and hydrothermal plumes (Feely et al. 1998) have ratios greater than 0.25 . This mechanism does require permanent burial of iron-bound phosphorus, either through rapid sedimentation in estuaries, or precipitation of secondary $\mathrm{P}$ minerals.

\subsubsection{Testing the iron trap}

The iron-trap mechanism is only plausible if it can explain a 5 -fold reduction in phosphorus without oxidizing more iron than is available today: the reactive iron load in modern rivers, overwhelmingly in ferric particulates, ranges from 100 to $¿ 500 \mu \mathrm{M}$ (Poulton \& Raiswell 2002). If co-precipitation forms particles with an excess P:Fe ratio of $\alpha$, then the ferrous iron concentration required for an $x$-fold reduction is given by:

$$
\left[F e^{2+}\right]=\alpha^{-1}[P]_{\text {riv }}\left(1-\frac{1}{x}\right)
$$

The appropriate $\mathrm{P}$ concentration is probably much larger than the instantaneously dissolved load, since loosely bound phosphorus may account for two-thirds of the bioavailable supply (Froelich 1988, Benitez-Nelson 2000). Using three times the average dissolved phosphate concentration in modern rivers $(0.6 \mu \mathrm{M}$, Carpenter and Bennett 2011), and $\alpha=0.45$ (Mayer \& Jarrell 2000), we find 2-4 $\mu \mathrm{M}$ of ferrous iron must have been oxidized in Proterozoic rivers, just a few percent of the modern load. 
Phosphorus adsorption is affected by a number of other factors, notably pH. Preferential adsorption occurs in more acidic water (Fuller et al. 1993) favoring our hypothesis given the high pCO2 required to offset the faint Proterozoic sun. However, other important factors, such as silica and organic ligand concentration, and the many determinants of oxide mineralogy, are difficult to assess for ancient rivers. Furthermore, the P:Fe ratios observed in laboratory experiments are typically generated with high initial P loads, and therefore the calculation above may underestimate the necessary iron load.

Nevertheless, we expect the supply of bioavailable phosphorus to increase with rising $\mathrm{pO}_{2}$. Iron minerals have maximum adsorption capacities that are reached at high ferrous iron concentration (Gunnars et al. 2002), so P uptake is likely less responsive to pO2 at lower levels. This corresponds to the type of phosphorus-oxygen relationships that produce two steady states in our model (Figure 6). More specifically, iron dynamics must produce a $\mathrm{P}$ vs. $\mathrm{O}_{2}$ relationship that crosses the oxygen stability curve (Figure 6), with smaller slope, at 1 and 0.1 PAL.

Our multiple-steady state model is the first quantitative hypothesis that explains both the modern and Proterozoic atmosphere. It also has important implications for the step-like rise in $\mathrm{pO}_{2}$ in the Neoproterozoic. A large, transient fluctuation in Neoproterozoic oxygen, perhaps driven by extreme glaciations, could have reduced co-precipitation of iron and phosphorus, driving up the riverine $\mathrm{P}$ flux and ultimately forcing the redox cycle into its high production, high oxygen regime. No fundamental innovation in the geochemical or biological system is required to explain the transition. The Proterozoic atmosphere had merely to wait for a large enough perturbation to drive it into a stable, high-oxygen state. 
Chapter 2 - Proterozoic / Phanerozoic dynamics

\subsection{Conclusions}

Our simple model for atmospheric $\mathrm{pO}_{2}$ is stabilized by oxygen-sensitive organic carbon and pyrite burial. Under low oxygen conditions, more efficient burial drives $\mathrm{O}_{2}$ back to modernday levels. To maintain a low oxygen equilibrium condition, we find the only plausible parameter change in our simple model is a feedback that reduces riverine phosphorus inputs under low oxygen conditions, preventing the phosphorus from stimulating new photosynthesis. Such a relationship compensates for higher burial efficiency with a smaller shuttle of organic material to the sediment. Therefore, multiple steady states in atmospheric oxygen requires some new positive feedback linking increased $\mathrm{pO}_{2}$ to increased phosphorus inputs.

We identify one possible mechanism for this feedback involving more efficient nutrient scavenging by iron under more reduced conditions. In a low oxygen atmosphere, rivers would carry more ferrous iron because the kinetics of iron oxidation are slower. Slow oxidation of iron in solution in rivers and estuaries more efficiently scavenges phosphorus, consistent with experimental evidence. Simple parameterizations of this feedback results in a model with two equilibrium states for oxygen, a low oxygen state with $\mathrm{pO}_{2}$ of a few percent PAL, potentially consistent with Proterozoic conditions, and a high oxygen state with $\mathrm{pO}_{2}$ near 1 PAL, consistent with the Phanerozoic. 

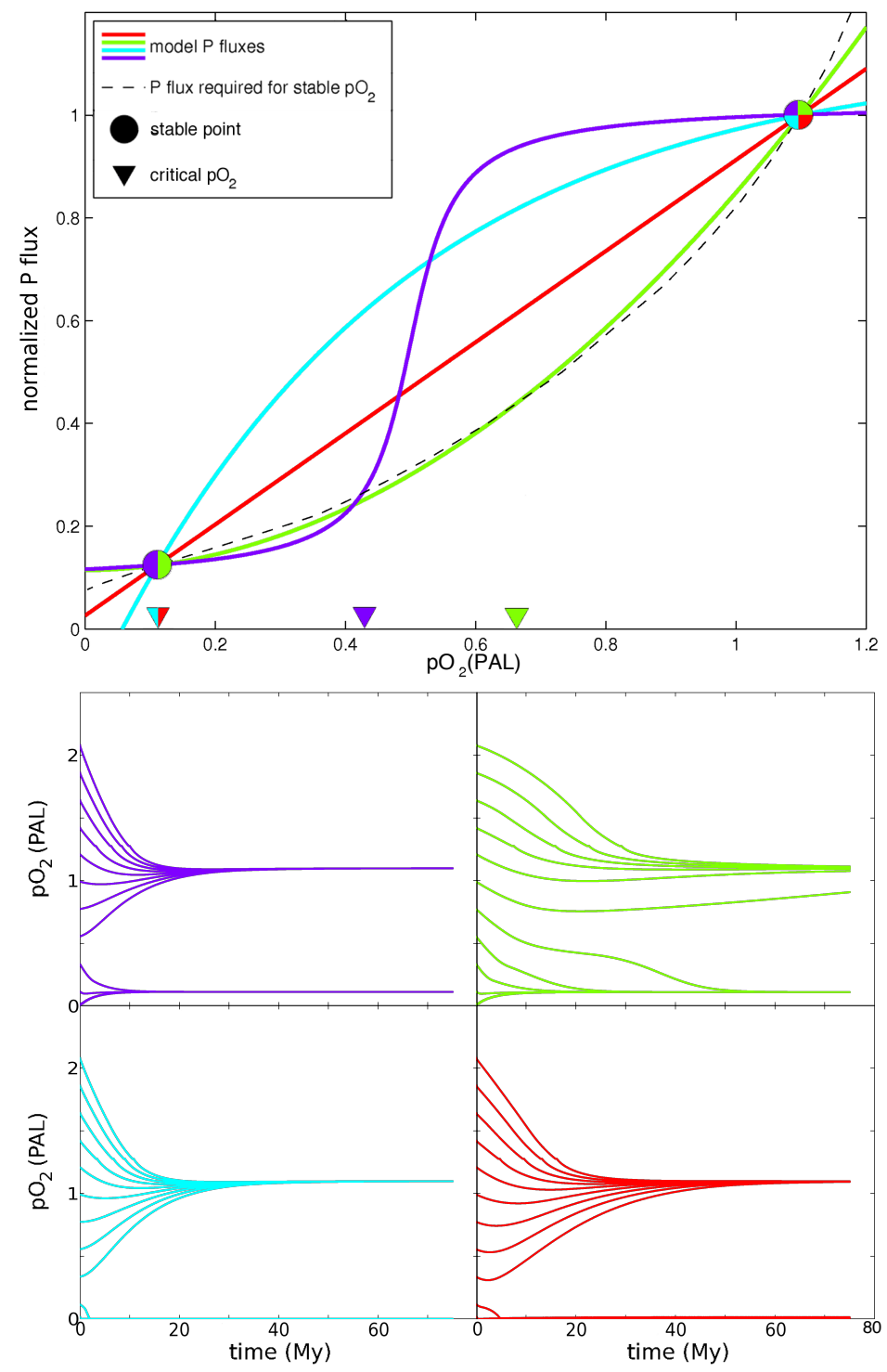

Figure 2.6: Models of multiple stable $\mathrm{pO}_{2}$ levels. Top: Four models of an oxygen-sensitive input of phosphate. The dashed line shows the $\mathrm{P}$ input required to maintain $\mathrm{pO}_{2}$ at a given level. Stable equilibria are marked with circles, unstable equilibria with triangles. Bottom: evolution of $\mathrm{pO}_{2}$ from various initial conditions for each of the $\mathrm{P}$ input models. The green and purple give multiple steady states. 
Table 2.1: Time-dependent evolution of the prognostic variables. $a$ : atmosphere; $s$ : shallow ocean; $d$ : deep ocean. $M$ is the volume of an ocean box.

$$
\begin{aligned}
& \frac{d}{d t}\left(\mathrm{O}_{2}\right)_{a}=-\mathrm{W}_{C}-\frac{15}{8} \mathrm{~W}_{p y r} \\
& \frac{d}{d t}\left[\mathrm{O}_{2}\right]_{s} M_{s}=-\left(\mathrm{R}_{w c}\right)-2 \mathrm{Q}+N P P \\
& \frac{d}{d t}\left[\mathrm{O}_{2}\right]_{d} M_{d}=-\left(\mathrm{R}_{w c}\right)-2 \mathrm{Q} \\
& \frac{d}{d t}\left[\mathrm{SO}_{4}^{2-}\right]_{s} M_{s}=\mathrm{Q}-\left(\mathrm{S}_{w c}+\mathrm{S}_{s d}\right)-\mathrm{B}_{S o x}-\frac{1}{16} \mathrm{~B}_{p y r}+W_{S} \\
& \frac{d}{d t}\left[\mathrm{SO}_{4}^{2-}\right]_{d} M_{d}=\mathrm{Q}-\left(\mathrm{S}_{w c}+\mathrm{S}_{s d}\right)-\mathrm{B}_{S o x}-\frac{1}{16} \mathrm{~B}_{p y r}-\mathrm{H}_{S_{o x}} \\
& \frac{d}{d t}\left[\mathrm{~S}^{2-}\right]_{s} M_{s}=-\mathrm{Q}+\left(\mathrm{S}_{w c}+\mathrm{S}_{s d}\right)-\frac{15}{16} \mathrm{~B}_{p y r} \\
& \frac{d}{d t}\left[\mathrm{~S}^{2-}\right]_{d} M_{d}=-\mathrm{Q}+\left(\mathrm{S}_{w c}+\mathrm{S}_{s d}\right)-\frac{15}{16} \mathrm{~B}_{p y r}+\mathrm{H}_{S_{r d}} \\
& \frac{d}{d t}\left[\mathrm{C}_{o r g}\right]_{s} M_{s}=-\left(\mathrm{R}_{w c}+2 \mathrm{~S}_{w c}\right)-\left(\mathrm{B}_{a}+\mathrm{B}_{C}\right)+\mathrm{NPP}-\mathrm{EP} \\
& \frac{d}{d t}\left[\mathrm{C}_{o r g}\right]_{d} M_{d}=-\left(\mathrm{R}_{w c}+2 \mathrm{~S}_{w c}\right)-\left(\mathrm{B}_{a}+\mathrm{B}_{C}\right)+\mathrm{EP} \\
& \frac{d}{d t}\left[P O_{4}^{3-}\right]_{s} M_{s}=\frac{1}{r}\left(\mathrm{R}_{w c}+2 \mathrm{~S}_{w c}\right)-\mathrm{B}_{P}+Y+\frac{1}{r} N P P+\mathrm{W}_{p} \\
& \frac{d}{d t}\left[P O_{4}^{3-}\right]_{d} M_{d}=\frac{1}{r}\left(\mathrm{R}_{w c}+2 \mathrm{~S}_{w c}\right)-\mathrm{B}_{P} \\
& \frac{d}{d t}(\mathrm{DIC})_{s}=\left(\mathrm{R}_{w c}+\mathrm{R}_{s d}\right)+2\left(\mathrm{~S}_{w c}+\mathrm{S}_{s d}\right)+\mathrm{V}_{C}-\mathrm{B}_{C O_{3}}+\mathrm{W}_{C O_{3}}+\mathrm{W}_{C}-N P P \\
& \frac{d}{d t}(\mathrm{DIC})_{d}=\left(\mathrm{R}_{w c}+\mathrm{R}_{s d}\right)+2\left(\mathrm{~S}_{w c}+\mathrm{S}_{s d}\right)+\mathrm{V}_{C}-\mathrm{B}_{C O_{3}} \\
& \frac{d}{d t}\left[\mathrm{Ca}{ }^{2+}\right]_{s} M_{s}=-\mathrm{B}_{C O_{3}}+\mathrm{W}_{C a} \\
& \frac{d}{d t}\left[\mathrm{Ca}^{2+}\right]_{d} M_{d}=-\mathrm{B}_{C O_{3}}
\end{aligned}
$$


Table 2.2: Flux parameterizations. Values for the rate constants $(k)$ and water mass volumes $(M)$ vary between deep $(d)$ and shallow $(s)$ waters, but subscripts are not given here unless needed. Parameter values are given in Tables 2.3-2.5. Note: $\left[\mathrm{C}_{\text {org }}\right]$ includes net primary production and excludes adsorbed carbon from the current time step.

\begin{tabular}{|l||l|l|}
\hline Process & Parameterization & $\mathrm{mol} x \mathrm{yr}^{-1}$ \\
\hline \hline Net primary production & $\mathrm{NPP}=r\left[\mathrm{PO}_{4}^{3-}\right]_{s} \mathrm{M}_{s}$ & $\mathrm{C}$ \\
\hline Oxic respiration, water col. & $\mathrm{R}_{w c}=k_{0}\left[\mathrm{O}_{2}\right]\left[\mathrm{C}_{o r g}\right] \mathrm{M}$ & $\mathrm{C}$ \\
\hline Sulfate reduction, water col. & $\mathrm{S}_{w c}=k_{1}\left[\mathrm{SO}_{4}^{2-}\right]\left[\mathrm{C}_{\text {org }}\right] \mathrm{M}$ & $\mathrm{S}$ \\
\hline Sulfide oxidation & $\mathrm{Q}=k_{2}\left[\mathrm{O}_{2}\right]\left[\mathrm{S}^{2-}\right] \mathrm{M}$ & $\mathrm{S}$ \\
\hline Gross burial of organic C & $\mathrm{B}_{C}=\alpha k_{3}\left(\left[\mathrm{C}_{o r g}\right] \mathrm{M}-\left(\mathrm{R}_{s d}-2 \mathrm{~S}_{w c}\right)\right)+\mathrm{B}_{a}$ & $\mathrm{C}$ \\
\hline Adsorption of organic C & $\mathrm{B}_{a}=k_{4} \mathrm{~W}_{a} \cdot \mathrm{NPP}$ & $\mathrm{C}$ \\
\hline Oxic respiration, sediment & $\mathrm{R}_{s d}=k_{5}\left[\mathrm{O}_{2}\right] \mathrm{M}$ & $\mathrm{C}$ \\
\hline Sulfate reduction, sediment & $\mathrm{S}_{s d}=\beta k_{6}\left[\mathrm{SO}_{4}^{2-}\right] \mathrm{M}$ & $\mathrm{S}$ \\
\hline Pyrite burial & $\mathrm{B}_{p y r}=\gamma \mathrm{S}_{s d}$ & $\mathrm{~S}$ \\
\hline Sulfate burial & $\mathrm{B}_{S_{o x}}=k_{7}\left[\mathrm{SO}_{4}^{2-}\right] \mathrm{M}$ & $\mathrm{S}$ \\
\hline Phosphorus scavenging & $\mathrm{B}_{P}=k_{8}\left[\mathrm{PO}_{4}^{3-}\right] \mathrm{M}$ & $\mathrm{P}$ \\
\hline Phosphorus regeneration & $\mathrm{Y}^{2}=\delta\left(\mathrm{R}_{s d}+2 \mathrm{~S}_{s d}\right) / r$ & $\mathrm{P}$ \\
\hline Weathering, organic C & $\mathrm{W}_{C}=k_{9}\left(p \mathrm{O}_{2}\right)^{1 / 2}$ & $\mathrm{O}$ \\
\hline Weathering, phosphorus & $\mathrm{W}_{P}=\omega \mathrm{W}_{a p}+f_{b} \mathrm{~W}_{C} / r$ & $\mathrm{P}$ \\
\hline Weathering, crust Fe & $\mathrm{W}_{F e}=k_{10}\left[\mathrm{O}_{2}\right]_{d} \mathrm{M}_{d}$ & $\mathrm{Fe}$ \\
\hline
\end{tabular}


Chapter 2 - Proterozoic / Phanerozoic dynamics

Table 2.3: Rate constant values. See Table 2.2 for defintions. Units are such that all fluxes are in moles per year. The multipliers $\alpha, \beta, \gamma$ and $\delta$ vary linearly with the quantities shown in the last column; the given pair of points defines the linear relationship.

\begin{tabular}{|c|c|c|c|c|c|}
\hline Abbr. & $k$ & deep $k$ & shallow $k$ & $\mathrm{y}_{1,2}$ & $\mathrm{x}_{1,2}$ \\
\hline $\mathrm{R}_{w c}$ & $k_{0}$ & 64 & 330 & & \\
\hline $\mathrm{S}_{w c}$ & $k_{1}$ & 0.14 & 1.49 & & \\
\hline $\mathrm{Q}$ & $k_{2}$ & $1.80 * 10^{5}$ & $1.80 * 10^{5}$ & & \\
\hline $\mathrm{B}_{C}$ & $k_{3}$ & $3.12 * 10^{-5}$ & $5.50 * 10^{-3}$ & $\begin{array}{l}\alpha=1 \\
\alpha=10\end{array}$ & $\begin{array}{l}f_{u p}=0 \\
f_{u p}=0.94\end{array}$ \\
\hline $\mathrm{B}_{a}$ & $k_{4}$ & $5.93 * 10^{-19}$ & $6.60 * 10^{-19}$ & & \\
\hline $\mathrm{R}_{s d}$ & $k_{5}$ & $1.64 * 10^{-5}$ & $1.40 * 10^{-3}$ & & \\
\hline$\overline{\mathrm{S}_{s d}}$ & $k_{6}$ & $2.04 * 10^{-8}$ & $5.31 * 10^{-6}$ & $\begin{array}{l}\beta=1 \\
\beta=10\end{array}$ & $\begin{array}{l}f_{R}=0.995 \\
f_{R}=0.6\end{array}$ \\
\hline $\mathrm{B}_{p y r}$ & & & & $\begin{array}{l}\gamma=0.2 \\
\gamma=0.7\end{array}$ & $\begin{array}{l}{\left[\mathrm{O}_{2}\right]_{s}=260 \mu \mathrm{M}} \\
{\left[\mathrm{O}_{2}\right]_{s}=0 \mu \mathrm{M}}\end{array}$ \\
\hline $\mathrm{B}_{S_{o x}}$ & $k_{7}$ & $5.42 * 10^{-8}$ & $5.42 * 10^{-8}$ & & \\
\hline $\mathrm{B}_{P}$ & $k_{8}$ & $1.00 * 10 * 10^{-7}$ & $1.00 * 10^{-7}$ & & \\
\hline $\mathrm{Y}$ & & & & $\begin{array}{l}\delta=0.25 \\
\delta=0.5\end{array}$ & $\begin{array}{l}{\left[\mathrm{O}_{2}\right]=260 \mu \mathrm{M}} \\
{\left[\mathrm{O}_{2}\right]=0 \mu \mathrm{M}}\end{array}$ \\
\hline $\mathrm{W}_{C}$ & $k_{9}$ & & $6.8 * 10^{12}$ & & \\
\hline $\mathrm{W}_{F e}$ & $k_{10}$ & $1.03 * 10^{-5}$ & & & \\
\hline
\end{tabular}


Chapter 2 - Proterozoic / Phanerozoic dynamics

Table 2.4: Fixed fluxes and reservoir sizes. See Table 2.2 for defintions. $\mathrm{W}_{a}, \mathrm{~W}_{a p}, \mathrm{~W}_{\mathrm{CO}_{3}}$ and $\mathrm{W}_{C a}$ do scale with the weathering factor $\omega$, defined in Table 2.5.

\begin{tabular}{|c|c|c|c|}
\hline Flux & Abbreviation & value & units \\
\hline Weathering, total sediment & $\mathrm{W}_{a}$ & 19.1 & Pg $\mathrm{yr}^{-1}$ \\
\hline Weathering, apatite & $\mathrm{W}_{a p}$ & 280 & Gmol P yr \\
\hline Weathering, carbonate & $\mathrm{W}_{\mathrm{CO}_{3}}$ & 8.5 & Tmol C yr ${ }^{-1}$ \\
\hline Weathering, $\mathrm{Ca}^{2+}$ & $\mathrm{W}_{C a}$ & 13.2 & Tmol Ca yr ${ }^{-1}$ \\
\hline Weathering, total sulfur & $\mathrm{W}_{S}$ & 3.7 & Tmol S yr ${ }^{-1}$ \\
\hline Weathering, pyrite & $\mathrm{W}_{\text {pyr }}$ & 0.8 & Tmol S yr ${ }^{-1}$ \\
\hline Hydrothermal, sulfate & $\mathrm{H}_{S_{o x}}$ & 0.8 & Tmol S yr ${ }^{-1}$ \\
\hline Hydrothermal, sulfide & $\mathrm{H}_{S_{r d}}$ & 0.7 & Tmol S yr ${ }^{-1}$ \\
\hline Volcanic, carbon & $\mathrm{V}_{C}$ & 2.5 & Tmol C yr ${ }^{-1}$ \\
\hline Reservoir & Abbreviation & value & units \\
\hline 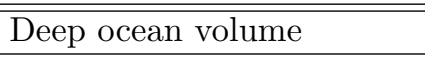 & $\overline{\mathrm{M}_{d}}$ & $1.3 * 10^{21}$ & $\overline{\mathrm{L}}$ \\
\hline Surface ocean volume & $\mathrm{M}_{s}$ & $3.6 * 10^{19}$ & $\mathrm{~L}$ \\
\hline Atmoshere mass & $\mathrm{M}_{a}$ & $5.3 * 10^{18}$ & $\mathrm{~kg}$ \\
\hline Mixing volume & $\mathrm{X}$ & $6.9 * 10^{18}$ & $\mathrm{~L} \mathrm{yr}^{-1}$ \\
\hline
\end{tabular}

Table 2.5: Additional model parameters. See Table 2.2 for definitions.

\begin{tabular}{|c|l||c|}
\hline Parameter & Defintion & Value \\
\hline \hline$f_{b}$ & bioavailable fraction of weathered $\mathrm{P}$ & 0.2 \\
\hline$f_{u}$ & fraction of new production from upwelling & $\frac{\mathrm{x}\left(\left[\mathrm{PO}_{4}^{3-}\right]_{d}-\left[\mathrm{PO}_{4}^{3-}\right]_{s}\right)}{\mathrm{W}_{P}+\mathrm{X}_{\left(\left[\mathrm{PO}_{4}^{3-}\right]_{d}-\left[\mathrm{PO}_{4}^{3-}\right]_{s}\right)}}$ \\
\hline$f_{R}$ & $\begin{array}{l}\text { NPP fraction remineralized } \\
\text { above anoxic sediment }\end{array}$ & $\frac{\mathrm{R}_{w c}+\mathrm{S}_{w c}+\mathrm{R}_{s d}}{\mathrm{NPP}}$ \\
\hline$\omega$ & chemical weathering scale factor & $\left(\frac{p \mathrm{CO}}{(280 p p m)}\right)^{0.3} \exp \left(\frac{T-288 K}{3}\right)$ \\
\hline$\eta$ & Ocean/atmosphere $\mathrm{O}_{2}$ partitioning constant & 4287 \\
\hline$\Omega_{s}, \Omega_{d}$ & Calcite saturation states & $4.0,1.1$ \\
\hline
\end{tabular}


Chapter 2 - Proterozoic / Phanerozoic dynamics

Table 2.6: Oxygen-sensitive $\mathrm{P}$ flux parameters.

\begin{tabular}{|l|r||l|r|}
\hline$\rho_{1}$ & 0.8868 & $\rho_{2}$ & 0.0260 \\
\hline$\rho_{3}$ & 1.1158 & $\rho_{4}$ & 1.2635 \\
\hline$\rho_{5}$ & 2.1757 & $\rho_{6}$ & 0.2990 \\
\hline$\rho_{7}$ & 20.0 & $\rho_{8}$ & 10.0 \\
\hline$\rho_{9}$ & 0.5563 & $\rho_{10}$ & 0.7260 \\
\hline$\rho_{11}$ & 0.0092 & $\rho_{12}$ & 0.1141 \\
\hline
\end{tabular}

Table 2.7: Reservoirs and mixing fluxes for the Black Sea model. From Murray et al. 1991.

\begin{tabular}{|l|l||r|l|}
\hline Parameter & Abberviation & Value & Units \\
\hline \hline Deep basin volume & $\mathrm{M}_{d}$ & $5.1 * 10^{17}$ & $\mathrm{~L}$ \\
\hline Surface basin volume & $\mathrm{M}_{s}$ & $1.1 * 10^{16}$ & $\mathrm{~L}$ \\
\hline Mixing rate & $\mathrm{X}$ & $1.0 * 10^{15}$ & $\mathrm{~L} \mathrm{yr}^{-1}$ \\
\hline Bosporus inflow rate & $\mathrm{X}_{M}$ & $3.1 * 10^{14}$ & $\mathrm{~L} \mathrm{yr}^{-1}$ \\
\hline Bosporus outflow rate & $\mathrm{X}_{o}$ & $6.0 * 10^{14}$ & $\mathrm{~L} \mathrm{yr}^{-1}$ \\
\hline River inflow rate & $\mathrm{X}_{r}$ & $3.6 * 10^{14}$ & $\mathrm{~L} \mathrm{yr}^{-1}$ \\
\hline
\end{tabular}

Table 2.8: Chemical concentrations in Mediterranean and river water for the Black Sea model. References: K\&M: Konovalov \& Murray 2001; P\&T: Polat \& Tugrul 1995; S\&G: Sarmiento \& Gruber 2006 (mean ocean); D: Deuser 1971 (Danube); PFV: Pawellek et al. 2002 (Danube); B\&B: Berner \& Berner 1996 (mean rivers); eq: equilibrium with modern atmosphere.

\begin{tabular}{|l||r|r|l|l|}
\hline Species & Mediterranean & river & Units & Ref. \\
\hline $\mathrm{O}_{2}$ & 50 & 240 & $\mu \mathrm{M}$ & K\&M, eq \\
\hline $\mathrm{SO}_{4}^{2-}$ & 30 & 0.5 & $\mathrm{mM}$ & S\&G, PFV \\
\hline $\mathrm{S}^{2-}$ & 0 & 0 & $\mu \mathrm{M}$ & $\mathrm{S} \& \mathrm{G}$ \\
\hline $\mathrm{C}_{\text {org }}$ & 0.1 & 1.0 & $\mathrm{mM}$ & $\mathrm{P} \& \mathrm{~T}, \mathrm{D}$ \\
\hline $\mathrm{PO}_{4}^{3-}$ & 1.0 & 50 & $\mu \mathrm{M}$ & $\mathrm{P} \& \mathrm{~T}, \mathrm{PFV}$ \\
\hline $\mathrm{C}_{\text {inorg }}$ & 2026 & 845 & $\mu \mathrm{M}$ & $\mathrm{S} \& \mathrm{G}$, eq \\
\hline $\mathrm{Ca}^{2+}$ & 10.3 & 0.36 & $\mathrm{mM}$ & $\mathrm{S} \& \mathrm{G}, \mathrm{B} \& \mathrm{~B}$ \\
\hline
\end{tabular}




\title{
Chapter 3
}

\section{Atmospheric oxygen as a constraint on Proterozoic carbon isotope systematics}

\begin{abstract}
The average $\delta^{13} \mathrm{C}$ of sedimentary carbonates has been close to $0 \%$ for billions of years. According to standard mass balance models, this isotopic signature requires the burial of organic matter to account for $\sim 20 \%$ of the total carbon removed from Earths surface reservoirs at any point in time. However, a fixed value of this fraction $\left(f_{\text {org }}\right)$ over most of Earth history is inconsistent with the radical changes to biogeochemical cycling required to explain the low atmospheric oxygen that prevailed during the Proterozoic. Using simple mass balance arguments and a model of ocean-atmosphere biogeochemical cycles, we show that stable atmospheric $\mathrm{pO}_{2}$ below $10 \%$ present-day levels requires an ocean characterized by low productivity and by values of $f_{\text {org }}$ much less than 0.2 . We propose that this paradox can be resolved by increased rates of authigenic carbonate formation during the Proterozoic, driven by more rapid sulfate and iron reduction beneath the low oxygen ocean.
\end{abstract}


Chapter 3 - Proterozoic $\delta^{13} \mathrm{C}$

\subsection{Introduction}

Organic carbon burial is one of the major sources of oxygen to the atmosphere. Understanding the evolution of oxygen, with its implications for the evolution of life, therefore depends on an understanding of the global carbon cycle. As there are no direct quantitative proxies for $\mathrm{pO}_{2}$ in the geological record, estimates of organic carbon burial are a particularly important constraint on redox cycling through time.

The rate of organic carbon burial is often expressed in terms of $f_{\text {org }}$, the organic fraction of total carbon burial in sediments. $f_{\text {org }}$ is a measure of the average oxidation state of buried carbon, and so shifts in $f_{\text {org }}$ record changes in the electron budget of the ocean and atmosphere, with larger $f_{\text {org }}$ reflecting additional organic carbon burial and a larger source of oxygen to Earths surface. The paleorecord of $f_{\text {org }}$ can be derived from carbon isotopes recorded in organic matter and in calcium carbonate through a simple mass balance relationship, assuming steady state and a constant fractionation $\epsilon_{p}$ between the two carbon pools:

$$
\delta^{13} \mathrm{C}_{\text {in }}=\left(\delta^{13} \mathrm{C}_{\text {carb }}-\epsilon_{p}\right) f_{\text {org }}+\left(\delta^{13} \mathrm{C}_{\text {carb }}\right)\left(1-f_{\text {org }}\right)
$$

where the subscript in denotes carbon inputs from the mantle, carb denotes dissolved carbonate species, and $\epsilon_{p}$ is the average fractionation associates with biological productivity. Modern carbonates mostly have $\delta^{13} \mathrm{C}_{\text {carb }} \sim 0$, giving $f_{\text {org }}=0.2$, assuming inputs $\left(\mathrm{C}_{\text {in }}\right)$ have $\delta^{13} \mathrm{C}$ close to the mantle value of $-5 \%$ and that the biological fractionation $\epsilon_{p}$ is $25 \%$. Independent estimates of burial of organic carbon ( $\sim 10$ Tmol C yr, Muller-Karger 2004, Hedges \& Keil 1995) and calcium carbonate (32 $\mathrm{Tmol} \mathrm{C} \mathrm{yr}^{-1}$, Milliman 1993) give a similar result. The Phanerozoic redox system is believed to be close to steady state (Scott \& Glasspool 2006), so variations from this modern value of $f_{\text {org }}$ reflect unbalanced burial of organic 
carbon and a net source or sink of oxygen, barring compensating changes in the cycling of other major redox species.

The isotopic record of carbonates has had an average value near 0\%o since the Archean (Shields \& Veizer 2002), consistent with static budgets of carbon and oxygen. This is troubling because the oxygen content of the atmosphere has likely varied by orders of magnitude between the Paleoproterozoic and today (Kump 2008), requiring significant changes to the surface electron budget on long time scales. Carbon is only one of several quantitatively significant redox-active species, but the concept of a dynamic electron budget with unvarying organic carbon burial seems counter-intuitive. For example, removal of oxygen due to oxic weathering was likely slower under a low- $\mathrm{pO}_{2}$ Proterozoic atmosphere (e.g. Chang \& Berner 1999). This should have quickly driven oxygen to high levels unless there was a compensating reduction in the oxygen source, organic carbon burial. However, less burial also implies a smaller value of $f_{\text {org }}$, contradicting the isotopic data.

This suggests a paradox, but a more complete treatment of the chemical dynamics is necessary to prove disagreement between the $\mathrm{pO}_{2}$ and $\delta^{13} \mathrm{C}$ records. The goal of this paper is to assess whether $f_{\text {org }} \sim 0.2$ can possibly be consistent with the constraints on biogeochemical cycling imposed by the $\mathrm{pO}_{2}$ proxy record over the past 2.4 billion years. We use a box model of ocean-atmosphere chemistry to explore the range of geochemical budgets consistent with our knowledge of the evolution of atmospheric oxygen. We then use these results to make predictions regarding $f_{\text {org }}$ and the $\delta^{13} \mathrm{C}$ record, which must be reconciled with existing isotopic data. 
Chapter 3 - Proterozoic $\delta^{13} \mathrm{C}$

\subsection{Model}

The biogeochemical model couples the carbon, iron and sulfur cycles through first-order chemical reactions in a two-layer, phosphorus-limited ocean, tuned to reproduce modern reservoir and flux values. Those processes directly relevant to $f_{\text {org }}$ are reviewed briefly here; the full model equations and sensitivities are described in detail in Chapter 2.

\subsubsection{Carbon cycle model}

Net organic carbon burial is modeled as the difference between gross deposition and sedimentary remineralization. Deposition scales with primary production, with an additional ballasted flux linked to the rate of silicate weathering on continents. Remineralization rates scale with the oxygen and sulfate concentrations in the overlying water; both linear and square root relationships are explored here.

Inorganic carbon burial is modeled as a calcite precipitation/dissolution flux. Volcanic fluxes and $\mathrm{pCO}_{2}$-dependent weathering drive $\mathrm{DIC}$ and calcium concentrations, which are used to compute changes to alkalinity, equilibrium carbonate chemistry, and calcite saturation.

The weathering rate for carbonates, silicates and apatite scale with $\mathrm{pCO} 2$ and temperature according to Walker et al. (1981). Global mean surface temperature is calculated assuming a climate sensitivity of $3 \mathrm{~K}$ per doubling of $\mathrm{CO} 2$ relative to a baseline of $\left(\mathrm{L}^{1 / 4}\right) * 288 \mathrm{~K}$ at 280 ppm, where L is the luminosity of the sun relative to its modern value. Volcanic inputs of carbon are constant at $0.2 \mathrm{Gt} \mathrm{CO}_{2}$ per year (Huybers \& Langmuir 2009).

To represent the precipitation and dissolution of calcite, the model maintains a fixed saturation state in the ocean, requiring computation of carbonate ion concentration from total 
carbon and alkalinity. Alkalinity varies from its modern day value of $2200 \mu \mathrm{M}$ based on variations in calcium around the modern mean ocean average of $10.3 \mathrm{mM}$ (Sarmiento \& Gruber 2006).

Based on the alkalinity and total carbon values, temperature-specific carbonate speciation is calculated for each box using the equilibrium constants from Zeebe \& Wolf-Gladrow (2000) with a salinity of $35,10 \%$ over saturation of the surface ocean with carbon dioxide, and a deep-water calcite saturation constant $\left(k_{s p}\right)$ corresponding to $3800 \mathrm{~m}$ depth. Given the solution for $\left[\mathrm{CO}_{3}^{2-}\right]$, the total precipitation/dissolution of calcite $p$ is chosen such that:

$$
\left(\left[\mathrm{Ca}^{2+}\right]-[p]\right)\left(\left[\mathrm{CO}_{3}^{2-}\right]-[p]\right)=k_{s p} \Omega
$$

where $\Omega$ is a fixed saturation state in each ocean box. Total carbon, alkalinity and carbonate speciation are re-calculated, yielding the $\mathrm{pCO}_{2}$ values fed to the next step.

These parameterizations are tuned to approximately reproduce modern biogeochemical cycles. At steady state, the model has 1.1 present atmospheric levels (PAL) $\mathrm{pO}_{2}$ and 250

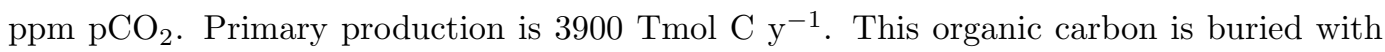
a long-term efficiency of $0.1 \%$. Bioavailable phosphorus inputs are $250 \mathrm{Gmol} \mathrm{P} \mathrm{y}^{-1}$. The low-oxygen "Proterozoic" simulations discussed in this paper are adjusted to have solar luminosity appropriate to $1.3 \mathrm{Ga}$ (Gough 1981) and continental sulfur reservoir composed entirely of pyrite, in keeping with both geological (Grotzinger \& Kasting 1993) and isotopic (Canfield 2004) evidence for a lack of sulfate deposition. Oxygen levels are then tuned by adjusting inputs of continental phosphorus and hydrothermal sulfides to the ocean. 


\subsubsection{Carbon isotope model}

For this study, the model discussed in Chapter 2 has been updated to include carbon isotopes. $\delta^{13} \mathrm{C}$ values are tracked for atmospheric carbon dioxide, dissolved $\mathrm{CO}_{2}$, carbonate and bicarbonate ion, precipitated calcium carbonate, and organic carbon. $\left(\delta^{13} \mathrm{C}\right.$ will be abbreviated as $\delta$ when there is no ambuiguity.)

At each time step, the model the calculates total inorganic carbon reservoirs $(\Sigma \mathrm{C})$ in both the deep ocean and the combined surface ocean /atmosphere. The relevant flux parameterizations are outlined in section 3.2.1, and discussed in detail in Chapter 2. The isotope-specific fluxes of ${ }^{13} \mathrm{C}$ and ${ }^{12} \mathrm{C}$ through these boxes are calculated by applying an isotopic ratio ${ }^{13} r$ to each of the carbon fluxes. For a carbon flux $F$, the associated flux of ${ }^{13} C$ is given by:

$$
\begin{aligned}
& { }^{13} F={ }^{13} r \cdot F \\
& { }^{13} r=\frac{{ }^{13} C}{{ }^{12} C+{ }^{13} C}
\end{aligned}
$$

These ratios ${ }^{13} r$ are determined from either fixed $\delta$ or $\epsilon$ values:

$$
\begin{aligned}
& \delta \sim\left(\frac{{ }^{13} R}{{ }^{13} R_{*}}-1\right) 10^{3} \\
& \epsilon \sim\left(\frac{{ }^{13} R}{{ }^{13} R_{\star}}-1\right) 10^{3} \\
& { }^{13} R \sim \frac{{ }^{13} C}{{ }^{12} C}=\frac{{ }^{13} r}{1-{ }^{13} r}
\end{aligned}
$$


where $*$ refers to a standard (here, VPDB), and $\star$ to another phase.

Volcanic carbon is assumed to have $\delta^{13} \mathrm{C}$ of $5 \%$. Primary production has a fixed $\epsilon$ of -27 \%orelative to bicarbonate ion; remineralization processes do not fractionate. Carbonate and organic carbon weathering have the $\delta^{13} \mathrm{C}$ of the calcite and organic carbon, respectively, buried in shallow sediments in the previous step. This last parameterization is very unrealistic, as exposure and weathering of buried carbon depends on tectonic processes on very long time scales. This assumption will result in unrealistic short-term transients, but should give better equilibrium solutions than assuming fixed $\delta$ values over all time. Ocean mixing transports dissolved inorganic carbon species without fractionation. These parameterizations are summarized in Table 3.1.

Given the total ${ }^{12} \mathrm{C}$ and $\delta^{13} \mathrm{C}$ in one of the model boxes, the isotopes are partioned among five inorganic carbon species: atmospheric $\mathrm{CO}_{2}$, calcium carbonate precipitated in the current time step, and the dissolved species $\mathrm{H}_{2} \mathrm{CO}_{3}, \mathrm{HCO}_{3}^{-}$, and $\mathrm{CO}_{3}^{2-} \cdot \delta^{13} \mathrm{C}$ for each of these species is found by solving the following system for the isotopic ratios $R \sim{ }^{13} \mathrm{C} /{ }^{12} \mathrm{C}$, given the carbon reservoirs $C$ :

$$
\begin{aligned}
R_{\mathrm{H}_{2} \mathrm{CO}_{3}} & =\left(1000 \epsilon_{1}+1\right) R_{\mathrm{CO}_{2}(\mathrm{~g})} \\
R_{\mathrm{HCO}_{3}^{-}} & =\left(1000 \epsilon_{2}+1\right) R_{\mathrm{CO}_{2}(\mathrm{~g})} \\
R_{\mathrm{CO}_{3}^{2-}} & =\left(1000 \epsilon_{3}+1\right) R_{\mathrm{CO}_{2}(\mathrm{~g})} \\
R_{\mathrm{CaCO}_{3}} & =\left(1000 \epsilon_{3}+1\right) R_{\mathrm{HCO}_{3}^{-}} \\
\Sigma \mathrm{C} & =C_{\mathrm{CO}_{2}(\mathrm{~g})}+C_{\mathrm{H}_{2} \mathrm{CO}_{3}}+C_{\mathrm{HCO}_{3}^{-}}+C_{\mathrm{CO}_{3}^{2-}}+C_{\mathrm{CaCO}_{3}}
\end{aligned}
$$

The temperature-dependent fractionation factors $\epsilon$ are from Zeebe \& Wolf-Gladrow (2000): 


$$
\begin{aligned}
& \epsilon_{1}=-0.1141 T+10.78 \\
& \epsilon_{2}=0.0049 T-1.31 \\
& \epsilon_{3}=-0.0520 T+7.22 \\
& \epsilon_{4}=0.9+\eta
\end{aligned}
$$

where $T$ is the surface temperature in degrees Celcius. Note that all $\epsilon$ values are relative to the gas phase, except $\epsilon_{4}$, which is relative to bicarbonate.In order to simulate a pool of authigenic calcium carbonate that is not in equilibrium with the marine carbon reservoir, a fixed offset $\eta$ is applied to the fractionation between calcium carbonate and bicarbonate: $\epsilon_{3} \rightarrow \epsilon_{3}+\eta$.

\subsection{Results}

Figure 1 shows $f_{\text {org }}$ as a function of the steady state $\mathrm{pO}_{2}$ in various low-oxygen simulations. The model atmosphere is forced to $\mathrm{pO}_{2}$ levels between $1 \%$ and $10 \%$ PAL by reducing the flux of phosphorus from weathering. These simulations are divided into four sets according to two parameterization decisions. First, the hydrothermal sulfide flux is either held at modern levels, or allowed to vary with heat flow (Turcotte 1980), giving roughly double the modern flux. Second, the sedimentary remineralization varies either linearly with the oxygen concentration of the overlying water, or with its square root.

In all cases $f_{\text {org }}$ is between 0.01 and 0.09 , compared to our modern simulation (Laakso \& Schrag 2014) with $f_{\text {org }}=0.24$. The reduction in $f_{\text {org }}$ is due to a drop in organic burial. Primary production is buried 20-60 times more efficiently in the low oxygen oceans, but pri- 


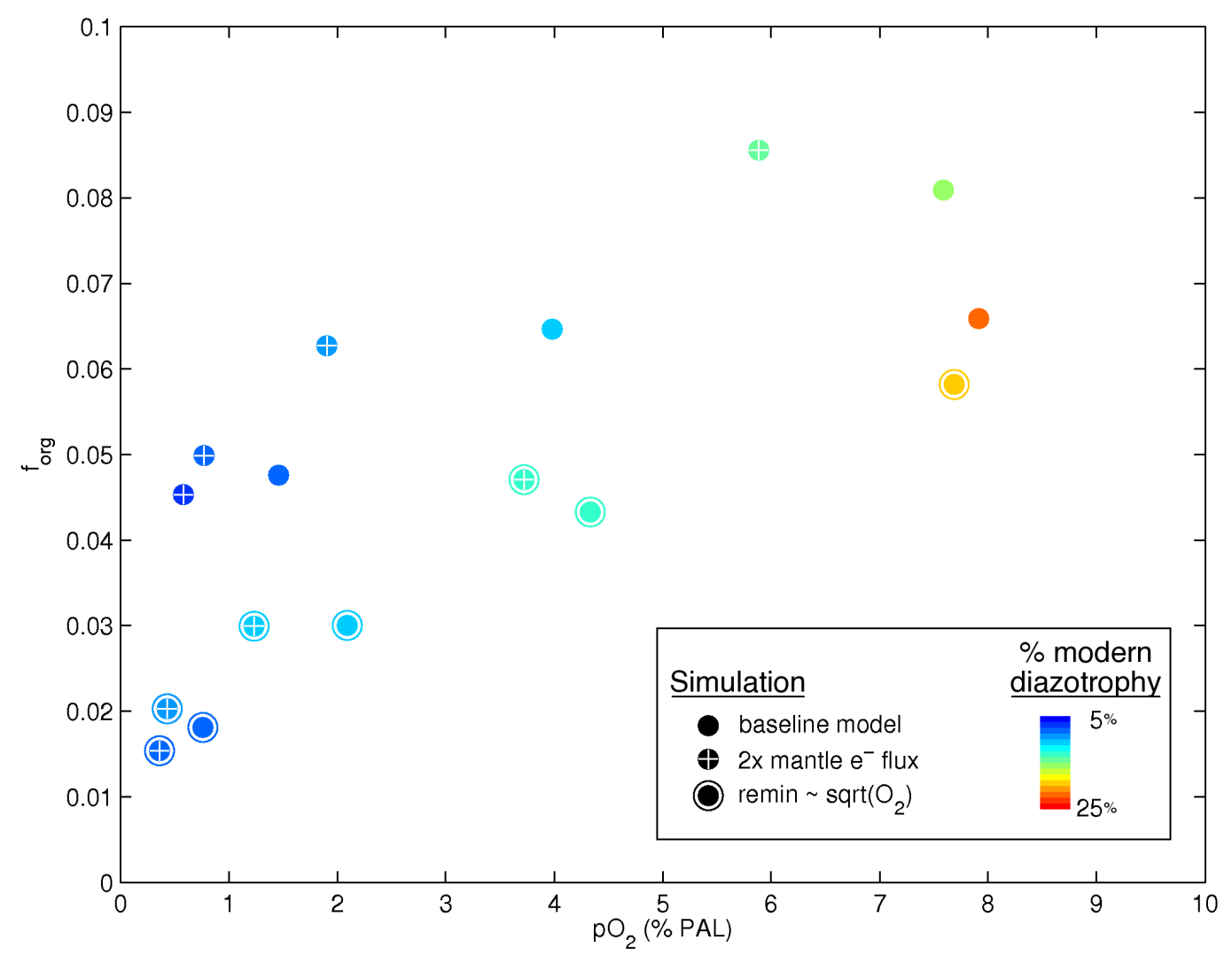

Figure 3.1: $\mathrm{pO}_{2}$ and $f_{\text {org }}$ for various simulations of a low oxygen atmosphere. A particular simulation has either modern (baseline) or 2-times modern mantle flux, a remineralization rate that varies linearly (baseline) or with the square root of $\left[\mathrm{O}_{2}\right]$, and a 3- to 5-fold reduction in phosphorus inputs. The color shows the fraction of modern biological $\mathrm{N}$-fixation that is compatible with a nitrogen-limited ocean for that simulation. Details of the nitrogen calculation are given in the text.

mary production is less than $1 \%$ of its modern value of $\sim 4000 \mathrm{Tmol} \mathrm{C}^{-1}$ in all simulations (Figure 1) due to low phosphorus availability. Lower organic burial is required to maintain low values of $\mathrm{pO}_{2}$, as the major oxygen sink, oxidative weathering processes, slows down under the low-oxygen atmoshere. Note that the low-oxygen simulations do not include the effect of increased volcanic outgassing of carbon during the Proterozoic, and as such are 
upper bounds on $f_{\text {org }}$.

\subsection{Discussion}

Most proxies suggest that atmospheric oxygen has been roughly constant near modern levels since the Devonian, but was systematically lower before the Neoproterozoic (Kump 2008), most likely between 1 and 10\% present atmospheric levels (PAL) (Holland 1984). $\mathrm{pO}_{2}$ may have varied during the Proterozoic, but evidence from paleosols, detrital pyrite and uraninite, sulfur isotopes and iron speciation all point to an atmosphere and ocean with oxygen levels well below Phanerozoic levels on long time scales.

Our simulations with $\mathrm{pO}_{2}$ less than $10 \% \mathrm{PAL}$ are all characterized by an upper limit on $f_{\text {org }}$ of less than 0.1 . These results are apparently inconsistent with the isotopic record, but low rates of organic carbon burial, and hence low $f_{\text {org }}$, are an inescapable consequence of evidence for low oxygen during the Proterozoic.

Under low oxygen conditions, the global sinks for $\mathrm{O}_{2}$ become smaller. Organic carbon weathering varies with the square root of $\mathrm{pO}_{2}$ in our model (following Lasaga \& Ohmoto 2002), resulting in a three-fold reduction in this flux, which accounts for roughly half the total oxygen sink (e.g. Catling \& Claire 2005). There is a relatively small increase in the total sink due to increased sulfide inputs, but these are further offset by more efficient pyrite burial in the low oxygen ocean. The result is a net source of oxygen to the atmosphere. Without a compensating reduction in the burial of organic carbon, $\mathrm{pO}_{2}$ rises to modern levels in less a few tens of million of years (Laakso \& Schrag 2014). Therefore, a stable, low-oxygen Proterozoic must be characterized by low organic carbon and low $f_{\text {org }}$. 
The mechanism by which organic burial is suppressed in our model is a reduction in phosphorus inputs. In a previous paper (Laakso \& Schrag 2014) we have shown that this is the only numerically plausible solution. Here, our goal is to derive a basic constraint on Borg, and hence $f_{\text {org }}$, from the relationship between organic carbon burial and the globally limiting nutrient for primary production. We begin by assuming phosphorus limitation on geologic time scale (Tyrell 1999), though we revisit the assumption later in this paper.

\subsubsection{Bounds on organic carbon burial}

The phosphorus cycle is a balance between the riverine supply of bioavailable phosphorus, ultimately derived from apatite weathering, and removal to the ocean floor almost exclusively as a component of sinking organic matter (Delaney 1998). Therefore, long-term phosphorus burial occurs in only two quantitatively significant forms: organic $\mathrm{P}$, and inorganic phases derived from diagenetic remineralization (Filippelli \& Delaney 1996). Phosphorus steady state must balance these sinks against the weathering flux:

$$
\begin{aligned}
r F_{P} & =B_{\text {org }}+\left(1-f_{P}\right) R \\
& \rightarrow B_{\text {org }}=r F_{P}-\left(1-f_{P}\right) R
\end{aligned}
$$

where $F_{P}$ is the flux of phosphorus into the oceans via weathering, $R$ is the rate of organic carbon remineralization in sediments, and $f_{P}$ is the fraction of remineralized phosphorus that recirculates into the water column. We have assumed a constant C:P ratio $r$ in organic matter. This simple cycle is stable in a phosphorus-limited ocean. Imbalance in the weathering source and the organic sink forces a compensating change in seawater nutrient 
concentrations, driving primary production and ultimately organic export until balance is re-achieved.

This budget is a very simple constraint on organic carbon burial. $B_{\text {org }}$ is determined entirely by the rate of phosphorus input, and by sedimentary remineralization processes. We consider how each of these might vary in the low oxygen environment of the Proterozoic.

\subsubsection{Remineralization in a low-oxygen ocean}

Use of equation 2 as a constraint on organic burial requires knowledge of how the global remineralization rate, $R$, varies over time. Local remineralization rates are correlated with a number of variables, including sedimentation rate (Canfield 1994), mineral surface area (Hedges \& Keil 1995), and oxygen availability (Hedges et al. 1999). Though all of these may be important, we focus here on the availability of electron acceptors.

The existence of an "oxygen effect", a positive relationship between remineralization rate and oxygen supply, has been the subject of debate. Some models have assumed modern organic carbon burial efficiencies in deep time, possibly due to accelerated rates of methanogenesis in electron-acceptor poor conditions (e.g. Habicht et al. 2002). However site-to-site comparisons (Hartnett \& Devol 2004, Hedges 1999) suggest the existence of such an effect on long enough time scales, as does a broad compilation of sediments by Canfield (1994). An oxygen effect has been identified in an investigation of a slumped turbidite by Cowie et al. (2005), which allowed direct comparison of identical sediments exposed to different levels of oxygen over tens of thousands of years.

Ideally, the oxygen effect could be used to infer the global remineralization rate $(R)$ from a simple measure of average oxygen availability such as $\mathrm{pO}_{2}$. This cannot be done precisely 
without detailed knowledge of ocean circulation and bathymetry. However, the existence of any degree of oxygen effect implies that global remineralization should be a monotonically increasing function of average seawater $\left[\mathrm{O}_{2}\right]$, which is directly related to atmospheric $\mathrm{pO}_{2}$.

Therefore, the $\mathrm{P}$ budget in equation 2 states that organic carbon burial $\left(B_{\text {org }}\right)$ will always increase as $\mathrm{pO}_{2}$ decreases, given fixed values of weathering $(\mathrm{Fp})$ and recycling efficiency $\left(f_{P}\right) . f_{P}$ may be a function of oxygen itself (Shaffer 1986, Van Cappellen \& Ingall 1994, Colman \& Holland 2000, Anderson et al. 2001), but as it most likely increases at lower levels of $\left[\mathrm{O}_{2}\right]$, it only reinforces the inverse relationship between oxygen and organic burial.

As discussed above, an increase in organic carbon burial is not consistent with the overall electron budget during the Proterozoic. Therefore, we conclude that the inputs of phosphorus to the ocean must have been lower throughout the Proterozoic: a smaller flux, $F_{p}$, offsets the decreased rate of remineralization $R$ in equation 2. Total organic burial falls due to efficient burial of a small gross flux of organic material to the sediment.

\subsubsection{Estimating $f_{\text {org }}$ from the electron budget}

With this mechanism in hand, equation 2 can provide a quantitative estimate of the $f_{\text {org }}$ values implied by the $\mathrm{P}$ and $\mathrm{O}_{2}$ constraints. As a first attempt, consider the case in which there is no change to the modern rates of organic carbon weathering or pyrite production. Steady state for oxygen then requires Borg be maintained at exactly modern levels by an appropriate adjustment in $F_{P}$. If either weathering or pyrite burial scales with oxygen as expected, a smaller value of $B_{\text {org }}$ would be needed to balance the Proterozoic O2 budget, and hence this estimate of $f_{\text {org }}$ is an upper bound.

With organic burial fixed, changes in $f_{\text {org }}$ are driven by changes in total carbon burial, 
which must balance $\mathrm{C}$ inputs on long time scales. These are primarily from the mantle, from weathering of continental carbonates, and oxidative weathering of organic carbon (Hayes \& Waldbauer 2006). Volcanic output should scale approximately with heat flow from the mantle, for a doubled flux at 2.4 Ga. (Canfield 2004). A larger volcanic flux requires a faster rate of carbonate and silicate weathering to produce the alkalinity needed to balance the C budget (Walker et al. 1981, Berner et al. 1983). Variations in the weathering rate can be estimated from the scaling factor given by Walker et al. (1981), which, assuming Proterozoic $\mathrm{pCO}_{2}$ of 1000-1500 ppm and a climate sensitivity of 3 degrees per doubling of $\mathrm{CO} 2$, is equivalent to a 2-3 fold increase in carbonate weathering. As the combination of the volcanic and weathering terms dominates inputs today, total Proterozoic carbon inputs are likely to have been two to three times their present-day value. This gives an upper bound on $f_{\text {org }}$ of 0.1 to 0.05 , compared to the modern value near 0.2 .

This can be compared to the more rigorous model predictions in Figure 1. For example, a Proterozoic simulation with $1 \%$ PAL is driven by a 5 -fold reduction in phosphorus inputs and doubled sulfide flux. Primary production is buried with an efficiency of $6 \%$, up from $<1 \%$ in the modern simulation. Deep-water phosphate values are an order of magnitude less than today due to the low recycling efficiency. The combination of nutrient-poor upwelling and

nutrient-poor river waters can drive only $11 \mathrm{Tmol} \mathrm{C} \mathrm{yr}^{-1}$ primary production, compared to nearly 4000 in the present-day. Even with efficient burial, this results in very low total burial, and an $f_{\text {org }}$ value of 0.05 , in the range predicted above.

\subsubsection{Phosphorus limitation}

The preceding arguments rely on the assumption of phosphorus limitation throughout time. Others have argued for nitrogen limitation via trace-metal stress on diazotrophs in a lowoxygen environment. Molybdenum concentrations in particular are though to have been 
low, due to efficient scavenging by free sulfides (Anbar \& Knoll 2002) and a slow down in the oxidative weathering of continental Mo (Planavsky et al. 2010). Note that slower growth rates in nitrogen fixing populations do not necessarily imply long-term nitrogen limitation, as suggested by Reinhard et al. (2013). The diazotroph population should expand to utilize any excess P (Tyrrell 1999), even if single-organism growth rates are slowed. Global N/Mo co-limitation on long time scales requires sufficiently low metal concentrations that the $\mathrm{N}$ fixing population cannot grow large enough to utilize the $\mathrm{P}$ reservoir.

Nitrogen fixation also has a lower bound imposed by lightning strikes, which at 0.4 Tmol $\mathrm{N} \mathrm{y}^{-1}$ (Galloway 2004) may be able to supply a large portion of the fixed nitrogen needed in the unproductive Proterzoic ocean. N demand can be derived from the steady-state Proterozoic NPP values discussed above; these are characteristic of an ocean/atmosphere with given $\mathrm{pO}_{2}$ and burial efficiencies, and are therefore independent of limiting nutrient. Nutrient recycling is estimated by applying the model remineralization rates to NPP, and then assuming that while organic $\mathrm{N}$ regenerated in the oxygenated surface ocean is reused for production, any $\mathrm{N}$ regenerated in the deep water or sediment is reduced to $\mathrm{N}_{2}$ via denitrification or anammox. Subtracting recycled nitrogen and lightning-strike fixation from total NPP gives the maximum possible rate of biological $\mathrm{N}$ fixation that would be consistent with both nitrogen limitation and low oxygen in the Proterozoic.

For the set of low oxygen simulations discussed above, $\mathrm{N}$ limitation requires biological fix-

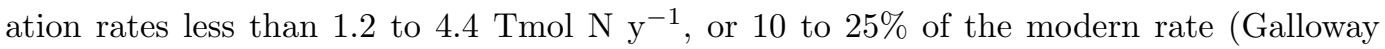
2004); see Figure 1, colors. This cap can be much lower if nitrification/denitrification is less efficient in an anoxic deep ocean (e.g. Anbar \& Knoll 2002), allowing ammonium to be recycled. Nitrogen limitation requires less than $1 \%$ modern fixation in the lower oxygen scenarios if denitrification is only $50 \%$ efficient. These results suggest only low rates of 
diazotrophy would have been required to ensure phosphorus limitation, and thus set a very low concentration threshold for long-term trace metal limitation.

\subsubsection{Reconciling isotopic and redox constraints on $f_{\text {org }}$}

The conventional isotopic calculation of $f_{\text {org }}$ via equation 1 assumes a fixed fractionation between carbonate and organic carbon, or alternatively fixed fractionations relative to dissolved inorganic carbon (DIC):

$$
\delta^{13} \mathrm{C}_{\text {in }} \approx\left(\delta^{13} \mathrm{C}_{D I C}-\epsilon_{p}\right) f_{\text {org }}+\left(\delta^{13} \mathrm{C}_{D I C}-\epsilon_{m c}\right)\left(1-f_{\text {org }}\right)
$$

where $\epsilon_{p}$ and $\epsilon_{m c}$ are the fractionations associated with primary production and precipitation of marine carbonate, respectively. One way of reconciling mass balance with a predicted Proterozoic $f_{\text {org }}<0.2$ is to allow calcite to be buried in two pools: one which precipitates from seawater with little fractionation ( $m c$, marine carbonate), and one of which forms during sediment authigenesis and has significant fractionation ( $a c$, authigenic carbonate) (Schrag et al. 2013):

$$
\begin{aligned}
\delta^{13} \mathrm{C}_{\text {in }} \approx & \left(\delta^{13} \mathrm{C}_{D I C}-\epsilon_{p}\right) f_{\text {org }} \\
& {\left[\left(\delta^{13} \mathrm{C}_{D I C}-\epsilon_{a c}\right) f_{a c}+\left(\delta^{13} \mathrm{C}_{D I C}-\epsilon_{m c}\right)\left(1-f_{a c}\right)\right]\left(1-f_{\text {org }}\right) }
\end{aligned}
$$

where $f_{a c}$ is the fraction of carbonates buried in the authigenic pool. We can rewrite this balance in terms of an effective or average calcite fractionation factor $\epsilon_{e c}$ :

$$
\delta^{13} \mathrm{C}_{\text {in }} \approx\left(\delta^{13} \mathrm{C}_{D I C}-\epsilon_{p}\right) f_{\text {org }}+\left(\delta^{13} \mathrm{C}_{D I C}-\epsilon_{\text {ec }}\right)\left(1-f_{\text {org }}\right)
$$


where

$$
\epsilon_{e c}=\left(\epsilon_{a c}-\epsilon_{m c}\right) f_{a c}+\epsilon_{m c} \approx \epsilon_{a c} f_{a c}
$$

The second equality assumes $\epsilon_{m c} \sim 0$. As argued by Schrag et al. (2013, figure 2), the factor $\epsilon_{a c}$ introduces an additional degree of freedom such that mass balance can in principle be satisfied with any value of $f_{\text {org }}$ while still maintaining $\delta^{13} \mathrm{C}_{D I C}=0$. Under those conditions, carbonate records biased toward the unfractionated marine calcite pool will show $\delta^{13} \mathrm{C}_{D I C}=0$, and naive application of equation 1 will erroneously give $f_{\text {org }}=0.2$.

In the Proterozoic case with $f_{\text {org }}=0.05$, an apparent $f_{\text {org }}$ of 0.2 from marine carbonates is possible for $\epsilon_{e c}=4$. In the full model, which includes a small but non-zero value of $\epsilon_{m c}$, dynamic $\epsilon_{p}$ and equilibrium among aqueous carbonate species, $\epsilon_{e c}$ must have a value of 3 . In short, authigenic carbonate may resolve the $f_{\text {org }}$ paradox only if:

$$
\begin{aligned}
& \left(\epsilon_{a c} f_{a c}\right)_{\text {Phan. }}=0 \\
& \left(\epsilon_{a x} f_{a c}\right)_{\text {Prot. }}=3
\end{aligned}
$$

Is this plausible? Authigenic carbonates today form in anoxic sediments as a result of alkalinity production during anaerobic respiration reactions that use sulfate or ferric iron as electron acceptors (Schrag et al. 2013). Remineralization of ${ }^{13} \mathrm{C}$-depleted organic matter or methane also lowers the $\delta^{13} \mathrm{C}$ of porewater DIC, resulting in carbonates that are isotopically depleted relative to seawater, or a positive value of $\epsilon_{a c}$. The exact degree of depletion depends on the rate of remineralization and relative proportions of organic matter oxidation and anaerobic oxidation of methane: for example, Naehr et al. (2007) found au- 
thigenic carbonates in widely distributed carbon seeps with $\delta^{13} \mathrm{C}$ between $-5 \%$ and nearly $-60 \%$. Positive values are also possible in the presence of methanogenesis (e.g. Meister et al. 2007). If we assume a typical $\epsilon_{a c}$ of $15 \%$, the calculations above imply that one-fifth of all carbonate burial during the Proterozoic must have had an authigenic origin, compared to almost none today.

The Proterozoic almost certainly had greater rates of iron reduction, sulfate reduction, and pyrite precipitation, and hence more extensive authigenic carbonate formation (Bergmann 2013). Mass balance in the sulfur isotope system requires almost all sulfur to have been buried as pyrite during the Proterozoic, compared to about $40 \%$ today (Canfield 2004), consistent with observations of greater total sulfate reduction in modern anoxic sediments than in their oxic counterparts (Canfield 1989). A change in the relative rates of aerobic and anaerobic respiration has similarly been invoked to explain aragonite fan deposition in the Precambrian and near the Permo-Triassic boundary (Bergmann et al. 2013).

Authigenic carbonate is therefore an internally consistent solution to the $f_{\text {org }}$ paradox: low oxygen requires small values of $f_{\text {org }}$, but also increases the rate of sulfate reduction and burial of isotopically depleted carbonate, allowing for seawater and marine carbonate near $0 \%$. One problem with this solution is that the $f_{\text {org }}$ will only appear to be close to 0.2 if carbonate samples are biased toward non-authigenic marine carbonates; Schrag et al. (2013) suggest that there may be a preservation bias toward shallow carbonate platforms that would experience the greatest rates of marine carbonate precipitation. A second issue is that authigenic carbonate burial must maintain mass balance at just the right level to maintain $\delta^{13} \mathrm{C}_{D I C}$ near its Phanerozoic value. Such perfect matching over so long a time period is an unsatisfying coincidence. 


\subsection{Conclusion}

The apparent lack of variation in the Proterozoic $\delta^{13} \mathrm{C}$ record, and its similarity to modern conditions, has led to its reputation as the boring billion, but this was a radically different environment from that of today. Organic burial must have been quite low to maintain a stable electron cycle in a low oxygen ocean with efficient burial rates, requiring limited nutrient inputs and very little primary production. The resulting low values of $f_{\text {org }}$ are in direct contradiction to the isotopic record, unless the standard mass balance model is wrong. However, low oxygen levels also encourage more extensive anaerobic respiration and authigenic carbonate production. These depleted carbonates effectively replace the lost organic carbon in the mass balance, damping any impact on the $\delta^{13} \mathrm{C}$ of DIC and marine carbonates despite large-scale reorganization of the carbon cycle.

Table 3.1: Parameterization of the carbon isotopic composition of various carbon fluxes. $\star$ refers to the relative phase in the definition of $\epsilon$; see section 3.2. $(t-\delta t)$ refers to the previous time step of the model.

\begin{tabular}{|l|l|l|l|}
\hline Flux & fixed parameter & value & $\star$ \\
\hline Volcanic outgassing & $\delta$ & $-5 \% 0$ & \\
\hline NPP & $\epsilon$ & $-27 \% 0$ & $\mathrm{HCO}_{3}^{-}$ \\
\hline Remineralization & $\epsilon$ & $0 \%$ & $\mathrm{HCO}_{3}^{-}$ \\
\hline $\mathrm{C}_{\text {org }}$ weathering & $\delta$ & $\delta_{\text {org }}(t-\delta t)$ & \\
\hline $\mathrm{C}_{\mathrm{CaCO}_{3}}$ weathering & $\delta$ & $\delta_{\mathrm{CaCO}_{3}}(t-\delta t)$ & \\
\hline
\end{tabular}




\title{
Chapter 4
}

\section{Scavenging of phosphorus during ferric oxide precipitation}

\begin{abstract}
Phosphorus is the globally limiting nutrient on geologic time scales, but only organic phosphorus and dissolved phosphate ions are readily available to microorganisms. Biological uptake must compete for bioavailable $\mathrm{P}$ with inorganic scavenging processes. In many environments, an important sink for phosphate is adsorption onto the surfaces of mature, crystalline iron oxides. However, observations suggest scavenging is most efficient when ferrous iron oxidizes in solution with $\mathrm{P}$, forming amorphous aggregates with high surface area (Mayer \& Jarrell 2000, Gunnars et al. 2002). Redox-sensitive scavenging of the globally limiting nutrient suggests there may be unstudied positive feedbacks in the carbon and oxygen cycles, with important implications for Earth's paleo-environment. This study presents precipitation experiments in which phosphorus adsorption is measured as a function of the average oxidation state of iron introduced to solution. We propose two simple models of phosphorus uptake based on the data. The results are consistent with the possibility of bioavailable phosphorus levels varying strongly with $\mathrm{pO}_{2}$.
\end{abstract}


Chapter 4 - Fe scavenging of $\mathrm{P}$

\subsection{Introduction}

The dominant source of phosphorus to the modern ocean is river water, which transports phosphorus released during the weathering of apatites (Benitez-Nelson 2000). Fluvial P is partitioned into several reservoirs, including dissolved phosphate, organic phosphorus, detrital apatite, and phosphate adsorbed to mineral surfaces, particularly iron. The dissolved and organic forms of $\mathrm{P}$ are "bioavailable" - that is, accessible to organisms that require $\mathrm{P}$ as a nutrient. Measurements of undisturbed river systems suggest dissolved and organic phosphorus account for $\sim 10 \%$ of total $\mathrm{P}$ (Froelich et al. 1982).

A portion of the remaining $90 \%$ is truly inaccessible detrital apatite. However, as much as 5 times the bioavailable fraction exists as phosphate ions adsorbed to suspended solids and sediment, with iron playing an important role (Delaney 1998). This phosphorus is not directly available to organisms, but does exchange with the dissolved reservoir at a rate determined by complex kinetic laws that depend on redox conditions, particle mineralogy, and solution chemistry (Froelich 1988). Estimates of the size of this reservoir range from 2 to 5 times the dissolved+organic fraction (Froelich 1988, Berner \& Rao 1994).

Given that the exchangeable $\mathrm{P}$ reservoir is several times the size of the instantaneous bioavailable reservoir, it is reasonable to infer that the bioavailability of riverine phosphate is controlled at last in part by adsorption processes. Given a 5:1 adsorbed-to-bioavailable ratio, even a 10\% change in adsorptivity would drive a 50\% change in the flux of phosphorus to the marine biosphere. However, while laboratory measurements of P-adsorption isotherms abound, the environmental controls on adsorption and desorption remain poorly understood (e.g. Froelich 1988). 
The size of the bioavailable phosphorus flux is critical to the global cycles of oxygen and carbon. Phosphorus is the limiting nutrient for primary production on geologic time scale: nitrogen-fixing diazotrophs ensure a sufficient supply of bioavailable nitrogen when bioavailable phosphorus is in excess (Tyrrell 1999). Phosphorus limitation guarantees that the flux of organic matter to the seafloor is always large enough to at least balance the supply of bioavailable $\mathrm{P}$ from rivers. If it becomes smaller, phosphorus will accumulate in the oceans until primary production and export become large enough to again balance the bioavailable budget.

Assuming a relatively constant C:P "Redfield" ratio in organic matter, the riverine supply of bioavailable phosphorus can thus be taken as a lower bound on the gross flux of organic carbon to the seafloor. As argued in the preceding chapters, this is an important constraint on atmospheric $\mathrm{pO}_{2}$. Sedimentary organic carbon is buried more efficiently under lower oxygen conditions; given a floor in gross deposition, this implies rising rates of net organic burial as oxygen levels in the atmosphere fall. This is a negative feedback on $\mathrm{pO}_{2}$ : decreasing oxygen levels increase the source of $\mathrm{O}_{2}$, organic carbon burial.

Due to this negative feedback, a reduction in the bioavailability of $\mathrm{P}$ is required to explain persistently low $\mathrm{pO}_{2}$ during the Proterozoic. A smaller supply of $\mathrm{P}$ allows a smaller flux of organic carbon to the seafloor, and thus no net increase in the oxygen source despite the elevated efficiency of burial.

As argued in Chapter 2, phosphorus may have been less bioavailable during the Proterozoic due to increased adsorption onto ferric iron particles in rivers. This hypothesis was motivated by the experiments of Mayer \& Jarrell (2000), who observed more efficient scavenging of phosphate when iron was oxidized in solution with phosphate, rather than added as a 
previously formed ferric particulate.

We suggested that these two cases were analogous to river systems under Proterozoic and Phanerozoic oxygen conditions, respectively. The majority of iron liberated during dissolution of silicate minerals is ferrous iron, $\mathrm{Fe}^{2+}$. Today, this iron is oxidized to ferric iron, $\mathrm{Fe}^{3+}$, immediately upon dissolution of the parent mineral. Oxidation rates were slower in the low-oxygen weathering environments of the Proterozoic (Millero et al. 1987b), allowing the soluble ferrous iron to be flushed out of the soil (Rye \& Holland 1998). Gradual oxidization would have taken place in phosphate-bearing groundwaters and riverwaters, allowing for more efficient scavenging than today.

Here we reproduce and expand upon the experiments of Mayer \& Jarrell (2000). In these experiments, we measure the steady state concentration of dissolved (bioavailable) phosphorus in artificial river water following the addition of iron. The goal of these experiments is to observe how the concentration of dissolved phosphate varies with the initial oxidation state of introduced iron. This data is used to derive simple models of the relationship between phosphorus bioavailibility and $\mathrm{pO}_{2}$.

\subsection{Methods}

\subsubsection{Experimental design}

Experiments were designed to study changes in dissolved phosphate concentration resulting from the addition of iron with varying redox state. All experiments were conducted in 500 $\mathrm{mL}$, tinted glass acid-washed vessels using only milli-Q water. Phosphorus was derived from a $1000 \pm \mu \mathrm{g} \mathrm{P} / \mathrm{mL}$ standard. Ferrous iron was introduced as $\mathrm{FeCl}_{2} \cdot 4 \mathrm{H}_{2} \mathrm{O}$, and ferric iron as 
powdered $\mathrm{Fe}_{2} \mathrm{O}_{3}$ unless otherwise stated. Several experiments were conducted in artificial river water (ARW), a phosphorus-free solution defined in Table 1. ARW was agitated under air by a spinning table for several days to ensure stable $\mathrm{pH}$. Measurements of $\mathrm{P}$ concentration were made colorimetrically, as described in Section 4.2.2.

i. Experiment 1 was designed to measure the scavenging of dissolved P by ferric particles. The goal was to compare scavenging by iron which was:

- oxidized in the presence of phosphorus.

- oxidized in advance of introduction to a phosphorus-bearing solution.

Two bottles of $500 \mathrm{~mL}$ ARW were prepared. Ferric iron was added to Bottle 1 to a concentration of $50 \mu \mathrm{M}$ Fe. This ferric iron was derived from ferrous iron oxidized in phosphorus-free ARW under air. A brownish precipitate was observed within seconds of addition of the ferrous iron. The characteristic time scale for the oxidation of iron at neutral $\mathrm{pH}$ is on the order of 30 minutes (Millero et al. 1987b), so this iron was assumed to be $100 \%$ ferric after 24 hours. At 24 hours, ferrous iron was added to Bottle 2, also to a concentration of $50 \mu \mathrm{M}$ Fe. Simultaneously, phosphorus was added to both bottles to a concentration of $10 \mu \mathrm{M}$. Both were stirred for one minute then sampled. The bottles were then stirred for an hour, and left under air for 11 days, with periodic sampling after stirring.

ii. Experiment 2 was designed to measure phosphate scavenging by ferric iron derived from different sources. This experiment follows the procedure of experiment 1 , but using ferric iron from commercial-prepared powdered hematite.

iii. Experiment 3 was designed to measure the scavenging of $\mathrm{P}$ from both $\mathrm{Si}$ - and non-Si solutions for additions of iron at varying average redox state. 
Four bottles of $500 \mathrm{~mL}$ milli-Q water were prepared. Phosphorus was added to all bottles to a concentration of $10 \mu \mathrm{M}$, and all were spun for 48 to achieve stable $\mathrm{pH}$. Iron was added to all bottles to a concentration of $50 \mu \mathrm{M} \mathrm{Fe}$. The iron additions were divided between ferrous and ferric iron to achieve varying oxidation states. Bottle 1 received only ferrous iron. Bottle 2 received two-thirds ferrous and one-thirds ferric iron; Bottle 3 one-thirds ferrous and two-thirds ferric iron. Bottle 4 received only ferric iron. All bottles were spun periodically and sampled after 10 days. This procedure was repeated for a second set of four bottles. These bottles were doped with $\mathrm{Na}_{2} \mathrm{Si}_{3} \mathrm{O}_{7}$ to achieve a silica concentration of $192 \mu \mathrm{M}$ Si before adding phosphorus or iron.

The experiments are summarized in Table 2.

\subsubsection{Analytical procedures}

Dissolved phosphorus concentrations were measured using the molybdate blue colorimetric method (Strickland \& Parsons 1972, Ruttenberg 1992). Samples were passed through a 0.02 $\mu \mathrm{m}$ syringe filter to remove iron particles. Each sample was divided into 3 to 5 subsamples of $1 \mathrm{~mL}$. $20 \mu \mathrm{L}$ of $25 \%$ concentrated hydrochloric acid was added to each subsample to reduce the $\mathrm{pH}$ to a range of 1-2. $200 \mu \mathrm{L}$ of the molybdate blue solution, described below, were then introduced to each subsample. The samples were manually shaken then allowed to sit for 15 minutes to allow formation of the phosphomolybdate complex. $880 \mathrm{~nm}$ absorbance was then measured on a spectrophotometer.

The molybdate blue reagent has the following composition per liter, which must be added in order to prevent solid precipitates. Milli-Q water is used throughout to prevent $\mathrm{P}$ or $\mathrm{Si}$ 
contamination.

$2.0 \mathrm{~g}$ ascorbic acid

$180 \mathrm{~mL} 10 \%$ concentrated sulfuric acid

$128 \mathrm{~mL} 2.22 \mathrm{mM}$ antimony potassium tartrate hydrate

$248 \mathrm{~mL} 6.41 \mathrm{mM}$ ammonium molybdate tetrahydrate

$880 \mathrm{~nm}$ absorbance was translated to phosphorus concentration assuming a linear relationship, derived from absorbance measurements on a phosphorus standard series. Standard concentrations were measured at 20.0, 10.0, 5.0, 2.5, 1.25 and $0.625 \mu \mathrm{M}$. A separate standard series was made and measured for each of the matrices used in the precipitation experiments (ARW, milli-Q, Si-doped milli-Q). Standards were subsampled and measured as above.

Phosphorus concentrations and errors were derived from the standard series using a bootstrapping method. Subsampling of the standards yielded multiple absorbance measurements for each standard phosphorus concentration. A separate ordinary least squares (OLS) solution was calculated using every possible combination of the subsampled standard series. The resulting OLS coefficients were assumed to be normally distributed with the observed mean and variance. A separate distribution was generated for each of the experimental matrices.

For a given experiment sample, the appropriate distribution was sampled 10,000 times, and each realization of the coefficients applied to the subsampled absorbance data. The final reported data consist of the mean and standard deviation of the resulting set. 
Chapter 4 - Fe scavenging of $\mathrm{P}$

\subsection{Results}

\subsubsection{Ferric v. ferrous iron addition}

The results of Experiment 1 are shown in Figure 1. Following addition of iron to the river water solution, phosphorus was removed quantitatively, independent of the initial oxidation state of the iron. After ten days, dissolved phosphorus concentrations returned to $70 \%$ of their original value in the initially-ferric bottle. Dissolved phosphorus concentrations in the initially-ferrous bottle remained indistinguishable from zero.

\subsubsection{Ferric iron source}

The results of Experiments 1 and 2 are compared in Figure 2. After ten days, dissolved phosphorus concentrations are greater than $6 \mu \mathrm{M}$ when ferric iron is added directly to the bottles. Dissolved phosphorus concentrations are $\sim 0$ when the iron is introduced to the system as $\mathrm{Fe}^{2+}$ and allowed to oxidize.

The $\mathrm{P}$ concentrations are somewhat different between the two sources of the ferric iron. The commercial hematite resulted in dissolved phosphate concentrations of $8.4 \mu \mathrm{M}$ after ten days. The ferric iron derived from $\mathrm{ARW}$-oxidized $\mathrm{FeCl}_{2}$ removed slightly more $\mathrm{P}$, resulting in a dissolved phosphorus concentration of $6.7 \mu \mathrm{M}$.

\subsubsection{Mixed valence iron}

The results of Experiment 3 are shown in Figure 3. In silica-bearing solutions, dissolved phosphorus concentrations decrease with the initial average oxidation state of the added iron. Define $f$ as the initial ratio of ferric-to-total iron:

$$
f=\frac{\mathrm{Fe}^{3+}}{\mathrm{Fe}^{2+}+\mathrm{Fe}^{3+}} \equiv \frac{\mathrm{Fe}^{3+}}{\Sigma \mathrm{Fe}}
$$




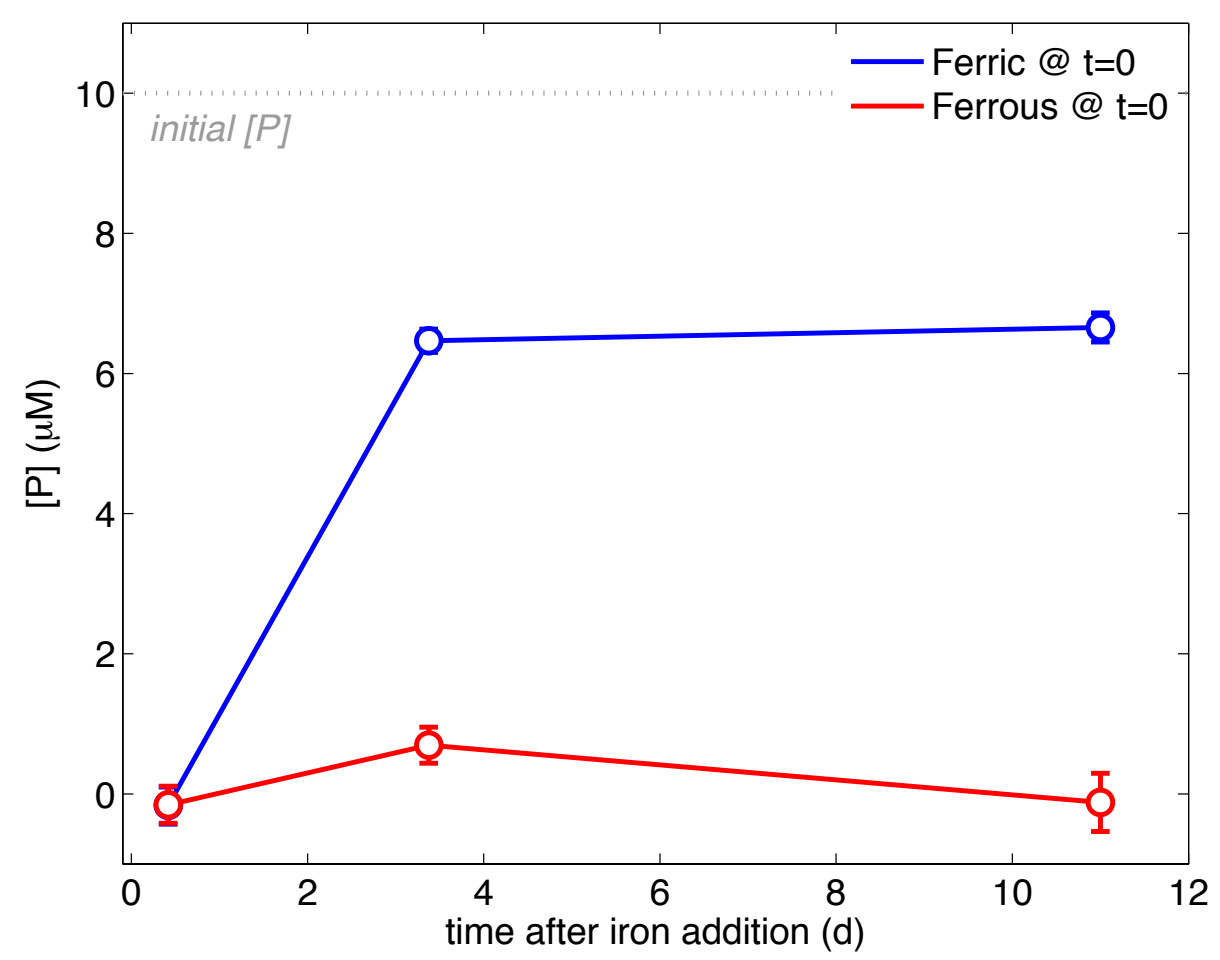

Figure 4.1: Experiment 1: dissolved phosphorus concentrations as a function of time. $t=0$ correpsonds to the point when both iron and phosphorus are present in the solution. The left-most points are associated with $\mathrm{t}=1 \mathrm{~min}$, but are plotted at a larger value of $t$ to emphasize the measurements were taken after the addition of iron.

After the addition of purely ferrous iron $(f=0)$ the steady state phosphate concentration was $0.6 \mu \mathrm{M}$. For $f=1 / 3$, concentration was $1.1 \mu \mathrm{M}$; for $f=2 / 3,4.6 \mu \mathrm{M}$; for entirely ferric addition of iron $(f=1)$, phosphate concentration was $8.8 \mu \mathrm{M}$. ferric additions drive phosphorus from $10 \mu \mathrm{M}$ to $\sim 9 \mu \mathrm{M}$,

This result is much weaker in silica-free solutions. Phosphorus concentrations are between 6.8 and $8.6 \mu \mathrm{M}$ regardless of the initial oxidation state of the iron. 


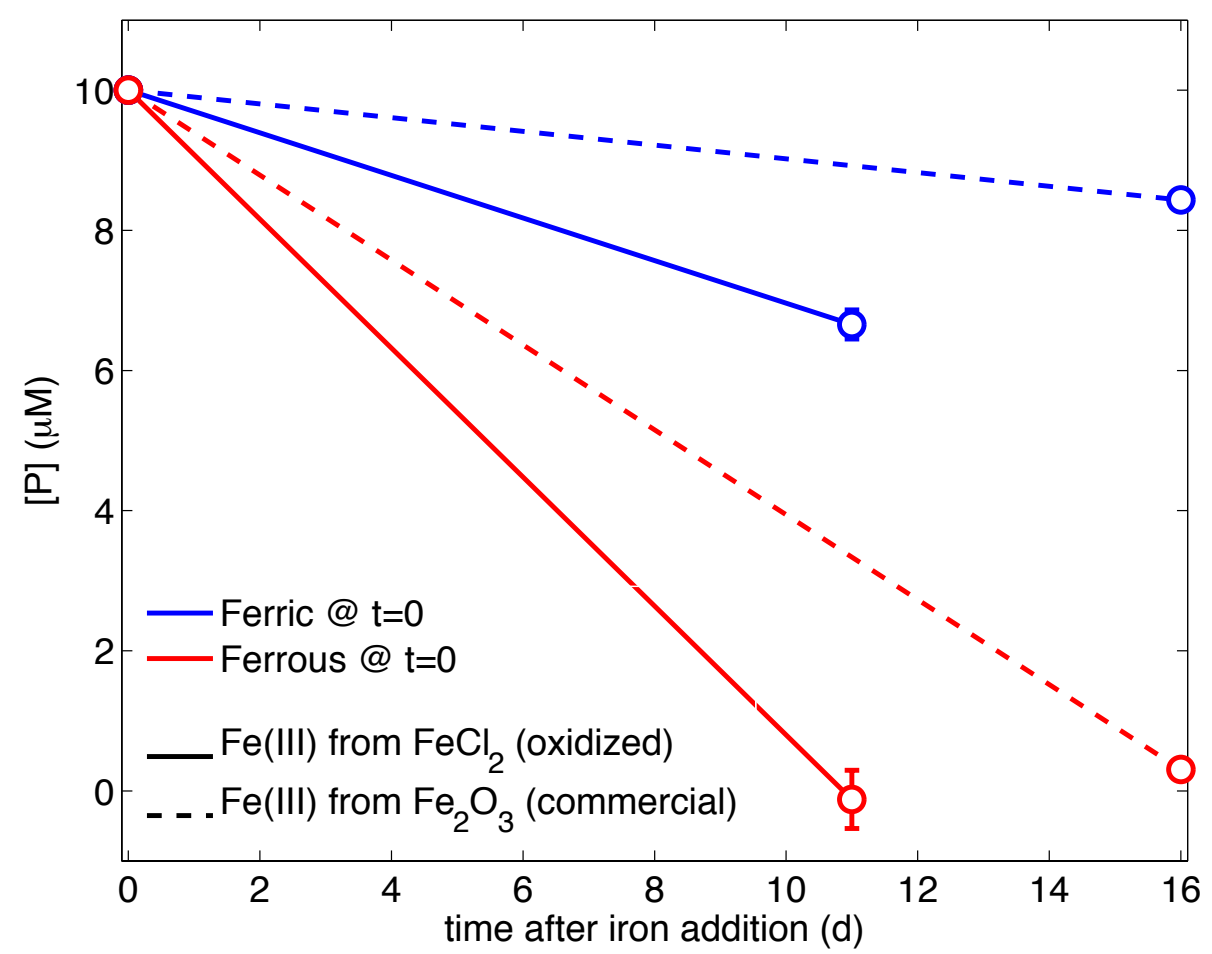

Figure 4.2: Dissolved phosphorus concentration over time in Experiments 1 and 2. The points plotted at $t=0$ represent the initial value of phosphorus in solution before the addition of iron, but are not measured values.

\subsection{Discussion}

\subsubsection{Characteristics of $\mathrm{P}$ adsorption by $\mathrm{Fe}^{3+}$}

The experiments presented here show that phosphorus is preferentially sorbed by ferric iron particles that form via oxidation and precipitation in the presence of phosphorus. This "co-precipitation" should be compared to adsorption of $\mathrm{P}$ onto ferric particles formed in the absence of phosphorus, then introduced to P-bearing solutions. 


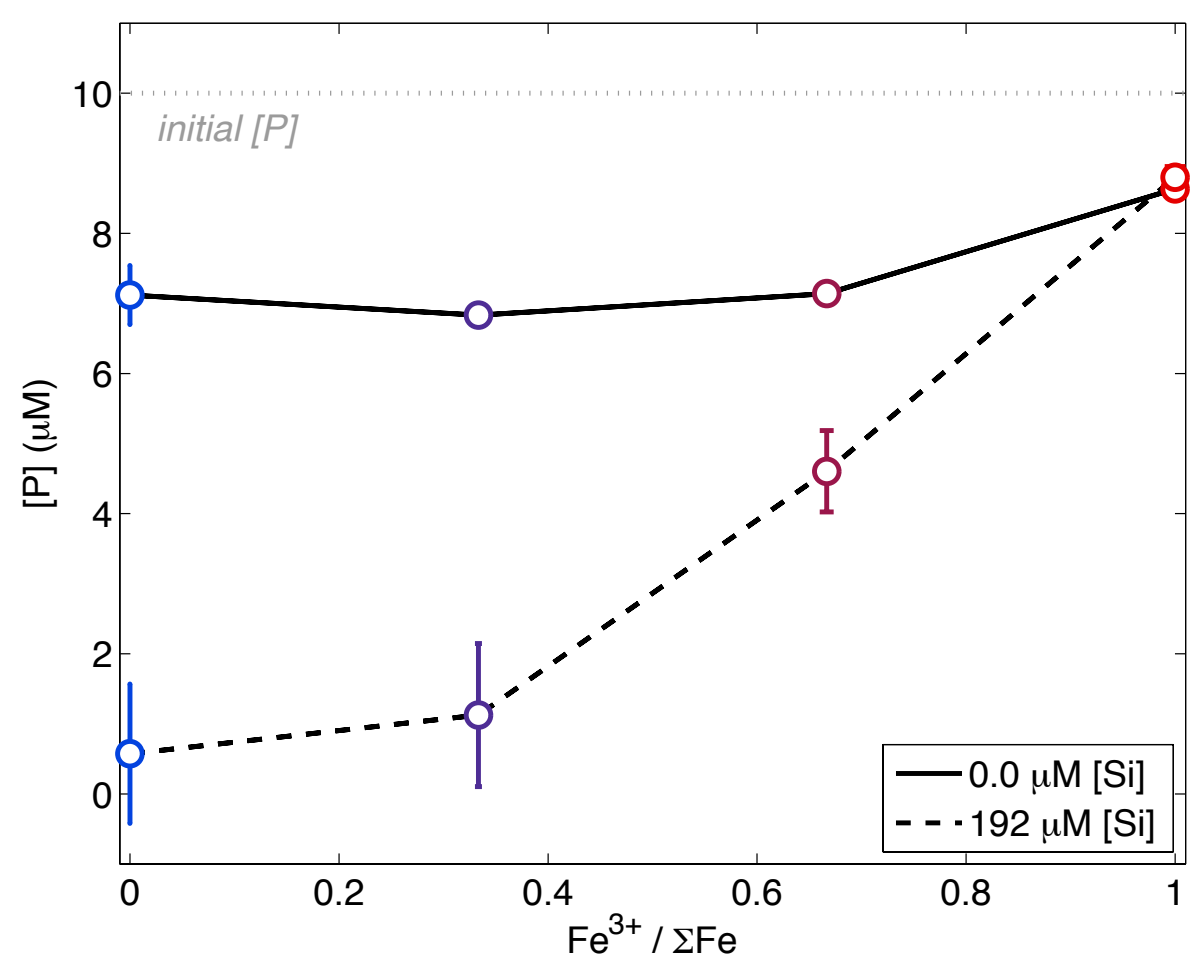

Figure 4.3: Dissolved phosphorus concentration after 10 days in Experiment 3. Each point represents a single bottle, characterized by the initial average oxidation state of the iron added, and the silica-content of the solution.

The cause of this effect is uncertain. Mayer \& Jarrell (2000) suggest it is due to the high surface area of freshly precipitated amorphous iron oxides such as ferrihydrite. This surface area is lost as the ferrihydrite ages toward goethite or some other well-ordered phase (Waychunas et al. 1993). However, the amorphous phase can be stabilized by the presence of anions, including phosphate itself. This is consistent with Experiment 1, in which oxides precipitated from solutions that differ only in phosphorus content show very different ad- 
sorption capacities. Ferrihydrite is also stabilized by silica (Mayer \& Jarrell 2000). A role for silica is consistent with Experiment 3, in which co-precipitation does not result in larger adsorption effects when silica is not present. Stabilization of ferrihydrite by silica can also explain the apparently counter-intuitive result that adsorption is larger in the presence of silica (Experiment 3), despite known competition between $\mathrm{P}$ and Si for adsorption sites on iron particles (Torrent et al. 1992).

Gunnars et al. (2002) have observed an upper-bound on the P:Fe ratio in precipitated particles, at a value of 0.5 . They argued that this is too high to be consistent with surface adsorption only. Thus, the co-precipitation process may allow for increased incorporation of $\mathrm{P}$ directly into the crystal structure itself. Alternatively, $\mathrm{P}$ may be trapped in the interior of large aggregate particles formed from colloidal iron with very high surface-to-volume ratios (Fuller et al. 1993). Hyacinthe \& Van Cappellen (2004) have argued that, at least in some environments, true ferric phosphate phases precipitate directly, with a P:Fe stoichiometry between 0.5 and 1 .

\subsubsection{Impact of iron oxidation state on riverine $[\mathrm{P}]$}

The experiments presented here cannot distinguish between the mechanism driving enhanced scavening during co-precipitation. However, Experiments 1 and 2 confirm the findings of Mayer \& Jarrell (2000) that the adsorption of P does vary between additions of ferric and ferrous iron.

Experiment 3 expands on these findings by testing a spectrum of average iron oxidation states between these two end members. This data allows us to estimate how $\mathrm{P}$ concentrations in river systems might vary given a change in the overall oxidation state of the iron being introduced via erosion. Today, this iron is oxidized essentially immediately after disso- 
lution of the parent mineral. The resulting, insoluble ferric particles are eventually removed from the soil by mechanical transport, resulting in $f \approx 1$ in a typical modern river. The low iron contents of Paleoproterozoic and Archean paleosols has been interpreted as rapid loss of soluble ferrous iron from poorly-oxidized soils at that time (Holland 1984, Rye \& Holland 1998), implying $f<1$. Given the change in $f$ between the modern and the Precambrian, what was the change in the concentration of dissolved phosphorus in rivers?

It is difficult to answer this question without understanding the exact mechanism involved in preferential adsorption during co-precipitation (section 4.4.1). We consider two possible models.

In the "equilibrium" model, phosphorus adsorption onto iron is a reversible process (e.g. Parfitt 1978, Froelich 1988). The equilibrium condition can be modeled as a simple linear isotherm relating the phosphorus concentration per solid surface area to the dissolved phophorus concentration. For simplicity, we can assume the surface area is proportional to the total dissolved iron present, and write the equilibrium condition as:

$$
\left(\frac{\mathrm{P}}{\mathrm{Fe}}\right)_{\text {solid }}=K[\mathrm{P}]_{\text {dissolved }}
$$

where the equilibrium constant $K$ is assumed to vary with the mineralogy of the solid, and therefore with the initial oxidation state of the iron forming that solid.

In the "stoichiometric" model, phosphorus is incorporated directly into the lattice of the iron precipitate at some regular P:Fe stoichiometry, $r$, which again varies with the initial oxidation state of the iron; presumably it is nearly zero for a mature ferric particle with a well-organized crystal lattice, but takes some non-zero value during a co-precipitation pro- 
cess. Using the data in Experiment 3 and the definitions above, $K$ and $r$ can be estimated as a function of the initial average oxidation state of the iron, $f$.

Consider a given river, in which the total $\mathrm{P}$ in the combined dissolved and sorbed reservoirs is defined as $\Sigma$ P. Applying mass balance and the above relationships, the dissolved phosphorus in the river, $[\mathrm{P}]$, is given by:

$$
\begin{aligned}
\text { Equilibrium model: }[\mathrm{P}] & =\frac{[\Sigma \mathrm{P}]}{1+K[\Sigma \mathrm{Fe}]} \\
\text { Stoichiometric model: }[\mathrm{P}] & =[\Sigma \mathrm{P}]-r[\Sigma \mathrm{Fe}]
\end{aligned}
$$

Dissolved phosphate concentration for each of these models is plotted as a function of $f$ in Figure 4, for a typical river with $\Sigma \mathrm{P}$ of $5 \mu \mathrm{M}$ (Meybeck 1982, Froelich 1988) and $\Sigma F e$ of 150 $\mu \mathrm{M}$ (Gaillardet et al. 1999, Poulton \& Raiswell 2002). $K$ and $r$ have been calculated from the data in Figure 3. A useful metric for comparing the models is the change in $f$ required to achieve a ten-fold reduction in dissolved $\mathrm{P}$ from the fully ferric end-member. Given that almost all iron in rivers is oxidized today, this is approximately equivalent to achieving a ten-fold reduction in modern bioavailable phosphorus, which is the level required to sustain Proterozoic levels of $\mathrm{pO}_{2}$ (Chapter 2). According to the equilibrium model, dissolved phosphate concentrations drop ten-fold when $f$ is reduced to $\sim 0.39$. Dissolved phosphate concentrations are much more sensitive to $f$ in the stoichiometric model. A ten-fold reduction in dissolved phosphorus is achieved at $f=0.96$, extrapolating linearly between values of $r$.

The implications of the two models are very different. According to the equilibrium model, 


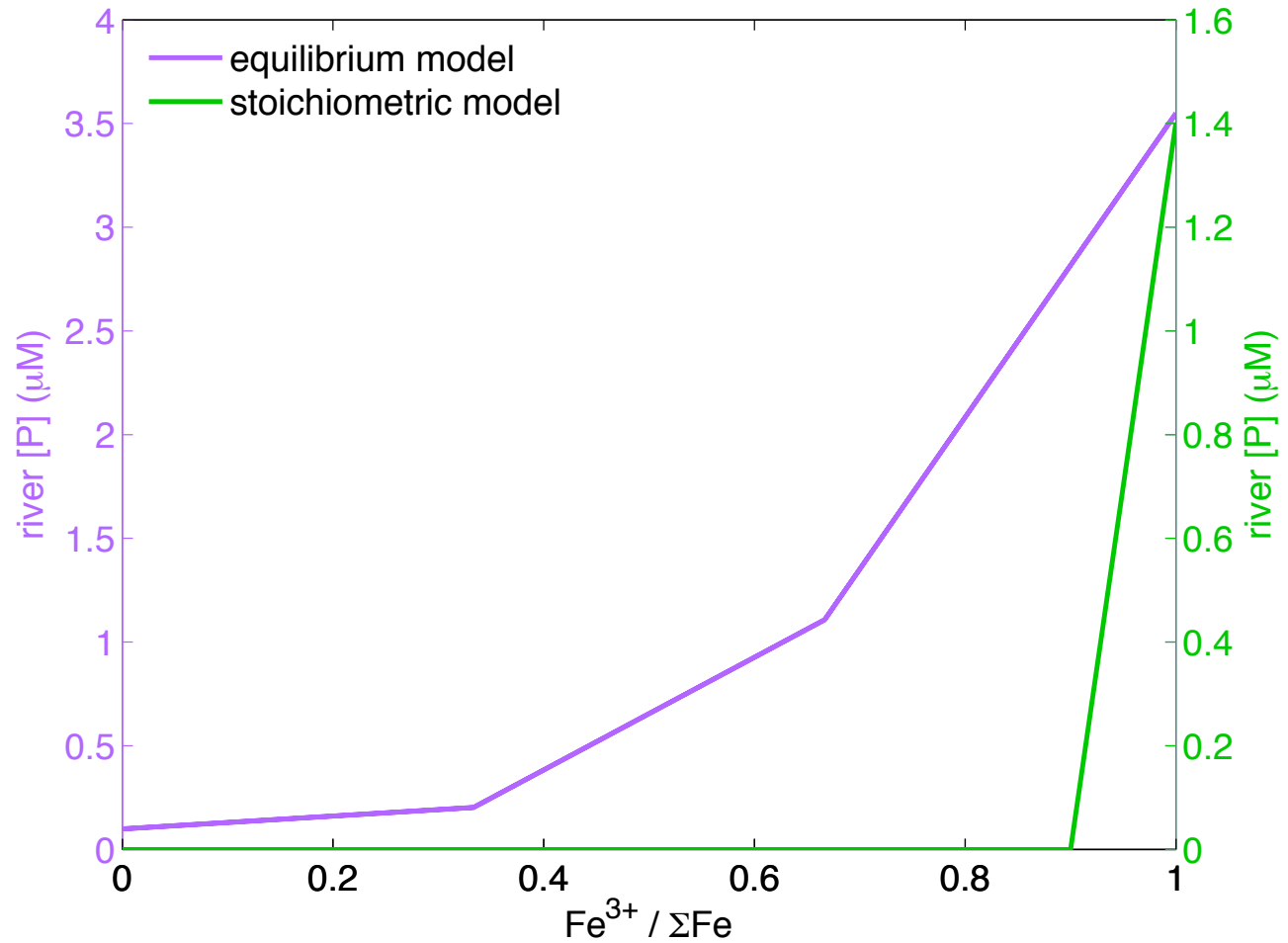

Figure 4.4: Dissolved phosphorus concentrations calculated for a hypothetical river system with $150 \mu \mathrm{M}$ of total iron, and $5 \mu \mathrm{M}$ of $\mathrm{P}$ in the combined dissolved and adsorbed reservoirs. The "equilibrium' and "stoichiometric" models are described in the text. The stoichiometric model gives negative concentrations for $f<1$; the linear extrapolation between $f=1$ and $f=2 / 3$ is shown until it intersects $[\mathrm{P}]=0$.

enhanced scavenging can justify Proterozoic oxygen levels only if there was a substantial increase in transport of ferrous iron from soils at that time. While this is conceptually plausible given the strong sensitivity of iron oxidation rates to $\mathrm{pO}_{2}$ (Millero et al. 1987), the paleosol record, though challenging to interpret in the absence of ancient $\mathrm{pCO}_{2}$ records (Holland 1984) does not show a consistent change in iron retention over the last 1.8 billion years. The stoichiometric model suggests that bioavailable phosphorus, and by extention 
atmospheric $\mathrm{pO}_{2}$, are extremely sensitive to $f$ : changes of a few percent can drive order of magnitude changes in riverine concentrations of dissolved P. In reality, the kinetics of precipitation of this hypothetical phase would almost certainly decrease as $[\mathrm{P}]$ approached zero. Such extreme sensitivity is also unlikely from a geological standpoint, as $\mathrm{pO}_{2}$ has remained at approximately modern levels since at least the Devonian (Kump 2008). Nevertheless, these models illustrate that the sensitivity of bioavailable riverine $\mathrm{P}$ to $\mathrm{pO}_{2}$ cannot be evaluated without a deeper understanding of the mechanisms underlying $\mathrm{Fe} / \mathrm{P}$ interactions.

\subsection{Conclusions}

Ferrous iron oxidizing and precipitating in solution with phosphorus is a more efficient scavenger of $\mathrm{P}$ than a mature ferric oxide introduced to the solution. The mechanism underlying this relationship is not yet understood. Progress will require spectroscopic anaylsis of $\mathrm{Fe} / \mathrm{P}$ precipitates to determine whether $\mathrm{P}$ is adsorbed onto the surface, at an interior site, between aggregated particles, or is part of a true Fe-P crystalline phase. Different mechanisms may result in different Fe:P ratios in the particles; a crystalline phase will have fixed stoichiometry, but an equilibrium adsorption process will allow buffering of aqueous concentrations by reversible exchange between solution and particle. Understanding this mechanism is critical to understanding how phosphorus cycling in rivers is affected by redox chemistry. Simple models of Fe-P dynamics show that co-precipitation effects may be very important in removing $\mathrm{P}$ from the bioavailable pool, but this behavior depends critically on how the $\mathrm{P}: \mathrm{Fe}$ ratio in the precipitate is controlled.

Redox-controlled phosphorus bioavailability introduces a positive feedback to the global oxygen system: rising $\mathrm{pO}_{2}$ would increase the rate of iron oxidation, resulting in more mature ferric oxides entering the ground water and river system. This in turn would reduce 
Table 4.1: Idealized artificial river water (ARW) used in this study (top) and the reagents used in its production (bottom). Note that ARW itself does not include phosphorus.

\begin{tabular}{|l|r|}
\hline Species & Concentration $(\mathrm{mM})$ \\
\hline \hline Silicon & 0.192 \\
Potassium & 0.035 \\
Sulfate & 0.155 \\
Magnesium & 0.160 \\
Chlorine & 0.230 \\
Sodium & 0.315 \\
Calcium & 0.364 \\
\hline \hline Species & Amount added $\left(\mathrm{mg} / \mathrm{L}_{A R W}\right)$ \\
\hline \hline $\mathrm{Na}_{2} \mathrm{Si}_{3} \mathrm{O}_{7}$ & 15.50 \\
$\mathrm{KCl}_{\mathrm{MgSO}_{4} \cdot 6 \mathrm{H}_{2} \mathrm{O}}$ & 2.61 \\
$\mathrm{NaCl}$ & 13.84 \\
$\mathrm{NaHCO}_{3}$ & 9.15 \\
$\mathrm{CaCO}_{3}$ & 6.13 \\
\hline
\end{tabular}

the adsorption of $\mathrm{P}$, leaving more phosphorus available for primary production, burial, and the production of even more $\mathrm{O}_{2}$. Enhanced $\mathrm{P}$ adsorption by co-precipitation is a necessary step in this feedback loop. However, it is not sufficient. The relative rates of iron transport and oxidation must also respond to $\mathrm{pO}_{2}$ as hypothesized. Testing this feedback will require integrating weathering, transport and precipitation dynamics. Future experiments will include driving precipitation experiments, of the type described here, with iron inputs from weathering columns. Such linked simulations of weathering and transport simulations can be maintained under various $\mathrm{pO}_{2}$ conditions, providing a coherent experimental model of phosphorus cycling across a billion years of environmental conditions. 
Chapter 4 - Fe scavenging of $\mathrm{P}$

Table 4.2: Experimental design for this study.

\begin{tabular}{|l|r|r|r|r|l|}
\hline Experiment & Bottle & {$[\mathrm{P}](t=0)(\mu \mathrm{M})$} & {$[\mathrm{Fe}](t=0)(\mu \mathrm{M})$} & $f$ & matrix \\
\hline \hline Ex. 1 & 1 & 10 & 50 & 1 & ARW \\
& 2 & 10 & 50 & 0 & ARW \\
\hline Ex. 2 & 1 & 10 & 50 & 1 & ARW \\
& 2 & 10 & 50 & 0 & ARW \\
\hline Ex. 3 & 1 & 10 & 50 & 1 & milliQ \\
& 2 & 10 & 50 & $2 / 3$ & milliQ \\
& 3 & 10 & 50 & $1 / 3$ & milliQ \\
& 4 & 10 & 50 & 0 & milliQ \\
& 5 & 10 & 50 & 1 & milliQ+Si \\
& 6 & 10 & 50 & $2 / 3$ & milliQ+Si \\
& 7 & 10 & 50 & $1 / 3$ & milliQ+Si \\
& 8 & 10 & 50 & 0 & milliQ+Si \\
\hline
\end{tabular}


Chapter $5-\mathrm{O}_{2}$-sensitive escape

\title{
Chapter 5
}

\section{The oxygen-dependence of hydrogen escape}

\begin{abstract}
The escape of hydrogen to space was likely an important part of the redox balance of Earth's early surface environment, when low oxygen levels would have permitted high concentrations of hydrogen-bearing species in the atmosphere. In most geochemical models, the flux of hydrogen from the mantle is balanced by escape to space at its diffusion-limited maximum rate, yielding a canonical late Archean hydrogen mixing ratio of $10^{-3}$ (Kasting 1993). However, several authors have proposed that diffusion limitation is unlikely from a low-oxygen Archean atmosphere. Escape rates vary with temperature, and $\mathrm{O}_{2}$ is an important source of heating in the modern atmosphere due to its large UV absorption cross section. Such a relationship implies both slower escape and higher $\mathrm{H}_{2}$ levels in the Archean. More generally, oxygen-sensitive hydrogen escape is a novel form of positive feedback in the global oxygen cycle. This study combines a simple thermosphere energy balance model with a hydrodynamic escape calculation to predict hydrogen escape rates as a function of atmospheric $\mathrm{pO}_{2}$ and $\mathrm{pH}_{2}$. Escape is found to be strongly dependent on oxygen levels when the mixing ratio of $\mathrm{H}_{2}$ is below $10^{-4}$. In this regime, escape occurs at less than the diffusion-limited rate when $\mathrm{pO}_{2}$ is less than $10^{-2}$ PAL. Given this result, the dynamics of oxygen and hydrogen cycling in biogeochemical models must be revisted.
\end{abstract}


Chapter $5-\mathrm{O}_{2}$-sensitive escape

\subsection{Introduction}

The escape of hydrogen to space may play an important role in controlling the chemistry of a planet's atmosphere, including that of the early Earth. In the absence of a significant biosphere, escape provides the primary sink for hydrogen-bearing species, such as methane or molecular hydrogen, derived from the mantle and crust (Kasting 1993). Escape of hydrogen following the photolysis of water can also result in abiotic generation of oxygen (e.g., Pierrehumbert 2011):

$$
\begin{array}{cl} 
& 2 \mathrm{H}_{2} \mathrm{O}+h \nu \rightarrow 2 \mathrm{H}+2 \mathrm{OH} \\
& 4 \mathrm{H}(\uparrow \text { space })+2 \mathrm{OH} \rightarrow \mathrm{H}_{2} \mathrm{O}+\mathrm{O} \\
\mathrm{O}+\mathrm{O} \rightarrow \mathrm{O}_{2} & \\
\text { net: } & 2 \mathrm{H}_{2} \mathrm{O}+h \nu \rightarrow \mathrm{O}_{2}+4 \mathrm{H}(\uparrow \text { space })
\end{array}
$$

The rate of hydrogen escape thus controls or influences the concentrations of $\mathrm{H}_{2}, \mathrm{CH}_{4}, \mathrm{H}_{2} \mathrm{O}$ and $\mathrm{O}_{2}$ in the atmosphere. These species have potentially important implications for the abiotic generation of hydrocarbons in the prebiotic environment (Kasting 1993), for the climate (Kasting \& Catling 2003) and for the availability of different electron acceptors and donors to the ancient biosphere.

The physics of escape have been studied extensively, but most methods of calculating the escape rate require a known temperature at some nominal altitude. Depending on the processes driving the escape, this may be the height at which the atmosphere becomes effectively collisionless, or at which vertical motions become a non-negligble portion of the atmosphere's internal energy budget (Pierrehumbert 2011). 
Chapter $5-\mathrm{O}_{2}$-sensitive escape

Even in the case of the early Earth, this temperature cannot be merely assumed based on its modern value. The temperature profile of the upper atmosphere almost certainly varied considerably over the course of the Archean eon, driven by very large changes in the budgets of radiatively important species such as oxygen and carbon dioxide. Oxygen can both warm the thermosphere via $\mathrm{O}_{2}$ adsorption of solar UV, or cool it via $\mathrm{O}$ emission at $63 \mu \mathrm{m}$ and collisional-activation of the $\mathrm{CO}_{2} 15 \mu \mathrm{m}$ band (Bougher et al. 1994). Oxygen is believed to have increased by at least three orders of magnitude around 2.4 Ga (Pavlov \& Kasting 2002). $\mathrm{pCO}_{2}$ levels were likely much higher than they are today due to the "faint young sun", and would have varied wildly during the Paleoproterozoic Snowball Earth events (Hoffman 2013).

In addition to its possible control of hydrogen escape, oxygen interacts with hydrogen chemically. Together, these effects allow for dynamical feedbacks on the composition of the atmosphere. For example, a transient rise in $\mathrm{pO}_{2}$ will increase EUV optical depth and thus temperature, leading to more rapid hydrogen escape, lower $\mathrm{pH}_{2}$, slowed consumption of oxygen (via the net reaction $2 \mathrm{H}_{2}+\mathrm{O}_{2} \rightarrow 2 \mathrm{H}_{2} \mathrm{O}$ ) and thus further increases in $\mathrm{O}_{2}$.

Estimating the hydrogen escape rate on early Earth therefore requires careful consideration of compositional effects on the temperature of the upper atmosphere (Visconti 1975, Tian et al. 2005). Many biogeochemical models of the Archean period (Kharecha et al. 2005, Claire et al. 2006, Goldblatt et al. 2006) have assumed a temperature-independent diffusion-limited escape rate based on the structure of the modern atmosphere (Hunten 1973). Establishing the relationship between the escape rate and concentrations of $\mathrm{O}_{2}$ and $\mathrm{H}_{2}$ in the lower atmosphere is particularly important for improving escape parameterizations for such biogeochemical models, which are typically parameterized in terms of overall atmospheric $\mathrm{pO}_{2}$ and $\mathrm{pH}_{2}$. The goal of this study is to examine the effect of variable at- 
mospheric $\mathrm{pO}_{2}$ on the mode and rate of escape. We focus on conditions most appropriate to the Archean and Proterozoic Earth, but the method used here may be generalized to a much wider array of conditions.

\subsection{Review of atmospheric escape}

\subsubsection{Escape mechanisms}

The classic treatment of escape by Jeans (1925) describes evaporation from the upper atmosphere. The bulk atmosphere is assumed to be tightly gravitationally bound, and thus in hydrostatic equilibrium. While the bulk gas is static, escape is still possible for those atoms or molecules with outward-directed thermal velocities greater than the escape velocity. Such a particle will escape as long as it can travel out to infinity without suffering a collision with another atom, molecule or ion. Collisionless paths become likely when the density of the atmosphere becomes so low that the mean free path of an escaping particle exceeds the e-folding distance, or scale height, of the atmosphere. This condition defines the exobase. In reality escape trajectories simply become more probable at greater altitude, but a well-defined exobase acts as a convenient boundary dividing the effectively collisionless exosphere from the thermalized atmosphere below. Given the temperature, height and number density of the atmosphere at the exobase, the escape flux can be calculated by integrating the Maxwell-Boltzmann distribution over outgoing velocities exceeding the local escape velocity. This evaporative process, along with the method of approximating its rate, is referred to as Jeans escape.

The key assumption in the Jeans approach is that the atmosphere is hydrostatic at the exobase. This is a good approximation as long as the gravitational potential energy dominates the energy budget of a molecule in the atmosphere. This condition is sometimes 
Chapter $5-\mathrm{O}_{2}$-sensitive escape

expressed in terms of the "escape parameter", the ratio of the gravitational to thermal energy of a molecule at the exobase, which by convention (e.g. Watson et al. 1981) should be greater than 2 for the Jeans solution to remain valid. This approximation may fail is there is sufficient heating of the thermosphere by absorption of solar UV, or if the exobase is at sufficiently high altitude. The exobase height can be quite sensitive to the concentration of the least-massive species in the atmosphere, which becomes the dominant component above the homopause, where diffusive separation occurs. Both conditions may be relevant to the early Earth, which was likely more hydrogen-rich (Kasting 1993) and subject to a larger EUV flux (Ribas et al. 2005).

If hydrostatic conditions cannot be assumed, bulk vertical motion of the atmosphere becomes possible. This motion modifies the structure of the atmosphere, resulting in different exobase properties. However, a consistent Jeans-like solution will still exist if the bulk mass and energy flow at the new exobase can be matched to the evaporative fluxes (Erwin et al. 2013). Under very dense or energetic conditions the exobase may move out to very large distances, and a Jeans solution is not possible. This collisional fluid extending far out into space must approach zero density at infinity, or else the atmosphere will not have finite mass. As argued by Parker (1963), this requires finite velocity at that limit despite vanishing temperature, and therefore the atmosphere must become supersonic at some altitude. This form of escape, in which a supersonic gas expands outward in bulk, is known as hydrothermal escape.

Jeans' escape is sometimes referred to as thermal escape, but Jeans and hydrodynamic loss processes both describe a neutral gas with a well-defined temperature. For cool and less dense atmospheres, Jeans escape is the more important mechanism; as temperatures or concentrations rise, the exosphere moves outward, and escape rates increase until bulk outflow becomes possible, marking a transition to hydrodynamic escape and rapid rates of loss (e.g. 
Chapter $5-\mathrm{O}_{2}$-sensitive escape

Kasting \& Pollack 1983).

Non-thermal loss processes can also be important, and are thought to represent significant portions of the total escape from both modern Earth and Venus. By definition these mechanisms operate above the exobase, since they involve particles that are not thermalized. Therefore, non-thermal escape is an excess loss above and beyond the loss due to Jeanstype evaporation. Generally, this involves ionization by the solar wind or EUV. Though the photon imparts little momentum, the resulting ion and electron may have large, opposing velocities (Pierrehumbert 2011). These ions can escape if unconstrained by the planet's magnetic field, or may transfer their kinetic energy to neutrals during charge-exchange collisions (e.g. Shizgal \& Arkos 1996).

Whatever the escape mechanism, the rate of loss cannot exceed the supply of the escaping species into the upper atmosphere. This limiting rate is set by diffusion through the background gas at the homopause, below which eddies produce a well-mixed "homosphere" (Hunten 1973). Diffusion limited escape will occur whenever the dominant escape mechanism, Jeans', hydrodynamic or non-thermal, exceeds this upper limit. Diffusion-limitation is believed to control the escape of hydrogen from the modern Earth, due to efficient evaporative and non-thermal loss from our relatively warm exopshere (Hunten \& Strobel 1974).

In general the hydrogen escape rate varies with the hydrogen content of the atmosphere, though the exact functional form of this relationship depends on the escape regime (e.g. Kasting \& Pollack 1983). However, both Jeans and hydrodynamic escape are also affected by the temperature of the upper atmosphere. In Jeans evaporation, the mean temperature at the exobase determines the portion of atoms exceeding the escape velocity via the Maxwell-Boltzmann distribution. The escape rate per unit area, $\phi$, is given in terms of the 
temperature $T$ by:

$$
\phi_{J}=n_{x}\left(\frac{k T_{x}}{2 \pi m}\right)^{\frac{1}{2}}\left(1+\frac{m g_{x} r_{x}}{k T_{x}}\right) \exp \left(-\frac{m g_{x} r_{x}}{k T_{x}}\right)
$$

where $m$ is the mass of the escape species, $g$ the acceleration due to gravity, $r$ the distance from the center of the earth, and $x$ denotes the exobase. This increases very rapidly with the exosphere temperature $T_{x}$. The hydrodynamic escape rate also generally increases with the temperature of the upper atmosphere, though there is no simple closed expression analogous to the Jeans case. Of particular importance is the temperature at the "base" of the expansion, the altitude where vertical motions become significant to the total energy budget (e.g. Pierrehumbert 2011). Therefore, an understanding of thermosphere temperature is important for calculating escape rates whenever thermal loss is a significant process, as it is for terrestrial hydrogen.

\subsubsection{Modern terrestrial hydrogen escape}

Hydrogen escapes from the modern earth at a rate of $\sim 1.5^{*} 10^{8} \mathrm{H}_{2} \mathrm{~cm}^{-2} \mathrm{~s}^{-1}$. This value is not a measurement, but is derived from photochemical models in which the escape flux is varied until the modeled hydrogen profile matches the high-altitude concentrations estimated from Lyman- $\alpha$ measurements (Liu \& Donahue 1974) or from mass spectrometry (Yung et al. 1989).

Based on the observed and modeled hydrogen profiles, Jeans escape can only account for about one-quarter of this flux. The remainder is presumably driven by non-thermal processes (Liu \& Donahue 1984). The required rates are consistent with models of charge exchange (Yung et al. 1989, Shizgal \& Arkos 1996), in which energetic ions confined by magnetic field 
lines collide with exospheric neutrals, accelerating them to escape velocity. The escape is most likely diffusion limited, as the rate matches the diffusive cap for Earth calculated by Hunten $(1973), \sim 1.7 * 10^{8} \mathrm{~cm}^{-2} \mathrm{~s}^{-1}$.

\subsection{Model}

The goal of the model described below is predict the escape rate of hydrogen as a function of the composition of the atmosphere at the surface. Conceptually, the model divides the atmosphere into three one-dimensional regions by height. The lower region extends from the surface to a fixed mesopause, and is well-mixed. It is characterized entirely by the mixing ratios of $\mathrm{N}_{2}, \mathrm{O}_{2}, \mathrm{H}_{2}$ and $\mathrm{CO}_{2}$, and the height, density and temperature of the mesopause. These values act as the lower boundary condition for the intermediate region. This zone reaches from the mesopause to a nominal base of expansion $\left(r_{b}\right)$ at $200 \mathrm{~km}$. The region is hydrostatic through, with a transition from well-mixed to diffusively separated at a nominal homopause height. The temperature and density profiles in this region are calculated by finding the steady-state solution to a simple energy balance. The resulting temperature and hydrogen density at $r_{b}$ serve as the lower boundary conditions for the upper region. This consists of a non-hydrostatic gas of atomic hydrogen. Continuity equations for mass, energy and momentum are solved in this region in order to determine the escape rate.

By specifying mixing ratios in the lower "homosphere" region, we are able to use the intermediate "thermosphere" region to derive lower boundary conditions on the upper "expanding" region, giving the escape rate as a function of surface atmospheric composition. 
Chapter $5-\mathrm{O}_{2}$-sensitive escape

\subsubsection{Hybrid Jeans Escape}

\section{Solution of the hydrodynamic equations}

We calculate the escape rate by solving the one-dimensional continuity equations for an expanding shell of gas composed of atomic hydrogen. Following Kasting \& Pollack (1983), the mass, momentum, and energy conservation laws can be expressed as:

$$
\begin{aligned}
\frac{d F}{d \lambda} & =0 \\
\left(1-\frac{\tau}{\psi}\right) \frac{d \psi}{d \lambda} & =2\left(1-\frac{2 \tau}{\lambda}-\frac{d \tau}{d \lambda}\right) \\
\frac{d}{d \lambda}\left(\kappa \frac{d \tau}{d \lambda}\right) & =-\frac{r_{c}^{2}}{T_{0}} \frac{q}{\lambda^{4}}+\frac{F k}{m r_{c}}\left(1-\frac{c_{p}}{R} \frac{d \tau}{d \lambda}-\frac{1}{2} \frac{d \psi}{d \lambda}\right)
\end{aligned}
$$

using the non-dimensionalization

$$
\tau=\frac{T}{T_{0}} ; \quad \psi=\frac{m u^{2}}{k T_{0}} ; \quad \lambda=\frac{r_{c}}{r}
$$

with distance from Earth's center $r$, gas temperature and velocity $T$ and $u$, hydrogen atom and Earth masses $m$ and $M$, boltzmann and gravitational constants $k$ and $G$, thermal diffusivity $\kappa$, volumetric heating rate $q$, and lower boundary temperature $T_{0} . F$ is the vertical mass flux $u r^{2} \rho$, with gas mass density $\rho . r_{c}$ is the critical distance parameter

$$
r_{c}=\frac{G M m}{k T_{0}}
$$

We solve these equations by integrating from a lower boundary altitude of $r_{b}$ up to $r=r_{c}$. This requires a knowledge of the volumetric heating rate from solar absorption, $q$, which is a function of the density profile $\rho$ : 


$$
q(r)=\int_{n u} d \nu \frac{\eta}{4} \sigma(\nu) F(\nu) \exp \left(-\frac{\sigma(\nu)}{\cos (\theta)} \int_{r}^{\mathrm{inf}} d r^{\prime} \frac{\rho\left(r^{\prime}\right)}{m}\right)
$$

where $F$ is the top-of-atmosphere solar flux, $\theta$ a mean solar incidence angle, and $\eta$ is the heating efficiency, and the total heating rate is found by integrating over frequencies $\nu$. A consistent solution is found iteratively by assuming an initial density profile, then using the resulting integration to update the profile until it changes by less than $1 \%$ per iteration.

A full solution requires four boundary conditions. At the lower boundary these are the temperature $\left(T_{0}\right)$ and mass density $\left(\rho_{0}\right)$, or for a single species the number density $\left(n_{0}\right)$. The upper boundary conditions are evaluated at the exobase $r_{x}$, defined as the point at which the mean path length of a hydrogen atom is equal to the scale height, i.e.

$$
\frac{1}{\sqrt{2} \chi \rho_{x}} \equiv \frac{k * T_{x}}{m g_{s}}\left(\frac{r_{x}}{r_{s}}\right)^{2}
$$

where $\chi$ is the collision cross-section for atomic $\mathrm{H}, r_{s}$ is Earth's radius and $g_{s}$ the gravitational acceleration at $r_{s}$. We require the mass $(\phi)$ and energy $\left(\phi_{E}\right)$ escape rates to match the equivalent Jeans rates at the exobase (e.g. Erwin et al. 2013):

$$
\begin{aligned}
\phi & =\frac{F}{m r_{x}^{2}} \\
\phi_{\text {Jeans }} & =\sqrt{k T_{x}} 2 \pi m\left(1-\lambda_{x}\right) e^{-\lambda_{x}} \\
\phi_{E} & =\phi\left(k * T_{0}\left(-\lambda_{x}+\frac{c_{p}}{R} \tau_{x}-\frac{1}{2} \psi_{x}\right)+\left.T_{0} \kappa \frac{\lambda_{x}^{2}}{r_{c}} \frac{d \tau}{d \lambda}\right|_{x}\right) \\
\phi_{E ; \text { Jeans }} & =\phi_{\text {Jeans }} k T_{x}\left(\frac{1}{1+\lambda_{x}}-\frac{3}{2}+\frac{m c_{p}}{k}\right)
\end{aligned}
$$


The use of Jeans boundary conditions in a non-hydrostatic model is known as a hybrid-Jeans solution. Given a choice of $T_{0}$ and $n_{0}$, the temperature gradient and total escape rate are varied until a solution is found which matches both conditions, with a tolerance of $0.1 \%$ for $\phi$ and $1 \%$ for $\phi_{E}$. The calculation is performed on an evenly spaced grid in $T_{0}$ and $n_{0}$. Escape at other values are found by linear interpolation on this grid.

\subsubsection{Diffusion limitation}

The Jeans solution is compared to the diffusion limited escape rate for atomic $\mathrm{H}, \phi_{l}$, which is calculated following Hunten (1973) for a diffusive bottleneck at a homopause at 100km altitude and temperature $T_{h}$ of $200 \mathrm{~K}$ :

$$
\phi_{l} \approx b \frac{f}{1+f}\left(\left(m_{H}-m_{j}\right) \frac{g}{k T_{h}}\right)
$$

where $m_{H}$ and $m_{j}$ are the masses of hydrogen and the background constituent, $\mathrm{N}_{2} . b$ is the binary diffusion parameter for $\mathrm{H}$ and $\mathrm{N}_{2}$, given in $\mathrm{cm}^{-1} \mathrm{~s}^{-1}$ by Hunten (1973):

$$
b=6.5 * 10^{1} 7 T_{h}^{0.7}
$$

$f$ is the molar mixing ratio of $\mathrm{H}$ at the homopause. $f$ is set to double the surface mixing ratio of $\mathrm{H}_{2}$, assuming perfect mixing up to the homopause and complete dissociation to $\mathrm{H}$ at that height. If the Jeans escape rate exceeds the diffusion limited rate, the latter is used.

\subsubsection{Thermosphere model}

\section{Conduction-dominated cooling}

The escape calcultion requires temperature and hydrogen number density values at the lower boundary, $r_{b}=200 \mathrm{~km}$. These values are calculated as a function of the $\mathrm{O}_{2}$ and $\mathrm{H}_{2}$ mixing 
ratios at Earth's surface using a thermosphere energy balance model. This approach allows the escape rate to be related to surface atmospheric composition.

The thermosphere model is a 1D model of temperature and hydrostatic number density profiles between the mesopause and a nominal "top of atmosphere" (TOA) upper boundary at $1000 \mathrm{~km}$. A steady-state solution is found by iterating between solving the hydrostatic equation for number densities, and solving an energy balance equation for temperature.

Thermospheric number density profiles for $\mathrm{H}_{2}, \mathrm{O}_{2}$ and $\mathrm{N}_{2}$ are calculated assuming wellmixed hydrostatic behavior between a fixed-altitude mesopause and homopause. The surface mixing ratios of $\mathrm{O}_{2}$ and $\mathrm{H}_{2}$ are applied throughout this range, with $\mathrm{N}_{2}$ making up the difference. Above the homopause, hydrostatic behavior is applied to each species individually up to TOA.

The initial calculation assumes an isothermal upper atmosphere. Given the resulting density profiles, a new temperature profile is derived by requiring absorption of shortwave radiation to be balanced by molecular conduction of heat down to the mesopause, following the models of Bougher \& Roble (1991). The mesopause is assumed to radiate efficiently to space in the $15 \mu \mathrm{m}$ band of $\mathrm{CO}_{2}$, maintaining its fixed temperature. The energy balance is expressed as:

$$
\frac{d}{d z}\left(\kappa \frac{d T}{d z}\right)+Q_{\odot}=0
$$

where $\kappa$ is the thermal diffusivity of the air and $\mathrm{Q}_{\odot}$ is the net volumetric heating from EUV absorption. Integrating the equation once and assuming zero temperature gradient at the top of the atmosphere (TOA) gives 


$$
\begin{aligned}
\kappa \frac{d T}{d z} & =\int_{z}^{\mathrm{TOA}} d z^{\prime}\left(Q_{\odot}\right) \\
& =\int_{z}^{\mathrm{TOA}} d z^{\prime}\left(\frac{e t a}{4} \frac{d}{d z^{\prime}} F_{\odot}\right) \\
& =\frac{e t a}{4}\left(F_{\odot}^{(\mathrm{TOA})}-F_{\odot}(z)\right) \\
& =\frac{e t a}{4} F_{\odot}^{(\mathrm{TOA})}\left(1-e^{-\tau}\right)
\end{aligned}
$$

where $\eta$ is a heating efficiency of $0.4, F$ is the down-going flux of solar radiation, and the factor of 0.25 accounts for spherical geometry (Chassefiere 1996). $\kappa$ is composition dependent thermal conductivity following Wilke's approximation (1950) with temperature-independent viscosity and conductivity ratios (CRC Handbook). The optical depth is given by

$$
\tau=-\int d \lambda \cdot\left(\sum_{i} \sigma_{i}(\lambda) \int_{z}^{\mathrm{TOA}} d z n_{i}\right)
$$

where the sum $i$ is taken over $\mathrm{H}_{2}, \mathrm{O}_{2}$ and $\mathrm{N}_{2}, n$ is the number density, and $\sigma$ is the absorption cross section (e.g. Chessefiere 1996). The wavelength integral is taken over the EUV (5-100nm) and Schumann-Runge continuum (130-170nm). $\mathrm{F}^{(\mathrm{TOA})}$ is the flux at these wavelengths at the top of the atmosphere, taken from Warren et al. (1998) and Heroux \& Hinteregger (1978) and scaled by factors of 2.4 and 1.7 respectively, following the solar flux evolution of Ribas et al. (2005). EUV absorption cross sections for $\mathrm{O}_{2}$ and $\mathrm{H}_{2}$ are from Avakyan et al. (1998). Schumann-Runge cross sections for $\mathrm{O}_{2}$ are from the HITRAN database. All other cross sections are set to zero.

For a given pair of surface $\mathrm{H}_{2}$ and $\mathrm{O}_{2}$ mixing ratios, the model iterates between solving 
the temperature and number density profiles until the temperature at each height varies by less than $10^{-10} \mathrm{~K}$ per iteration. The equations are solved on a $1 \mathrm{~km}$ vertical grid starting at the mesopause and reaching $1000 \mathrm{~km}$. This upper boundary reaches well above the base of expansion $r_{b}$, where vertical velocities for hydrogen are assuemd non-negligible and hydrostatic behavior cannot be applied. This is an inconsistency, but allows a simple estimation of EUV extinction by all chemical species.

The temperature $\left(T_{0}\right)$ and hydrogen density $\left(n_{0}\right)$ at $r_{b}=200 \mathrm{~km}$ are extracted from the resulting profiles. $T_{0}$ and $n_{0}$ are translated to an escape rate by linear interpolation of the escape model output, which is gridded on $T_{0}$ and $\log n_{0}$ as described in section 5.3.1. This process is repeated on an evenly spaced grid of log mixing surface of $\mathrm{O}_{2}$ and $\mathrm{H}_{2}$. Escape at arbitrary surface conditions can then be found by interpolation on this grid.

In some cases, the thermosphere model predicts boundary conditions outside the grid on which the escape model was solved. In this case, a solution is not found by extrapolation. However, the results (section 4) suggest that the Jeans escape rate only increases with both $\mathrm{H}_{2}$ (due to increasing availability of atoms to escape) and $\mathrm{O}_{2}$ (due to increasing temperature and average thermal velocity of atoms). Therefore, if the Jeans escape rate exceeds the diffusion limited rate at a given combination of surface $\mathrm{O}_{2}$ or $\mathrm{H}_{2}$, diffusion limitation is applied if a solution cannot be found when mixing ratios are larger than those threshold values.

The model requires fixed parameter values for the mesopause height $\left(r_{m}\right)$, total number density $\left(n_{m}\right)$, and temperature $\left(T_{m}\right)$, and the homopause height $\left(r_{h}\right)$. The baseline model is defined by: 


$$
\begin{aligned}
& r_{h}=100 \mathrm{~km} \\
& r_{m}=80 \mathrm{~km} \\
& n_{m}=200 * 10^{12} \mathrm{~cm}^{-3} \\
& T_{m}=200 \mathrm{~K}
\end{aligned}
$$

Sensitivity tests are performed around these baseline values.

\section{$15 \mu \mathrm{m}$ cooling}

We also consider an alternative model, in which the energy budget includes significant radiation by $\mathrm{CO}_{2}$ in the $15 \mu \mathrm{m}$ band. Though molecular conduction does dominate cooling at altitudes about 160km, $15 \mu$ cooling can be significant at lower altitudes (Bougher \& Roble 1991). $\mathrm{CO}_{2}$ emits at $15 \mu \mathrm{m}$ following de-excitation from the first vibrational mode. Collisions with atomic oxygen are known to be efficient at exciting this mode (Bougher et al. 1994).

To account for this effect, the species in the thermosphere are expanded to include atomic oxygen and carbon dioxide, adjusting the nitrogen content to maintain the fixed mesosphere number density. EUV absorption cross sections for $\mathrm{CO}_{2}$ and $\mathrm{O}$ are from Avakyan et al. (1998). Only ionization cross-sections are reported for O, and these are assumed equal to the photoabsorption cross-sections, though this assumption is known to fail at some wavelengths (e.g. Fennelly \& Torr 1992). Schumann-Runge cross sections for $\mathrm{CO}_{2}$ are from the HITRAN database, and set to zero for atomic oxygen. Viscosities are from the CRC Handbook $\left(\mathrm{CO}_{2}\right)$ and Dalgarno \& Smith (1961) (O). 
The energy balance equation is modified to:

$$
\frac{d}{d z}\left(\kappa \frac{d T}{d z}\right)+Q_{\odot}+Q_{15}=0
$$

where $\mathrm{Q}_{15}$ is the net heating from $15 \mu \mathrm{m}$ emission by $\mathrm{CO}_{2}$. Due to the long collisional relaxation time of the vibrational mode in the thermosphere (Dickinson et al. 1984), spontaneous emission dominates relaxation. The emitted photons are thus assumed to rapidly re-emit and ultimately "cool to space" even if reabsorbed, and the cooling rate is given by:

$$
Q_{15}=-\frac{1}{2} h \nu A n^{*}
$$

where $\mathrm{A}$ is the Einstein coefficient for spontaneous emission per excited molecule, $h \nu$ is the energy associated with the transition, $n^{*}$ is the number density of $\mathrm{CO}_{2}$ in the relevant excited state, and only half the emitted photons are in the upward direction. The excited population cannot reliably be found in the modern atmosphere by assuming local thermodynamic equilibrium (LTE), so it is derived from a balance equation permitting only two states (modified from Dickinson 1984):

$$
\left(A+\sum_{i} n_{i} \gamma_{i}^{\downarrow}\right) n^{*}=n_{g} \sum_{i} \gamma_{i}^{\uparrow}
$$

where $\gamma^{\uparrow} / \gamma^{\downarrow}$ is the rate constant for collision-induced excitation and de-excitation, respectively, $n_{g}$ is the number density of ground-state $\mathrm{CO}_{2}$, and the sum is over all atmospheric species $i$. As noted by Dickinson (1984), detailed balance requires

$$
\frac{\gamma^{\uparrow}}{\gamma^{\downarrow}}=2 \cdot \exp \left(-\frac{h \nu}{k T}\right)
$$

and thus, applying $\mathrm{CO}_{2}$ mass balance $\left(n_{\mathrm{CO} 2}=n_{g}+n^{*}\right)$ 


$$
\begin{aligned}
f_{15} & =\frac{\exp \left(-\frac{h \nu}{k T} \sum_{i} \gamma_{i}^{\downarrow}\right)}{A+\sum_{i} \gamma_{i}^{\downarrow}} \\
Q_{15} & =\frac{f_{15}}{1+f_{15}} h \nu A n_{\mathrm{CO} 2}
\end{aligned}
$$

$\gamma^{\downarrow}$ is set to $3.0 * 10^{-} 12 \mathrm{~cm}^{3} \mathrm{~s}^{-1}$ for atomic oxygen (Bougher et al. 1994) and $2.5 * 10^{-} 15$ for all other species including $\mathrm{CO}_{2}$ itself (Dickinson 1984). A is $1.51 \mathrm{~s}^{-1}$ (Dickinson 1984), and $\nu 15 \mu \mathrm{m}$.

The integration processes used for the conduction model is also applied to the $15 \mu$ m model. To prevent numerical difficulties associated with the sensitivity of $\mathrm{Q}_{15}$ to $n$, after each iteration the temperature profile is updated to a weighted average of the old and new profiles, with a $1 \%$ weighting toward the new result.

The $15 \mu \mathrm{m}$ model was run using three different $\mathrm{CO}_{2}$ surface mixing ratios, $100 \mathrm{ppm}, 1000$ ppm (the baseline case), and 10,000 ppm. Rather than explicitly model the complex cycling of atomic $\mathrm{O}$, we consider two limiting cases: one with no atomic oxygen, and another in which half of all molecular oxygen is photolyzed to atomic $\mathrm{O}$ at the homopause height.

\subsubsection{Naming Convention}

For brevity, the thermosphere model in which cooling is entirely by molecular conduction is referred to as the $\kappa$ model. The model including $15 \mu \mathrm{m}$ emission (5.3.3.2) will be referred to as the $15 \mu \mathrm{m}$ model. 
Chapter $5-\mathrm{O}_{2}$-sensitive escape

\subsection{Results}

\subsubsection{Escape v. lower boundary conditions}

Figure 1 shows the escape rate calculated using Jeans boundary conditions, as a function of the lower boundary conditions $n_{0}$ and $T_{0}$. Escape increases with both parameters. Consistent Jeans solutions were found over most of the range tested, but at simultaneously high values of both parameters $\left(n_{0}>\sim 10^{1} 5 \mathrm{~cm}^{-3}, \mathrm{~T}_{0}>\sim 800 \mathrm{~K}\right)$, the model failed to converge. This could be a numerical problem, but may also suggest a lack of Jeans solutions and a transition to a hydrodynamic regime.

\subsubsection{Thermosphere model of lower boundary conditions}

Figure 2 shows steady-state altitude profiles of temperature and $\mathrm{H}_{2} / \mathrm{O}_{2}$ mixing ratios from the $\kappa$ thermosphere model, for selected homosphere compositions. In all cases, hydrogen mixing ratios and temperatures increase upward from the homopause. Hydrogen mixing ratios always asymptote toward unity, with the asymptotic temperature increasing with the oxygen content of the lower atmosphere. Asymptotic values are reached by $\sim 300 \mathrm{~km}$, except in the warmest, most oxygen-rich case, in which hydrogen mixing ratio continues to rise even at $1000 \mathrm{~km}$.

Figure 3 shows the value of both temperature and hydrogen mixing ratio at $r_{b}=200 \mathrm{~km}$ in the $\kappa$ model. These values, $T_{0}$ and $n_{0}$, respectively, are the lower boundary of the escape model. They are given as a function of the surface mixing ratios of $\mathrm{O}_{2}$ and $\mathrm{H}_{2} \cdot n_{0}$ is a nearly linear function of surface $\mathrm{H}_{2}$, but only a weak function of $\mathrm{O}_{2} . T_{0}$ is essentially independent of oxygen levels below $10^{-4} \mathrm{PAL}$, but rises from $200 \mathrm{~K}$ to over $2000 \mathrm{~K}$ between $10-4$ and $10^{-1}$ PAL.

Sample altitude profiles of temperature and $\mathrm{CO}_{2} / \mathrm{O}$ mixing ratios in the $15 \mu$ m model are shown in Figure 4. The particular case shown has 1,000 ppm $\mathrm{CO}_{2}$ and $50 \%$ photolysis of $\mathrm{O}_{2}$ 


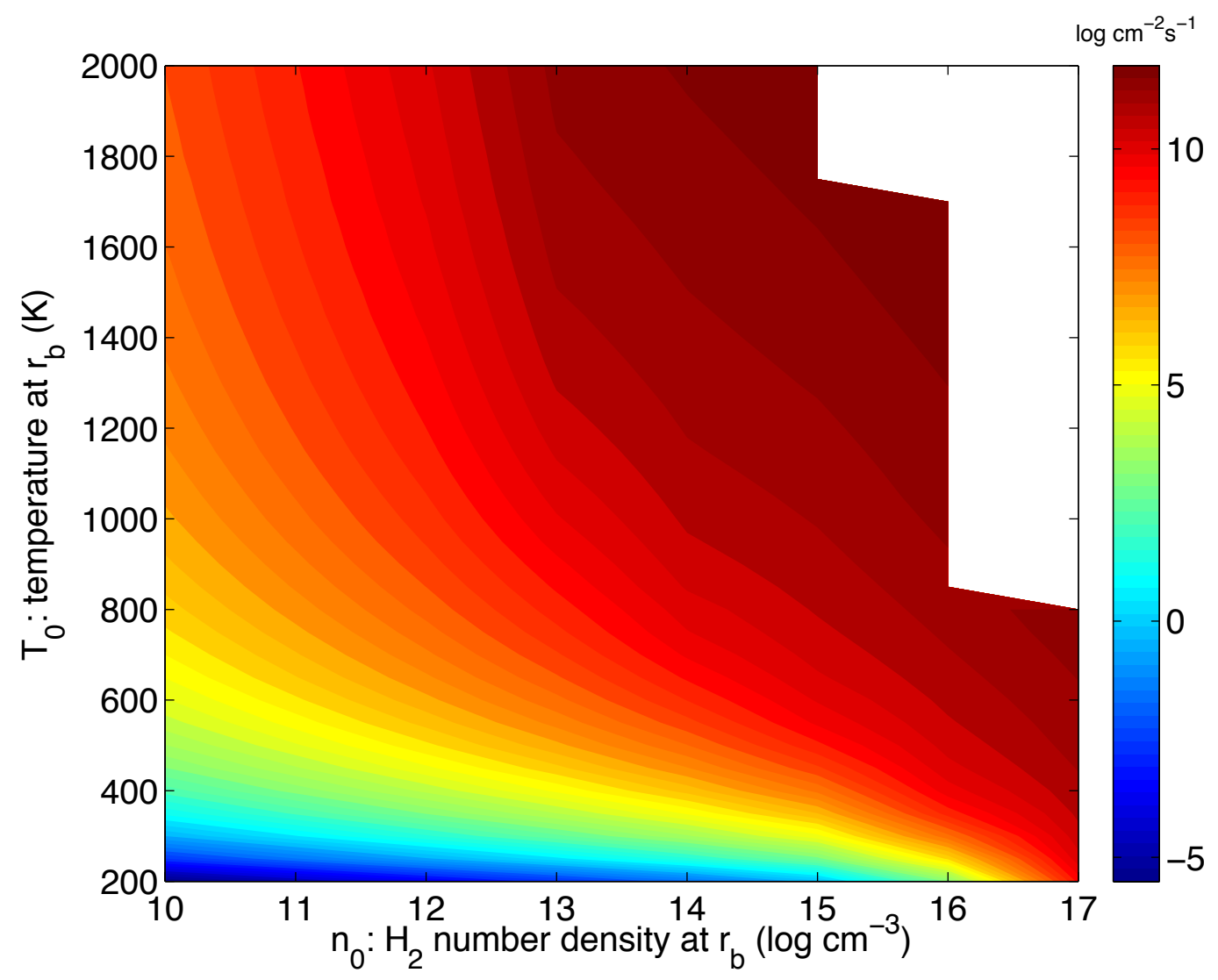

Figure 5.1: The hydrogen escape flux as function of the lower boundary conditions on the escape model

to $\mathrm{O}$ at the homopause. $\mathrm{CO}_{2}$ mixing ratios decline very rapidly above the homopause; atomic oxygen profiles rise toward a peak at 150-350 km before declining upward. Temperatures are suppressed relative to the $\kappa$ case, particular in the high-oxygen regime.

\subsubsection{Global rate of hydrogen escape}

The hybrid-Jeans escape rate in the $\kappa$ model is given as a function of the surface mixing ratios of $\mathrm{O}_{2}$ and $\mathrm{H}_{2}$ in Figure 5 (top). The Jeans rate increases smoothly with the surface 

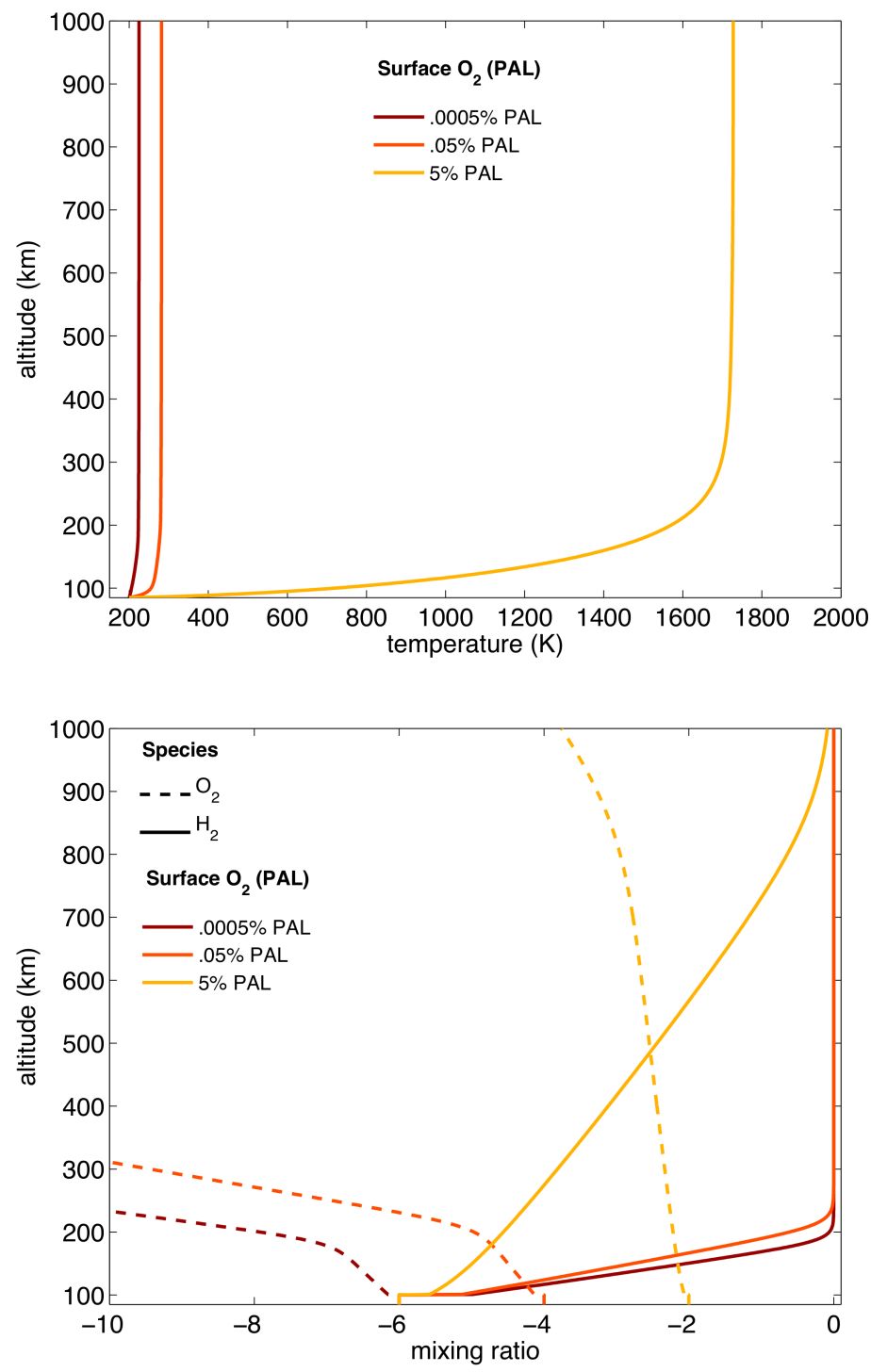

Figure 5.2: Steady-state mixing ratios and temperature profiles of the $\kappa$ thermosphere model. Each curve corresponds to a different homosphere mixing ratio of $\mathrm{O}_{2}$. Homosphere $\mathrm{H}_{2}$ mixing ratio is at $10^{-6}$ in all cases. 

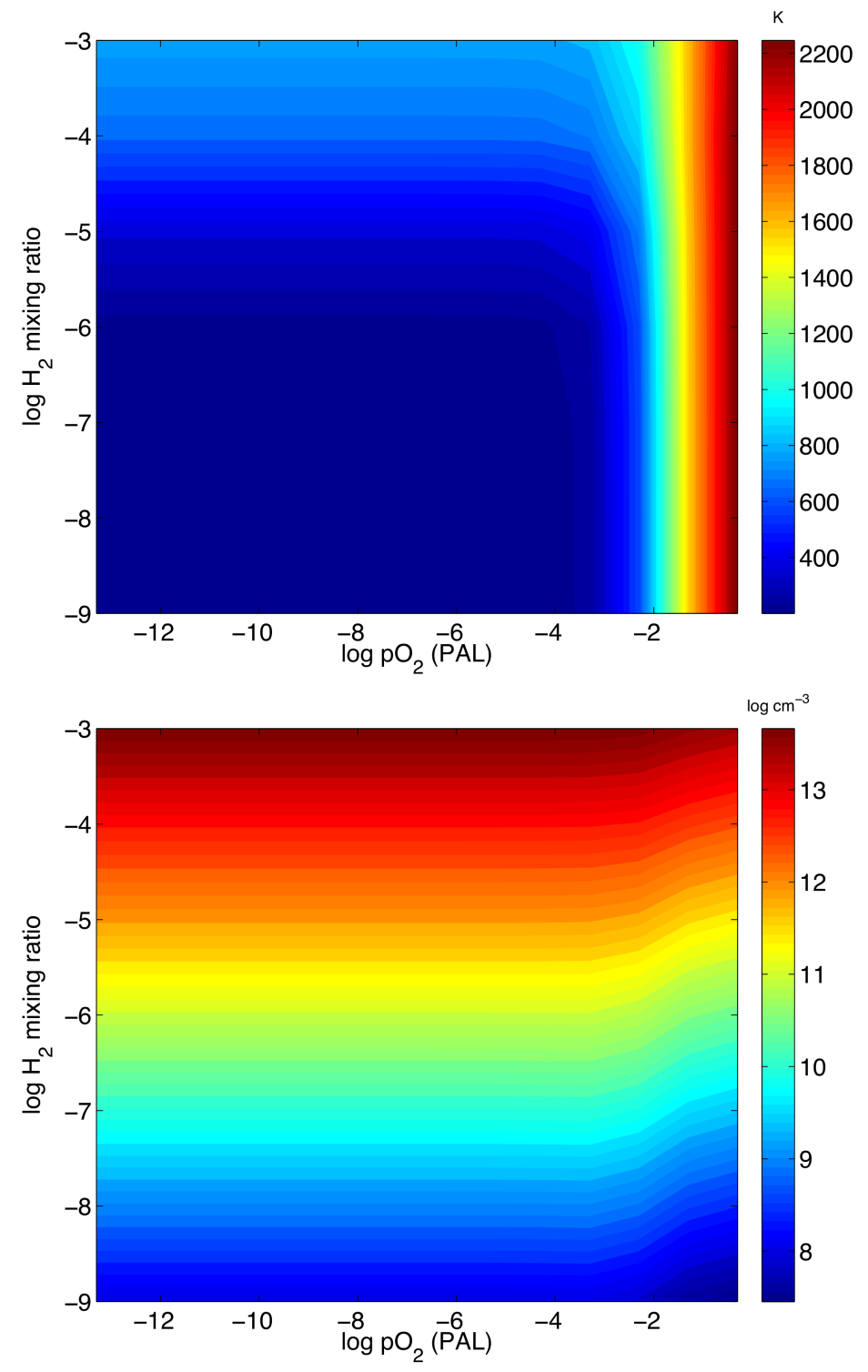

Figure 5.3: Temperature (top) and hydrogen number densities (bottom) at $200 \mathrm{~km}$ as a function of the surface mixing ratios of $\mathrm{H}_{2}$ and $\mathrm{O}_{2}$, predicted by the $\kappa$ thermosphere model. 
Chapter $5-\mathrm{O}_{2}$-sensitive escape
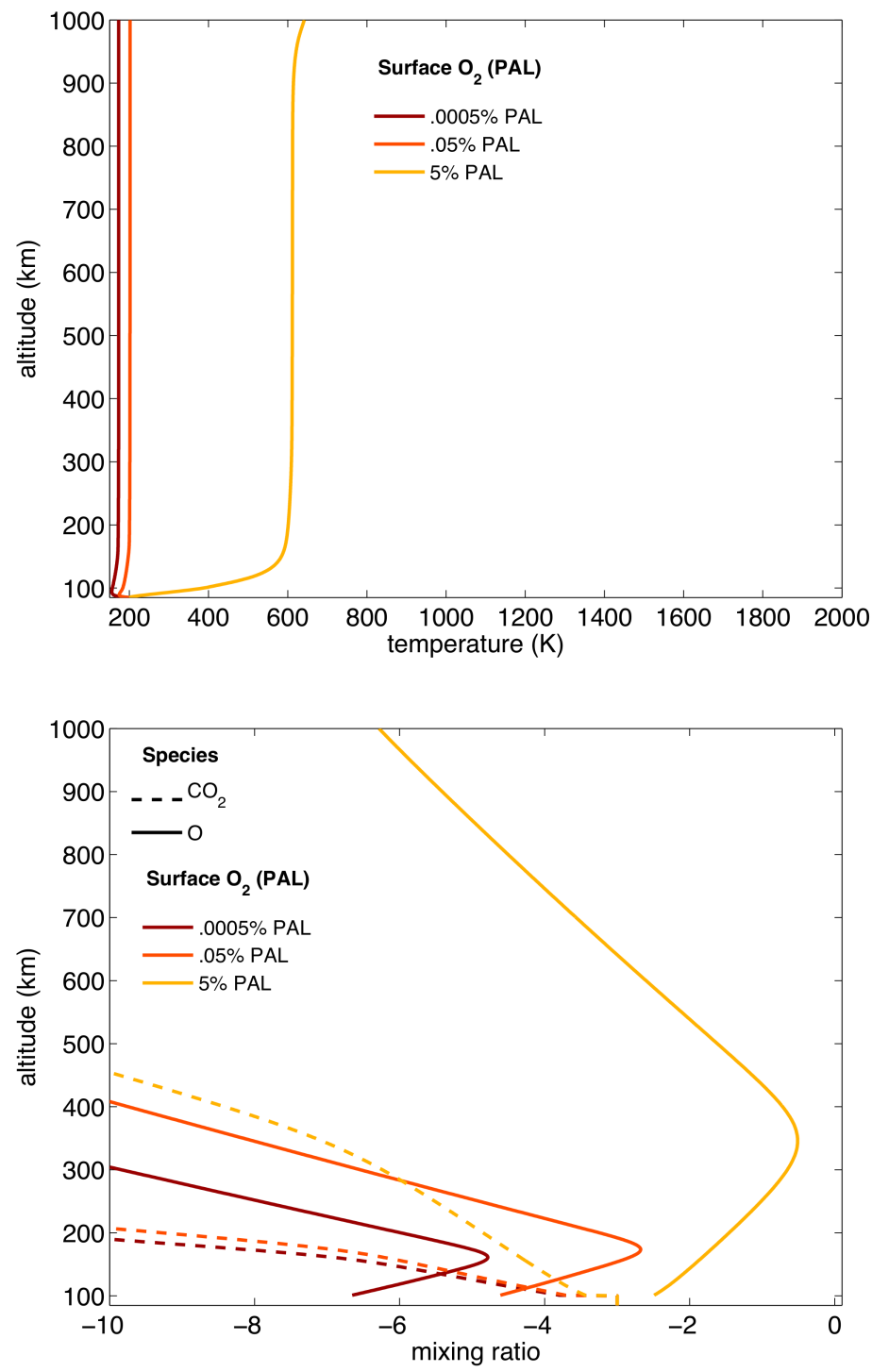

Figure 5.4: Steady-state mixing ratios and temperature profiles of the $15 \mu \mathrm{m}$ thermosphere model with $50 \% \mathrm{O}_{2}$ photolysis at the homopause. Each curve corresponds to a different homosphere mixing ratios of $\mathrm{O}_{2}$. Homosphere $\mathrm{H}_{2}$ mixing ratio is at $10^{-6}$ in all cases. 
hydrogen mixing ratio. It is essentially independent of the oxygen mixing ratio below $10^{-4}$ PAL, but increases by many orders of magnitude for $\mathrm{O}_{2}$ mixing ratios between $10^{-4}$ and $10^{-2}$ PAL. At larger $\mathrm{O}_{2}$ levels, temperatures exceed the range of lower boundary conditions explored in the escape calculations (Figure 1). The diffusion-limited escape rate increases with hydrogen levels, but is essentially independent of $\mathrm{O}_{2}$ mixing ratios (Figure 5, center).

The actual escape rate is shown in Figure 5 (bottom); diffusion limitation has been applied when the Jeans rate exceeds the diffusion-limited rate and at any jointly-greater values of $\mathrm{O}_{2}$ and $\mathrm{H}_{2}$ (see section 5.3). Diffusion limitation is achieved for surface $\mathrm{H}_{2}$ mixing ratios greater than $\sim 10^{-4}$. Below this level, the escape rate is independent of $\mathrm{O}_{2}$ at low mixing ratios, but increases strongly with oxygen above $\sim 10^{-4} \mathrm{PAL}$, before achieving diffusion limitation at $10^{-2}$ PAL.

Figure 6 compares the escape rate in the $\kappa$ model to both versions of the $1,000 \mathrm{ppm} \mathrm{CO}_{2}$ $15 \mu \mathrm{m}$ model: without atomic oxygen, and with $50 \%$ photolysis of $\mathrm{O}_{2}$ at the homopause. The two $15 \mu \mathrm{m}$ models are nearly indistinguishable. They differ from the $\kappa$ model primarily in that the threshold for a significant oxygen effect is increased from $10^{-4}$ to $10^{-3} \mathrm{PAL}$, and the threshold for diffusion limitation is increased from $10^{-2}$ to $10^{-1}$ PAL.

\subsubsection{Sensitivity: meso- and homopause characteristics}

The $\kappa$ model was run with varying values of mesopause temperature, height and total number density, and homopause height. For each parameter, figure 7 plots the ratio $\phi_{\uparrow}: \phi_{\downarrow}$ as a function of surface conditions. $\phi_{\uparrow}$ is the escape rate under the largest parameter value tested, and $\phi_{\downarrow}$ is the escape rate under the smallest parameter value tested.

The mesopause and homopause heights $\left(r_{m}\right.$ and $\left.r_{h}\right)$ were varied over ranges of $85-95 \mathrm{~km}$ and 90-100 km respectively. The escape rate is a weak function of these variables over the tested invervals. 
The mesopause number density $n_{m}$ was varied over a range of $(15-25)^{*} 10^{13} \mathrm{~cm}^{-3}$. The escape rate increases with number densities, with the effect more pronounced for larger escape rates. Escape is nearly 100x larger in the high $n_{m}$ case than the low as escape approaches the diffusion limit (compare Figure 5). Once the diffusion limit is achieved, the escape rate does not vary with $n_{m}$.

The mesopause temperature $T_{m}$ was varied over a range of 150-250 K. Escape increases strongly with $T_{m}$, with escape rates in the $250 \mathrm{~K}$ case as much as one million times faster than the $150 \mathrm{~K}$ case for the highest, non-diffusion limited escape rates. Again, escape rate becomes independent of $\mathrm{T}$ once diffusion limitation is achieved.

\subsubsection{Sensitivity: $\mathrm{pCO}_{2}$}

The $15 \mu \mathrm{m}$ model was run assuming different surface-level values of $\mathrm{pCO}_{2}: 100 \mathrm{ppm}, 1,000$ ppm (the baseline case) and 10,000 ppm. Figure 8 shows the ratio of the escape rates in the $10,000 \mathrm{ppm}$ case to the $1,000 \mathrm{ppm}$ case. Only the scenario with $50 \%$ photolysis of $\mathrm{O}_{2}$ at the homopause is shown; the scenario without atomic oxygen is nearly identical. Escape is much slower in the high $\mathrm{CO}_{2}$ atmosphere, between 10 and 100 billion times slower than the 1,000 ppm case. The biggest differential occurs where the absolute escape rates are fastest, near the diffusion limit (compare Figure 6). Once diffusion limitation is achieved, the escape rate is independent of $\mathrm{pCO}_{2}$. 
Chapter $5-\mathrm{O}_{2}$-sensitive escape

\subsection{Discussion}

\subsubsection{Jeans Escape}

The escape calculation used here is a hydrodynamic model coupled to a Jeans boundary. The result is an escape rate that increases with both the temperature and hydrogen number density at the base of the expanding region, $r_{b}$, where vertical velocities are assumed to become non-negligible (Figure 1). A positive relationship between the escape rate and one or both of these properties has been noted by many earlier studies using a variety of models in many contexts (e.g. Kasting \& Pollack 1983, hybrid Jeans model for Venus; Chassefiere 1996, thermal + non-thermal model for Venus; Tian et al. 2008, hydrodynamic flow on early Earth).

This relationship is expected from a general consideration of thermal escape processes. Escape occurs when a particle achieves escape velocity at a height where it is not likely to suffer a collision during its flight to space. Loosely speaking, increasing either the number of particles (i.e., the hydrogen number density) or the temperature (i.e., the average thermal velocity) in the upper atmosphere should result in greater escape rates.

The results in Figure 1 are therefore qualitatively reasonable for a thermal escape mechanism. Historically, there has been considerable debate over when to apply a Jeans solution as opposed to a supersonic solution (Johnson et al. 2013; section 5.2). Mathematically, the difference is in the upper boundary condition; the Jeans solution is calculated up to the exobase, where the solution becomes collisionless and the hydrodynamic equations do not apply, while the blow-off solution must be computed to infinity, through a singularity at the sonic point. 
Chapter $5-\mathrm{O}_{2}$-sensitive escape

One computationally-intensive solution to this problem has been to model individual particles in the expanding gas using a Monte-Carlo method. This has approach has shown that, when a classically-defined exobase (section 2) does exist, a hydrodynamic calculation with a Jeans boundary condition of the type used here results in a reliable estimate of total escape rates to within an order of magnitude (Erwin et al. 2013). The solutions used here find an exobase for almost all of the atmospheric conditions explored (Figure 1), suggesting that the Jeans-type solution is a reliable choice for the early Earth.

More problematic is the assumption of thermally-dominated escape. A significant contribution from non-thermal processes are required to explain the escape rates observed on present-day Earth (e.g. Liu \& Donahue 1984). It is tempting to ignore this aspect of escape and focus on the temperature dependence of more easily modeled thermal processes; however, it has been suggested that charge-exchange processes actually decrease with rising exosphere temperatures, which would work to dampen the T- $\phi$ relationship observed here. An estimate of the relative scale of these two effects, particularly under Archean magnetic field and solar wind conditions, awaits a more detailed study.

\subsubsection{The thermosphere}

The thermosphere models presented here results in asymptotic temperatures that vary very strongly with the oxygen content of the lower atmosphere (Figures 2). This is due to absorption of EUV radiation by $\mathrm{O}_{2}$; the thermal conductivites of molecular oxygen and nitrogen are similar, so the addition of oxygen only impacts the radiative heating rates. Atomic oxygen also cools the model given its efficient excitation of the $15 \mu \mathrm{m} \mathrm{CO}_{2}$ vibrational state. This results in weaker thermospheric heating as a function of oxygen when $15 \mu \mathrm{m}$ heating is accounted for (compare Figures 2 and 3). However, oxygen does produce net heating in all variants of the model. The basic reason for this is illustrated in Figure 3; oxygen atoms 
Chapter $5-\mathrm{O}_{2}$-sensitive escape

only exist in the model above the homopause, at which altitude $\mathrm{CO}_{2}$ number densities have already declined dramatically from their mesopause value. In reality oxygen atoms can be found at all levels of the atmosphere; however, even in much more complex photochemical models, $\mathrm{O}$ atoms do not become significant relative to $\mathrm{O}_{2}$ until altitudes above $100 \mathrm{~km}$ (Roble et al. 1987, Tian et al. 2008).

Individual profiles can be compared to more complex photochemical transport models to evaluate the reliability of the simple energy balance formulation used here. Kulikov et al. (2007) produce a thermosphere profile that asymptotes to $1000 \mathrm{~K}$ at $\sim 300 \mathrm{~km}$ in a model with present-day oxygen and EUV fluxes. Our 5\% PAL models (Figure 2) result in temperatures ranging between 600 and $1700 \mathrm{~K}$ over the same length scale. Tian et al. (2008) estimate asymptotic temperatures of 1000-2000 K for EUV fluxes between 1.5 and 3.3 times modern, bracketing the values used in this study, though with modern $\mathrm{pO}_{2}$. Though not directly comparable due differences in $\mathrm{O}_{2}$ and EUV flux, these results suggest the thermosphere model here is well-tuned at least to an order of magnitude.

The variation of the asymptotic temperature with oxygen has been suggested before by Tian et al. (2005), and modeled explicitly by Visconti (1975), using a simple energy balance model. Visconti found asymptotic temperatures increase from 600 to $2000 \mathrm{~K}$ for an increase in $\mathrm{pO}_{2}$ from $10^{-3}$ to $1.0 \mathrm{PAL}$, similiar to the increase shown in the $\kappa$ model in Figure 2.

Though the models show plausible asymptotic behavior, the thermosphere only interacts with the escape calculation by supplying lower boundary conditions (Figure 4), which are assumed to apply at $200 \mathrm{~km}$. This lower boundary, $r_{b}$, properly corresponds to the point at which the atmosphere can be approximated as dominated by atomic hydrogen. This is problematic, as the model only sometimes achieves both hydrogen dominance of asymptotic 
Chapter $5-\mathrm{O}_{2}$-sensitive escape

behavior by this height (Figures 2,3). There is also a more fundamental inconsistency in the assumption that hydrogen is $\mathrm{H}_{2}$ throughout the thermosphere model (which reaches 1000 $\mathrm{km}$ ), but is present as atomic $\mathrm{H}$ in the escape model (which reaches from $200 \mathrm{~km}$ to the exobase). A more coherent simulation would calculate initial density profiles from a hydrostatic thermosphere of the type described here, but including explicit photolysis rates. This would allow identification of $r_{b}$, which could then be used drive an escape simulation which would provide updated extinction rates to the next iteration of thermosphere modeling. The use of a fixed altitude for $r_{b}$ greatly simplifies the problem, but a dynamic treatment is called for in future work.

\subsubsection{Escape as a function of $\mathrm{pO}_{2}$}

All variants of the model, including the conduction-dominated model and the the $15 \mu \mathrm{m}$ cooling variant both with and without atomic oxygen, produce escape rates that vary predictably with $\mathrm{O}_{2}$ and $\mathrm{H}_{2}$ concentrations at the surface (Figure 6).

Escape is always below the diffusion limit when $\mathrm{pO}_{2}$ is less than $\sim 10^{-2}$ PAL and (simultaneously) hydrogen mixing ratios are less than $10^{-} 4$ PAL. This range plausibly includes large portions of Earth history. Oxygen concentrations may have been below this threshold through the Proterozoic, and were certainly much lower during the Archean (Kump 2008 and references therein). Hydrogen concentrations are estimated at $10^{-3}$ PAL during the Archean (Kasting 1993), but this assumes a modern volcanic $\mathrm{H}_{2}$ flux of $5 \mathrm{Tmol} \mathrm{y}^{-1}$ (Holland 1984), which may be a severe overestimate (Canfield et al. 2006). The assumption of diffusion limitation over Earth history (Catling et al. 2001) appears to be unjustified.

Additional structure exists within the sub-diffusion limited regime. Above oxygen concentrations of $10^{-3}$ or $10-4$ PAL (depending on model choices), the escape rate increases 
rapidly until achieving diffusion limitation. This is driven the rapid increase in temperature that occurs when oxygen levels become large enough to make EUV heating a significant portion of the energy budget (Figure 4). In this model, the threshold is very abrupt: escape rates can increase by ten million fold for a 100 -fold change in $\mathrm{pO}_{2}$.

The extreme size of this relationship suggest an interesting dynamical feedback in the oxygen system. If the atmosphere is as at steady state close to this boundary, a transient pulse in $\mathrm{pO}_{2}$ will lead to very large hydrogen escape rates. Depending on the time scale of the perturbation, this could reduce hydrogen levels enough to impact the chemcial consumption of oxygen via the simplified net reaction $2 \mathrm{H}_{2}+\mathrm{O}_{2} \rightarrow 2 \mathrm{H}_{2} \mathrm{O}$. This is a positive feedback, as increases in $\mathrm{pO}_{2}$ lead to a decline in the sink for oxygen. This effect could lead to surprisingly large or long-lived oscillations in $\mathrm{pO}_{2}$ in Precambrian, or even to multiple equilibrium behavior.

These basic relationships are maintained in all sensitivity tests. Though the escape rate in the sub-diffusion limited regime varies strongly with mesopause temperature and $\mathrm{pCO}_{2}$ (Figures 7,8$)$, an abrupt rise to the diffusion-limited maximum rate always occurs at sufficiently high levels of oxygen, driven by efficient escape from an EUV-heated thermosphere.

\subsection{Conclusions}

This study has shown a strong relationship between the rate of hydrogen escape and the oxygen content of the atmosphere, driven by $\mathrm{O}_{2}$-mediated warming of the exosphere by EUV radiation. For oxygen levels less than $1 \% \mathrm{PAL}$, the escape rate may orders of magnitude below the diffusion limit. Escape levels increase rapidly as a function of $\mathrm{pO}_{2}$ when it falls in the range of $0.01 \%$ PAL and $1 \%$ PAL. 
Chapter $5-\mathrm{O}_{2}$-sensitive escape

A positive relationship between availability of an oxidant $\left(\mathrm{O}_{2}\right)$ and loss of a reductant $\left(\mathrm{H}_{2}\right)$ suggests a wide range of dynamical effects on the oxidation state of the atmosphere over compositional range relevant to the Archean and Proterozoic, when variations in $\mathrm{pO}_{2}$ are believed to have been large and rapid. By linking surface conditions to escape, these results can easily be integrated into biogeochemical models. This will allow more realistic simulations of surface redox cycling which include these feedbacks.

Coupling between $\mathrm{H}_{2}$ and $\mathrm{O}_{2}$ dynamics may also be important in understanding whether oxygen in the atmospheres of exoplanets is indicative of the presence of life (Wordsworth \& Pierrehumbert 2014). An observed redox state can only be considered a positive signal if it cannot be produced by abiolgical cycling, which must be modeled in a framework that includes both surface level geochemical cycling, and atmospheric processes such as escape. The model presented here provides a basic framework for incorporating escape models into geochemical models, and may be generalized to apply to a wide range of solar conditions and atmospheric compositions. 

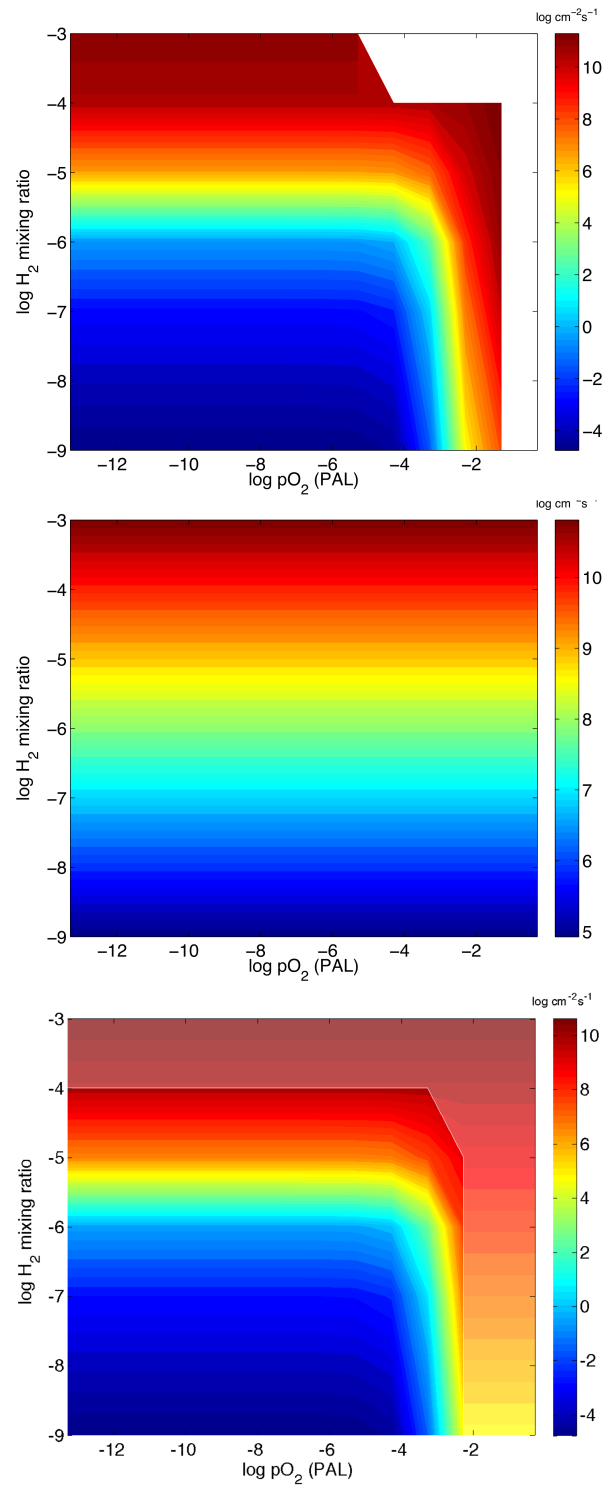

Figure 5.5: Hydrogen escape rate as a function of the surface mixing ratios of $\mathrm{O}_{2}$ and $\mathrm{H}_{2}$ using the $\kappa$ thermosphere model. Top: hydrodynamic model with Jeans boundary conditions. Center: diffusion-limitation. Bottom: hydrodynamic/Jeans model with diffusion-limited maximum. White shading indicates where diffusion limited rates have been applied. 

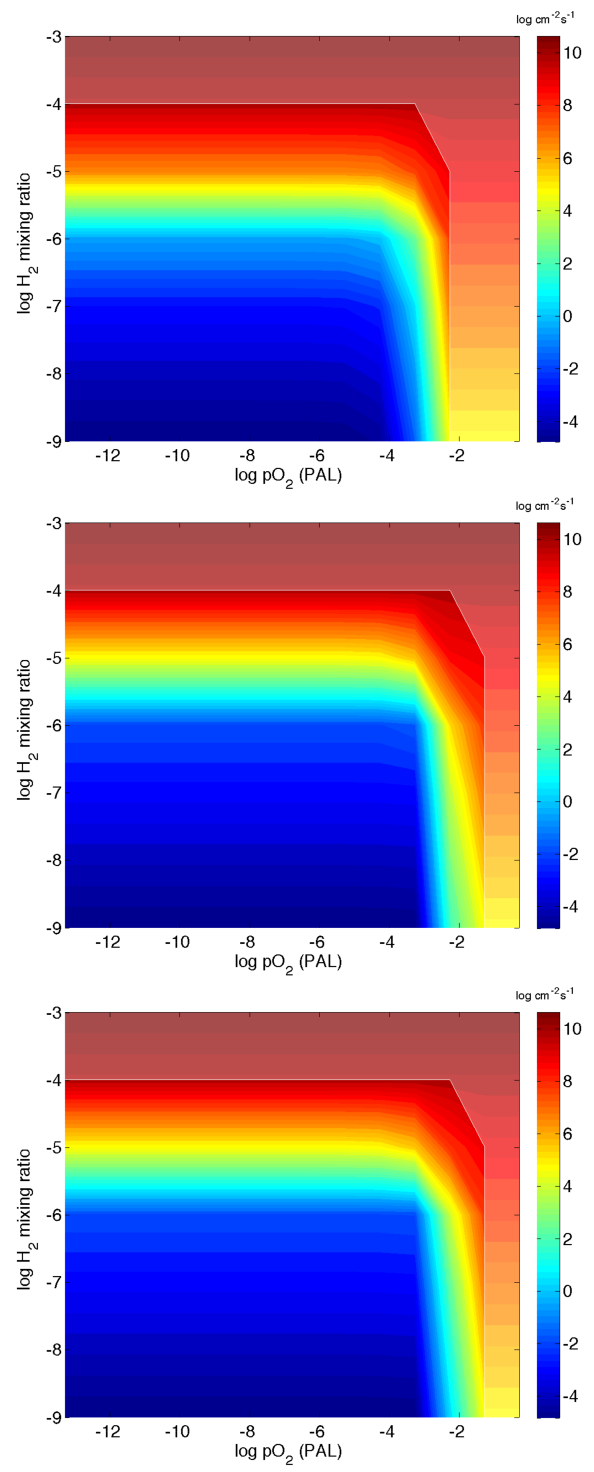

Figure 5.6: Hydrogen escape rate as a function of the surface mixing ratios of $\mathrm{O}_{2}$ and $\mathrm{H}_{2}$ using different thermosphere models. Top: $\kappa$ model. Center: $15 \mu \mathrm{m}$ model without atomic oxygen. Bottom: $15 \mu \mathrm{m}$ model with $50 \%$ photolysis of $\mathrm{O}_{2}$ at homopause. White shading indicates where diffusion limited rates have been applied. 

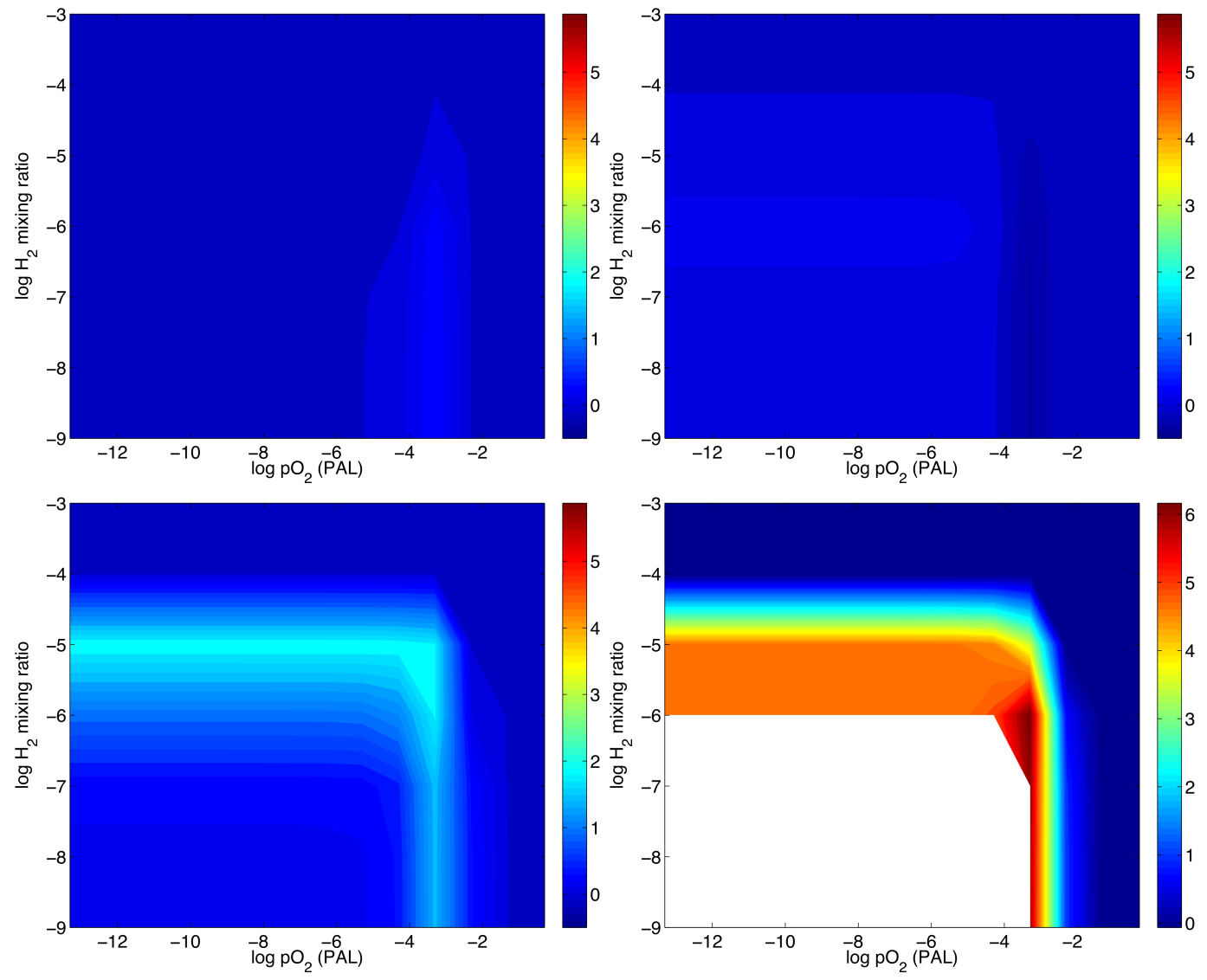

Figure 5.7: Ratio of the escape rate calculated using two different parameter values in the $\kappa$ thermomsphere model. Relative escape rates are given as a function of the surface mixing ratios of $\mathrm{O}_{2}$ and $\mathrm{H}_{2}$. Upper left: $\left(r_{h}=110 \mathrm{~km}\right):\left(r_{h}=90 \mathrm{~km}\right)$. Upper right: $\left(r_{m}=95 \mathrm{~km}\right):\left(r_{m}=75 \mathrm{~km}\right)$. Lower left: $\left(n_{m}=25^{*} 10^{13} \mathrm{~cm}^{-3}\right):\left(n_{m}=15^{*} 10^{13} \mathrm{~cm}^{-3}\right)$. Lower right: $\left(T_{m}=250 \mathrm{~K}\right):\left(T_{m}=150 \mathrm{~K}\right)$. Parameters are defined in the text. Jeans rates were only calculated for lower boundary $\left(r_{b}=200 \mathrm{~km}\right)$ temperatures greater than $200 \mathrm{~K}$, so solutions could not be found for some cases with cool mesopause temperature $T_{m}$. 


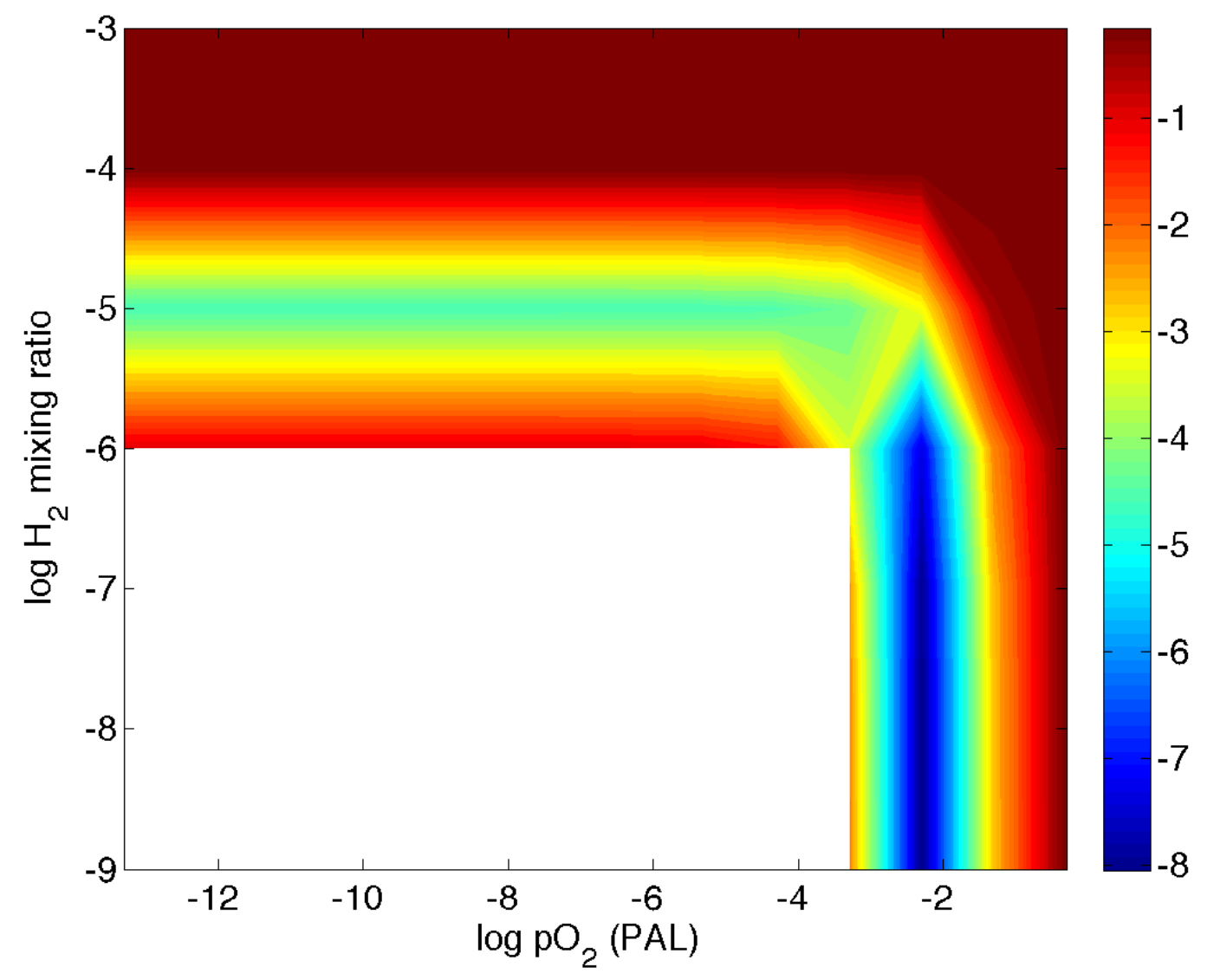

Figure 5.8: Ratio of the hydrogen escape rate at 10,000 $\mathrm{ppm}^{\mathrm{CO}_{2}}$ to the escape rate at $1,000 \mathrm{ppm} \mathrm{CO}_{2}$. Relative escape rates are given as a function of the surface mixing ratios of $\mathrm{O}_{2}$ and $\mathrm{H}_{2}$. The thermosphere model is the $15 \mu \mathrm{m}$ model with $50 \%$ photolysis of $\mathrm{O}_{2}$ at the homopause. 
Chapter 6 - Archean $\mathrm{pO}_{2}$

\title{
Chapter 6
}

\section{Evolution of atmospheric oxygen during the Archean}

\begin{abstract}
Proxy data and modeling studies suggest atmospheric $\mathrm{pO}_{2}$ was below $10^{-5}$ present atmospheric levels (PAL) during the Archean, until increasing by many orders of magnitude around 2.4 Ga, a transition known as the Great Oxidation Event (GOE). We use a model of biogeochemical cycling to show that the Archean atmosphere may have passed through several equilibrium states as new metabolic processes evolved. We also present a novel positive feedback on surface oxygen levels, in which rising $\mathrm{pO}_{2}$ reduces ferrous iron concentrations, driving down alkalinity and ultimately leading to additional phosphate weathering and organic carbon burial via the silicate weathering thermostat. Including this effect in the model leads to multiple equilbria in atmosheric oxygen. $\mathrm{pCO}_{2}$ changes associated with the a simulation of the Snowball glacial are sufficient to drive the model permanently between the two states, providing a new hypothesis for simultaneity between the Great Oxidation Event and a Paleoproterozoic Snowball Earth.
\end{abstract}


Chapter 6 - Archean $\mathrm{pO}_{2}$

\subsection{Introduction}

In 1968, Preston Cloud argued that oxygen must have been scarce in the atmosphere before about 2 billion years ago, due to the presence of detrital uranite and pyrite grains, and the absence of oxidized iron "red beds, in sedimentary rocks of that age. This argument was given a widely-accepted quantitative bound 30 years later, when James Farquhar et al. (2000) reported mass-independent fractionation of $\mathrm{S}$ isotopes in sulfur minerals older than $2.4 \mathrm{Ga}$. Mass-independent fractionation (MIF) is generated during photolysis of sulfur compounds in the atmosphere, but in a sufficiently oxidized surface environment this signal is homogenized by rapid cycling of sulfur between its oxidized and reduced reservoirs (e.g. Farquhar et al. 2001). Photochemical modeling suggests the Archean MIF signal would only be preserved if $\mathrm{pO}_{2}$ were less than $0.001 \%$ present atmospheric levels (PAL) (Pavlov \& Kasting 2002).

Other proxy records also indicate very low levels of oxygen during the Archean. The low iron content of Archean paleosols may result from the flushing of soluble ferrous iron from

poorly-oxidized weathering environments (Holland 1984), requiring $\mathrm{pO}_{2}$ less than $\sim 10^{-3}$ PAL in a simple soil model (Rye \& Holland 1998). The detritral pyrite and uraninite grains mentioned by Cloud (1968), which are oxidized rapidly during transport under modern conditions, are only found in sedimentary deposits older than 2.4 Ga (Johnson et al. 2014a). Banded iron formations (BIFs) are also deposited primarily during the Archean (Isley \& Abbott 1999). These are evidence for an anoxic ocean, which is required to transport sufficient quantities of soluble reduced iron to the site of deposition (Holland 1984). Local enrichments of redox-sensitive trace metals such as Mo and Re at 2.5 Ga have been used to argue for transient oxidative processes during the latest Archean, but Mo mobilization does not require oxygen levels above $10^{-5} \mathrm{PAL}$ (Anbar et al. 2007). 
Chapter 6 - Archean $\mathrm{pO}_{2}$

Between 2.4 and $2.3 \mathrm{Ga}$, the MIF sulfur signal disappears from the record (Bekker et al. 2004), indicating a rise in oxygen above the $0.001 \%$ PAL threshold of Pavlov \& Kasting (2002). By 2.1 Ga, uraninite and pyrite grains are no longer preserved, and paleosol iron content increases (Rye \& Holland 1998). "Red bed" deposits of oxidized iron first appear at this time (Cloud 1968), and BIF deposition largely ceases by 1.8 Ga (Isley \& Abbot 1999). Though each of these proxies may respond to a different threshold in $\mathrm{pO}_{2}$, the nearly simultaneous change in behavior suggests a large and abrupt increase in oxygen beginning at $2.4 \mathrm{Ga}$, the Great Oxidation Event (GOE). Following the GOE, Proterozoic $\mathrm{pO}_{2}$ is believed to have been between 1-10\% PAL, based on modeling of paleosol iron content (Rye \& Holland 1998), and pyrite and uraninite oxidation rates (Johnson et al. 2014a). Many qualitative redox proxies show little variation for the next 2 billion years, implying oxygen levels did not vary outside this range after the early Paleoproterozoic. The molybdenum content of sediments, which is controlled by a balance of oxidative weathering and redoxdependent scavenging mechanisms, falls in a consistent range distinct from both the Archean and Phanerozoic (Scott et al. 2008). $\delta^{34} \mathrm{~S}$ in pyrites also show a distinct Proterozoic range, which has been argued to represent oceanic sulfate concentrations above 200M, in contrast to the Archean (Canfield \& Teske 1996). Iron speciation studies consistently point to ferruginous deep waters by the Mesoproterozoic (Johnston et al. 2010, Poulton et al. 2010).

The early history of atmospheric oxygen can thus be divided into two broad periods (Kump 2008): the Archean, with $\mathrm{pO}_{2}$ below $10^{-5} \mathrm{PAL}$, and the Proterozoic, with $\mathrm{pO}_{2} \sim 1-10 \%$ PAL. There are several, mostly conceptual hypotheses that seek to explain how Archean oxygen was maintained at such low levels, and why oxygen ultimately rose to greater concentrations. These mechanisms can be broadly divided into two categories: those calling on larger sinks for oxygen, or on smaller sources. 
Chapter 6 - Archean $\mathrm{pO}_{2}$

Some authors have proposed that there was essentially no source of oxygen in the Archean (e.g. Kopp et al. 2005), aside from photolytic splitting of water vapor, which results in $\mathrm{pO}_{2}$ near $10^{-13} \mathrm{PAL}$ in photochemical models (Kasting 1993). In this view, low oxygen is simply due to a lack of any biological $\mathrm{O}_{2}$ production, and the GOE is the result of the evolution of oxygen photosynthesis. This claim is based on a lack of definitive evidence for oxygenic photosynthesis before the Proterozoic, when oxygen levels rise sharply. However, several pieces of evidence suggest oxygenic photosynthesis evolved at least 100 million years before the end of the Archean. The discovery of a biomarker for cyanobacteria, $2 \alpha$-methylhopane, in shales from the Pilbara Craton indicate oxygenic photosynthesis at 2.7 Ga (Brocks et al. 1999), though this has since been attributed to contamination (Rasmussen et al. 2008). Stromatolite structures associated only with oxygen-producing photosynthetic communities have been identified as early as 3.0 Ga in the Pongola Supergroup (Bosak et al. 2013). The organic carbon content of Archean sediments is similar to their modern equivalents, and it has been questioned if this would have been possible without use of water as an electron donor, given reasonable assumptions about the supply of alternative donors such as $\mathrm{H}_{2}$ or $\mathrm{H}_{2} \mathrm{~S}$ (Lyons et al. 2014). Local enrichments of oxidatively-mobilized molybdenum in the 2.5 Ga Mt. McRae shale (Anbar et al. 2007) also indicate biological production of $\mathrm{O}_{2}$.

Given these challenges, other authors have instead called on larger oxygen sinks to explain low Archean $\mathrm{pO}_{2}$. Kasting et al. (1993) argue that the mantle was more reducing in the Archean than it is today, resulting in a flux of more reduced volcanic gases that overwhelmed the production of oxygen from photosynthesis. The difference in oxidation state between the modern and Archean mantle is attributed to slow oxidation of the bulk Earth by photolysis of water followed by escape of hydrogen to space. Constant V/Sc ratios in peridotite melts dating back to $3.5 \mathrm{Ga}$ indicate that the redox state of the mantle has not changed signifi- 
cantly since the earliest Archean (Li \& Lee 2004), and so Catling et al. (2001) argue that $\mathrm{H}_{2}$ escape must only have oxidized the crust, allowing for progressively slower consumption of oxygen by weathering of continental surfaces. In either case, photolysis and escape drive progressive oxidation of the solid Earth, leading to a declining oxygen sink and an eventual rise in $\mathrm{O}_{2}$ to Proterozoic levels.

Alternatively, Kump \& Barley (2007) propose that volcanic gases were more reducing in the Archean despite the relatively oxidized mantle, due to a predominance of submarine rather than subaerial volcanism. Once large continental crators stabilized, subaerial volcanism became more important, resulting in more oxidized volcanic gases and a subsequent rise in $\mathrm{O}_{2}$. Cooling of the mantle may also have resulted in a smaller flux of mantle gases over time, with the same result (Claire et al. 2006).

It is difficult to evaluate these hypotheses without a more complete understanding of the biogeochemical cycles of oxygen, carbon, sulfur, iron that is, the major redox sensitive geochemical cycles. It is impossible to predict how $\mathrm{pO}_{2}$ will respond to a given change in the redox cycle, such as a change in mantle oxidation state, or the rate of outgassing, without first understanding the negative feedbacks that stabilize $\mathrm{pO}_{2}$ at a particular steady state value. A theory for the GOE must articulate how these negative feedback allow $\mathrm{pO}_{2}$ to be stable at both Archean and Proterozoic levels. Only then is it possible to ask how the atmosphere moved between these two steady states.

In this study we present a general model of the Precambrian biogeochemical cycles of oxygen, hydrogen, carbon, iron, and sulfur. We first use our redox cycle model to predict fluctuations in the composition of the Archean atmosphere before the GOE. We then explore the dynamics that permit stable $\mathrm{pO}_{2}$ at both Archean and Proterozoic levels. We 
Chapter 6 - Archean $\mathrm{pO}_{2}$

identify processes capable of driving oxygen between Archean and Proterozoic levels in a hundred million years, allowing discrimination between existing hypotheses for the GOE. We use our redox cycle model to explore possible tests of our hypotheses by considering impacts on a variety of geochemical proxies and other observations.

\subsection{Oxygen Cycling in the Archean}

\subsubsection{Pre-biotic oxygen cycling}

Before the rise of oxygenic photosynthesis, the major source of molecular oxygen is recombination of oxygen atoms liberated during photolysis of carbon dioxide and water (Kasting 1993). The exact production rate depends on poorly constrained $\mathrm{CO}_{2}$ concentrations, but allowing for $\sim 0.1$ bar to compensate for the faint young sun, photochemical models find the $\mathrm{O}_{2}$ flux is approximately $0.01 \mathrm{Tmol} \mathrm{O}_{2} \mathrm{y}^{-1}$ (Kasting \& Catling 2003), more than 100,000 times smaller than the modern photosynthetic production of oxygen.

The photolysis-derived oxygen is lost to oxidation reactions, particularly with hydrogenbearing species in the upper atmosphere where the oxygen is produced. Today, hydrogen enters the atmosphere through volcanic outgassing and from interactions with the crust and mantle at a rate between $\sim 0.5$ to $5 \mathrm{Tmol} \mathrm{H}_{2} \mathrm{y}^{-1}$ (section 6.2.3). Assuming a net oxidation stoichiometry of

$$
\mathrm{H}_{2}+\mathrm{O}_{2} \rightarrow 2 \mathrm{H}_{2} \mathrm{O}
$$

the modern hydrogen flux is large enough to completely overwhelm the prebiotic oxygen source. The Archean hydrogen flux may have been even larger (section 6.2.3), implying very low levels of prebiotic $\mathrm{O}_{2}$. More precisely, the Archean atmosphere will stabilize at the $\mathrm{pO}_{2}$ level for which the oxygen sink, reaction 1 , balances the oxygen source from photolysis. 
Though [1] is only a net reaction, it suggests the rate of oxygen consumption, and thus $\mathrm{pO}_{2}$, depends on hydrogen levels. In steady state, $\mathrm{H}_{2}$ must be removed from the ocean and atmosphere at the rate it is supplied from the mantle. The primary sink cannot be oxidation via reaction [1]; the source of $\mathrm{H}_{2}$ dwarfs the supply of oxygen from photolysis. Therefore, hydrogen will accumulate in the pre-biotic atmosphere until inputs are balanced by escape to space (Walker 1977).

\subsubsection{Pre-biotic hydrogen cycling: hydrogen escape}

Hydrogen is lost to space when an atom or molecule achieves escape velocity in the upper reaches of the atmosphere, known as the exosphere, where collisions are rare and an escaping particle has a clear path away from the Earth. Escape may be driven by a variety of mechanisms, but whatever the loss process, hydrogen must be supplied to the exosphere by diffusion through the background components of the atmosphere. If the escape process is very efficient for example, if UV heating results in very high temperatures and rapid thermal loss (Chapter 5) the escape rate may exceed the supply of hydrogen from below. Hydrogen concentrations in the upper atmosphere will fall until the escape rate matches the rate of diffusion. This is referred to as diffusion-limited escape, and is believed to control the loss of hydrogen from Earth today (Hunten 1973).

Diffusion-limitation therefore provides an upper bound on the escape rate. Balancing the the modern hydrogen flux with diffusion-limited escape yields a lower bound on pre-biotic $\mathrm{H}_{2}$ levels. This calculation has been performed in several photochemical models, and gives $\mathrm{pH}_{2}$ around $10^{-3} \mathrm{~atm}$ (Kasting 1993, Tian et al. 2005). Balancing the photolytic source of oxygen against its consumption by this $\mathrm{H}_{2}$-rich atmosphere, pre-biotic surface-level $\mathrm{pO}_{2}$ is estimated to be $10^{-13}$ PAL (Kasting 1993). 
Chapter 6 - Archean $\mathrm{pO}_{2}$

This is a useful limiting case. However, hydrogen escape was not necessarily diffusion-limited in the Archean, as is commonly assumed in biogeochemical models (e.g. Pavlov et al. 2001, Kharecha et al. 2005, Goldblatt et al. 2006). Heating by $\mathrm{O}_{2}$-absorption of ultraviolet is an important process in the modern thermosphere (Roble et al. 1987). In the oxygenpoor Archean, the thermosphere could have been much colder, even after accounting for the importance of radiative cooling associated with $\mathrm{O}$ atoms (Bougher et al. 1994). Though nonthermal processes are also important in todays atmosphere, colder temperatures generally imply less efficient escape, perhaps well below the diffusion limit (Tian et al. 2005). An accurate estimate of Archean hydrogen and oxygen levels calls for a more general treatment of the escape process (Chapter 5).

\subsubsection{Pre-biotic hydrogen cycling: hydrogen sources}

The hydrogen content of the atmosphere is determined by balancing escape and oxidation against the source of hydrogen from the mantle, which is itself poorly constrained. Mantlederived hydrogen species, primarily $\mathrm{H}_{2}$ and $\mathrm{H}_{2} \mathrm{~S}$, are injected into the ocean and atmosphere via volcanism, at a rate ranging from 0.1 (Canfield et al. 2006) to $5 \mathrm{Tmol} \mathrm{H}_{2} \mathrm{y}^{-1}$ (Holland 1978, 2002). Hydrogen is also released during serpentinization reactions in the ocean crust, which oxidize mantle-derived ferrous iron to magnetite. The global rate of serpentinization has been estimated based on both average crustal compositions (Emmanuel \& Ague 2007, Canfield et al. 2006) and low-temperature hydrothermal water fluxes (Keir et al. 2010, yielding production rates in the range 0.1 to $0.3 \mathrm{Tmol} \mathrm{H}_{2} \mathrm{y}^{-1}$.

This gives a total modern hydrogen source of 0.2 to $5 \mathrm{Tmol} \mathrm{H}_{2} \mathrm{y}^{-1}$. The flux during the Archean may have been larger or smaller. Greater heat loss from the Archean mantle (Turcotte 1980) was likely accommodated at least in part by more rapid seafloor spreading and 
Chapter 6 - Archean $\mathrm{pO}_{2}$

ocean crust creation (Abbott \& Hoffman 1984). An increase in the formation of crust implies an equivalent increase in the exposure of unaltered basalt to serpentinizing conditions at the seafloor. The overall acceleration in tectonic cycling may also increase the release of mantle gases at spreading centers and subduction zones (Emmanuel \& Ague 2007). If we naively assume these processes scale linearly with heat flow, serpentinization and outgassing rates would double at $2.4 \mathrm{Ga}$ (Turcotte 1980), though other, more dramatic scaling relationships have been proposed (Canfield et al. 2004).

Serpentinization rates depend not only on the areal rate of crust generation, but on its composition. Average Archean crust was likely more mafic than its modern equivalent, given the elevated Mg content in typical Archean basalts (Herzberg et al. 2010). A more mafic composition suggests greater primary iron content and thus more hydrogen liberation during low-temperature alteration. Hydrogen yields depend on temperature and hydrothermal fluid composition in complex ways (McCollom \& Bach 2009), so it is difficult to infer exactly how much more hydrogen may have been produced per volume. However, peridotite-hosted vents in the modern ocean, such as the Lost City or Rainbow fields, can have hydrogen concentrations of more than $10 \mathrm{mM}$ in their hydrothermal fluids, compared to typical concentrations of $<1 \mathrm{mM}$ in typical basalt-hosted vents (Keir 2010).

The $\mathrm{Mg}$ content of Archean basalts can be explained by higher melt temperatures in the upper mantle, which leads to much thicker crust in melting models (e.g. Johnson et al. 2014b). Thickening of the crust does generate a greater volume of basalt potentially subject to low-temperature alteration. However, today extensive serpentinization occurs near very slow spreading ridges, where uplift of mantle material is associated with outcrop and serpenitinization of peridotites (Cannat 1993). Thickening may limit exposure of such olivine-rich upper mantle rocks to seawater, reducing global serpentinization rates. 
Chapter 6 - Archean $\mathrm{pO}_{2}$

Taken together, the increased seafloor spreading rate, a more mafic composition of the seafloor, and increased crust thickness, are consistent with either a net decrease or increase in hydrogen production. If the lowest estimate of modern rates represents a lower bound, and an upper bound allows for 10 times the serpentinization rate and double the outgassing, the Archean hydrogen source was between 0.1 and $10 \mathrm{Tmol}_{2} \mathrm{y}^{-1}$, a range spanning two orders of magnitude. Estimating the range in $\mathrm{O}_{2}$ and $\mathrm{H}_{2}$ levels that are permitted by this range is one of the goals of this study.

\subsubsection{Oxygen cycling at the origin of life}

The origin of life introduces an additional sink for $\mathrm{H}_{2}$. As an abundant electron donor, hydrogen may have been consumed via number of metabolic pathways; for example (Kharecha et al. 2005):

$$
\begin{aligned}
& 2 \mathrm{H}_{2}+\mathrm{CO}_{2} \rightarrow \mathrm{CH}_{2} \mathrm{O}+\mathrm{H}_{2} \mathrm{O} \\
& 4 \mathrm{H}_{2}+\mathrm{CO}_{2} \rightarrow \mathrm{CH}_{4}+2 \mathrm{H}_{2} \mathrm{O}
\end{aligned}
$$

The first pathway may represent an early form of photosynthesis, or a chemotrophic metabolism. Methanogenesis may be important for its impact on surface temperatures (e.g. Kasting \& Catling 2003), but conversion of $\mathrm{H}_{2}$ to $\mathrm{CH}_{4}$ will not significantly alter the surface electron cycle; methane oxidation pathways in the atmosphere are similar to those of $\mathrm{H}_{2}$, with similar rate constants (Warneck 2000). Hydrogen escape is dominated by loss of the lightest species, atomic $\mathrm{H}$, which is produced by photolysis of both $\mathrm{H}_{2}$ and $\mathrm{CH}_{4}$ in the upper atmosphere. Regardless of which pathways existed in the early Earth, production and burial of organic carbon ultimately represents a sink for hydrogen-bearing species. 
When carbon is fixed to solid biomass, burial of that organic carbon effectively removes $\mathrm{H}_{2}$ to the sediments. We can estimate the approximate scale of this sink by assuming these organisms were phosphorus-limited, with a Redfield ratio of 100 C:P. Given the modern supply of phosphorus to the marine biosphere, $\sim 250 \mathrm{Gmol} \mathrm{P} \mathrm{y}^{-1}$, the hydrogen sink can be

as large as 50 Tmol $\mathrm{H}_{2} \mathrm{y}^{-1}$, assuming $100 \%$ of organic matter is ultimately buried. This is an extreme upper bound, as burial efficiency is unlikely to have been exactly $100 \%$, and the supply of bioavailable phosphorus must have been substantially lower than it is today (see section 2.5). Nevertheless, life may have provided a hydrogen sink on the scale of the outgassing rate.

\subsubsection{Oxygen cycling after the evolution of oxygenic photosynthesis}

At some time after the origin of the life, the evolution of oxygenic photosynthesis introduces a new source of oxygen to the system:

$$
\mathrm{CO}_{2}+\mathrm{H}_{2} \mathrm{O} \rightarrow \mathrm{CH}_{2} \mathrm{O}+\mathrm{O}_{2}
$$

which produces oxygen as long as the organic carbon is buried without being re-oxidized. Remineralization is slow in a low-oxygen, low-sulfate ocean like that of the Archean (e.g. Hedges et al. 1999), and so organic burial is roughly equivalent to export production. At steady state, export must be equal to the supply of the limiting nutrient, likely phosphorus (Tyrrell 1999), to the biosphere. Therefore, the source of oxygen is determined by the supply of $\mathrm{P}$ to photosynthetic organisms.

The portion of phosphorus that is available for use by biology is the bioavailable fraction, and consists primarily of dissolved phosphate. Today, most phosphorus in rivers is derived from apatite weathering, but only a small fraction, $\sim 10 \%$, is bioavailable; the rest is inaccessible 
detrital apatite, or is immobilized by scavenging onto mineral surfaces during transport or in estuaries (e.g. Froelich et al. 1988). The portion of riverine phosphorus that reaches the photic zone in bioavaible form we term the bioavailable phosphorus flux. Today, this flux is about 250 Gmol P y ${ }^{-1}$ (Benitez-Nelson 2000).

The bioavailable $\mathrm{P}$ flux must have been smaller during the Precambrian. Proterozoic $\mathrm{pO}_{2}$ levels were 1-10\% PAL (Kump 2008). At such low levels, oxygen would have been consumed much more slowly by oxidative processes such as organic carbon weathering and remineralization. Without a compensating decrease in the size of the oxygen source, the $\mathrm{O}_{2}$ budget would be imbalanced, and $\mathrm{pO}_{2}$ would rise back toward its modern steady state value. As argued above, the oxygen source is ultimately determined by the flux of bioavailable phosphorus to the oceans, so Proterozoic $\mathrm{pO}_{2}$ can only be explained by a reduction in the size of this flux (Chapter 2).

The overall flux of $\mathrm{P}$ is controlled by apatite weathering rates, which are not likely to have been smaller than today in the high $\mathrm{CO}_{2}$ environments required to compensate for the Faint Young Sun. Therefore, a decrease in the flux of bioavailable P is best explained by an increase in inorganic scavenging processes under low oxygen conditions, resulting in a larger fraction of dissolved phosphorus being immobilized on mineral surfaces. This may be related to iron cycling; today phosphate adsorbs to ferric oxides, but low-oxygen conditions favor several additional, potentially larger sinks, such as vivianite precipitation, scavenging by green rust, and co-precipitation of phosphate-laden ferric oxides (Laakso \& Schrag 2014, Chapters 2,3). For the purposes of this model, we are agnostic regarding the mechanism, but require a decrease in the size of the bioavailable phosphorus flux relative to modern.

Given the uncertainty in the size of the bioavailable $\mathrm{P}$ flux and the hydrogen flux, we 
consider two limiting cases. For simplicity, oxygenic autotrophs are assumed to outcompete their anoxygenic predecessors in both limits. In the first limiting case, the source of oxygen from photosynthesis is small relative to the source of hydrogen from the mantle. This limit can be stated as:

$$
r F_{\mathrm{P}}<<0.5 F_{\mathrm{H}}
$$

where $\mathrm{F}_{\mathrm{H}}$ is the mantle hydrogen flux, and $\mathrm{F}_{\mathrm{P}}$ is the flux of bioavailable phosphate into the oceans, 0.5 is the stoichiometry of reaction [1], and $\mathrm{r}$ is an average C:P ratio in biomass. This case is similar to the pre-biotic oxygen cycle. The oxygen source is overwhelmed by hydrogen inputs, resulting in high $\mathrm{H}_{2}$ levels controlled by the escape rate, and low $\mathrm{pO}_{2}$ controlled by the rate of $\mathrm{H}_{2}$ oxidation.

In the second limit, the source of oxygen is large, i.e.

$$
r F_{\mathrm{P}}>>0.5 F_{\mathrm{H}}
$$

Here, the oxygen source overwhelms hydrogen inputs. Therefore, hydrogen oxidation can be neglected in the $\mathrm{O}_{2}$ budget, and oxygen levels will rise until balanced by other oxidative sinks, such as weathering of the crust, and reaction with dissolved sulfides and ferrous iron. As with oxygen in the pre-biotic world, hydrogen concentrations will be low, set by the kinetics of its reaction with abundant atmospheric $\mathrm{O}_{2}$.

\subsubsection{The Great Oxidation Event: quantitative modeling of the Archean atmosphere}

An explanation for the Great Oxidation Event, or of any change in steady state, requires an understanding of the stabilizing mechanisms that operate on either side of the transition. 
The goal of this study is to use a biogeochemical model to explore, in a quantitative way, how the processes described above hydrogen outgassing, escape, organic carbon burial, oxidative reactions work together to produce the different steady state conditions observed over early Earth history. Only in this context can we test whether a particular perturbation leads to a transition between states.

In order to model the Archean atmosphere, we must consider the four stages outlined above: 1) the prebiotic era, 2) the era of non-oxygenic autotrophy 3) the oxygenic photosynthesis era, and 4) the oxidized era, which follows the GOE and is essentially the Paleoproterozoic.

The qualitative overview of these periods presented above raises important issues that can only be resolved in a quantitative framework. What were $\mathrm{pO}_{2}$ and $\mathrm{pH}_{2}$ in the prebiotic era? How much did hydrogen fall after the origin of life, and is there a record of this change in the rock record? What was the change in $\mathrm{pO}_{2}$ driven by the evolution of oxygenic photosynthesis? What changes to biogeochemical cycling are capable of triggering a change in steady state large enough and rapid enough to explain the GOE?

Some of these questions have been addressed individually using simplified models. Kasting (1993) considered the prebiotic oxygen level using a photochemistry model. Claire et al. (2006) and Goldblatt et al. (2006) model the response of $\mathrm{pO}_{2}$ to changing mantle fluxes across the GOE, though both employ heavily parameterized ocean biogeochemical cycles. The goal of this study is to model the full history of the Archean in a single, unified biogeochemical framework. 
Chapter 6 - Archean $\mathrm{pO}_{2}$

\subsection{Model \& Methods}

Our model couples the phosphorus, carbon, oxygen, iron, sulfur and hydrogen cycles through mostly first-order chemical reactions in a two-box, phosphorus-limited ocean consisting of a photic zone and a deep ocean. The surface ocean box communicates with a one-box atmosphere with varying mixing ratios of $\mathrm{O}_{2}, \mathrm{CO}_{2}$ and $\mathrm{H}_{2}$. This model is modified from the Phanerozoic/Proterozoic model of Laakso \& Schrag (2014) to include explicit iron and molecular hydrogen cycles, updated flux parameterizations, and an improved integration scheme.

The time-dependent model equations are given in Table 6.1, flux parameterizations in Table 6.2, and parameter values in Table 6.3. The model is tuned to reproduce modern geochemical cycling; equilibrium simulations for modern conditions are summarized in Figure 6.1.

\subsubsection{Organic carbon cycle}

Primary production (NPP) and all subsequent organic cycling occurs at a fixed C:P ratio (r) of 106:1. The rate of primary production is defined by quantitative uptake of photic-zone phosphate over a single time-step. Any production remaining after respiration, adsorption, and burial in shallow-water sediments is exported to the deep ocean (EP). Remineralization in the water column includes both oxic respiration $\left(\mathrm{R}_{\mathrm{wc}}\right)$ and, in the absence of $\mathrm{O}_{2}$, sulfate reduction (Swc). Iron reduction is assumed to be negligible in the water column due to rapid sinking of insoluble ferric iron particles. Both modes of respiration are modeled as linear in the concentration of the electron acceptor and in organic carbon concentrations.

Organic carbon is deposited on the seafloor $\left(\mathrm{B}_{\mathrm{Corg}}\right)$ both directly and by adsorption onto ballast. Ballasted deposition scales with bulk sediment delivery $\left(\mathrm{W}_{\mathrm{B}}\right)$ and NPP. Unballasted 
Chapter 6 - Archean $\mathrm{pO}_{2}$

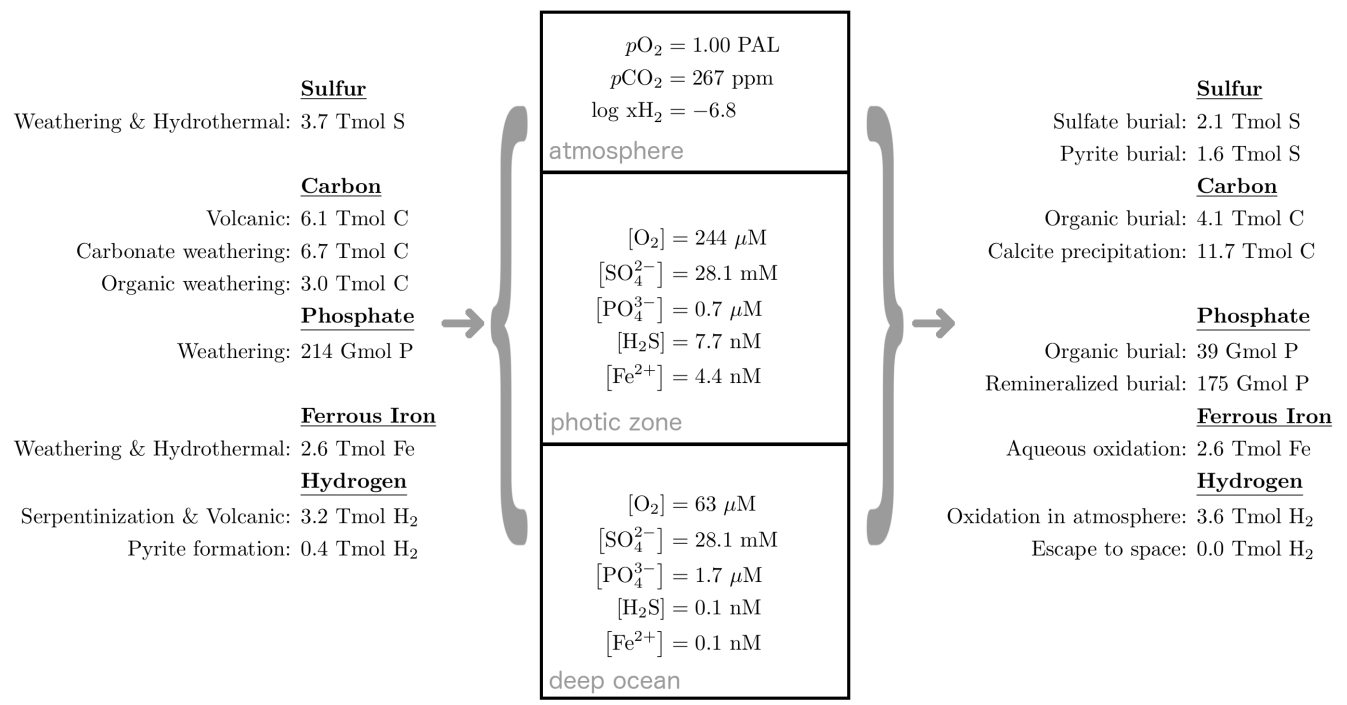

Figure 6.1: Steady-state reservoirs and fluxes for the model run under present-day solar luminosity and phosphorus bioavailability (see text). Model parameters are tuned to reproduce modern values.

deposition is proportional to the unadsorbed, unremineralized organic carbon concentration. The rate of deposition in shallow water sediments also scales with the river-borne fraction of nutrient supply to the photic zone. This allows for more coastal burial and less plagic export when rivers dominate over upwelling as a source of phosphate, despite the lack of horizontal resolution in the model.

After deposition in the sediment, organic carbon is remineralized by oxic respiration $\left(\mathrm{R}_{\mathrm{sd}}\right)$, iron reduction $\left(\mathrm{F}_{\mathrm{sd}}\right)$ and sulfate reduction $\left(\mathrm{S}_{\mathrm{sd}}\right)$. Oxic respiration and sulfate reduction are first-order in the concentration of the electron acceptor in the overlying water column. Iron reduction is first order in the ferric iron deposited in the sediment during that time step. If the resulting rate of total anaerobic respiration exceeds the total carbon deposited in the 
time step, sulfate and iron reduction are scaled to result in complete $\mathrm{C}_{\text {org }}$ consumption while maintaining the originally calculated ratio of rates.

\subsubsection{Phosphorus cycle}

Phosphate enters the ocean/atmosphere system through a bioavailable flux $\left(\mathrm{W}_{\mathrm{a}}\right)$ assumed to derive from apatite weathering, and a bioavailable fraction $f_{b}$ of oxidative weathering of continental organic matter $\left(\mathrm{W}_{\mathrm{C}}\right)$. An ideal model would explicitly simulate the processes that control the bioavailable fraction of total $\mathrm{P}$ (Chapter 2, Figure 6; Chapter 3). Given our incomplete understanding of phosphate immobilization, our model does not explicitly represent this effect. Instead, the bioavailable phosphorus flux (at a given global chemical weathering rate, see below) is set to a fraction of the modern value, tuned to produce a model that can simulate stable levels of Proterozoic $\mathrm{pO}_{2}$ (Laakso \& Schrag 2014). The bioavailable flux is assumed to scale proportionally with the silicate weathering rate (section 6.3.8), as both apatite and silicates weather by acidic dissolution.

The combined bioavailable flux ( $W_{\mathrm{P}}$; equivalent to $F_{P}$ in the conceptual discussion of section 6.2) is dominated by the apatite source (e.g. Benitez-Nelson 2000). Weathering fluxes are described in detail below. Phosphate cycles through organic matter following the parameterization for carbon described in section 6.3.2, with a fixed C:P ratio of 106:1.

Following remineralization of organic matter deposited in the sediments, phosphate may diffuse back into the water column $(\mathrm{Y})$ or be retained in authigenic phases. The fraction lost back to the water column $(\gamma)$ increases with decreasing oxygen, in accordance with observation (Colman \& Holland 2000, Anderson et al. 2001). This effect may be due to a relationship between oxygen levels and the depth of the iron redox front, which sets the effective diffusion scale by concentrating $\mathrm{P}$ due to cycles of adsorption and desorption (e.g. 
Chapter 6 - Archean $\mathrm{pO}_{2}$

Schaffer 1986, Sundby et al. 1992). See Laakso \& Schrag 2014 for further discussion and sensitivity analysis.

Phosphate is also removed from the water column by adsorptive scavenging from the oceanic water column, distinct from the implicit scavenging in rivers in estuaries which controls the size of the bioavailable phosphate flux to the oceans, $\mathrm{W}_{\mathrm{P}}$. This term is first order in the phosphate concentration, and very small relative to biological uptake.

\subsubsection{Sulfur cycle}

The prognostic sulfur species in the model are sulfate ion $\left(\mathrm{SO}_{4}^{2-}\right)$ and hydrogen sulfide $\left(\mathrm{H}_{2} \mathrm{~S}\right)$. Sulfur is introduced to the ocean/atmosphere system through a hydrothermal flux of sulfide $\left(\mathrm{H}_{\mathrm{S}}\right)$, oxidative weathering of terrestrial pyrite $\left(\mathrm{W}_{\mathrm{pyr}}\right)$ and weathering of terrestrial sulfate minerals $\left(\mathrm{W}_{\mathrm{S}}\right)$. Weathering fluxes are described in detail below. Dissolved sulfate is reduced to sulfide via microbial sulfate reduction as described in section 6.3.1. Sulfide is oxidized to sulfate by dissolved oxygen at a rate $\left(\mathrm{Q}_{\mathrm{S}}\right)$ first order in the concentration of both reactants.

Deposition of sulfate minerals occurs only via precipitation of anhydrite/gypsum. The net flux $\left(\mathrm{B}_{\mathrm{G}}\right)$ is first order in calcium and sulfate concentrations. Sulfide is removed exclusively as pyrite. Pyrite precipitation in the water column $\left(\mathrm{B}_{\mathrm{pyr} ; \mathrm{wc}}\right)$ is first order in sulfide and ferrous iron concentration. The formation of pyrite from sulfide requires oxidation of the sulfur from an oxidation state of -2 to -1 ; we represent this by release of $\mathrm{H}_{2}$. This closes the electron budget, but also follows a plausible pyrite-formation pathway (Rickard \& Luther 2007):

$$
\mathrm{Fe}^{2+}+2 \mathrm{H}_{2} \mathrm{~S} \rightarrow \mathrm{FeS}_{s}+\mathrm{H}_{2}+2 \mathrm{H}^{+}
$$


Chapter 6 - Archean $\mathrm{pO}_{2}$

Pyrite precipitation in the sediment $\left(\mathrm{B}_{\mathrm{pyr}: \mathrm{sd}}\right)$ is proportional to the rates of sulfate reduction and iron deposition in the sediment, with a rate constant that decreases linearly with the oxygen content of the overlying water column. $\mathrm{Fe}^{2+}$ released during iron reduction provides the initial source of $\mathrm{Fe}$, following the reaction above. When the total rate of pyrite formation exceeds the rate of iron reduction, iron is drawn from the remaining pool of ferric iron deposited during the time step. The ferric iron is assumed to oxidize one of the two sulfur atoms, i.e. the effective reaction is:

$$
\mathrm{Fe}^{3+}+2 \mathrm{H}_{2} \mathrm{~S} \rightarrow \mathrm{FeS}_{2}+\frac{1}{2} \mathrm{H}_{2}+3 \mathrm{H}^{+}
$$

\subsubsection{Iron cycle}

The prognostic iron species in the model is dissolved ferrous iron, $\mathrm{Fe}^{2+}$. Ferrous iron enters the ocean system through a hydrothermal flux and weathering of terrestrial silicate minerals. Weathering fluxes are described in detail below. Dissolved ferrous iron is oxidized to ferric iron by dissolved oxygen at a rate $\left(\mathrm{Q}_{\mathrm{Fe}}\right)$ first order in the concentration of both reactants. Ferric iron is assumed to sink immediately into the sediments, where it is available for microbial iron reduction following the parameterization described in section 6.3.1. Iron released during oxidative weathering of pyrite is added to this ferric iron pool in shallowwater sediments.

Ferrous iron is removed as pyrite following the parameterization described in section 6.3.3. Ferric iron that is not reduced by carbon or sulfur is considered permanently buried after a single time step. Ferrous iron can also precipitate as siderite, $\mathrm{FeCO}_{3}$. Calculation of the siderite precipitation flux is described in section 6.3.5.

Ferrous iron in the ocean crust is directly oxidized by dissolved $\mathrm{O}_{2}$ at a rate $\left(\mathrm{W}_{\text {basalt }}\right)$ 
Chapter 6 - Archean $\mathrm{pO}_{2}$

proportional to the oxygen concentration in the deep ocean. However, this iron is assumed to remain in the crust, and therefore does not interact with the surface iron cycle, despite representing a sink for oxygen.

\subsubsection{Inorganic carbon cycling}

$\mathrm{CO}_{2}$ enters the ocean/atmosphere system through subaerial $\left(\mathrm{V}_{\mathrm{C}}\right)$ and submarine $\left(\mathrm{U}_{\mathrm{C}}\right)$ volcanic outgassing oxidative weathering of continental organic carbon $\left(\mathrm{W}_{\mathrm{C}}\right.$, and weathering of terrestrial carbonates $\left(\mathrm{W}_{\mathrm{CaCO} 3}\right)$. Weathering fluxes are discussed in detail below.

Dissolved inorganic carbon in the ocean exists as carbonic acid $\left(\mathrm{H}_{2} \mathrm{CO}_{3}\right)$, bicarbonate ion $\left(\mathrm{HCO}_{3}^{-}\right)$and carbonate ion $\left(\mathrm{CO}_{3}^{2-}\right)$. These species are forced to temperature-dependent equilibrium at the end of each time step based on total DIC and alkalinity (see section 6.3.6), using speciation constants from Zeebe \& Wolf-Gladrow (2001) with fixed temperature and pressure offset between the surface and deep boxes.

DIC cycles through the organic carbon reservoir following the parameterization discussed in Section 6.3.1. Carbon in the atmosphere exists as $\mathrm{CO}_{2}$, and exchanges with the surface ocean via a piston velocity parameterization, in which the net rate of exchange is proportional to the departure from equilibrium between atmospheric $\mathrm{pCO}_{2}$ and $\left[\mathrm{H}_{2} \mathrm{CO}_{3}\right]$ in the surface ocean.

DIC is removed from the ocean via precipitation of calcite $\left(\mathrm{B}_{\mathrm{CaCO} 3}\right)$ and siderite $\left(\mathrm{B}_{\mathrm{FeCO} 3}\right)$. A similar approach is used to calculate both fluxes.

The rate of precipitation in the surface ocean is proportional to the oversaturation $(\Omega-1)$, with zero precipitation when the surface is perfectly saturated, $\Omega=1$. Net dissolution is not 
allowed in the surface. A fraction of the precipitate, equal to the proportion $f$ of seafloor area deeper than $100 \mathrm{~m}$, is exported to the deep ocean. The remainder is buried in shallow water sediments.

The exported calcite or siderite may be buried or dissolved, depending on the saturation state of the deep ocean. Though a box model only allows a single saturation state in the deep ocean, applying this value of $\Omega$ over such a large volume results in very sensitive dissolution rates. An artificial $\Omega$ depth profile is assumed, varying linearly such that the depth-averaged $\Omega$ is equal to its value in the deep ocean box. This curve yields a depth at which the ocean becomes undersaturated with respect to calcite or siderite. The proportion of seafloor area under this lysocline, $f_{\mathrm{A}}$, is calculated from a simplified two-dimensional bathymetry with linear slope down to an abyssal plain, which is at the depth of the deep box and covers a fraction $g$ of the deep seafloor. The fraction of export falling on undersaturated sediments, $f_{\mathrm{A}}$, dissolves, while the rest is permanently buried. Additional precipitation and burial is then calculated for the deep waters overlying supersaturated sediments.

The resulting flux is illustrated as a function of $\Omega$ in Figure 6.2. Though more complex than other flux parameterizations in the model, this approach results in precipitation rates that vary smoothly with the concentrations of calcium/iron and carbonate.

\subsubsection{Alkalinity cycle}

In addition to $\mathrm{Fe}^{2+}$ and $\mathrm{SO}_{4}^{2-}$, the model tracks 3 conservative ions: $\mathrm{Ca}^{2+}, \mathrm{Mg}^{2+}$ and an artificial species combining $\mathrm{Na}^{+} / \mathrm{K}^{+}$.

All three species enter the ocean via continental weathering, described in detail below. $\mathrm{Na}+/ \mathrm{K}+$ are removed via an unspecified sink $\left(\mathrm{B}_{\mathrm{NaK}}\right)$ proportional to their concentration 
Chapter 6 - Archean $\mathrm{pO}_{2}$

in seawater. Magnesium is removed via calcium-exchange $\left(\mathrm{B}_{\mathrm{Mg}}\right)$ in hydrothermal systems, taken here to represent the entire magnesium sink for simplicity. This flux is proportional to the magnesium concentration in seawater.

In addition to weathering, calcium enters the ocean via the $\mathrm{Mg} / \mathrm{Ca}$ exchange referenced above, which is given a 1:1 Mg:Ca stoichiometry. Calcium is removed via calcite precipitation (see Section 6.3.5) and gypsum burial (see Section 6.3.3).

\subsubsection{Hydrogen cycle}

Hydrogen exists in the model as $\mathrm{H}_{2}$. Hydrogen enters the ocean/atmosphere system through volcanic outgassing $\left(\mathrm{V}_{\mathrm{H}}\right)$ to atmosphere and a serpentinization flux $\left(\mathrm{U}_{\mathrm{H}}\right)$ into the deep ocean. Hydrogen in the ocean is assumed to be inert, but exchanges with the atmosphere.

Atmospheric hydrogen can escape to space, or react with oxygen to form water. The escape rate $\phi$ is calculated by solving the hydrodynamic escape equations (e.g. Kasting \& Pollack 1983) for atomic hydrogen above $200 \mathrm{~km}$. The calculation is described in detail in Chapter 5 (section 5.3.3, baseline $\kappa$ thermosphere model). Briefly, computation of the escape rate requires a lower boundary condition on both temperature and the molecular hydrogen concentration (assuming total dissociation above 200km), which are computed from a simple energy balance model of the thermosphere. The base of the thermosphere is taken to have the mixing ratios of the one-box atmosphere. At greater altitudes $\mathrm{H}_{2}, \mathrm{O}_{2}, \mathrm{~N} 2$ and temperature profiles are calculated assuming diffusive separation, hydrostatic balance, total dissociation of $\mathrm{H}_{2}$ at $200 \mathrm{~km}$, and a dominant energy balance (Bougher \& Roble 1991) between absorption of solar EUV and downward diffusion of heat. The result is a hydrogen escape rate that varies with the hydrogen and oxygen mixing ratios of the lower atmosphere (Figure 6.2). The oxidation of hydrogen in the atmosphere is assumed to have a stoichiom- 
etry of $2 \mathrm{H}_{2}: \mathrm{O}_{2}$, i.e. the effective net reaction is [1]. In reality this net reaction can proceed via many different pathways, with the dominant pathway dependent on altitude-dependent photolysis effects that vary with the oxygen level itself, due to UV shielding (e.g. Kasting \& Donahue 1980).

A simple parameterization of these effects is not plausible over the very wide range of $\mathrm{H}_{2}$ and $\mathrm{O}_{2}$ levels we wish to simulate, and so we calculate the net $\mathrm{H}_{2}$-oxidation rate $\mathrm{A}$ using existing 1-D photochemical Following Kasting \& Pavlov (2002), the Pavlov et al. (2001) model is used for oxygen mixing ratios ¡ $10-4$, and the Kasting \& Pavlov model for larger $\mathrm{O}_{2}$ mixing ratios.

The models are run to equilibrium fixed surface mixing ratios of $\mathrm{O}_{2}, \mathrm{CO}_{2}$, and $\mathrm{H}_{2}$, and zero hydrogen escape. The resulting column-integrated hydrogen loss rates can be taken as an approximation of the total instantaneous consumption of hydrogen by oxygen for a given atmospheric composition. This assumes that the vertical mixing profiles adjust to equilibrium more quickly than the total inventories of $\mathrm{O}_{2}$ or $\mathrm{H}_{2}$ change. By repeating this process over a wide range of surface $\mathrm{O}_{2} / \mathrm{H}_{2}$ conditions, we have generated a reaction-rate look up table with a 1 log-unit resolution in both the $\mathrm{O}_{2}$ and $\mathrm{H}_{2}$ surface mixing ratio. For simplicity we use a constant $\mathrm{CO}_{2}$ mixing ratios of $10-3$, chosen as a middle ground between modern levels $\left(\sim 10^{-4}\right)$ and model and paleosol estimates for the Archean $\left(10^{-2}\right.$ to $10^{-1}$, Pavlov et al. 2000). In reality some net sinks for hydrogen and oxygen exist other than formation of water, such as rainout of formaldehyde and peroxide, and so the net sinks of hydrogen and oxygen calculated in this way do not differ by exactly a factor of 2 . We therefore generate look-up tables for both the $\mathrm{O}_{2}$ sink and twice the $\mathrm{H}_{2}$ sink, and always take the smaller of the two to represent reaction [1]. The value at an arbitrary atmospheric composition is found by linear interpolation of the look-up values. The resulting reaction 
Chapter 6 - Archean $\mathrm{pO}_{2}$

rates are shown in Figure 6.2.

\subsubsection{Weathering}

Oxidative weathering of continental organic carbon $\left(\mathrm{W}_{\mathrm{C}}\right)$ and pyrite $\left(\mathrm{W}_{\mathrm{pyr}}\right)$ is proportional to atmospheric $\mathrm{pO}_{2}$. The pyrite oxidation rate is capped above a certain $\mathrm{pO}_{2}$ level, in keeping with the disappearance of detrital pyrite grains in the Paleoproterozoic (e.g. Johnson et al. 2014a).

Acidic weathering processes include dissolution of apatite $\left(\mathrm{W}_{\mathrm{a}}\right)$, carbonates $\left(\mathrm{W}_{\mathrm{CaCO} 3}\right)$ and silicate rocks, which releases iron, $\left(\mathrm{W}_{\mathrm{Fe}}\right)$, calcium $\left(\mathrm{W}_{\mathrm{Ca}}\right)$, magnesium $\left(\mathrm{W}_{\mathrm{Mg}}\right)$, sodium and potassium $\left(\mathrm{W}_{\mathrm{NaK}}\right)$ and bulk mineral surface area $\left(\mathrm{W}_{\mathrm{B}}\right)$. These processes are assumed to scale with temperature, following the silicate weathering thermostat hypothesis of Walker et al. 1981 and Berner et al. 1983.The relative weathering factor $(\omega)$ for any acidic weathering flux (W) is taken from the parameterization of Walker et al. 1981, which is of the form:

$$
\omega(T)=\frac{W(T)}{W\left(T_{0}\right)} \sim \exp \left(c_{w}\left(T-T_{0}\right)\right)
$$

for a reference temperature $\mathrm{T}_{0}$ and a relaxation scale $c_{w}$. Temperature is calculated by assuming a climate sensitivity of $3 \mathrm{~K}$ per doubling of $\mathrm{pCO}_{2}$. The baseline value of $\mathrm{pCO}_{2}$ is $280 \mathrm{ppm}$, while the baseline temperature $\mathrm{T}_{0}$ is $288 \mathrm{~K}$ at modern solar luminosity. This baseline temperature varies with $L^{1 / 4}$, where $L$ is solar luminosity relative to its modern value, as given by Gough (1981). The exponent on L derives from the simplest possible energy balance model, in which incoming solar energy is balanced by Earths blackbody radiation without consideration of greenhouse effects.

Given the uncertainty in the strength of the silicate weathering feedback $\left(c_{w}\right)$ and in the 
Chapter 6 - Archean $\mathrm{pO}_{2}$

crudeness of the temperature calculation, the equilibrium $\mathrm{pCO}_{2}$ level in our pre-modern simulations are quite uncertain. However, these parameterizations give results that are correct in sign (e.g. Kasting \& Catling 2003): relative to the modern, the faint young sun results in cooler temperatures, lower relative weathering rates, low alkalinity levels, slow calcite precipitation and thus rising values of $\mathrm{CO}_{2}$; the Archean is therefore characterized by a high- $\mathrm{CO}_{2}$ atmosphere.

\subsubsection{Ocean-atmosphere exchange and ocean mixing}

$\mathrm{O}_{2}, \mathrm{CO}_{2}$ and $\mathrm{H}_{2}$ all exchange between the atmosphere and surface ocean via a piston velocity parameterization, in which the net rate of exchange of species $\mathrm{X}_{2}, \mathrm{G}_{\mathrm{X} 2}$, is proportional to the departure from equilibrium between $\mathrm{pX}_{2}$ and $\left[\mathrm{X}_{2}\right]$ in the surface ocean, with species specific exchange rates and Henrys constant $K_{H}$. The flux $\left(\mathrm{M}_{X}\right)$ due to mixing of species $\mathrm{X}$ between the deep and surface oceans is calculated using a fixed water exchange rate $\mathrm{F}_{W}$, i.e. $\mathrm{M}=\left([\mathrm{X}]_{\text {surf }}-[\mathrm{X}]_{\text {deep }}\right) \mathrm{F}_{W}$. Nutrient uptake in the photic zone is assumed to be fast, in the sense that the NPP flux is applies to surface phosphate concentrations before calculating the phosphate mixing rate.

\subsubsection{Integration}

Integration is performed via Eulers method with a variable time step. Given the initial concentrations and mixing ratios, all fluxes are calculated on an annual basis, and then length of the time step is scaled such that no species changes by more than $1 \%$. This prevents the net consumption of a species over a time step exceeding its reservoir size which is quite likely when simulating small-reservoir, high-flux species such as Archean oxygen, or modern-day ferrous iron. After the fluxes are applied, equilibrium carbonate 
Chapter 6 - Archean $\mathrm{pO}_{2}$

chemistry is enforced as described in Section 6.3.5.

\subsubsection{Methods}

\section{i. Modern and Mesoproterozoic tuning}

The model was manually tuned to reproduce modern conditions, and then subjected to Mesoproterozoic conditions as a test of parameterization robustness. The Mesoproterozoic simulations are defined by: a solar luminosity for 1.2 Ga (Gough 1981); no evaporite weathering (e.g. Grotzinger \& Kasting 1993); and a baseline flux of bioavailable phosphorus at one-third of the modern value (Laakso \& Schrag 2014). This baseline rate is defined relative to modern weathering conditions (Tables $6.1 \& 6.2$ ); after accounting for the change in weathering regime associated with the Proterozoic solar luminosity, the total bioavailable P flux is $\sim 20 \%$ the modern value. Both modern and Mesoproterozoic runs were conducted under a range of $\mathrm{H}_{2}$ inputs, using a modern, low $\mathrm{H}_{2}$ scenario as the initial condition. All equilibrium runs were integrated for a minimum of 15 million years.

\section{ii. Steady-state Archean simulations}

Archean conditions were simulated with no evaporite weathering, a solar luminosity for 2.4 Ga, and a one-third modern baseline bioavailable phosphorus flux, for a bioavailable P flux $\sim 17 \%$ of modern after accounting for equilibration of the weathering system under the faint young sun. Simulations were conducted using a range of hydrogen inputs and an arbitrary initial condition with low oxygen, low sulfate and high $\mathrm{pCO}_{2}$. We conducted three classes of Archean simulations based on the type of primary producers dominating the biosphere: pre-biotic, non-oxygenic, and oxygenic.

The oxygenic simulations follow the parameterizations discussed in Section 6.3.1. Prebiotic simulations have no net primary production. Non-oxygenic simulations are based on 
Chapter 6 - Archean $\mathrm{pO}_{2}$

hydrogen-consuming photoautotrophy assumed to create organic matter with a 106:1 C:P ratio following an overall stoichiometry of [2] (Kharecha et al. 2005). In each time step, primary production results in complete uptake of either phosphate or dissolved $\mathrm{H}_{2}$, whichever proves limiting given the $212: 1 \mathrm{H}_{2}: \mathrm{P}$ demand.

To prevent very long integration times, atmospheric $\mathrm{pO}_{2}$ is fixed at a mixing ratio of $10^{-14}$ whenever it falls below this level - approximately the $10^{-13} \mathrm{PAL}$ predicted for the prebiotic atmosphere by Kasting (1993). This introduces some error in the $\mathrm{H}_{2}$ budgets for the prebiotic and non-oxygenic simulations. This error is small; at steady state, the atmospheric chemistry term is less than $2 \%$ of the total hydrogen sink in all prebiotic and non-oxygenic simulations.

\section{iii. Response to initial conditions}

To test for the possibility of multiple steady states, the oxygenic Archean model was run to steady state after initialization from a variety of initial conditions. A single rate of hydrogen input, $3.2 \mathrm{Tmol} \mathrm{H}_{2} \mathrm{y}^{-1}$, was used throughout these tests. The process was then repeated for several different values of the hydrogen flux surrounding this central value. The initial conditions were identical to the baseline run, except for $\left[\mathrm{O}_{2}\right], \mathrm{pO}_{2}$ and $\mathrm{pCO}_{2}$, which scaled together.

Initial $\mathrm{pCO}_{2}$ was allowed to vary between 1 and 2 times a baseline value of $2800 \mathrm{ppm}$. Initial $\mathrm{O}_{2}$ concentrations varied between 1 and $10^{5}$ times their baseline values at $\log \mathrm{pO}_{2} \sim-7.2$ PAL. The joint scaling of initial condition $(i)$ relative to baseline $(b)$ was according to a 
parameter $j=[0,1]$ :

$$
\begin{aligned}
\left(p \mathrm{CO}_{2}\right)_{i} & =\left(p \mathrm{CO}_{2}\right)_{b}(1+j) \\
\left(p \mathrm{O}_{2}\right)_{i} & =\left(p \mathrm{O}_{2}\right)_{b} \cdot 10^{5 j} \\
{\left[\mathrm{O}_{2}\right]_{i} } & =\left[\mathrm{O}_{2}\right]_{b} \cdot 10^{5 j}
\end{aligned}
$$

\section{iv. Glaciation}

Global glaciation was simulated by applying a $2 / 7(\sim 30 \%)$ reduction in solar luminosity over 1000 years, beginning from the low-oxygen oxygenic Archean equilibrium found in from experiments described above. The $2 / 7$ reduction represents an increase in the planetary albedo from 0.3 to 0.5 , i.e. the absorbed solar radiation falls from 0.7 to 0.5 , roughly between the albedo of the modern Earth and a Snowball planet (e.g. Caldeira \& Kasting 1992). The solar luminosity returns instantly to its original value once $\mathrm{pCO}_{2}$ reaches 10,000 ppm (Abbott et al. 2012), representing rapid meltdown.

\section{v. Sensitivity}

It is important to test whether the existence of multiple equilibria, and the values of those equilibrium $\mathrm{pO}_{2}$ levels, are sensitive to various model parameters. We first tested sensitivity to the hydrogen input rate. For various values of the flux, the model was run to equilibrium after initialization at both the high and low equilibrium states indentified by the experiments described above.

This process was repeated for various other parameters, listed in the Results section. Because the $\mathrm{H}_{2}$ test demonstrated that the existence of equilibrium is sensitive to the hydrogen flux, each test is actually a joint variation between the parameter in question and the hydro- 
Chapter 6 - Archean $\mathrm{pO}_{2}$

gen flux. The chosen parameter was set to its new value, and equilibrium runs conducted for a wide variety of $\mathrm{H}_{2}$ inputs. The critical flux at which $\mathrm{pO}_{2}$ switches from a low to a high value (section 6.4.1; Figure 6.3) was identified, and a new set of runs conducted on a finer grid of $\mathrm{H}_{2}$ flux values, centered around the critical flux. This process was repeated until a flux spacing of $0.02 \mathrm{Tmol} \mathrm{H}_{2} / \mathrm{y}$ was achieved. Existence of multiple steady states was defined as a separation in steady state of more than $0.1 \log$ PAL units after 15 millions years of integration. If multiple equilibrium conditions were found, the representative run was chosen to give the largest observed separation in steady-state $\mathrm{pO}_{2}$. If multiple equilibria were not found at this spacing, then only one equilibrium state is assumed to be stable.

This procedure allows us to ascertain the existence of multiple equilibria for each parameter value, but makes direct comparison of the resulting $\mathrm{pO}_{2}$ levels difficult.

\subsection{Results}

\subsection{Proterozoic and Archean $\mathrm{pO}_{2}$}

Figure 6.3 shows the steady state value of $\mathrm{pO}_{2}$ for the Mesoproterozoic and oxygenic Archean models as a function of the $\mathrm{H}_{2}$ to bioavailable $\mathrm{P}$ flux ratio, initialized from an arbitrary initial condition. Mesoproterozoic $\mathrm{pO}_{2}$ varies smoothly between $1 \%$ and $20 \% \mathrm{PAL}$ for a $0.5 \mathrm{~F}_{\mathrm{H}}: r \mathrm{~F}_{\mathrm{P}}$ ratio less than $\sim 0.4\left(4 \mathrm{Tmol} \mathrm{H}_{2} \mathrm{y}^{-1}\right)$, but is abruptly suppressed to $\sim 10^{-7} \mathrm{PAL}$ for ratios above this threshold, and to $\sim 10^{-10} \mathrm{PAL}$ for ratios greater than $\sim 0.9\left(6 \mathrm{Tmol} \mathrm{H}_{2}\right)$. The oxygenic Archean model shows similar behavior, with three regimes of $\mathrm{pO}_{2}$. Representative oxygen budgets for the three oxygen branches are shown in Table 6.4. Due to the small time step required for accuracy at such low oxygen values, note that the lowest oxygen runs $\left(\sim 10^{-10} \mathrm{PAL}\right)$ are only integrated for $\sim 1$ million years. 
Chapter 6 - Archean $\mathrm{pO}_{2}$

All prebiotic and non-oxygenic Archean simulations have $\mathrm{pO}_{2}$ at the minimum value permitted in the model, $10^{-13}$ PAL (see section 6.3.11).

\subsubsection{Atmospheric hydrogen in the Archean}

The mixing ratio of hydrogen in the atmosphere is shown in Figure 6.4 for the prebiotic and non-oxygenic simulations. The $\log \mathrm{H}_{2}$ mixing ratio in the pre-biotic simulations varies between -3.5 and -4 for hydrogen inputs between 1 and $8 \mathrm{Tmol} \mathrm{H}_{2} / \mathrm{y}$. The atmospheric hydrogen concentration drops when non-oxygenic primary producers are introduced. This behavior has two regimes: the $\mathrm{H}_{2}$ mixing ratio drops by about 2 orders of magnitude for $0.5 \mathrm{~F}_{\mathrm{H}}: r \mathrm{~F}_{\mathrm{P}}$ ratios below $\sim 1.0\left(6 \mathrm{Tmol} \mathrm{H}_{2} \mathrm{y}^{-1}\right)$, which is also the range over which the biosphere is hydrogen-limited. For larger hydrogen inputs, the biosphere is phosphorus limited, and the drop in $\mathrm{H}_{2}$ mixing ratio is about half an order of magnitude, or $30 \%$. The results are nearly the same when diffusion limitation is assumed (Figure 6.4).

\subsubsection{Response to initial conditions}

Figure 6.5 shows the evolution of atmospheric $\mathrm{pO}_{2}$ in the oxygenic Archean model from various initial conditions in $\mathrm{pO}_{2}$ and $\mathrm{pCO}_{2}$ (see Methods). The hydrogen flux is fixed at 3.2 Tmol $\mathrm{H}_{2} \mathrm{y}^{-1}$, and the baseline bioavailable phosphorus flux at one-third modern. Those

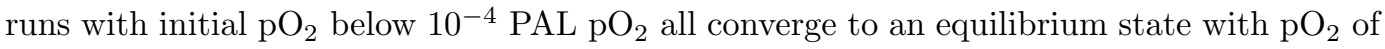
$\sim 10^{-7}$ PAL. Runs with initial $\mathrm{pO}_{2}$ above $10^{-4}$ converge to a steady-state $\mathrm{pO}_{2}$ of $0.15 \% \mathrm{PAL}$.

The low-oxygen equilibrium has $\mathrm{pCO}_{2} \sim 1360 \mathrm{ppm}$, compared to $\sim 1810 \mathrm{ppm}$ in the highoxygen state, corresponding to an $19 \%$ increase in weathering rate and bioavailable phosphate flux between the low- and high- $\mathrm{O}_{2}$ states. Ocean alkalinity is $\sim 940 \mu \mathrm{M}$ and $\sim 1100$ $\mu \mathrm{M}$ in the low and high-oxygen states, respectively. The low-oxygen carbon budget is closed annually by $4.8 \mathrm{Tmol} \mathrm{C}$ calcite burial and $1.1 \mathrm{Tmol} \mathrm{C}$ siderite burial; the high-oxygen budget 
Chapter 6 - Archean $\mathrm{pO}_{2}$

by $6.0 \mathrm{Tmol} \mathrm{C}$ of calcite alone, with residual due to a change in the rate of carbonate weathering. The difference in calcium removal is accounted for by the difference in carbonate and silicate weathering inputs (1.1 Tmol Ca), and a small contribution from increased sulfate burial in the high oxygen environment $(\sim 0.1 \mathrm{Tmol} \mathrm{Ca})$. These budgets are summarized in Table 6.5.

In the low oxygen equilibrium, the annual $\mathrm{O}_{2}$ budget is dominated by $1.6 \mathrm{Tmol} \mathrm{O}_{2}$ of hydrogen oxidation and $1.4 \mathrm{Tmol}_{2}$ continental pyrite oxidation. In the high oxygen state, the additional $0.5 \mathrm{Tmol}_{2}$ of organic carbon burial driven by the accelerated weathering rates are balanced by an additional $0.1 \mathrm{Tmol}_{2}$ continental pyrite oxidation, and $0.4 \mathrm{Tmol}$ $\mathrm{O}_{2}$ oxidation of dissolved ferrous iron and sulfide previously removed as pyrite.

\subsubsection{Glaciation}

The glacial simulation is summarized in Figure 6.6. The atmosphere begins at the lowoxygen steady state described in section 6.4.3., with $\mathrm{pO}_{2}$ of $10^{-7} \mathrm{PAL}$. The drop in solar luminosity - corresponding to glacial initiation results in a drop in temperatures and thus weathering rate. Following a brief oscillation, this is seen as an abrupt drop in $\mathrm{pO}_{2}$ to $10^{-11}$ PAL, driven by falling phosphate levels, where it remains for the duration of the glaciation. The loss of alkalinity inputs from weathering results in a slow rise in $\mathrm{pCO}_{2}$, as expected from the silicate weathering thermostat. $\mathrm{pCO}_{2}$ reaches $10,000 \mathrm{ppm}$ after several hundred thousand years. Once the glacial ends (i.e., the solar luminosity is restored), the intense weathering of apatite drives a very rapid increase in oxygen production, but a relatively small increase in the sink, as only the flux of ferrous iron rises proportionally with the weathering rate. Pre, intra- and post-meltdown oxygen budgets are shown in Table 6.6. $\mathrm{pO}_{2}$ rises by six orders of magnitude in approximately 1000 years, which cannot be resolved in Figure 6.6. As $\mathrm{pCO}_{2}$ declines toward its new, elevated equilibrium value over the next million 
years, oxygen continues rising, reaching $\sim 1 \%$ PAL before reversing slightly and relaxing to the stable high oxygen state at $\sim 10^{-3} \mathrm{PAL}$, where it remains.

\subsubsection{Sensitivity}

Figure 6.7 (top) shows the equilibrium $\mathrm{pO}_{2}$ levels of the oxygenic Archean model when run with different values of the bioavailable phosphorus-to-hydrogen flux ratio. Multiple equilibria exist over a flux range of 3.14 to $3.22 \mathrm{Tmol} \mathrm{H}_{2} \mathrm{y}^{-1}$. Though the phosphate input varies between the different steady states, this range is approximately equivalent to a spread of 0.52 to 0.53 in the ratio $0.5 \mathrm{~F}_{\mathrm{H}}: r \mathrm{~F}_{\mathrm{P}}$. Within this window, the high-oxygen $\mathrm{pO}_{2}$ level varies between $10^{-2}$ and $10^{-4.5} \mathrm{PAL}$, while the low-oxygen equilibrium level is essentially constant at $10^{-7}$ PAL. Outside this window, $\mathrm{pO}_{2}$ always converges to a single value, independent of initial condition. The bottom panel of figure 6.7 repeats this analysis when the rate of siderite precipitation has been suppressed by a factor of 500,000, and the rate of pyrite precipitation increased by a factor of 1000 . In this case, multiple steady states are found for any tested value of the hydrogen flux.

Figure 6.8 shows the equilibrium $\mathrm{pO}_{2}$ levels as a function of ten other model parameters: the maximum rate of oxidative pyrite weathering, $\mathrm{W}_{\text {pyr }}^{*}$; the hydrothermal fluxes of ferrous iron, $\mathrm{H}_{\mathrm{Fe} 2+}$, and sulfide, $\mathrm{H}_{\mathrm{S} 2-}$; the rate of ferrous iron release via silicate weathering, $\mathrm{W}_{\mathrm{Fe} 2+}$; the rate constants for aqueous ferrous iron oxidation, $\mathrm{k}_{\mathrm{Fe}-\mathrm{ox}}$, water-column pyrite precipitation, $\mathrm{k}_{\mathrm{pyr}}$, and siderite precipitation, $\mathrm{k}_{\mathrm{FeCO} 3}$; the atmospheric oxygen level at which continental

pyrite weathers to completion (i.e., at a rate of $\mathrm{W}_{\mathrm{pyr}}^{*}$ ), $\mathrm{pO}_{2}^{*}$; the baseline apatite weathering rate at modern $\mathrm{pCO}_{2}, \mathrm{~W}_{\mathrm{P}}$; and the volcanic flux of $\mathrm{CO}_{2}, \mathrm{~V}_{\mathrm{C}}$.

Multiple equilibria exist for almost all parameter values if the $\mathrm{H}_{2}$ flux is also allowed to vary (see section 6.3.11). The exception is the special case illustrated in Figure 6.7 (bottom), 
Chapter 6 - Archean $\mathrm{pO}_{2}$

described above.

When multiple equilibria exist, the $\mathrm{pO}_{2}$ level in the low-oxygen equilibrium is nearly independent of every parameter except $\mathrm{pO}_{2}^{*}$, the threshold at which oxidative weathering of pyrites goes to completion; the equilibrium value is typically very close this threshold value. The high-oxygen equilibrium $\mathrm{pO}_{2}$ is much more variable, though falls within the range $10^{-4}$ to $10^{-1.5} \mathrm{PAL}$ in all sensitivity experiments.

\subsection{Discussion}

\subsubsection{Atmospheric hydrogen and the origins of life}

Our prebiotic model has hydrogen mixing ratios in the range $10^{-4}$ to $10^{-3}$, varying with the hydrogen flux from volcanoes and serpentinization. In these simulations, the hydrogen cycle consists entirely of mantle-sourced $\mathrm{H}_{2}$ and escape to space, with a small contribution, less than $2 \%$ of the escape flux, from net formation and photolysis of atmospheric water vapor. Therefore, hydrogen accumulates until escape to space is rapid enough to balance inputs.

The resulting mixing ratios are similar to those found in photochemically more-complex models (Kasting 1993) that assume diffusion-limited hydrogen escape. Though we account for temperature effects in the escape rate, the hydrogen levels required to balance the $\mathrm{H}_{2}$ budget are sufficiently high that diffusion limitation is achieved, even from the relatively cool thermosphere in our model (Figures 6.2, 6.4).

Our pre-oxygenic Archean experiments show a large drop in hydrogen concentrations relative to the prebiotic era, between $70 \%$ and $>99 \%$. The drop is generated by the appearance 
of a new sink for $\mathrm{H}_{2}$ via reaction [2]. Hydrogen concentrations in the atmosphere must fall until the escape rate decreases enough to bring the total sink back into balance with the rate of hydrogen supply.

The magnitude of this drop in $\mathrm{H}_{2}$ mixing ratio is controlled by the relative inputs of phosphorus and hydrogen in the surface environment. Given the large uncertainty in both these values, we discuss results in terms of the oxygen sink-to-source ratio, $0.5 \mathrm{~F}_{\mathrm{H}}: r \mathrm{~F}_{\mathrm{P}}$, whenever possible.

If the bioavailable phosphorus flux exceed the supply of hydrogen into the photic zone, the dissolved hydrogen concentration will be drawn toward zero, resulting in the most rapid rate of diffusion from the atmosphere, and the largest possible reduction in atmospheric $\mathrm{H}_{2}$, relative to the prebiotic atmosphere (Figure 6.5). A hydrogen-limited biosphere was suggested by Kharecha et al. (2005), though their model did not explicit model the nutrient cycle, and simply assumed hydrogen-limitation.

Alternatively, hydrogen supply may exceed bioavailable phosphorus, resulting in nutrient limitation. In this case, non-zero hydrogen concentrations are maintained in the surface ocean, resulting in slower net rates of ocean-atmosphere exchange, and thus a smaller relative drop in $\mathrm{pH}_{2}$ relative to the prebiotic era. Given our choice of bioavailable phosphorus flux, the threshold for this behavior is at an annual hydrogen input rate of $\sim 6 \mathrm{Tmol} \mathrm{H}_{2}$ slightly larger than the modern flux estimated by Holland, but about an order of magnitude larger than the more recent modern flux estimates of Canfield et al. (2006).

The assumption of diffusion limitation does not change this basic behavior. When the biosphere is hydrogen-limited, $\mathrm{H}_{2}$ levels are so low that escape rates are a small portion of 
Chapter 6 - Archean $\mathrm{pO}_{2}$

the total hydrogen sink, so differences in the escape rate between models, though large, are irrelevant to the overall budget. When the biosphere is $\mathrm{P}$ limited, hydrogen levels rise high enough that the system is truly diffusion limited, so little difference exists between models (Figures 6.2, 6.4).

This drop in hydrogen concentrations may be recorded in the rock record. Though there is no biological source of $\mathrm{O}_{2}$ at this time, non-trivial oxygen concentrations are still generated in the high atmosphere due to the photolysis of water (Kasting 1993). The drop in hydrogen availability should increase the lifetime of oxygen species against reduction by photolytically derived H-bearing, allowing for increased concentrations of radiatively important species such as $\mathrm{O}_{2}$ and $\mathrm{O}_{3}$, (Kasting \& Donahue 1980), increasing the UV optical depth of the upper atmosphere. A change in optical depth may leave a fingerprint in the sulfur isotope record. Photolytic reactions generating mass-independent fraction of sulfur occur in the UV range (Farquhar et al. 2000, 2001), so any increase in UV shielding impacts the generation of MIF, which is ultimately recorded in sulfate and sulfide minerals.

Our model predicts therefore suggests that MIF generation should have decreased after the appearance of a globally-significant biosphere. A more specific prediction will require linking our geochemical model to a complete representation of sulfur isotope systematics in the atmosphere, such as that of Pavlov \& Kasting (2002). Such a hypothesis may provide an explanation for the structure of the MIF record in the Archean (Halevy et al. 2010), and act as a geological marker for the onset of geochemically influential life.

This signal should exist regardless of the metabolism dominating the early biosphere. Our model represents this metabolism as hydrogen-consuming organisms living in the photic zone. However, from the perspective of the global electron budget, these organisms are 
Chapter 6 - Archean $\mathrm{pO}_{2}$

important only as a sink for hydrogen-bearing species, and thus electrons. The production and burial of organic matter represents such a sink whether the electron donor is molecular hydrogen, methane, or hydrogen sulfide, and whether the locus of production is in the photic zone, or in the deep ocean, dominated by chemoautotrophs. Due to differences in oxidation kinetics, slight differences in the redox budget might arise if one assumes different chemical species dominate the hydrogen reservoir, but the fundamental dynamics remain unchanged.

\subsection{2 $\mathrm{pO}_{2}$ in the wake of oxygenic photosynthesis}

We do not directly simulate the response of the atmosphere to the evolution of oxygenic photosynthesis, which may have involved an extended period of competition separating a period dominated by non-oxygenic photoautotrophs, and the primarily oxygenic biosphere of today. The late Archean itself may have hosted large populations of both types of organism. However, by comparing the non-oxygenic simulations to the oxygenic, we can estimate the maximum possible change in $\mathrm{pO}_{2}$.

The upper bound on $\mathrm{pO}_{2}$ in the non-oxygenic Archean simulations is $10^{-13} \mathrm{PAL}$, similar to the pre-biotic value estimated by Kasting (1993). In the oxygenic phototroph-dominated experiments, $\mathrm{pO}_{2}$ may range anywhere between $10^{-11}$ and $10^{-2} \mathrm{PAL}$, depending on the ratio of hydrogen supply to the bioavailable phosphorus flux (Figure 6.3).

The lowest values of $\mathrm{pO}_{2}\left(10^{-11}\right.$ to $\left.10^{-10} \mathrm{PAL}\right)$ occur when the potential oxygen sink from the hydrogen flux $\left(0.5 \mathrm{~F}_{\mathrm{H}}\right)$ exceeds the source of oxygen, as controlled by the bioavailable phosphorus flux $\left(r \mathrm{~F}_{\mathrm{P}}\right)$ (see Section 6.2.5). The rate of reaction between atmospheric $\mathrm{O}_{2}$ and $\mathrm{H}_{2}$ is quite fast at low levels of oxygen (Figure 6.2) when compared to the first order rates of the other major $\mathrm{O}_{2}$ sinks. These fast dynamics therefore set the rate of oxygen consumption, and ultimately $\mathrm{pO}_{2}$, when there is enough hydrogen available to consume the 
entire oxygen supply.

Intermediate values of $\mathrm{pO}_{2}\left(10^{-8}\right.$ to $\left.10^{-7} \mathrm{PAL}\right)$ occur when the hydrogen sink falls below this threshold. The fast dynamics of atmospheric reactions result in most of the hydrogen being consumed by oxygen reduction, but excess $\mathrm{O}_{2}$ production remains. $\mathrm{pO}_{2}$ rises until an additional sink becomes large enough to balance this excess. In our model, this sink is oxidative weathering of pyrite, which achieves its maximum possible rate at a threshold value, $\mathrm{pO}_{2}^{*}=10^{-7} \mathrm{PAL}$.

High values of $\mathrm{pO}_{2}\left(>10^{-3} \mathrm{PAL}\right)$ occur when the hydrogen flux becomes so small that the combined hydrogen and pyrite sink cannot balance oxygen production. Therefore, $\mathrm{O}_{2}$ rises until other sinks primarily organic carbon weathering and aqueous oxidation of ferrous iron and sulfide become large enough to achieve equilibrium. These budgets are summarized in Table 6.4.

The bioavailable flux of phosphate to organisms in the Archean model is equivalent to approximately $\sim 3 \mathrm{Tmol} \mathrm{O}_{2}$, assuming perfect preservation of organic matter once exported from the surface ocean, and a Redfield ratio of 106P:C. The maximum rate of annual pyrite weathering is $0.8 \mathrm{Tmol} \mathrm{FeS}_{2}$. This places the threshold for hydrogen-controlled $\mathrm{O}_{2}$ near 6 Tmol $\mathrm{H}_{2} / \mathrm{y}$, and the threshold for pyrite controlled dynamics at $3 \mathrm{Tmol} \mathrm{H}_{2} / \mathrm{y}$. These rough calculations are consistent with Figure 6.3.

The evolution of oxygenic photosynthesis therefore places very few dynamical constraints on the level of oxygen in the atmosphere, barring precise knowledge of the bioavailable phosphorus flux and the hydrogen flux at that time. $\mathrm{pO}_{2}$ may have increased only slightly, from $10^{-13}$ to $10^{-11} \mathrm{PAL}$, or may have risen immediately to Proterozoic-like values of $1 \%$ PAL. 
Given the wide uncertainty in the fluxes of both bioavailable phosphorus and hydrogen, the full range of results in Figure 6.3 are at least dynamically plausible.

From this purely dynamical perspective, the Great Oxidation Event could have resulted directly from the evolution of oxygenic photosynthesis. Given appropriate $\mathrm{H}_{2}$ and bioavailable $\mathrm{P}$ fluxes, it can induce an increase in $\mathrm{pO}_{2}$ from below the pyrite weathering threshold to values greater than $10^{-5} \mathrm{PAL}$, as required by the geological record (Holland 1984, Pavlov \& Kasting 2002). However, this explanation for the GOE requires that the evolutionary event occurred close to 2.4 Ga. Biomarker evidence for cyanobacteria in the Archean has been elusive (Rasmussen et al. 2008), but stromatolitic structures associated with oxygenic photosynthesis are first found as early as 3.0 Ga (Bosak et al. 2013), and trace metal mobilization at $\sim 2.7 \mathrm{Ga}$ is consistent with local production of $\mathrm{O}_{2}$.

Given the evidence for an earlier appearance of oxygenic photosynthesis, the late Archean was more likely to have a bioavailable phosphorus-to-hydrogen flux ratio such that $\mathrm{pO}_{2}$ was stable at one of the low oxygen states in Figure 6.3, stabilized by oxygen-sensitive kinetics for hydrogen oxidation and pyrite weathering. In this case, the GOE then occurs some time after the evolution of oxygenic photosyntheis. More specifically the Great Oxidation takes place only once there is an increase in the bioavailable phosphorus flux, or a decline in hydrogen outgassing rates, such that the ratio $0.5 \mathrm{~F}_{\mathrm{H}}: r \mathrm{~F}_{\mathrm{P}}$ declines across the threshold separating intermediate $\mathrm{pO}_{2}\left(10^{-7}\right)$ from Proterozoic levels (Figure 6.3).

Several hypotheses for the GOE focus on a decline in the hydrogen flux. Claire et al. (2006) argue that the flux of electrons from the mantle declined due to gradual oxidation of the whole planet via hydrogen escape. Other hydrogen-based hypotheses include a drop in the hydrogen flux due to secular cooling of the mantle (Claire et al. 2006) and a change in the 
oxidation state of volcanic gases (Kump \& Barley 2007).

These conceputal models for the GOE focus on the mantle as a driver of the $\mathrm{F}_{\mathrm{P}}: \mathrm{F}_{\mathrm{H}}$ ratio. However, the flux of bioavailable phosphorus may also vary over time.

\subsubsection{An oxygen-alkalinity feedback: multiple steady states in $\mathrm{pO}_{2}$}

There is no reason to assume the bioavailable phosphorus flux was fixed throughout the Archean. The bioavailable flux is the fraction of total phosphorus weathering that is available to biology; even if we allow the fraction to be fixed over time, the bioavailable flux could still change due to shifts in the apatite weathering rate.

Apatite dissolution occurs via acid attack, similar to the dissolution of silicate or carbonate rocks. These weathering processes are controlled on a global scale by the silicate weathering thermostat, a negative feedback on temperature believed to have maintained equable temperatures over much of Earth history (Walker et al. 1981). The rate of silicate weathering is dependent on temperature, and thus on $\mathrm{pCO}_{2}$ (Walker et al. 1981, Berner et al. 1983). Any increase in $\mathrm{pCO}_{2}$ results in higher temperatures and increased rates of silicate weathering, releasing additional calcium and magnesium into river water. This flux of alkalinity into the oceans forces the speciation of dissolved inorganic carbon (DIC) species towards carbonate ion, raising the saturation state of calcium carbonate. Calcite precipitation rates rise, sequestering carbon until $\mathrm{CO}_{2}$ is stabilized, with temperature and weathering rates following.

This link between the bioavailable phosphorus flux and the silicate weathering thermostat gives rise to a positive feedback in the oxygen cycle. The feedback allows for a very rapid, permanent rise in $\mathrm{pO}_{2}$ without calling on any change in the supply of reducing power from 
the mantle. These dynamics arise from interactions between the carbon, phosphorus, and iron/sulfur cycles.

The silicate weathering thermostat will operate differently under low-oxygen and highoxygen atmospheres. Dissolution of silicate rocks releases ferrous iron, $\mathrm{Fe}^{2+}$. Today this iron are typically removed from solution by immediate oxidation to insoluble ferric oxides. Paleosol records suggest that much of this ferrous iron was flushed into groundwaters during the Archean (Rye \& Holland 1998), implying a flux of cations into the hydrologic system. Therefore, dissolution of a single unit of silicate rock produces more alkalinity in a low oxygen environment than in a high-oxygen one. This effect is enhanced by a smaller supply of sulfate anions from pyrite weathering in a sufficiently low-oxygen environment (Johnson et al. 2014).

Consider both a low- and high-oxygen atmosphere, both with the same initial level of $\mathrm{pCO}_{2}$. The larger alkalinity flux in the low-oxygen environment will result in more rapid calcite precipitation, drawing down $\mathrm{pCO}_{2}$ relative to the high-oxygen case. This process will continue until $\mathrm{pCO}_{2}$, the silicate weathering rate, and ultimately the alkalinity flux, become low enough to achieve a rate of calcium carbonate burial that balances the flux of carbon from volcanoes. However, the reduction in weathering rate also applies to apatite weathering, resulting in a smaller supply of phosphate $\left(\mathrm{F}_{\mathrm{P}}\right)$, and lower rates of organic carbon burial. This is a positive feedback: lower oxygen results in a lower source of oxygen, and vice-versa. If the low oxygen and high oxygen conditions are both stable, then multiple steady state levels of $\mathrm{pO}_{2}$ are possible.

For both conditions to be stable, the change in biogeochemical cycling between the high- and low-oxygen equilibria must result in steady-state mass balance for all major chemical, not 
just $\mathrm{O}_{2}$. This is problematic if the carbon and calcium budgets are dominated by calcite precipitation, as is the case today. Calcite burial sufficient to balance volcanic $\mathrm{C}$ inputs cannot simultaneously balance the different calcium fluxes associated with the high- and lowoxygen atmospheres. However, calcium mass-balance may be possible in both cases when other redox-sensitive elements are accounted for. In the low oxygen world, the alkalinity budget may be balanced not by accelerated calcite burial, but by significant precipitation of siderite $\left(\mathrm{FeCO}_{3}\right)$ promoted by the flux of ferrous iron from silicate weathering. This allows for more efficient $\mathrm{CO}_{2}$ burial in a low-oxygen ocean while still burying less calcite. Furthermore, decreases in the calcium supply in the low oxygen environment can be balanced by a decrease in anhydrite $\left(\mathrm{CaSO}_{4}\right)$ deposition from the sulfate-poor ocean.

\subsubsection{Analyis of the multiple steady state model}

These dynamics explain why the oxygenic Archean model is able to converge to one of two steady state $\mathrm{pO}_{2}$ levels, depending on the initial conditions (Figure 6.5). The low-oxygen state is in the pyrite-dominated regime (section 5.2), with $\mathrm{pO}_{2}$ slightly below the threshold for complete oxidative weathering of subaerial pyrite exposure, set here to $10^{-7}$ PAL. The high-oxygen state is in the regime dominated by aqueous oxidation reactions, $\sim 10^{-3}$ PAL.

When initialized at a low oxygen state, the oxidation of $\mathrm{Fe}^{2+}$ is sufficiently slow that siderite precipitation becomes an important sink for iron. $\mathrm{pCO}_{2}$ and temperature will adjust such that the weathering flux of calcium and iron into the ocean allow for steady state calcite/siderite precipitation that balance any volcanic carbon input that remains after organic burial.

However, if initialized at a high oxygen sink, iron is removed quantitatively by oxidation. Without the removal of a siderite sink for carbon, $\mathrm{pCO}_{2}$ rises, and calcium weathering rates 
increase until the calcite burial flux becomes large enough to replace the siderite sink for carbon. The resulting increase in acidic weathering processes also releases additional phosphorus, driving additional organic carbon burial. This excess source of oxygen allows $\mathrm{O}_{2}$ to remain at its initially elevated state.

The importance of siderite to this feedback is demonstrated by Figure 6.7. When siderite precipitation rates are suppressed relative to pyrite precipitation, multiple equilibria do not exist. Iron is removed from the low-oxygen ocean as pyrite, and thus the carbon and weathering cycles are not impacted by changes in $\mathrm{pO}_{2}$.

The steady-state budgets (Table 6.5) show that the increase in phosphate supply between the high- and low- $\mathrm{pO}_{2}$ states is about $20 \%$. However, the oxygen level differs by five 4 orders of magnitude. This is possible due to the sensitivity of $\mathrm{pO}_{2}$ to the source/sink ratio, as discussed in the preceding section. The large spread in $\mathrm{O}_{2}$ only results if the FH:FP ratio is close to one of the boundaries shown in Figure 6.3. This sensitivity is illustrated in Figure 6.7; widely divergent steady states only exist within a finite $0.5 \mathrm{~F}_{\mathrm{H}}: r \mathrm{~F}_{\mathrm{P}}$ window, centered around a value of 0.52 . Close to this flux, the total source-to-sink ratio for oxygen, $r \mathrm{~F}_{\mathrm{P}}:\left(0.5 \mathrm{~F}_{z H}+(15 / 8) \mathrm{W}_{\mathrm{pyr}}^{*}\right)$, is approximately unity. Far from this ratio, the model converges to nearly the same $\mathrm{pO}_{2}$ value (within $0.1 \log \mathrm{PAL}$ ) no matter the starting condition.

Steady-state $\mathrm{pO}_{2}$ values separated by more than $0.1 \log \mathrm{PAL}$ exist for $0.5 \mathrm{~F}_{\mathrm{H}}: r \mathrm{~F}_{\mathrm{P}}$ ratios between 0.52 and 0.53 . For the phosphate fluxes used in this model, the width of this window is on the order of the total modern $\mathrm{H}_{2}$ flux according to Canfield et al. (2006), though it is only $5 \%$ of the total flux in the simulation. If the hydrogen flux has varied by several Tmol $\mathrm{H}_{2}$ over Earth history (see Section 6.2.2), this result suggests that multiple equilibria were only possible during a particular phase of Earth history. It is difficult to estimate how 
long this period may have lasted without a numerical theory for the rate of outgassing and serpentinization over time.

The existence of multiple steady states is robust to other major model parameters (Figure 6.8). The stable $\mathrm{pO}_{2}$ levels are mostly weak functions of these variables. The low-oxygen equilibrium is dependent only on the oxygen threshold for complete pyrite weathering. The threshold value determines at what $\mathrm{pO}_{2}$ level the pyrite sink becomes quantitatively significant, allowing it to balance organic burial. The value of this threshold is not well known, though the disappearance of detrital pyrite in the Paleoproterozoic suggests that it is below a value of $10^{-5}$ PAL (Pavlov \& Kasting 2002). The high-oxygen $\mathrm{pO}_{2}$ value is more sensitive, as it is controlled by the oxidation rates of ferrous iron and sulfide, which are controlled by hydrothermal fluxes, weathering rates, and oxidation rate constants. However, the stable level falls between $10^{-3}$ and $10^{-1}$ PAL in most of our simulations. Modern levels of oxygen are not possible due to the reduced rate of phosphate input relative to today (Laakso \& Schrag 2014).

The existence of multiple steady state relies on differences in carbon cycling between lowand high-oxygen environments. In our model, this requires substantial siderite precipitation during the Archean, more than $1 \mathrm{Tmol}^{-1}$. Unfortunately, the kinetics of the various sinks for iron are difficult to constrain. Effective rate laws exist for these phases in some environments, but even within the environmental ranges permitted in the modern ocean, rate constants may vary by multiple orders of magnitude (e.g., pyrite in modern sedimentary systems, Rickard \& Luther 2007). Here, we have assumed siderite precipitates at 50x supersaturation at the rate calcite does at $5 \mathrm{x}$ supersaturation; we also use iron oxidation kinetics slower than those found in modern seawater (Millero et al. 1987), and water-column pyrite kinetics near the slower limit observed in modern sedimentary systems. We have also 
excluded a number of possible other iron sinks, such as greenalite or other silicate phases. These choices tend to favor siderite precipitation. Multiple equilibria continue to exist for both ten-fold increases and decreases in each of these rate constants (Figure 6.8). However, if siderite precipitation becomes sufficiently slow relative to alternative iron sink that do not involve the carbon cycle, such as pyrite, the feedback may cease to operate. This is demonstrated in Figure 6.7 (bottom), where the pyrite precipitation rate constant is increased by 1,000-fold, and siderite precipitation essentially forced to zero by decreasing its rate constant by a factor of 500,000 .

These uncertainties are too large to be entirely confident in our baseline parameterizations. However, if siderite precipitation was sufficiently important to allow for multiple steady states, our model predicts that there should be a large difference in sedimentary carbon phases before and after the Great Oxidation Event. Iron carbonates, represented here as siderite but possibly including ankerite, should be much more prevalent before $2.4 \mathrm{Ga}$. Banded iron formations (BIFs) have an average iron oxidation state of +2.4 , and commonly contain a major siderite and ankerite component (Klein \& Beukes 1993). BIFs essentially vanish after the Paleoproterozoic, with a volumetric peak around roughly $2.5 \mathrm{Ga}$ (Klein 1995). Veizer (1978) observes a continuous increase in the iron content of carbonate rocks back through time, with the change dominated by ferrous iron. This is consistent with our prediction, though the data does not show a step-function in the Paleoproterozoic. Veizer notes that the ferrous iron may not be present as primary siderite, but may have substituted into the carbonate lattice in early diagenesis. Iron isotopic analysis (Johnson et al. 2008, Planavsky et al. 2012) suggests that BIF siderite may also be early diagenetic. Though mechanistically different than our model of primary siderite, iron carbonate formation during early diagenesis should yield similar dynamical behavior, as long as the rate of formation is dependent on iron concentration. 
Chapter 6 - Archean $\mathrm{pO}_{2}$

Our model is not the first model of multiple equilibria in $\mathrm{pO}_{2}$ for the late Archean. Goldblatt et al. (2006) proposed a model based on a photochemical feedback, in which rising $\mathrm{pO}_{2}$ shielded the lower atmosphere from photolysis reactions that generate $\mathrm{OH}$, which mediates the net consumption of oxygen via reactions such as [1]. Our study uses the same photochemical model, and includes this effect; the loss of oxygen due to hydrogen oxidation decreases with $\mathrm{pO}_{2}$ at sufficiently high levels (Figure 6.2). This feedback is not sufficient to produce widely separated equilibrium $\mathrm{pO}_{2}$ values in our model when the oxygen-alkalinity feedback is suppressed by slowing siderite precipitation kinetics relative to those of pyrite (Figure 6.7). The Goldblatt study is primarily a photochemical model. Our ocean-atmosphere model includes a number of important negative feedbacks that arise from sedimentary processes (Laakso \& Schrag 2014), which render $\mathrm{pO}_{2}$ less sensitive to minor positive feedbacks.

\subsubsection{Glacial-initiated model for the Great Oxidation}

Multiple steady states provide a compelling explanation for the sudden rise in oxygen at 2.4 Ga. These dynamics allow oxygen to rise suddenly due to a large peturbation, which forces the system between steady states without invoking a background change in the oxygen or hydrogen sources. A perturbation-based theory for the Great Oxidation Event has the advantage that it can explain both very rapid oxidation (see Figure 6.6), and the apparent synchronicity with the Paleoproterozoic Snowball Earth events (Hoffman 2013).

"Snowball Earth" events are global glaciations known from the Paleoproterozoic and the Neoproterozoic (Hoffman \& Schrag 2002). The initiation of these events is poorly understood, but global glaciation results from a runaway ice-albedo process (Caldeira \& Kasting 1992). $\mathrm{pCO}_{2}$ rises steadily once glaciation occurs, due to a catastrophic slow-down in silicate weathering processes resulting from very low temperatures and possibly from extensive con- 
tinental ice cover. Eventually, greenhouse warming offsets the high albedo of the ice-covered world, melting begins, and the ice retreats extremely rapidly as the ice-albedo feedback operates in reverse. The result is a "hothouse" environment with extremely rapid weathering rates, which lead to the characteristic post-glacial cap carbonates (e.g. Hoffman et al. 1998). Termination of Snowball glaciations therefore represent large positive perturbations in both $\mathrm{pCO}_{2}$ and the weathering rate.

Due to the nature of the oxygen-alkalinity feedback, a perturbation in $\mathrm{pCO}_{2}$ can drive an abrupt, permanent increase in $\mathrm{pO}_{2}$. The transient $\mathrm{CO}_{2}$ increase leads to additional weathering of phosphate, driving additional organic carbon burial and rising $\mathrm{pO}_{2}$. If oxygen levels become high enough, dissolved iron is stripped from the ocean by rapid oxidation, eliminating the siderite sink for $\mathrm{CO}_{2}$. This leads to further increases in $\mathrm{pCO}_{2}$, weathering, and phosphate input.

The Paleoproterozoic Snowball events are conspicuously well-correlated with the collapse of the mass-independent sulfur isotope signal associated with the rise in oxygen (Hoffman 2013 and references therein). This synchronicity motivates our glacial simulation, shown in Figure 6.6. During the immediate post-glacial period, with $\mathrm{pCO}_{2}$ at $10,000 \mathrm{ppm}$, the transient increase in weathering rate results in very high organic carbon burial rates, nearly three times the pre-glacial value. There is not a compensating rise in oxygen sinks. Oxidation of the iron released during the weathering pulse does provide some negative feedback, but this represents only a fraction of the total oxygen sink, while there is a proportional increase in the entire oxygen source (Table 6). Furthermore, though $\mathrm{pO}_{2}$ rises to $\sim 1 \% \mathrm{PAL}$, this is still low enough to permit efficient burial of organic matter, and limited oxidation of organic carbon on continents. Oxygen thus rises permanently to Proterozoic levels in approximately 1000 years (Table 6). Complete relaxation of the redox system requires tens of millions of 
years. This extremely rapid rise is consistent with the MIF signal, which appears to collapse in less than 100 million years (Bekker et al. 2004).

If meltdown occurred at lower levels of $\mathrm{pCO}_{2}$, oxygen need not have risen permanently due to glaciation, as the perturbation could have been much smaller. Therefore, the GOE need not be associated with the first of the Neoproterozoic glacial events, as suggested by Hoffman (2013). This places restrictions on the $\mathrm{CO}_{2}$ deglaciation thresholds of the various Snowball events, which could be attributed to differences in global albedo due to changes in the distribution of land mass (Hoffman \& Schrag 2002).

\subsection{Conclusions}

The evolution of $\mathrm{pO}_{2}$ must be understood in the context of the steady state geochemical cycles possible over time. Any theory for a rapid change in $\mathrm{pO}_{2}$, such as the Great Oxidation Event, can only be evaluated in the context of the dynamical processes that stabilize oxygen on either side of these major transient events.

Our model of Archean biogeochemical cycling has five stable atmospheric compositions. The most reducing has $\mathrm{pO}_{2}<10^{-13} \mathrm{PAL}$ and hydrogen mixing ratios between $10^{-4}$ and $10^{-3}$. This composition is a stable balance between the injection of hydrogen from outgassing and serpentinization, and its escape to space. It is only possible before the appearance of a global, autotrophic biosphere. Following the rise of life, stability is achieved by balancing hydrogen inputs by a combination of escape and biological uptake. The resulting oxygen levels are still $<10^{-13} \mathrm{PAL}$, but $\mathrm{H}_{2}$ mixing ratios fall to as little as $10^{-6}$. This change may have influenced the generation of MIF in the sulfur system, suggesting a geological 
fingerprint of the first geochemically important biosphere in Earth history.

Three additional steady states are possible after the appearance of oxygenic photosynthesis. If phosphate-limited oxygen production is small relative to hydrogen availability, the oxygen budget is a balance between organic carbon burial and rapid oxidation by hydrogen-species in the atmosphere. $\mathrm{pO}_{2}$ is suppressed to $<10^{-11} \mathrm{PAL}$. If oxygen production is large enough to overwhelm hydrogen inputs, $\mathrm{pO}_{2}$ will rise until the source is balanced by oxidative weathering of pyrite. This state has $\mathrm{pO}_{2}$ set by the threshold at which pyrite weathering outpaces pyrite exposure, which must be below $10^{-5}$ PAL. Finally, if nutrient supplies allow oxygen production that exceeds both the hydrogen supply and the rate of pyrite exposure, a fifth steady state is achieved, in which photosynthetic flux of $\mathrm{O}_{2}$ is balanced by aqueous oxidation of organic carbon, ferrous iron, and sulfide. The resulting $\mathrm{pO}_{2}$ level is in the range $10^{-4}$ to $10^{-2}$ PAL.

We describe a novel positive feedback that allows for the two most oxidized steady states to be simultaneously stable at a given point in Earth history. This "oxygen-alkalinity" feedback arises from a combination of phosphate-limitation and the silicate weathering thermostat. We show that the Great Oxidation Event can be explained as a jump between these equilibrium states, driven by the transient perturbation in $\mathrm{pCO}_{2}$ associated with a Snowball glacial. While other theories for the GOE are consistent with our modeling, a glacial trigger provides a mechanistic explanation for the apparent correlation between the Great Oxidation and the Paleoproterozoic Snowball events. 

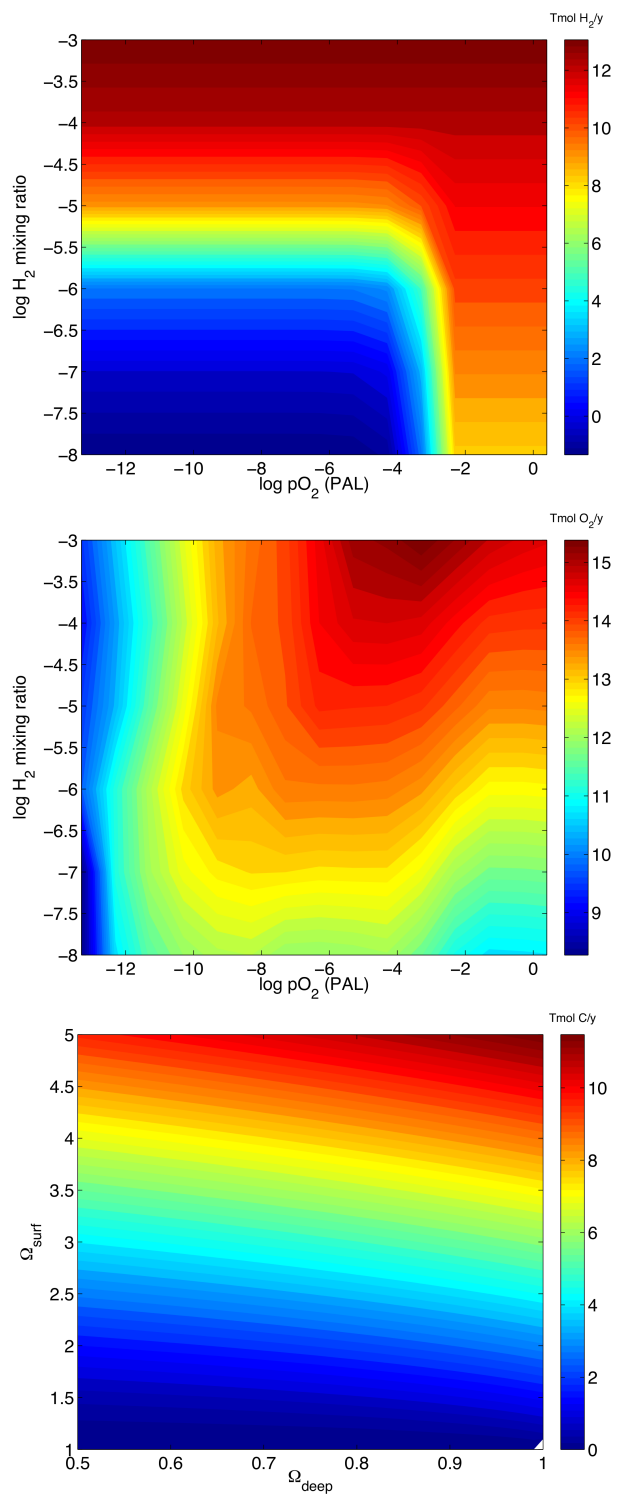

Figure 6.2: Selected flux parameterizations. Top: hydrogen escape rate as a function of atmospheric $\mathrm{pO}_{2}$ and $\mathrm{H}_{2}$ (Section 6.3.7, Chapter 5). Center: oxidation of $\mathrm{H}_{2}$ in the atmosphere as a function of $\mathrm{pO}_{2}$ and $\mathrm{H}_{2}$ (Section 6.3.7). Bottom: net precipitation of calcium carbonate as a function of the saturation state of the deep and surface ocean boxes (Section $6.3 .5)$. 


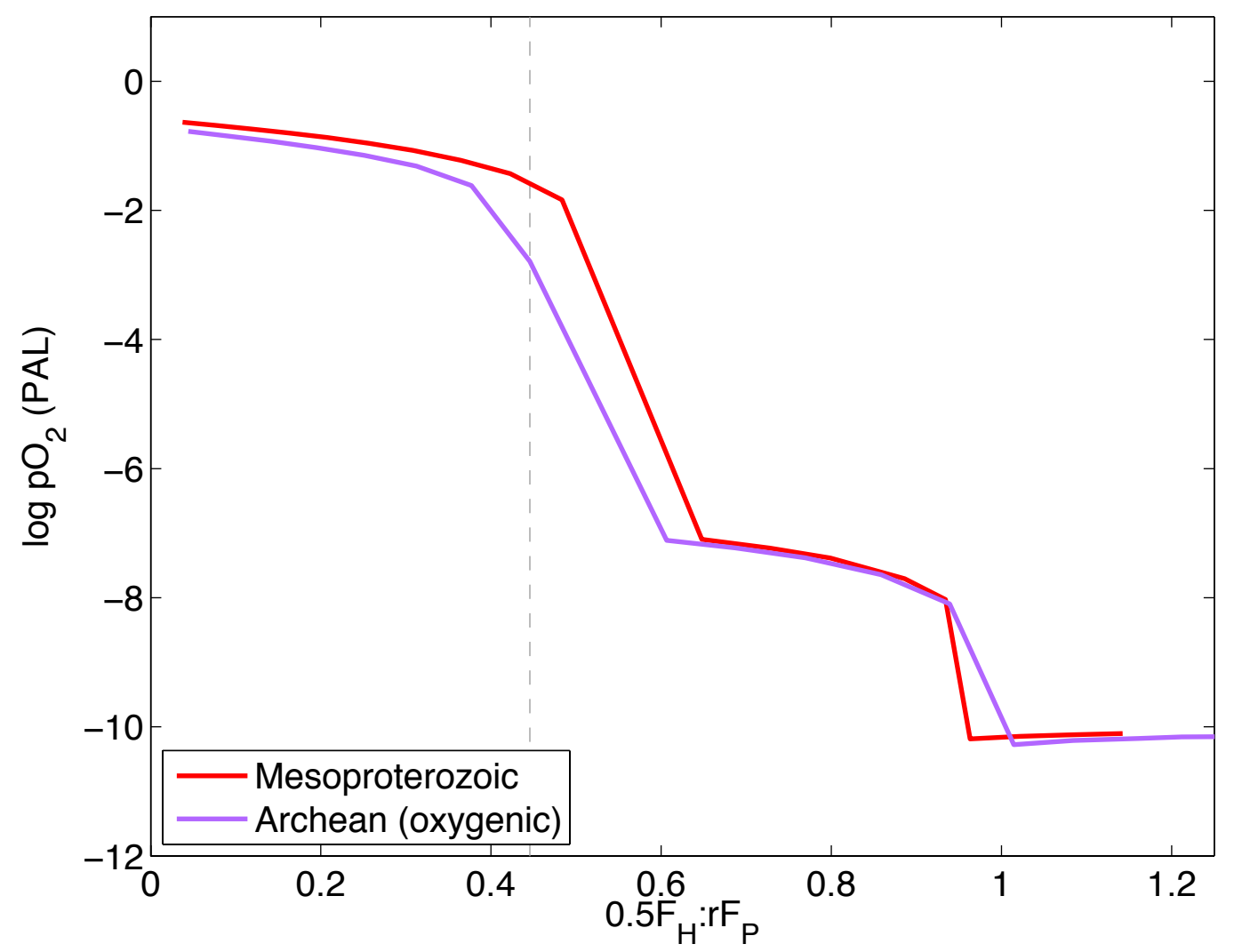

Figure 6.3: Steady-state $\mathrm{pO}_{2}$ of the model for various values of the hydrogen-to-bioavailable phosphorus flux ratio, $0.5 \mathrm{~F}_{H}: \mathrm{rF}_{P}$. The dashed line shows the baseline ratio used in the multiple equilibrium experiments shown in Figures 5 \& 6 . 


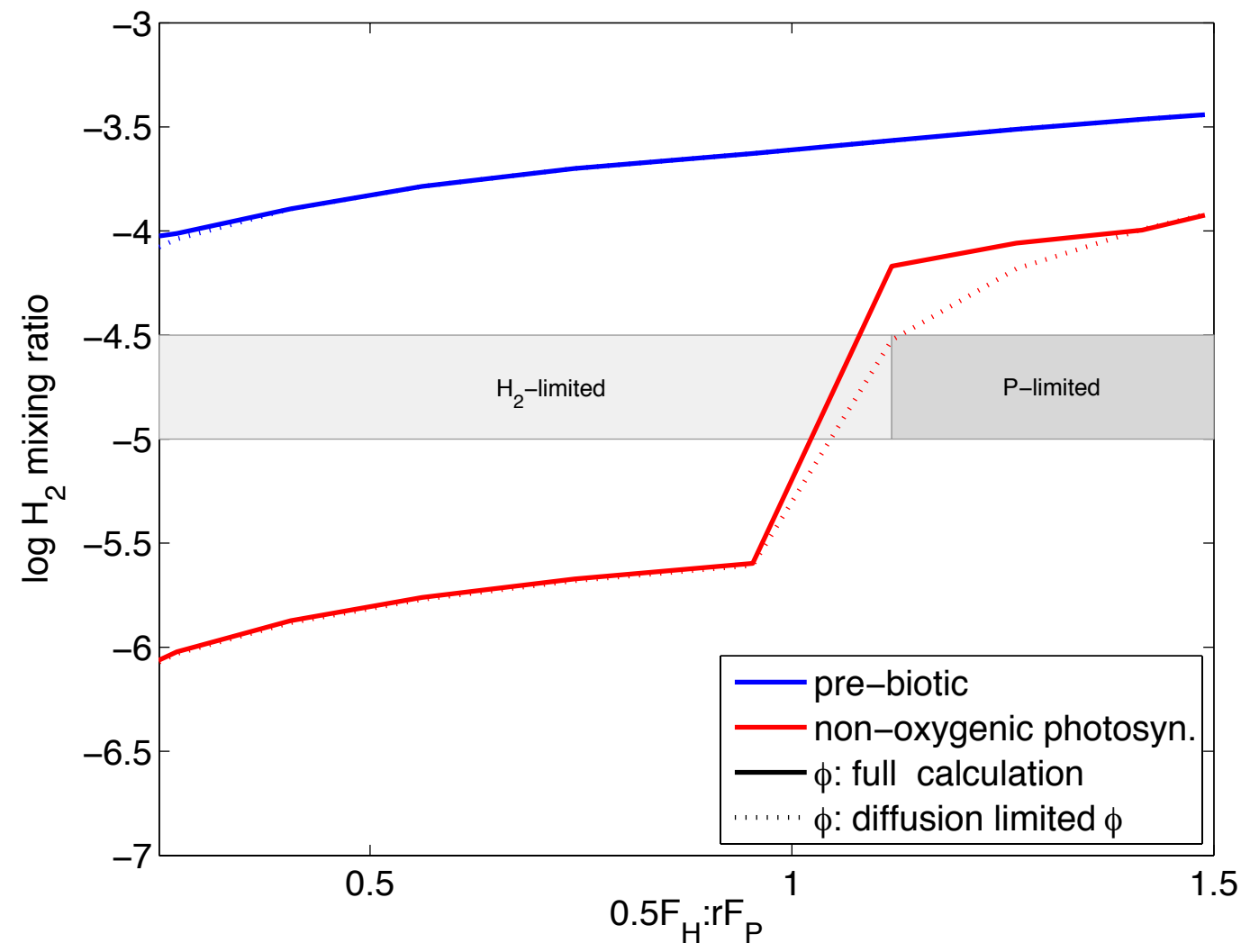

Figure 6.4: Steady state mixing ratio of $\mathrm{H}_{2}$ in the atmosphere for various values of the hydrogen-to-bioavailable phosphorus flux ratio, $0.5 \mathrm{~F}_{H}: \mathrm{rF}_{P}$. Both prebiotic (blue) and nonoxygenic (red) models are shown for different parameterizations of the hydrogen escape rate (solid v. dashed). The shaded bars indicated whether the biosphere is hydrogen or phosphate limited in the steady state non-oxygenic model. 


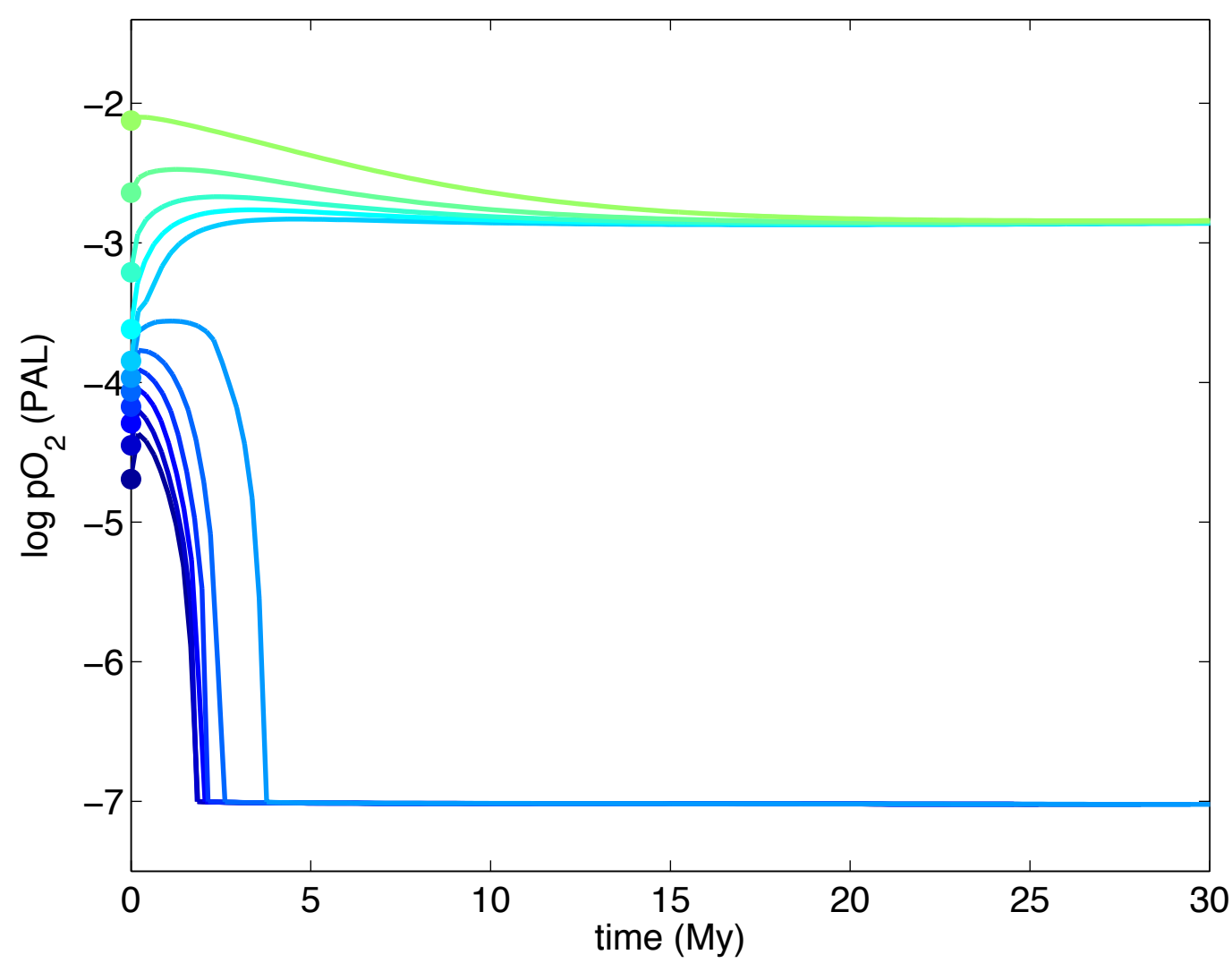

Figure 6.5: The evolution of $\mathrm{pO}_{2}$ over time from various initial starting conditions, for a single configuration of the oxygenic Archean model (2.4 Ga solar luminosity, $30 \$$ baseline bioavailibity of $\mathrm{P}, 3.2 \mathrm{Tmol} \mathrm{H}_{2} \mathrm{y}-1$ ). The initial value of $\mathrm{pCO}_{2}$ scales with the initial $\mathrm{pO}_{2}$ (see text). Two equilibrium conditions are observed, one with $\mathrm{pO}_{2} \sim 10^{-7} \mathrm{PAL}$, the other with $\mathrm{pO}_{2} \sim 10^{-3}$ PAL. 


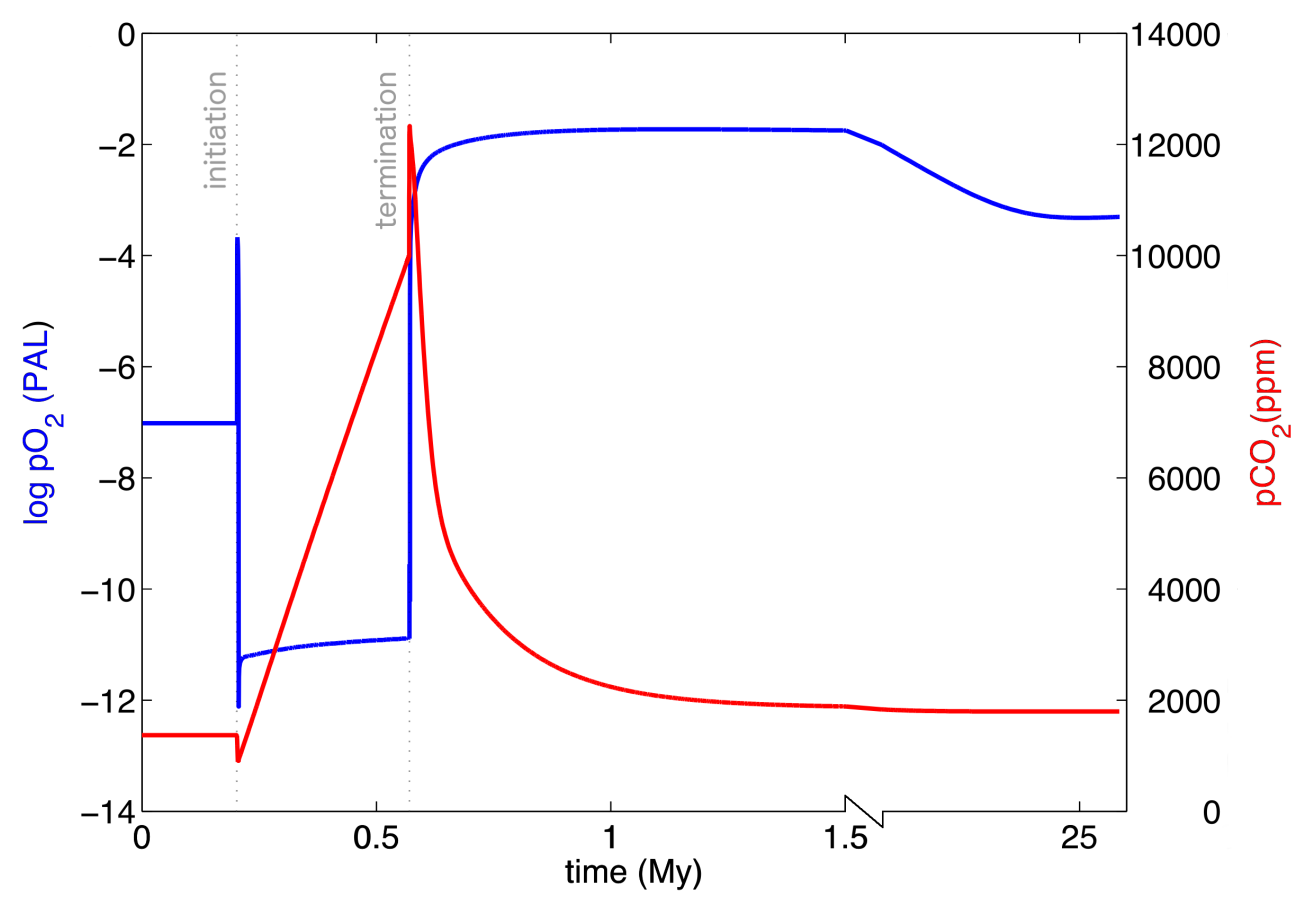

Figure 6.6: Evolution of $\mathrm{pO}_{2}$ (blue) and $\mathrm{pCO}_{2}$ (red) in the "Snowball" simulation. The model is initialized at its low-oxygen equilibrium (Figure 5). After 200,000 years, the solar luminosity declines by $\sim 30 \%$ over 1000 years. Once $\mathrm{pCO}_{2}$ reaches $10,000 \mathrm{ppm}$, luminosity returns to its baseline $2.4 \mathrm{Ga}$ value. The perturbation resulting from the transient $\mathrm{CO}_{2}$ pulse permanently raises oxygen to its high equilibrium condition. Note the change in scale at $1.5 \mathrm{My}$. 
Chapter 6 - Archean $\mathrm{pO}_{2}$
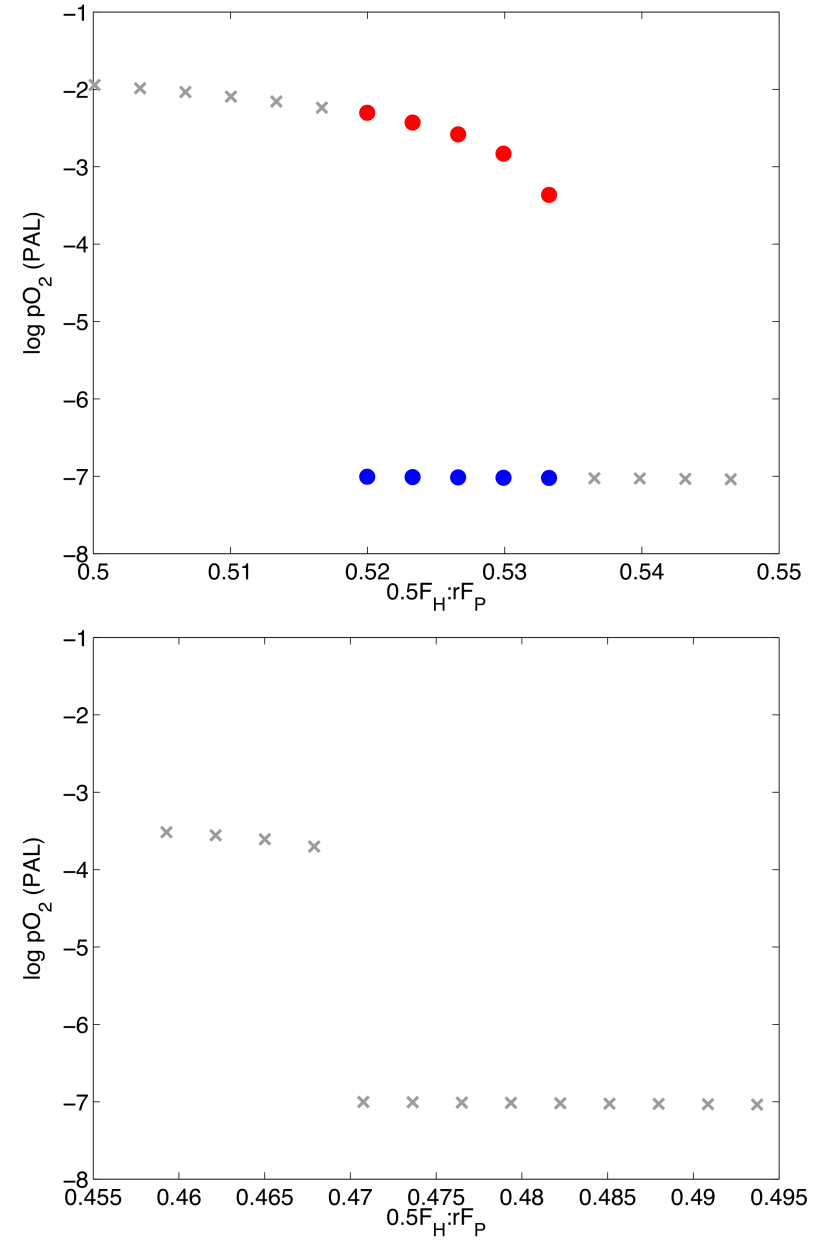

Figure 6.7: Equilibrium $\mathrm{pO}_{2}$ values of the oxygen Archean model for varying values of the hydrogen-to-bioavailable phosphorus flux ratio, $0.5 \mathrm{~F}_{H}: \mathrm{rF}_{P}$. At each ratio, the model is initiated at both the high and low oxygen states shown in Figure 5 and run for $\sim 15$ million years. If the resulting steady state $\mathrm{pO}_{2}$ values are within $0.1 \log \mathrm{PAL}$ unit, the average values is plotted with a gray $\mathrm{X}$. When the equilibrium $\mathrm{pO}_{2}$ values are more widely separated, they are plotted as red and blue dots. Top: baseline oxygenic Archean model. Bottom: siderite precipitation rate constant decreased by a factor of 500,000 ; pyrite precipitation rate constant increased by a factor of 1000 . These choices suppress the oxygen-alkalinity feedback. 


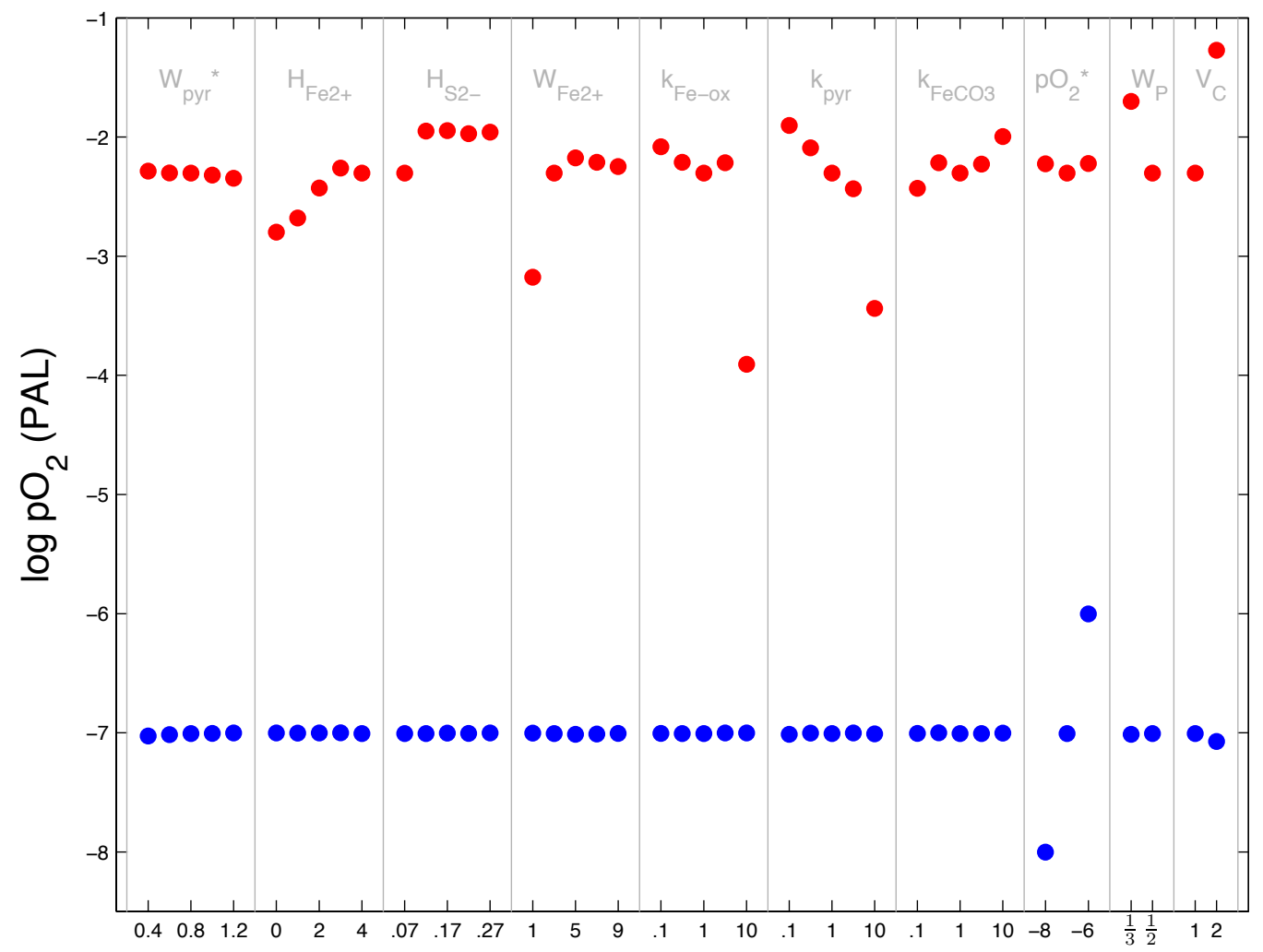

Figure 6.8: Sensitivity of the equilibrium $\mathrm{pO}_{2}$ levels to various model constants: the rate of pyrite exposure $\left(\mathrm{W}_{\mathrm{pyr}}\right.$, Tmol $\left.\mathrm{FeS}_{2} \mathrm{y}^{-1}\right)$, hydrothermal fluxes of ferrous iron and sulfide $\left(\mathrm{H}_{\mathrm{Fe} 2+}, \mathrm{H}_{\mathrm{S} 2-}\right.$, Tmol $\left.\mathrm{y}^{-1}\right)$, the rate constants for iron oxidation, pyrite precipitation, and siderite precipitation $\left(\mathrm{k}_{\mathrm{Fe}-\mathrm{ox}}, \mathrm{k}_{\mathrm{pyr}}, \mathrm{k}_{\mathrm{FeCO}}\right)$, the oxygen threshold at which pyrite weathers to completion $\left(\mathrm{pO} 2^{*}, \log \mathrm{PAL}\right)$, the baseline bioavailability of phosphate $\left(\mathrm{W}_{P}\right.$, relative to modern at $\left.280 \mathrm{pCO}_{2}\right)$ the input flux of $\mathrm{H}_{2}\left(\mathrm{~V}_{\mathrm{H} 2}\right.$, Tmol $\left.\mathrm{H}_{2} \mathrm{y}^{-1}\right)$. For a given parameter setting, the high oxygen state is plotted in red, the low oxygen state in blue. 
Table 6.1: Time-dependent evolution of the prognostic variables. $a$ : atmosphere; $s$ : shallow ocean; $d$ : deep ocean. Box subscripts are omitted from flux terms for clarity. Ocean mixing fluxes are shown for the oxygen equations, but are omitted from the other equations for brevity. Table 6.1 continues below.

$$
\begin{aligned}
& \frac{d}{d t}\left(\mathrm{O}_{2}\right)_{a}=G_{\mathrm{O} 2}-\frac{15}{8} W_{\mathrm{pyr}}-\frac{1}{2} A-W_{\mathrm{C}} \\
& \frac{d}{d t}\left[\mathrm{O}_{2}\right]_{s} v_{s}=\mathrm{NPP}_{\mathrm{O}}-\left(R_{\mathrm{wc}}+R_{\mathrm{sd}}\right)-2 Q_{\mathrm{S}}-\frac{1}{4} Q_{\mathrm{Fe}}-G_{\mathrm{O} 2}-M_{\mathrm{O} 2} \\
& \frac{d}{d t}\left[\mathrm{O}_{2}\right]_{d} v_{d}=-\left(R_{\mathrm{wc}}+R_{\mathrm{sd}}\right)-2 Q_{\mathrm{s}}=\frac{1}{2} Q_{\mathrm{Fe}}+M_{\mathrm{O} 2} \\
& \frac{d}{d t}\left(\mathrm{H}_{2}\right)_{a}=V_{\mathrm{H}}+G_{\mathrm{H} 2}-A-\phi \\
& \frac{d}{d t}\left[\mathrm{H}_{2}\right]_{s} v_{s}=-2 \mathrm{NPP}_{\mathrm{H}}-G_{\mathrm{H} 2}+\frac{1}{2}\left(B_{\mathrm{pyr}: \mathrm{wc}}+\left(1-\frac{1}{2} f_{3: 2}\right) B_{\mathrm{pyr}: \mathrm{sd}}\right) \\
& \frac{d}{d t}\left[\mathrm{H}_{2}\right]_{d} v_{d}=U_{\mathrm{H}}+\frac{1}{2}\left(B_{\mathrm{pyr}: \mathrm{wc}}+\left(1-\frac{1}{2} f_{3: 2}\right) B_{\mathrm{pyr}: \mathrm{sd}}\right) \\
& \frac{d}{d t}\left(\mathrm{CO}_{2}\right)_{a}=V_{\mathrm{C}}+G_{\mathrm{CO} 2} \\
& \frac{d}{d t}[\mathrm{DIC}]_{s} v_{s}=W_{\mathrm{C}}+W_{\mathrm{CaCO} 3}-(\mathrm{NPP} \mathrm{O}+\mathrm{NPP} \mathrm{H})+\left(R_{\mathrm{wc}}+R_{\mathrm{sd}}\right) \\
& \quad+2\left(S_{\mathrm{wc}}+S_{\mathrm{sd}}\right)+\frac{1}{4}\left(F_{\mathrm{sd}}\right)-\left(B_{\mathrm{CaCO} 3}+B_{\mathrm{FeCO} 3}\right)-G_{\mathrm{CO} 2} \\
& \frac{d}{d t}[\mathrm{DIC}]_{d} v_{d}=U_{\mathrm{C}}+\left(R_{\mathrm{wc}}+R_{\mathrm{sd}}\right)+2\left(S_{\mathrm{wc}}+S_{\mathrm{sd}}\right)+\frac{1}{4}\left(F_{\mathrm{sd}}\right)-\left(B_{\mathrm{CaCO} 3}+B_{\mathrm{FeCO} 3}\right) \\
& \frac{d}{d t}\left[\mathrm{H}_{2} \mathrm{~S}\right]_{s} v_{s}=\left(S_{\mathrm{wc}}+S_{\mathrm{sd}}\right)-Q_{\mathrm{S}}-\left(B_{\mathrm{pyr}: \mathrm{wc}}+B_{\mathrm{pyr}: \mathrm{sd}}\right) \\
& \frac{d}{d t}\left[\mathrm{H}_{2} \mathrm{~S}\right]_{d} v_{d}=\left(S_{\mathrm{wc}}+S_{\mathrm{sd}}\right)-Q_{\mathrm{S}}-\left(B_{\mathrm{pyr}: \mathrm{wc}}+B_{\mathrm{pyr}: \mathrm{sd}}\right)+H_{S} \\
& \frac{d}{d t}\left[\mathrm{SO}_{4}^{2-}\right]_{s} v_{s}=-\left(S_{\mathrm{wc}}+S_{\mathrm{sd}}\right)+Q_{\mathrm{S}}-B_{\mathrm{G}}+W_{\mathrm{S}}+W_{\mathrm{pyr}} \\
& \frac{d}{d t}\left[\mathrm{SO}_{4}^{2-}\right]_{d} v_{d}=-\left(S_{\mathrm{wc}}+S_{\mathrm{sd}}\right)+Q_{\mathrm{S}}-B_{\mathrm{G}}
\end{aligned}
$$


Table 6.1 (Continued): Time-dependent evolution of the prognostic variables. $a$ : atmosphere; $s$ : shallow ocean; $d$ : deep ocean. Box subscripts are omitted from flux terms for clarity. Ocean mixing fluxes are shown for the oxygen equations, but are omitted from the other equations for brevity.

$$
\begin{aligned}
& \frac{d}{d t}\left[\mathrm{Fe}^{2+}\right]_{s} v_{s}=F_{\mathrm{sd}}-Q_{\mathrm{Fe}}-\frac{1}{2}\left(B_{\mathrm{pyr}: \mathrm{wc}}+\left(1-f_{3: 2}\right) B_{\mathrm{pyr}: \mathrm{sd}}\right)-B_{\mathrm{FeCO} 3}+W_{\mathrm{Fe}} \\
& \frac{d}{d t}\left[\mathrm{Fe}^{2+}\right]_{d} v_{d}=F_{\mathrm{sd}}-Q_{\mathrm{Fe}}-\frac{1}{2}\left(B_{\mathrm{pyr}: \mathrm{wc}}+\left(1-f_{3: 2}\right) B_{\mathrm{pyr}: \mathrm{sd}}\right)-B_{\mathrm{FeCO} 3}+H_{\mathrm{Fe}} \\
& \frac{d}{d t}\left[\mathrm{C}_{\mathrm{org}}\right]_{s} v_{s}=\left(\mathrm{NPP}_{\mathrm{O}}+\mathrm{NPP}_{\mathrm{H}}\right)-E P-\left(R_{\mathrm{wc}}+2 S_{\mathrm{wc}}\right)-B_{\mathrm{Corg}} \\
& \frac{d}{d t}\left[\mathrm{C}_{\mathrm{org}}\right]_{d} v_{d}=E P-\left(R_{\mathrm{wc}}+2 S_{\mathrm{wc}}\right)-B_{\mathrm{Corg}} \\
& \frac{d}{d t}\left[\mathrm{PO}_{4}^{3-}\right]_{s} v_{s}=\frac{1}{r}\left(R_{\mathrm{wc}}+2 S_{\mathrm{wc}}\right)-B_{\mathrm{P}}+Y-\frac{1}{r}\left(\mathrm{NPP}_{\mathrm{O}}+\mathrm{NPP}_{\mathrm{H}}\right)+\mathrm{W}_{p} \\
& \frac{d}{d t}\left[\mathrm{PO}_{4}^{3-}\right]_{d} v_{d}=\frac{1}{r}\left(R_{\mathrm{wc}}+2 S_{\mathrm{wc}}\right)-B_{\mathrm{P}}+Y \\
& \frac{d}{d t}\left[\mathrm{Ca}^{2+}\right]_{s} v_{s}=\left(W_{\mathrm{Ca}}+W_{\mathrm{CaCO} 3}\right)-\left(B_{\mathrm{CaCO} 3}+B_{\mathrm{G}}\right) \\
& \frac{d}{d t}\left[\mathrm{Ca}^{2+}\right]_{d} v_{d}=B_{\mathrm{Mg}}-\left(B_{\mathrm{CaCO} 3}+B_{\mathrm{G}}\right) \\
& \frac{d}{d t}\left[\mathrm{Mg}^{2+}\right]_{s} v_{s}=W_{\mathrm{Mg}} \\
& \frac{d}{d t}\left[\mathrm{Mg}^{2+}\right]_{d} v_{d}=-B_{\mathrm{Mg}} \\
& \frac{d}{d t}\left[\mathrm{Na}^{+}+\mathrm{K}^{+}\right]_{s} v_{s}=W_{\mathrm{NaK}} \\
& \frac{d}{d t}\left[\mathrm{Na}^{+}+\mathrm{K}^{+}\right]_{d} v_{d}=-B_{\mathrm{NaK}}
\end{aligned}
$$


Chapter 6 - Archean $\mathrm{pO}_{2}$

Table 6.2: Flux parameterizations. All fluxes are in mol $X \mathrm{y}^{-1}$, with $X$ defined in the "units" column. Values for the rate constants $(k)$ and water mass volumes $(M)$ vary between deep $(d)$ and shallow $(s)$ waters, but subscripts are not given here unless needed. See text for a full description of the escape rate, $\phi$, atmospheric hydrogen oxidation $(A)$, and deep water calcite and pyrite precipitation. Note: $\left[\mathrm{C}_{\text {org }}\right]$ includes net primary production and excludes adsorbed carbon from the current time step. Table 6.2 continues below.

\begin{tabular}{|l|l|l|}
\hline Process & Parameterization & units \\
\hline \hline Net primary production (oxygenic) & $\mathrm{NPP}_{\mathrm{O}}=r\left[\mathrm{PO}_{4}^{3-}\right]_{s} v_{s}$ & $\mathrm{C}$ \\
Net primary production (non-oxygenic) & $\mathrm{NPP}_{\mathrm{H}}=\min \left(r\left[\mathrm{PO}_{4}^{3-}\right]_{s}, \frac{1}{2}\left[\mathrm{H}_{2}\right]_{s}\right) v_{s}$ & $\mathrm{C}$ \\
Oxic respiration, water column & $R_{\mathrm{wc}}=k_{0}\left[\mathrm{O}_{2}\right]\left[\mathrm{C}_{\text {org }}\right] v$ & $\mathrm{C}$ \\
Sulfate reduction, water column & $S_{\mathrm{wc}}=k_{1}\left[\mathrm{SO}_{4}^{2-}\right]\left[\mathrm{C}_{\text {org }}\right] v$ & $\mathrm{~S}$ \\
Oxic respiration, sediment & $R_{\mathrm{sd}}=k_{2}\left[\mathrm{O}_{2}\right] v$ & $\mathrm{C}$ \\
Sulfate reduction, sediment & $S_{\mathrm{sd}}=k_{3}\left[\mathrm{SO}_{4}^{2-}\right] v$ & $\mathrm{~S}$ \\
Iron reduction, sediment & $F_{\mathrm{sd}}=k_{4}\left(Q_{\mathrm{Fe}}+\frac{1}{2} W_{\mathrm{pyr}} \delta_{s}\right)$ & $\mathrm{Fe}$ \\
Sulfide oxidation & $Q_{\mathrm{S}}=k_{5}\left[\mathrm{O}_{2}\right]\left[\mathrm{H}_{2} \mathrm{~S}\right] v$ & $\mathrm{~S}$ \\
Iron oxidation & $Q_{\mathrm{Fe}}=k_{\mathrm{Fe}-\mathrm{ox}}\left[\mathrm{O}_{2}\right]\left[\mathrm{Fe}{ }^{2+}\right] v$ & $\mathrm{Fe}$ \\
Gross burial of organic C & $B_{\mathrm{Corg}}=k_{6}\left[\mathrm{C}_{\text {org }}\right]^{\prime}\left(1+\alpha \delta_{s}\right)+\mathrm{B}_{a}$ & $\mathrm{C}$ \\
& {$\left[\mathrm{C}_{\text {org }}\right]^{\prime}=\left[\mathrm{C}_{\text {org }}\right] v-(\mathrm{R}-2 \mathrm{~S})_{w c}$} & $\mathrm{C}$ \\
Adsorption of organic C & $B_{\mathrm{a}}=k_{7} \mathrm{~W}_{B} \cdot \mathrm{NPP}$ & $\mathrm{C}$ \\
Pyrite precipitation, water column & $B_{\mathrm{pyr}: \mathrm{wc}}=k_{\mathrm{pyr}}\left[\mathrm{Fe}{ }^{2+}\right]\left[\mathrm{H}_{2} \mathrm{~S}\right] v$ & $\mathrm{~S}$ \\
Pyrite precipitation, sediment & $B_{\mathrm{pyr}: \mathrm{sd}}=\beta \cdot \min \left(S_{\mathrm{sd}}, \frac{1}{2}\left(Q_{\mathrm{Fe}}+\frac{1}{2} F_{\mathrm{Fe}}\right)\right)$ & $\mathrm{S}$ \\
Ferric iron flux to sediment & $F_{\mathrm{Fe}}=Q_{\mathrm{Fe}}+\frac{1}{2} W_{\mathrm{pyr}} \delta_{s}$ & $\mathrm{Fe}$ \\
Sulfate burial & $B_{\mathrm{G}}=k_{8}\left[\mathrm{SO}_{4}^{2-}\right] v$ & $\mathrm{~S}$ \\
Phosphorus scavenging & $B_{P}=k_{9}\left[\mathrm{PO}_{4}^{3-}\right] v$ & $\mathrm{P}$ \\
Phosphorus regeneration & $Y=\gamma\left(R_{\mathrm{sd}}+2 S_{\mathrm{sd}}+\frac{1}{4} F_{\mathrm{sd}}\right) / r$ & \\
\hline
\end{tabular}


Table 6.2 (Continued): Flux parameterizations. All fluxes are in mol $X \mathrm{y}^{-1}$, with $X$ defined in the "units" column. Values for the rate constants $(k)$ and water mass volumes $(M)$ vary between deep $(d)$ and shallow $(s)$ waters, but subscripts are not given here unless needed. See text for a full description of the escape rate, $\phi$, atmospheric hydrogen oxidation $(A)$, and deep water calcite and pyrite precipitation. Note: $\left[\mathrm{C}_{\text {org }}\right]$ includes net primary production and excludes adsorbed carbon from the current time step.

\begin{tabular}{|c|c|c|}
\hline Process & Parameterization & units \\
\hline Calcite precipitation, net & $B_{\mathrm{CaCO} 3}=k_{\mathrm{CaCO} 3}\left(\Omega_{\mathrm{CaCO} 3}-1\right)$ & $\mathrm{C}$ \\
\hline Siderite precipitation, net & $B_{\mathrm{FeCO} 3}=k_{\mathrm{FeCO} 3}\left(\Omega_{\mathrm{FeCO} 3}-1\right)$ & $\mathrm{C}$ \\
\hline Magnesium burial & $B_{\mathrm{Mg}}=k_{10}\left[\mathrm{Mg}^{2+}\right] v_{d}$ & $\mathrm{Mg}$ \\
\hline Sodium/potassium burial & $B_{\mathrm{NaK}}=k_{11}\left[\mathrm{Na}^{+}+\mathrm{K}^{+}\right] v_{d}$ & $\mathrm{Na} / \mathrm{K}$ \\
\hline Oxidative weathering, organic $\mathrm{C}$ & $W_{\mathrm{C}}=k_{12} \cdot p \mathrm{O}_{2}$ & $\mathrm{O}_{2}$ \\
\hline Oxidative weathering, pyrite & $W_{\mathrm{pyr}}=W_{p y r}^{*} \frac{p \mathrm{O}_{2}}{p \mathrm{O}_{2}^{*}}$ & $\mathrm{~S}$ \\
\hline Oxidative weathering, ocean crust & $W_{\text {basalt }}=k_{13}\left[\mathrm{O}_{2}\right]_{d} v_{d}$ & $\mathrm{O}_{2}$ \\
\hline Weathering, total $\mathrm{P}$ & $W_{\mathrm{P}}=W_{\mathrm{a}}+f_{\mathrm{b}} W_{\mathrm{C}} / r$ & $\mathrm{P}$ \\
\hline \multirow[t]{2}{*}{ Weathering, dissolutive } & $W_{\mathrm{a}, \mathrm{CaCO} 3, \mathrm{Fe}}=\omega W_{\mathrm{a}, \mathrm{CaCO} 3, \mathrm{Fe}}^{0}$ & various \\
\hline & $W_{\mathrm{Ca}, \mathrm{Mg}, \mathrm{NaK}, \mathrm{B}}=\omega W_{\mathrm{Ca}, \mathrm{Mg}, \mathrm{NaK}, \mathrm{B}}^{0}$ & various \\
\hline Mixing & $M_{\mathrm{X}}=F_{W}\left([\mathrm{X}]_{s}-[\mathrm{X}]_{d}\right)$ & $\mathrm{X}$ \\
\hline Ocean-atmosphere exchange & $G_{\mathrm{X}}=u_{\mathrm{X}}\left([\mathrm{X}]_{s}-p \mathrm{X} \cdot K_{H}^{(\mathrm{X})}\right) A_{\mathrm{oc}}$ & $\mathrm{X}$ \\
\hline Relative weathering factor & $\omega=k_{w} \cdot \exp \left(c_{w} \log _{2} \frac{p \mathrm{CO}_{2}}{\left(p \mathrm{CO}_{2}\right)_{0}}\right)$ & \\
\hline \multirow[t]{2}{*}{ Burial-vs-export factor } & $\alpha=\frac{\alpha^{(2)}-\alpha^{(1)}}{f_{\mathrm{up}}^{(2)}-f_{\mathrm{up}}^{(1)}}\left(f_{\mathrm{up}}--f_{\mathrm{up}}^{(1)}\right)+\alpha^{(1)}$ & \\
\hline & $f_{\mathrm{up}}=\frac{\mathrm{x}\left(\left[\mathrm{PO}_{4}^{3-}\right]_{d}-\left[\mathrm{PO}_{4}^{3-}\right]_{s}\right)}{\mathrm{W}_{P}+\mathrm{X}\left(\left[\mathrm{PO}_{4}^{3-}\right]_{d}-\left[\mathrm{PO}_{4}^{3-}\right]_{s}\right)}$ & \\
\hline Pyrite reoxidation factor & $\beta=\frac{\beta^{(2)}-\beta^{(1)}}{\left[\mathrm{O}_{2}\right]^{(2)}\left[\mathrm{O}_{2}\right]^{(1)}}\left(\left[\mathrm{O}_{2}\right]-\left[\mathrm{O}_{2}\right]^{(1)}\right)+\beta^{(1)}$ & \\
\hline Phosphorus trapping factor & $\gamma=\frac{\gamma^{(2)}-\gamma^{(1)}}{\left[\mathrm{O}_{2}\right]^{(2)}\left[\mathrm{O}_{2}\right]^{(1)}}\left(\left[\mathrm{O}_{2}\right]-\left[\mathrm{O}_{2}\right]^{(1)}\right)+\gamma^{(1)}$ & \\
\hline
\end{tabular}


Chapter 6 - Archean $\mathrm{pO}_{2}$

Table 6.3: Model parameter values. See Table 6.2 for definitions of point-slope terms. Table 6.3 continues below.

\begin{tabular}{|c|c|c|c|}
\hline Rate constant & Abbr. & deep value & shallow value \\
\hline Oxic respiration, water column & $k_{0}$ & 64 & 825 \\
\hline Sulfate reduction, water column & $k_{1}$ & 0.14 & 3.7 \\
\hline Oxic respiration, sediment & $k_{2}$ & $1.64 \mathrm{e}-5$ & $1.42 \mathrm{e}-3$ \\
\hline Sulfate reduction, sediment & $k_{3}$ & $2.02 \mathrm{e}-8$ & 5.26 e- 6 \\
\hline Iron reduction, sediment & $k_{4}$ & $4.15 \mathrm{e}-2$ & $2.92 \mathrm{e}-2$ \\
\hline Sulfide oxidation & $k_{5}$ & $5.53 \mathrm{e}+4$ & $5.53 \mathrm{e}+4$ \\
\hline Iron oxidation & $k_{\mathrm{Fe}-\mathrm{ox}}$ & $5.53 \mathrm{e}+4$ & $5.53 \mathrm{e}+4$ \\
\hline Gross burial of organic $\mathrm{C}$ & $k_{6}$ & 3.12 e-5 & 5.00 e-3 \\
\hline Adsorption of organic C & $k_{7}$ & 5.93 e-20 & 6.59 e-21 \\
\hline Pyrite precipitation, water column & $k_{\mathrm{pyr}}$ & 3.15 & 3.15 \\
\hline Sulfate burial & $k_{8}$ & 5.26 e- 6 & 5.26 e- 6 \\
\hline Phosphorus scavenging & $k_{9}$ & $1.00 \mathrm{e}-7$ & $1.00 \mathrm{e}-7$ \\
\hline Calcite precipitation & $k_{\mathrm{CaCO} 3}$ & $1.08 \mathrm{e}-7$ & $1.08 \mathrm{e}-7$ \\
\hline Siderite precipitation & $k_{\mathrm{FeCO} 3}$ & 8.82 e-9 & 8.82 e-9 \\
\hline Magnesium burial & $k_{10}$ & $5.07 \mathrm{e}-8$ & - \\
\hline Sodium/potassium burial & $k_{11}$ & $1.07 \mathrm{e}-8$ & \\
\hline Oxidative weathering, organic $\mathrm{C}$ & $k_{12}$ & - & $7.91 \mathrm{e}-8$ \\
\hline Oxidative weathering, ocean crust & $k_{13}$ & 1.03 e-5 & - \\
\hline Flux & Abbr. & value & units \\
\hline Weathering, total sediment & $\mathrm{W}_{\mathrm{B}}^{0}$ & 1.9 & $\operatorname{Pg} \mathrm{yr}^{-1}$ \\
\hline Weathering, apatite & $\mathrm{W}_{\mathrm{a}}^{0}$ & 280 & Gmol P yr ${ }^{-1}$ \\
\hline Weathering, carbonate & $\mathrm{W}_{\mathrm{CaCO} 3}^{0}$ & 9.0 & Tmol C yr ${ }^{-1}$ \\
\hline Weathering, $\mathrm{Ca}^{2+}$ & $\mathrm{W}_{\mathrm{Ca}}^{0}$ & 4.5 & Tmol Ca yr ${ }^{-1}$ \\
\hline Weathering, pyrite & $\mathrm{W}_{\mathrm{pyr}}^{0}$ & 0.8 & Tmol S $\mathrm{yr}^{-1}$ \\
\hline Weathering, sulfates & $\mathrm{W}_{\mathrm{S}}$ & 2.8 & Tmol S yr ${ }^{-1}$ \\
\hline Hydrothermal, sulfide & $\mathrm{H}_{\mathrm{S}}$ & 0.07 & Tmol S $\mathrm{yr}^{-1}$ \\
\hline Subaerial volcanic, carbon & $\mathrm{V}_{\mathrm{C}}$ & 3.1 & Tmol C $\mathrm{yr}^{-1}$ \\
\hline Submarine volcanic, carbon & $\mathrm{U}_{\mathrm{C}}$ & 3.1 & Tmol C yr ${ }^{-1}$ \\
\hline
\end{tabular}


Chapter 6 - Archean $\mathrm{pO}_{2}$

Table 6.3 (Continued): Model parameter values. See Table 6.2 for definitions of point-slope terms.

\begin{tabular}{|l|l|r|r|}
\hline Reservoir & Abbr. & value & units \\
\hline Deep ocean volume & $\mathrm{v}_{d}$ & $1.3 \mathrm{e}+21$ & $\mathrm{~L}$ \\
Surface ocean volume & $\mathrm{v}_{s}$ & $3.6 \mathrm{e}+19$ & $\mathrm{~L}$ \\
Atmoshere mass & $\mathrm{m}_{a}$ & $5.3 \mathrm{e}+18$ & $\mathrm{~kg}$ \\
Mixing volume & $\mathrm{F}_{w}$ & $5.0 \mathrm{e}+18$ & $\mathrm{~L} \mathrm{yr}^{-1}$ \\
Ocean area & $\mathrm{A}_{\mathrm{oc}}$ & $361 \mathrm{e}+12$ & $\mathrm{~m}^{2}$ \\
\hline Point-slope parameter & $\mathrm{Abbr}$. & $y^{(1,2)}$ & $y^{(1,2)}$ \\
\hline Burial-vs-export factor & $\alpha$ & 1,10 & $0.00,0.94$ \\
Pyrite reoxidation factor & $\beta$ & $0.2,0.7$ & $260,0.00 \mu \mathrm{M}$ \\
Phosphorus trapping factor & $\gamma$ & $0.25,0.50$ & $260,0.00 \mu \mathrm{M}$ \\
\hline Piston velocity & Abbrevation & value & $\mathrm{units}^{-1}$ \\
\hline Oxygen & $\mathrm{u}_{\mathrm{O} 2}$ & $0.53 \mathrm{e}-2$ & $\mathrm{~cm} \mathrm{~s}^{-1}$ \\
Hydrogen & $\mathrm{u}_{\mathrm{H} 2}$ & $1.30 \mathrm{e}-2$ & $\mathrm{~cm} \mathrm{~s}^{-1}$ \\
Carbon dioxide & $\mathrm{u}_{\mathrm{CO} 2}$ & $0.48 \mathrm{e}-2$ & $\mathrm{~cm} \mathrm{~s}^{-1}$ \\
\hline Other parameter & $\mathrm{Abberviation}$ & $\mathrm{value}$ & \\
\hline Relative weathering factor & $k_{w}$ & 0.7653 & \\
& $c_{w}$ & 0.14 & \\
Baseline surface temperature & $T_{0}$ & $288 \mathrm{~K}$ & \\
Baseline pCO & $\left(p C O_{2}\right)_{0}$ & $280 \mathrm{ppm}$ & \\
Bioavailable fraction & $f_{b}$ & 0.2 & \\
Shelf fraction of seafloor & $f$ & 0.1 & \\
Slope fraction of seafloor & $g$ & 0.2 & \\
Surface indicator & $\delta_{s}$ & in surf: 1 & \\
& & in deep: 0 & \\
\hline
\end{tabular}

Table 6.4: Oxygen budgets for three representative Archean equilibrium states, corresponding to different $\mathrm{H}_{2}$ input fluxes. $\mathrm{H}_{2}$ fluxes are in units of $T m o l \mathrm{H}_{2} \mathrm{y}^{-1}$. All other fluxes are in units of Tmol $\mathrm{O}_{2} \mathrm{y}^{-1}$.

\begin{tabular}{|l|r|r|l|}
\hline & state 1 & state 2 & state 3 \\
\hline \hline $\mathrm{H}_{2}$ flux & 2.8 & 4.0 & 6.0 \\
\hline $\mathrm{pO}_{2}(\log$ PAL) & -1.7 & -7.2 & -10.3 \\
\hline $\mathrm{B}_{\text {Corg }}$ & 3.3 & 2.9 & 2.8 \\
$\mathrm{~A}$ & 1.4 & 2.0 & 2.8 \\
$\mathrm{~W}_{\text {pyr }}$ & 1.5 & 0.9 & 0.0 \\
$\mathrm{~W}_{\mathrm{C}}$ & 0.1 & 0.0 & 0.0 \\
Net oxidation $\mathrm{Fe}^{2+} \& \mathrm{H}_{2} \mathrm{~S}$ & 0.3 & 0.0 & 0.0 \\
\hline
\end{tabular}


Chapter 6 - Archean $\mathrm{pO}_{2}$

Table 6.5: Carbon-oxygen-iron budget for the two states of the multiple equilibrium configuration of the oxygenic Archean model $\left(\mathrm{H}_{2}\right.$ input flux $=3.2 \mathrm{Tmol} \mathrm{H}_{2} \mathrm{y}^{-1}$.) All fluxes are in units of Tmol $\mathrm{X}^{-1}$.

\begin{tabular}{|c|c|c|c|}
\hline & low- $\mathrm{pO}_{2}$ state & high-pO $\mathrm{p}_{2}$ state & units \\
\hline$\overline{\mathrm{p \textrm {pO } _ { 2 }}}$ & $\overline{-7.0}$ & $\overline{-2.8}$ & log PAL \\
\hline $\mathrm{B}_{\text {Corg }}$ & 3.0 & 3.4 & $\mathrm{O}_{2}$ \\
\hline A & 1.6 & 1.6 & $\mathrm{O}_{2}$ \\
\hline $\mathrm{W}_{\text {pyr }}$ & 1.4 & 1.5 & $\mathrm{O}_{2}$ \\
\hline Net oxidation $\mathrm{Fe}^{2+} \& \mathrm{H}_{2} \mathrm{~S}$ & 0.0 & 0.3 & $\mathrm{O}_{2}$ \\
\hline $\mathrm{pCO}_{2}$ & 1358 & 1806 & $\mathrm{ppm}$ \\
\hline $\mathrm{V}_{\mathrm{C}}+\mathrm{W}_{\mathrm{CaCO} 3}$ & 8.8 & 9.4 & $\mathrm{C}$ \\
\hline $\mathrm{B}_{\mathrm{CaCO} 3}$ & 4.8 & 6.0 & $\mathrm{C}$ \\
\hline $\mathrm{B}_{\mathrm{FeCO} 3}$ & 1.1 & 0.0 & $\mathrm{C}$ \\
\hline $\mathrm{B}_{\text {Corg }}$ & 2.9 & 3.4 & $\mathrm{C}$ \\
\hline$\omega$ & $\equiv 1$ & 1.19 & - \\
\hline$\left[\mathrm{Fe}^{2+}\right]$ & 6700 & 69 & $\mathrm{nM}$ \\
\hline $\mathrm{W}_{\mathrm{Fe}}+\mathrm{H}_{\mathrm{Fe}}$ & 1.3 & 1.5 & $\mathrm{Fe}$ \\
\hline $\mathrm{B}_{\mathrm{FeCO} 3}$ & 1.1 & 0.0 & $\mathrm{Fe}$ \\
\hline $\mathrm{Q}_{\mathrm{Fe}}$ & 0.1 & 1.5 & $\mathrm{Fe}$ \\
\hline $\mathrm{B}_{\mathrm{pyr}}$ & 0.1 & 0.0 & $\mathrm{Fe}$ \\
\hline
\end{tabular}

Table 6.6: Instantaneous oxygen budgets before, during, and after the Snowball glaciation depicted in Figure 7. All units are Tmol $\mathrm{O}_{2} \mathrm{y}^{-1-1}$, except $\mathrm{pO}_{2}$, which is given in $\log$ PAL. The $\mathrm{O}_{2}$ imbalance during the glacial implies a transition between the two end members in $\sim 4000$ years.

\begin{tabular}{|l|r|r|r|}
\hline & pre-glacial & $\begin{array}{c}1100 \text { y post- } \\
\text { termination }\end{array}$ & $\begin{array}{c}25 \text { My post- } \\
\text { termination }\end{array}$ \\
\hline \hline $\mathrm{pO}_{2}$ & -7.0 & -6.4 & -3.3 \\
\hline $\mathrm{W}_{\mathrm{P}}$ & 3.1 & 11.8 & 3.7 \\
$\mathrm{~B}_{\mathrm{Corg}}$ & 3.0 & 8.7 & 3.4 \\
$\mathrm{~A}$ & 1.6 & 2.2 & 1.6 \\
$\mathrm{~W}_{\text {pyr }}$ & 1.4 & 1.5 & 1.5 \\
$\mathrm{~W}_{\mathrm{C}}$ & 0.0 & 0.0 & 0.0 \\
$\mathrm{Net} \mathrm{oxidation} \mathrm{Fe}^{2+} \& \mathrm{H}_{2} \mathrm{~S}$ & 0.0 & 0.8 & 0.3 \\
\hline Net $\mathrm{O}_{2}$ flux & 0.0 & 4.2 & 0.0 \\
\hline
\end{tabular}




\section{Chapter 7}

\section{Conclusion}

Figure 7.1 is a schematic resprentation of the evolution of atmospheric oxygen over geologic time. Similar figures have been drawn before (Kump 2008); the goal of this dissertation has been to articulate how biogeochemical cycling sets the value of $\mathrm{pO}_{2}$ over time, and to identify which processes lead to the stability or instability of those values. Based on the results presented above, it is possible to describe a coherent theory for atmospheric oxygen over much of Earth history.

Before the appearance of life on Earth, the production of atmospheric oxygen is limited to photochemical reactions (Kasting 1993). This source is swamped by the flux of hydrogenbearing species from the mantle, which react rapidly with $\mathrm{O}_{2}$. The steady state balance between photolysis and hydrogen oxidation is at a $\mathrm{pO}_{2}$ value less than $10^{-13} \mathrm{PAL}$ (Equilibrium A). $\mathrm{pO}_{2}$ cannot be more finely resolved with the existing model; incorporation of more sophisticated photochemistry will allow a more precise evaluation of prebiotic $\mathrm{pO}_{2}$. However, while chemical reactions in the atmosphere are critical to the oxygen cycle, they are a small component of the hydrogen cycle; balancing the mantle source against escape to space leads to $\mathrm{H}_{2}$ mixing ratios between $10^{-4}$ and $10^{-3}$ (Chapters $5 \& 6$ ).

The rise of a geochemically important biosphere leads to a second steady state for the atmosphere (equilibrium B). Production of organic carbon by hydrogen-consuming autotrophs introduces a new sink for hydrogen. This draws down atmospheric $\mathrm{H}_{2}$ levels until the combined biological and escape sinks again match the mantle hydrogen source. The change 
in $\mathrm{H}_{2}$ mixing levels may be as large as several orders of magnitude. $\mathrm{pO}_{2}$ almost certainly rises in response, but remains below $10^{-13} \mathrm{PAL}$ without a source larger than photolysis (Chapter 6). Atmospheric oxygen may have evolved along several different paths after the

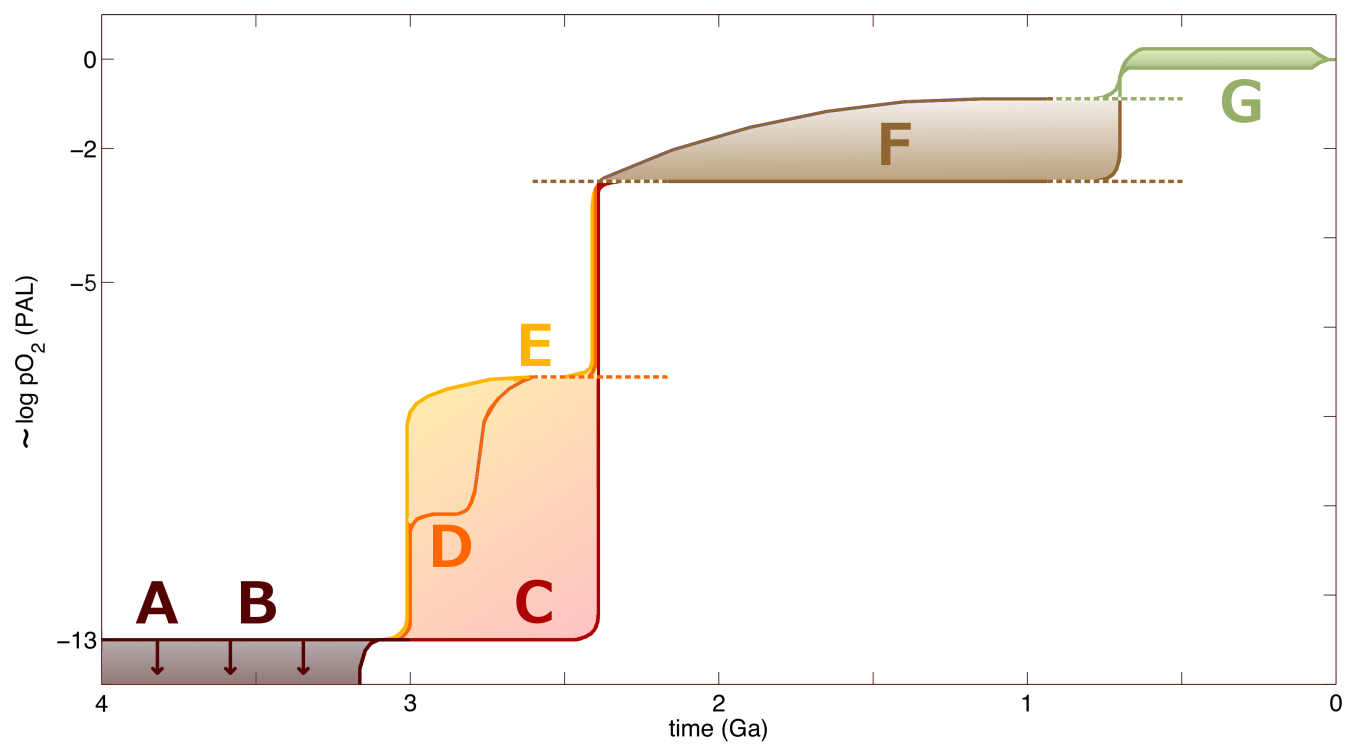

Figure 7.1: Schematic of the evolution of atmospheric oxygen over geologic history. Dashed lines loosely represent periods in which multiple equilibrium values of $\mathrm{pO}_{2}$ are simultaneously stable.

evolution of oxygenic photosynthesis. The introduction of a new source of oxygen must cause oxygen to begin rising from its pre-oxygenic equilibrium. However, the new steady state value of $\mathrm{pO}_{2}$ depends on the size of the photosynthetic oxygen source relative to total sinks. The source of oxygen is organic carbon burial, which in a low-oxygen environment is approximately proportional to the flux of the limiting nutrient to the oceans, bioavailable phosphorus (Chapter 2). The size of this flux is very poorly known. As a result, atmospheric oxygen may have evolved along several different paths after the evolution of oxygenic photosynthesis (Chapter 6). 
$\mathrm{pO}_{2}$ remains at very low values $\left(10^{-11}\right.$ to $\left.10^{-10} \mathrm{PAL}\right)$ following oxygenic photosynthesis if the potential oxygen sink from $\mathrm{H}_{2}$ oxidation exceeds the source of oxygen, as controlled by the bioavailable phosphorus flux. This condition can be states as $0.5 F_{H}>r F_{P}$, where $F_{H}$ is the flux of hydrogen from the mantle, $F_{P}$ the flux of bioavailable phosphorus from apatite weathering, and 0.5 and $r$ the relevant oxygen stoichiometries. The rate of reaction between atmospheric $\mathrm{O}_{2}$ and $\mathrm{H}_{2}$ is fast even at very low $\mathrm{pO}_{2}$. Therefore, is sufficient hydrogen is available to consume the oxygen supply, these rapid kinetics set the rate of oxygen loss, and $\mathrm{pO}_{2}$ is suppressed to low values.

Intermediate values of $\mathrm{pO}_{2}\left(10^{-8}\right.$ to $\left.10^{-5} \mathrm{PAL}\right)$ occur if the ratio of hydrogen to phosphorus inputs falls below the critical threshold when oxygenic photosynthesis evolves, i.e. $0.5 F_{H}<r F_{P}$. The fast kinetics of $\mathrm{H}_{2}$ oxidation results in most of the hydrogen being consumed, but excess $\mathrm{O}_{2}$ production remains. $\mathrm{pO}_{2}$ rises until an additional sink becomes large enough to balance this excess. This is most likely oxidative weathering of pyrite.

High values of $\mathrm{pO}_{2}(\sim 10-3 \mathrm{PAL})$ result if the phosphorus source is sufficiently large that the the combined hydrogen and pyrite sink cannot balance oxygen production. $\mathrm{O}_{2}$ rises until other sinks primarily organic carbon weathering and aqueous oxidation of ferrous iron and sulfide become large enough to restore steady state to the oxygen cycle.

Given the large uncertainties in the phosphorus bioavailability and the hydrogen flux, it is not possible to assert which steady states were actually achieved in the Archean. Several distinct trajectories are consistent with the dynamics.

The first possibility (path $\mathbf{C}$ ) is that bioavailable phosphorus was abundant at the moment 
oxygenic photosynthesis evolved. The source of oxygen was larger than the combined sinks from hydrogen outgassing and oxidation of pyrite, and $\mathrm{pO}_{2}$ rose immediately toward its Proterozoic equilibrium (discusssed further below). In this case case, oxygenic photosynthesis becomes globally significant at $2.4 \mathrm{Ga}$, and the Great Oxidation Event is a direct consequence of this biological innovation (Kopp et al. 2005).

The second possibility (path $\mathbf{E}$ ) is that phosphorus bioavailability was large enough to overwhelm the flux of hydrogen, but not so large that oxygen was produced fast enough to result in complete oxidation of pyrite as it was exposed by erosion and tectonics. In this case, pyrite oxidation kinetics control $\mathrm{pO}_{2}$ levels. The existence of detrital pyrite grains before 2.4 Ga suggests that continental pyrite was not oxidized to completion until after the GOE (Johnson et al. 2014a). Therefore, in this scenario, the evolution of oxygenic photosynthesis occurs earlier in the Archean, but $\mathrm{pO}_{2}$ is held below $10^{-5}$ PAL by dynamics. The Great Oxidation Event would only occur when either hydrogen inputs fell (Claire et al. 2006, Kump \& Barley 2007), decreasing the total oxygen sink, or the flux of bioavailable phosphorus rose. The latter possibility is discussed below.

The third possibility (path D) occurs only if the phosphorus source is smaller than the hydrogen flux, in the sense of $0.5 F_{H}<r F_{P}$. Oxygen is initially suppressed to very low values by the rapid kinetics of hydrogen oxidation. This scenario also requires oxygenic photosynthesis to have evolved before $2.4 \mathrm{Ga}$. Eventually, a decline in hydrogen outputs or a rise in phosphorus availability must have occurred in order to explain the GOE. If these fluxes varied smoothly over time, oxygen must have passed through the pyrite-controlled regime (path E) for a portion of the latest Archean.

At $2.4, \mathrm{pO}_{2}$ rises abruptly to greater than $10^{-5} \mathrm{PAL}$, and as large as 1-10\% PAL. There are 
several dynamically-consistent models for this Great Oxidation Event. The first, discussed above (path C), is that the evolution of oxygenic photosynthesis allowed for an oxygen source large enough to overwhelm both the flux of reduced gases from the mantle, and the exposure of pyrite on the continents. A second possibility is that the oxygen flux from autotrophy was not initially large enough to overwhelm these sinks, but this eventually occurred due to a secular decline in hydrogen outgassing and serpentinization rates, possibly driven by cooling of the mantle (Claire et al. 2006).

An alternative explanation is that the supply of bioavailable phosphorus rose abruptly at $2.4 \mathrm{Ga}$, allowing the oxygen source to overwhelm the sinks. A permanent increase in phosphate supply can be explained by a positive feedback linking the carbon and oxygen cycles (Chapter 6). A transient rise in $\mathrm{pCO}_{2}$ leads to warmer temperatures and additional apatite weathering. The increased phosphorus flux results in additional organic carbon burial, and oxygen begins to rise. This drives oxidation of ferrous iron in the oceans, decreasing alkalinity. The saturation state of siderite and calcite fall, leading to imbalance in the carbon cycle, and further increases in $\mathrm{pCO}_{2}$. This process can continue until $\mathrm{pCO}_{2}$ and $\mathrm{pO}_{2}$ rise to some new equilibrium state, the Proterozoic (discussed further below).

This hypothesis for the GOE has the advantage that it can explain the apparent synchronicity between oxygenation and the second Paleoproterozoic Snowball Earth event (Hoffman 2013), which terminates with a large spike in $\mathrm{pCO}_{2}$, temperature, and weathering rate. It is not immediately obvious under what conditions or duration one glacial would induce oxygenation rather than another; this problem remains for future investigation.

Once the GOE occurs, the oxygen source must be large enough to completely reduce the hydrogen and pyrite being exposed to the atmosphere while leaving some excess $\mathrm{O}_{2}$. This 
additional production is balanced by a combination of other sinks, including oxidation of ferrous iron and sulfide from hydrothermal systems, and oxidative weathering of organic carbon on the continents. These processes are oxygen-sensitive, and $\mathrm{so}^{\mathrm{pO}} \mathrm{O}_{2}$ is stabilized at its Proterozoic value of a few percent PAL (equilibrium F) (Chapters $2 \& 3$ ). Bounds on $\mathrm{pO}_{2}$ are weak during this era. Indeed, the hydrogen flux may have declined over the Proterozoic due to mantle cooling, allowing for a gradual increase in $\mathrm{pO}_{2}$ on time scales far longer than the residence time of any redox-sensitive species in the surface environment. However, mantle cooling rates slow substantially by the Mesoproterozoic (Turcotte 1980), suggesting essentially stable $\mathrm{pO}_{2}$ after that time.

The processes that stabilize Proterozoic oxygen are similar to those known to operate today. Therefore, a second increase in $\mathrm{O}_{2}$ in the Neoproterozoic or early Phanerozoic is most easily explained by a second increase in the bioavailability of phosphorus. An increase in P drives additional oxygen production, and $\mathrm{pO}_{2}$ rises until the rates of organic carbon weathering and remineralization become large enough to return the system to equilibrium (equilibrium G. The Phanerozoic equilibrium is thus characterized by higher $\mathrm{pO}_{2}$ in the Phanerozoic, though it is stabilized by the same mechanisms.

The increase in phosphate bioavailability between the two states may be due to preferential scavenging by iron in low-oxygen river systems (Chapters $2 \& 4$ ), but other mechanisms related to iron redox cycling, including formation of green rust or a true iron-phosphorus phase such as vivianite, are equally plausible. This rise in oxygen also shows a conspicuous correlation with Snowball glacial events, but the trigger for this second transition is left for future study. 
References

\section{REFERENCES}

Abbott, D., \& S. Hoffman (1984) Archean plate tectonics revisited. 1. Heat flow, spreading rate, and the age of subducting oceanic lithosphere and their effects on the origin and evolution of continents. Tectonics 3, 429-448.

Abbott, D., A. Voigt, M. Branson, R. Pierrehumbert, D. Pollard, G. Le Hir, \& D. Koll (2012) Clouds and Snowball Earth deglaciation. Geophys. Res. Lett. 39, 1-4.

Anbar, A., Y. Duan, T. Lyons, G. Arnold, B. Kendall, R. Creaser, A. Kaufman, G. Gordon, C. Scott, J. Garvin, \& R. Buick (2007) A Whiff of Oxygen Before the Great Oxidation Event? Science 317, 1903-1906.

Anbar, A., \& A. Knoll (2002) Proterozoic Ocean Chemistry and Evolution: A Bioinorganic Bridge? Science 297, 1137-1142.

Anderson L, M. Delaney, \& K. Faul (2001) Carbon to phosphorus ratios in sediments: Implications for nutrient cycling. Glob. Biogeochem. Cycles 15, 65-79.

Armstrong, R., C. Lee, J. Hedges, S. Honjo, \& S Wakeham (2002) A new, mechanistic model for organic carbon fluxes in the ocean based on the quantitative association of POC with ballast materials. Deep-Sea Res. II 49, 219-236.

Arthur, M., W. Dean, E. Neff, B. Hay, J. King, \& G. Jones (1994) Varve calibrated records of carbonates and organic carbon accumulation over the last 2000 years in the Black Sea. Glob. Biogeochem. Cycles 8, 195-217.

Avakyan, S., R. Il'in, V. Lavrov, \& G. Ogurtsov (1998) Collision Processes and Excitation of UV Emission from Planetary Atmospheric Gases. A Handbook of Cross Sections. Gordon \& Breach Amsterdam.

Bekker, A., H. Holland, P. Wang, D. Rumble III, H. Stein, J. Hannah, L. Coetzee, \& N. Beukes (2004) Dating the rise of atmospheric oxygen. Nature 427, 117-120.

Benitez-Nelson, C. (2000) The biogeochemical cycling of phosphorus in marine systems. Earth Sci. Rev. 51, 109-135.

Bergman, N., T. Lenton, \& A. Watson (2004) COPSE: A new model of biogeochemical cycling over Phanerozoic time. Am. J. Sci. 304, 397-437.

Bergmann, K., J. Grotzinger, \& W. Fischer (2013) Biological influences on seafloor carbonate precipitation. Palaios 28, 1-17. 
Berner, E., \& R. Berner (1996) Global Environment: Water, Air, and Geochemical Cycles. Princeton U. Press, Princeton.

Berner, R. (2006) GEOCARBSULF: A combined model for Phanerozoic atmospheric $\mathrm{O}_{2}$ and $\mathrm{CO}_{2}$. Geochem. Cosmochim. Acta 70, 5653-5664.

Berner, R., \& D. Canfield (1989) A new model for atmospheric oxygen over Phanerozoic time. Am. J. Sci. 289, 333-361.

Berner, R., A. Lasaga, \& R. Garrels (1983) The carbonate-silicate geochemical cycle and its effects on atmospheric carbon dioxide over the past 100 million years. Am. J. Sci. 283, 641-683.

Berner, R., \& J. Rao (1994) Phosphorus in sediments of the Amazon River and estuary: Implications for the globa flux of phosphorus to the sea. Geochim. Cosmochim. Acta 58, 2333-2339.

Berner, R., \& J. Westrich (1985) Bioturbation and the early diagenesis of carbon and sulfur. Am. J. Sci. 285, 193-206.

Bjerrum, C., \& D. Canfield (2002) Ocean productivity before 1.9 Gyr ago limited by phosphorus adsorption onto iron oxides. Nature 417, 159-162.

Bougher, S., D. Hunten, \& R. Roble (1994) $\mathrm{CO}_{2}$ cooling in terrestrial planet thermospheres. J. Geophys. Res. 99, 14609-14622.

Bougher, S., \& R. Roble (1991) Comparative Terrestrial Planet Thermospheres. 1. Solar Cycle Variation of Global Mean Temperatures. J. Geophys. Res. 96, 11045-11055.

Bosak, T., A. Knoll, \& A. Petroff (2013) The Meaning of Stromatolites. Annu. Rev. Earth Planet. Sci. 41, 21-44.

Brocks, J., G. Logan, R. Buick, \& R. Summons (1999) Archean molecular fossils and the early rise of eukaryotes. Science 285, 1033-1036.

Buffle, J., R. De Vitre, D. Perret, \& G. Leppard (1989) Physico-chemical characteristics of a colloidal iron phosphate species formed in the oxic-anoxic interface of a eutrophic lake. Geochem. Cosmochim. Acta 53, 399-408.

Cai, W., \& F. Sayles (1996) Oxygen penetration depths and fluxes in marine sediments. Mar. Chem. 52, 123-131.

Caldeira, K., \& J. Kasting (1992) Susceptibility of the early Earth to irreversible glacia- 
References

tion caused by carbon dioxide clouds. Nature 359, 226-228.

Canfield, D. (1989) Sulfate reduction and oxic respiration in marine sediments: implications for organic carbon preservation in euxinic environments. Deep-Sea Res. 36, 121-138.

Canfield, D. (2004) The evolution of the earth surface sulfur reservoir. Am. J. Sci. 304, 839-861.

Canfield, D., M. Rosing, \& C. Bjerrum (2006) Early anaerobic metabolisms. Phil. Trans. R. Soc. B 361, 1819-1836.

Canfield, D., \& A. Teske (1996) Late Proterozoic rise in atmospheric oxygen concentration inferred from phylogenetic and sulphur-isotopes studies. Nature 382, 127-132.

Cannat, M. (1993) Emplacement of Mantle Rocks in the Seafloor in Mid-Ocean Ridges. J. Geophys. Res. 98, 4163-4172.

Capone, D., \& R. Kiene (1988) Comparison of microbial dynamics in marine and freshwater sediments: Contrasts in anaerobic carbon catabolism. Limnol. Oceanogr. 33, 725-749.

Carpenter, S., \& E. Bennett (2011) Reconsideration of the planetary boundary for phosphorus. Environ. Res. Lett. 6, 1-12. Catling, D., \& M. Claire (2005) How Earth's atmosphere evolved to an oxic state: A status report. Earth Planet. Sci. Lett. 237, 1-20.

Catling D., K. Zahnle, \& C. McKay (2001) Biogenic Methane, Hydrogen Escape, and the Irreversible Oxidation of the Early Earth. Science 293, 839-843.

Chang, S., \& R. Berner (1999) Coal weathering and the geochemical carbon cycle. Geochim. Cosmochim. Acta 63, 3301-3310.

Chassefiere, E. (1996) Hydrodynamic escape of hydrogen from a hot water-rich atmosphere: The case of Venus. J. Geophys. Res. 101, 26039-26056.

Claire, M., D. Catling, \& K. Zahnle (2006) Biogeochemical modelling of the rise in atmospheric oxygen. Geobiol. 4, 239-269.

Cloud, P. (1968) Atmospheric and Hydrospheric Evolution of the Primitive Earth. Science 160, 729-736.

Colman, A., \& H. Holland (2000) The Global Diagenetic Flux of Phosphorus from Marine Sediments to the Oceans: Redox Sensitivity and the Control of Atmospheric Oxygen Levels, in: Glenn, C., J. Lucas, \& L. Prevot-Lucas (Eds.) Marine Authigenesis: from Global to Microbial. SEMP Spec. Pub. 66, pp. 53-75. 
Cowie, G., J. Hedges, F. Prahl, \& G. Lange (1995) Elemental and major biogeochemical changes across an oxidation front in a relict turbidite: An oxygen effect. Geochim. Cosmochim. Acta 59, 33-46.

Crowe, S., S. Katsev, A. Sturm, C. Magen, S. Nomosatryo, M. Pack, J. Kessler, W. Reeburgh, J. Roberts, L. Gonzalez, G. Haffner, A. Mucci, B. Sundby, \& D. Fowle (2011) The methane cycle in ferruginous Lake Matano. Geobiol. 9, 61-78.

Dahl, T., E. Hammarlund, A. Anbar, D. Bond, B. Gill, G. Gordon, A. Knoll, A. Nielsen, N. Schovsbo, D. Canfield (2010) Devonian rise in atmospheric oxygen correlated to the radiations of terrestrial plants and large predatory fish. PNAS 107, 17911-17915.

Dalgarno, A., \& F. Smith (1962) The thermal conductivity and viscosity of atomic oxygen. Planet. Space Sci. 9, 1-2.

Delaney, M. (1998) Phosphorus accumulation in marine sediments and the oceanic phosphorus cycle. Glob. Biogeochem. Cycles 12, 563-572.

Deuser, W. (1971) Organic-carbon budget of the Black Sea. Deep-Sea Res. 18, 995-1004.

DeVries, T., C. Deutsch, F. Primeau, B. Chang, \& A. Devol (2012) Global rates of watercolumn denitrification derived from nitrogen gas measurements. Nature Geosci. 5, 547-550.

Dickinson, R. (1984) Infrared radiative cooling in the mesosphere and lower thermosphere. J. Atmos. Terr. Phys. 46, 995-1008.

Dunne, J., J. Sarmiento, \& A. Gnanadesikan (2007) A synthesis of global particle export from the surface ocean and cycling through the ocean interior and on the seafloor. Glob. Biogeochem. Cycles 21, 1-16.

Elderfield, H., \& A. Schultz (1996) Mid-ocean ridge hydrothermal fluxes and the chemical composition of the ocean. Annu. Rev. Earth Planet. Sci. 24, 191-224.

Emmanuel, S., \& J. Ague (2007) Implications of present-day abiogenic methane fluxes for the early Archean atmosphere. Geophys. Res. Lett. 34, 1-5.

Erwin, J., O. Tucker, \& R. Johnson (2013) Hybrid fluid/kinetic modeling of Pluto's escaping atmosphere. Icarus 226, 375-384.

Farquhar, J., H. Bao, \& M. Thiemens (2000) Atmospheric Influence of Earth's Earliest Sulfur Cycle. Science 289, 756-758.

Farquhar, J., J. Savarino, S. Airieau, \& M. Thiemens (2001) Observation of wavelength- 
sensitive mass-independent sulfur isotope effects during $\mathrm{SO}_{2}$ photolysis: Implications for the early atmosphere. J. Geophys. Res. 106, 32829-32839.

Feely, R., J. Trefry, G. Lebon, \& C. German (1998) The relationship between P/Fe and $\mathrm{V} / \mathrm{Fe}$ ratios in hydrothermal precipitates and dissolved phosphate in seawater. Geophys. Res. Lett. 25, 2253-2256.

Fennel, K., M. Follows, \& P. Falkowski (2005) The co-evolution of the nitrogen, carbon and oxygen cycles in the Proterozoic ocean. Am. J. Sci. 305, 526-545.

Fennelly, J., \& D. Torr (1992) Photoionization and photoabsorption cross sections of O, $\mathrm{N}_{2}, \mathrm{O}_{2}$, and $\mathrm{N}$ for aeronomic calculations. Atomic Data and Nuclear Data Tables 51, 321363.

Filippelli, G. (2002) The Global Phosphorus Cycle. Rev. Mineral. Geochem. 48, 391425 .

Filippelli, G., \& M. Delaney (1996) Phosphorus geochemistry of equatorial Pacific sediments. Geochim. Cosmochim. Acta 60, 1479-1495.

Fox, L. (1990) Geochemistry of dissolved phosphate in the Sepik River and Estuary, Papua, New Guinea. Geochim. Cosmochim. Acta 54, 1019-1024.

Fox, L. (1991) Phosphorus chemistry in the tidal Hudson River. Geochim. Cosmochim. Acta 55, 1529-1538.

Froelich, P. (1988) Kinetic control of dissolved phosphate in natural rivers and estuaries: A primer on the phosphate buffer mechanism. Limnol. Oceanogr. 22, 649-668. Froelich, P., M. Bender, A. Luedtke, G. Heath, \& T. DeVries (1982) The marine phosphorus cycle. Am. J. Sci. 282, 474-511.

Fuller, C., J. Davis, \& G. Waychunas (1993) Surface chemistry of ferrihydrite: Part 2. Kinetics of arsenate adsorption and coprecipitation. Geochim. Cosmochim. Acta, 57, 22712282.

Gaillardet, J., B Dupre, P. Louvat, \& C. Allegre (1999) Global silicate weathering and $\mathrm{CO}_{2}$ consumption rates deduced from the chemistry of large rivers. Chem. Geol. 159, 3-30.

Galloway, J., F. Dentener, D. Capone, E. Boyer, R. Howarth, S. Seitzinger, G. Asner, C. Cleveland, P. Green, E. Holland, D. Karl, A. Michaels, J. Porter, A. Townsend \& C. Vŏrŏsmarty (2004) Nitrogen cycles: past, present, and future. Biogeochem. 70, 153-226.

Goldblatt, C., T. Lenton, \& A. Watson (2006) Bistability of atmospheric oxygen and the 
References

Great Oxidation. Nature 44, 683-686.

Gough, D. (1981) Solar interior structure and luminosity variations. Solar Phys. 74, 21-34.

Grotzinger, J., \& J. Kasting (1993) New Constraints on Precambrian Ocean Composition. J. Geol. 101, 235-243.

Gunnars, A., S. Blomqvist, P. Johansson, \& C. Andersson (2002) Formation of Fe(III) oxyhydroxide colloids in freshwater and brackish seawater, with incorporation of phosphate and calcium. Geochim. Cosmochim. Acta 66, 745-758.

Habicht, K., M. Gade, B. Thamdrup, P. Berg, \& D. Canfield (2002) Calibraration of Sulfate Levels in the Archean Ocean. Science 298, 2372-2374.

Halevy, I., D. Johnston, \& D. Schrag (2010) Explaining the Structure of the Archean MassIndependent Sulfur Isotope Record. Science 329, 204-207.

Halevy, I., S. Peters, \& W. Fischer (2012) Sulfate Burial Constraints on the Phanerozoic Sulfur Cycle. Science 337, 331-334.

Hartnett, G., \& A. Devol (2003) Role of a strong oxygen-deficient zone in the preservation and degradation of organic matter: A carbon budget for the continentalmargins of northwest Mexico and Washington State. Geochim. Cosmochim. Acta 67, 247-264.

Hayes, J., \& J. Waldbauer (2006) The carbon cycle and associated redox processes through time. Phil. Trans. R. Soc. B 361, 931-950.

Haynes, W., Ed. (2014) CRC Handbook of Chemistry \& Physics. http://www . hbcpnetbase. com/

Hedges, J., F. Hu, A. Devol, H. Hartnett, E. Tsamakis, \& R. Keil (1999) Sedimentary organic matter preservation: a test for selective degradation under oxic conditions. Am. J. Sci. 299, 529-555.

Hedges, J., \& R. Keil (1995) Sedeimentary organic matter preservation: an assessment and speculative synthesis. Mar. Chem. 49, 81-115.

Herroux, L., \& H. Hinteregger (1978) Aeronomical Reference Spectrum for Solar UV below 2000 Å. J. Geophys. Res. 83, 5305-5308.

Herzberg, C., K. Condie, \& J. Korenaga (2010) Thermal history of the Earth and its petrological expression. Earth Planet. Sci. Lett. 292, 79-88. 
Hoffman, P. (2013) The Great Oxidation and a Siderian snowball Earth: MIF-S based correlation of Paleoproterozoic glacial epochs. Chem. Geo. 362, 143-156.

Hoffman, P., A. Kaufman, G. Halverson, \& D. Schrag (1998) A Neoproterozoic Snowball Earth. Science 281, 1342-1346.

Hoffman, P., \& D. Schrag (2002) The snowball Earth hypothesis: testing the limits of global change. Terra Nova 14, 129-155.

Holland, H. (1978) The Chemistry of the Atmosphere and Oceans. Wiley \& Sons, New York.

Holland, H. (1984) The Chemical Evolution of the Atmosphere and Oceans. Princeton U. Press, Princeton.

Holland, H. (2002) Volcanic gases, black smokers, and the great oxidation event. Geochim. Cosmochim. Acta 66, 3811-3826.

Hunten, D. (1973) The Escape of Light Gases from Planetary Atmospheres. J. Atmos. Sci. 30, 1481-1494.

Hunten, D., \& D. Strobel (1974) Production and Escape of Terrestrial Hydrogen. J. Atmos. Sci. 31, 305-317.

Huybers, P., \& C. Langmuir (2009) Feedback beteween deglaciation, volcanism, and atmospheric $\mathrm{CO}_{2}$. Earth Planet. Sci. Lett. 286, 479-491.

Hyacinth, C., \& P. Van Cappellen (2004) An authigenic iron phosphate phase in estuarine sediments: composition, formation and chemical reactivity. Mar. Chem. 9, 227-251.

Ingvorsen K., A. Zehnder, \& B. Jorgensen (1984) Kinetics of Sulfate and Acetate Uptake by Desulfobacter postgatei. App. Env. Microbio. 47, 403-408.

Isley, A., \& D. Abbott (1999) Plume-related mafic volcanism and the deposition of banded iron formation. J. Geophys. Res. 104, 15461-15477.

Jeans, J. (1925) The Dynamical Theory of Gases. Cambridge University Press, Cambridge.

Johnson, C., B. Beard, \& E. Roden (2008) The Iron Isotope Fingerprints of Redox and Biogeochemical Cycling in Modern and Ancient Earth. Annu. Rev. Earth Planet. Sci. 36, 457-493.

Johnson, J., A. Gerpheide, M. Lamb, \& W. Fischer (2014a) $\mathrm{O}_{2}$ constraints from Paleo- 
proterozoic detrital pyrite and uraninite. Geol. Soc. Am. Bull. 126, 813-830.

Johnson, T., M. Brown, B. Kaus, \& J. VanTongeren (2014b) Delamination and recycling of Archaean crust caused by gravitational instabilities. Nature Geosci. 7, 47-52.

Johnson, R., A. Volkov, \& J. Erwin (2013) Molecular-kinetic simulations of escape from the ex-planet and exoplanets: criterion for transonic flow. Ap. J. Lett. 768, 1-6.

Johnston, D., S. Poulton, C. Dehler, S. Porter, J. Husson, D. Canfield, \& A. Knoll (2010) An emerging picture of Neoproterozoic ocean chemistry: Insights from the Chuar Group, Grand Canyon, USA. Earth Planet. Sci. Lett. 290, 64-73.

Jorgensen B., A. Weber, \& J. Zopfi (2001) Sulfate reduction and anaerobic methane oxidation in Black Sea sediments. Deep-Sea Res. I 48, 2097-2120.

Kasting, J. (1993) Earth's Early Atmosphere. Science 259, 920-926.

Kasting, J., \& D. Catling (2003) Evolution of a Habitable Planet. Annu. Rev. Astron. Astrophys. 41, 429-463.

Kasting. J., \& T. Donahue (1980) The Evolution of Atmospheric Ozone. J. Geophys. Res. 85, 3255-3263.

Kasting, J., \& J. Pollack (1983) Loss of Water from Venus. I. Hydrodynamic Escape of Hydrogen. Icarus 53, 479-508.

Keir, R. (2010) A note on the fluxes of abiogenic methane and hydrogen from mid-ocean ridges. Geophys. Res. Lett. 37, 1-5.

Kennedy, M., M. Droser, L. Mayer, D. Pevear, \& D. Mrofka (2006) Late Precambrian Oxygenation; Inception of the Clay Mineral Factor. Science 311, 1446-1449.

Kharecha, P., J. Kasting \& J. Siefert (2005) A coupled atmosphere-ecosystem model of the early Archean Earth. Geobiol. 3, 53-76.

Klein, C. (2005) Some Precambrian banded iron-formations (BIFs) from around the world: Their age, geologic setting, mineralogy, metamorphism, geochemistry, and origin. Am. Mineral. 90, 1473-1499.

Klein, C., \& N. Beukes (1993) Sedimentology and Geochemistry of the Glaciogenic Late Proterozoic Rapitan Iron-Formation in Canada. Econ. Geol. 88, 542-565.

Konovalov, S., J. Murray (2001) Variations in the chemistry of the Black Sea on a time 
scale of decades (1960-1995). J. Mar. Sys. 31, 217-243.

Kopp, R., J. Kirschvink, I. Hilburn, \& C. Nash (2005) The Paleoproterozoic snowball Earth: A climate disaster triggered by the evolution of oxygenic photosynthesis. PNAS 102, 1113111136.

Kulikov, Y., H. Lammer, H. Lichtenegger, T. Penz, D. Breuer, T. Spohn, R. Lundfin, $\&$ H. Biernat (2007) A Comparative Study of the Influences of the Active Young Sun on the Early Atmospheres of Earth, Venus, and Mars. Space Sci. Rev. 129, 207-243.

Kump, L. (2008) The rise of atmospheric oxygen. Nature 451, 277-278.

Kump, L., \& M. Barley (2007) Increased subaerial volcanism and the rise of atmospheric oxygen 2.5 billion years ago. Nature 448, 1033-1036.

Kump, L., \& R. Garrels (1986) Modeling atmospheric $\mathrm{O}_{2}$ in the global sedimentary redox cycle. Am. J. Sci. 286, 337-360.

Kump, L., J. Kasting, \& M. Barley (2001) Rise of atmospheric oxygen and the "upsidedown" Archean mantle. Geochem. Geophys. Geosys. 2.

Kump, L., J. Kasting, \& R. Crane (2009) The Earth System, $3^{\text {rd }}$ ed. Prentice Hall.

Laakso, T., \& D. Schrag (2014) Regulation of atmospheric oxygen during the Proteorzoic. Earth Planet. Sci. Lett. 388, 81-91.

Lasaga, A., \& H. Ohmoto (2002) The oxygen geochemical cycle: Dynamics and stability. Geochim. Cosmochim. Acta 66, 361-381.

Lenton, T., \& A. Watson (2004) Biotic enhancement of weathering, atmospheric oxygen and carbon dioxide in the Neoproterozoic. Geophys. Res. Lett. 31, 1-5.

Li, Z., \& C. Lee (2004) The constancy of upper mantle $\mathrm{fO}_{2}$ through time inferred from V/Sc ratios in basalts. Earth Planet. Sci. Lett. 228, 483-493.

Liu, S., \& T. Donahue (1974) Realistic Model of Hydrogen Constituents in the Lower Atmosphere and Escape Flux from the Upper Atmosphere. J. Atmos. Sci. 31, 2238-2242.

Liu, S., \& T. Donahue (1984) The Aeronomy of Hydrogen in the Atmosphere of the Earth. J. Atmos. Sci. 31, 1118-1136.

Logan, G., J. Hayes, G. Hieshima, \& R. Summons (1995) Terminal Proterozoic reorganization of biogeochemical cycles. Nature 376, 53-56. 
Lyons, T., C. Reinhard, \& N. Planavsky (2014) The rise of oxygen in Earth's early ocean and atmosphere. Nature 506, 307-315.

Martens, C., \& J. Klump (1984) Biogeochemical cycling in an organic-rich coastal marine basin 4 . An organic budget for sediments dominated by sulfate reduction and methanogenesis. Geochim. Cosmochim. Acta 48, 1987-2004.

Mayer, T., \& W. Jarrell (2000) Phosphorus sorption during iron(II) oxidation in the presence of dissolved silica. Water Res. 34, 3949-3956.

McCollom, T., \& W. Bach (2009) Thermodynamic constraints on hydrogen generation during serpentinization of ultramafic rocks. Geochim. Cosmochim. Acta 73, 856-875.

Meister, P., J. McKenzie, C. Vasconcelos, S. Bernasconi, M. Frank, M. Gutjahr, \& D. Schrag (2007) Dolomite formation in the dynamic deep biosphere: results from the Peru Margin. Sedimentology 54, 1007-1032.

Meybeck, M. (1982) Carbon, nitrogen and phosphorus transport by world rivers. Am. J. Sci. 282, 401-450.

Millero, F., S. Hubinger, M. Fernandez \& S. Garnett (1987a) Oxidation of $\mathrm{H}_{2} \mathrm{~S}$ in Seawater as a Function of Temperature, $\mathrm{pH}$, and Ionic Strength. Environ. Sci. Technol. 21, 439-443.

Millero, F., S. Sototlongo, \& M. Izaguirre (1987b) The oxidation kinetics of Fe(II) in seawater. Geochi. Cosmochim. Acta 51, 793-801.

Milliman, J. (1993) Production and accumulation of calcium carbonate in the ocean: Budget of a nonsteady state. Glob. Biogeochem. Cyc. 7, 927-957.

Muller-Karger, F., R. Varela, R. Thunell, R. Luerssen, C. Hu, \& J. Walsh (2005) The importance of continental margins in the global carbon cycle. Geophys. Res. Lett. 32, 1-4.

Murray, J., Z. Top, \& E. Ŏzsoy (1991) Hydrographic properties and ventilation of the Black Sea. Deep-Sea Res. 38, S663-S689.

Naehr T., P. Eichhubl, V. Orphan, M. Hovland, C. Paull, W. Ussler III, T. Lorenson, \& G. Greene (2007) Authigenic carbonate formation at hydrocarbon seeps in continental margin sediments: A comparative study. Deep-Sea Res. II 54, 1268-1291.

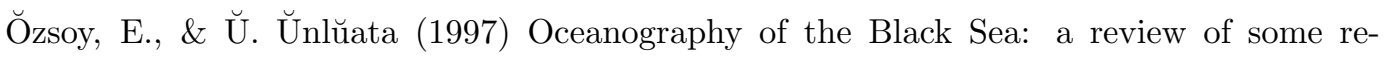
cent results. Earth Sci. Rev. 42, 231-272. 
Parfitt, R. (1978) Anion adsorption by soils and soil materials. Adv. Agron. 30, 1-50.

Parker, E. (1963) Interplanetary Dynamical Processes. Interscience Publishers, Rochester.

Partin, C., A. Bekker, N. Planavsky, C. Scott, B. Gill, C. Li, V. Podkovyrov, A. Maslov, K. Konhauser, S. Lalonde, G. Love, S. Poulton, \& T. Lyons (2013) Large-scale fluctuations in Precambrian atmospheric and oceanic oxygen levels from teh recrod of $\mathrm{U}$ in shales. Earth Planet. Sci. Lett. 369, 284-293.

Pavlov, A., \& J. Kasting (2000) Mass-Independent Fractionation of Sulfur Isotopes in Archean Sediments: Strong Evidence for an Anoxic Archean Atmosphere. Astrobiol. 2, $27-41$.

Pavlov, A., J. Kasting, L. Brown, K. Rages, \& R. Freedman (2000) Greenhouse warming by $\mathrm{CH}_{4}$ in the atmosphere of the early Earth. J. Geophys. Res. 105, 11981-11990.

Pawellek, F., F. Frauenstein, \& J. Veizer (2002) Hydrochemistry and isotope geochemistry of the upper Danube River. Geochim. Cosmochim. Acta 66, 3839-3854.

Pierrehumbert, R. (2011) Principles of Planetary Climate. Cambridge U. Press, Cambridge.

Polat, S., \& S. Tugrul (1995) Nutrient and organic carbon exchanges between the Black and Marmara Seas through the Bosphorus Strait. Cont. Shelf Res. 15, 1115-1132.

Planavsky, N., O. Rouxel, A. Bekker, A. Hofmann, C. Little, \& T. Lyons (2012) Iron isotope composition of some Archean and Proterozoic iron formations. Geochim. Cosmochim. Acta 80, 158-169.

Planavsky, N., O. Rouxel, A. Bekker, S. Lalonde, K. Konhauser, C. Reinhard, \& T. Lyons (2010) The evolution of the marine phosphate reservoir. Nature 467, 1088-1090.

Poulton, S., \& D. Canfield (2011) Ferruginous Conditions: A Dominant Feature of the Ocean through Earth's History. Elements 7, 107-112.

Poulton, S., P. Fralick, \& D. Canfield (2010) Spatial variability in oceanic redox structure 1.8 billion year ago. Nature Geosci. 3, 486-490.

Poulton S., \& R. Raiswell (2002) The low-temperature geochemical cycle of iron: from continental fluxes to marine sediment deposition. Am. J. Sci. 302, 774-805.

Rasmussen, B., I. Fletcher, J. Brocks, \& M. Kilburn (2008). Reassessing the first appearance of eukaryotes and cyanobacteria. Nature 455, 1101-1105. 
Reinhard, C., N. Planavsky, L. Robbins, C. Partin, B. Gill, S. Lalonde, A. Bekker, K. Konhauser, \& T. Lyons (2013) Proterozoic ocean redox and biogeochemical stasis. Proc. Natl. Acad. Sci. USA 110, 5357-5362.

Ribas, I., G. Porto de Mello, L. Ferreira, E. Hebrard, F. Selsis, S. Catalan, A. Garces, J. do Nascimento, \& J. de Medeiros (2005) Evolution of the solar activity over time and effects on planetary atmospheres. II. $\kappa^{1}$ Ceti, an analogue of the sun when life arose on Earth. Ap. J. 714, 384-395.

Rickard, D., \& G. Luther III (2007) Chemistry of Iron Sulfides. Chem. Rev. 107, 514562 .

Roble, R., E. Ridley, \& R. Dickinson (1987) On the Global Mean Structure of the Thermosphere. J. Geophys. Res. 92, 8745-8758.

Ruttenberg, K. (1992) Development of a Sequential Extraction Method for Different Forms of Phosphorus in Marine Sediments. Limnol. Oceanogr. 37, 1460-1482.

Rye, R., \& H. Holland (1998) Paleosols and the evolution of atmospheric oxygen: a critical review. Am. J. Sci. 298, 621-672.

Sarmiento, J., \& N. Gruber (2006) Ocean Biogeochemical Dynamics. Princeton U. Press, Princeton.

Schrag, D., J. Higgins, F. Macdonald, \& D. Johnston (2013) Authigenic Carbonate and the History of the Global Carbon Cycle. Science 339, 540-543.

Scott, A., \& I. Glasspool (2006) The diversification of Paleozoic fire systems and fluctuations in atmospheric oxygen concentration. PNAS 103, 10861-10865.

Schaffer, G. (1986) Phosphate pumps and shuttles in the Black Sea. Nature 321, 515517.

Scott, C., T. Lyons, A. Bekker, Y. Shen, S. Poulton, X. Chu, \& A. Anbar (2008) Tracing the stepwise oxygenation of the Proterozoic ocean. Nature 452, 456-460.

Shields, G., \& J. Veizer (2002) Precambrian marine carbonate isotope database: Version 1.1. Geochem. Geophys. Geosys. 3, 1-12.

Shizgal, B., \& G. Arkos (1996) Nonthermal escape of the atmospheres of Venus, Earth, and Mars. Rev. Geophys. 34, 483-505. 
Strickland, J., \& T. Parsons (1972) A Practical Handbook of Seawater Analysis. Dept. of Fisheries and the Environment of Canada, Ottawa.

Sundby, B., C. Gobeil, N. Silverberg, \& A. Mucci (1992) The phosphorus cycle in coastal marine sediments. Limnoc. Oceanogr. 37, 1129-1145.

Tian, F., J. Kasting, H. Liu, \& R. Roble (2008) Hydrodynamic planetary themosphere model: 1. Response of the Earth's thermosphere to extreme solar EUV conditions and the significance of adiabatic cooling. J. Geophys. Res. 113, 1-19.

Tian, F., O. Toon, A. Pavlov, \& H. De Sterck (2005) A Hydrogen-Rich Early Earth Atmosphere. Science 308, 1014-1017.

Torrent, J., U. Schwertmann, \& V. Barron (1992) Fast and slow phosphate sorption by goethite-rich natural materials. Clays \& Clay Min. 40, 14-21.

Turcotte, D. (1980) On the thermal evolution of the Earth. Earth Planet. Sci. Lett. 48, $53-58$.

Tyrrell, T. (1999) The relative influences of nitrogen and phosphorus on oceanic primary production. Nature 400, 525-531.

Van Cappellen, P., \& E. Ingall (1994) Benthic phosphorus regeneration, net primary production, and ocean anoxia: A model of the coupled marine and biogeochemical cycles of carbon and phosphorus. Paleoceanogr. 9, 677-692.

Veizer, J. (1978) Secular variations in the composition of sedimentary carbonate rocks: II. Fe, Mn, Ca, Mg, Si and minor constituents. Precamb. Res. 6, 381-413.

Visconti, G. (1975) The Exospheric Temperature of a Primitive Terrestrial Atmosphere with Evolving Oxygen Content. J. Atmos. Sci. 32, 1631-1637.

Walker, J. (1977) Evolution of the Atmosphere. Macmillian, London.

Walker, J., B. Hays, \& J. Kasting (1981) A negative feedback mechanism for the longterm stabilization of Earth's surface temperature. J. Geophys. Res. 86, 9776-9782.

Wang, Y., \& P. Van Cappellen (1996) A multicomponent reactive transport model of early diagenesis: Application to redox cycling in coastal marine sediments. Geochim. Cosmochim. Acta 60, 2993-3014.

Warneck, P. (2000) Chemistry of the Natural Atmosphere. Academic Press, San Diego. Warren, H., J. Mariska, \& J. Lean (1998) A new reference spectrum for the EUV irradiance 
of the quiet Sun. 1. Emission measure formulation. J. Geophys. Res. 103, 12077-12089.

Watson A., T. Donahue, \& J. Walker (1981) The Dynamics of a Rapidly Escaping Atmosphere: Applications to the Evolution of Earth and Venus. Icarus 48, 150-166.

Waychunas, G., B. Rea, C. Fuller, \& J. Davis (1993) Surface chemistry of ferrihydrite: Part 1. EXAFS studies of the geometry of coprecipitated and adsorbed arsenate. Geochim. Cosmochim. Acta 57, 2251-2269.

Westrich, J., \& R. Berner (1984) The role of sedimentary organic matter in bacterial sulfate reduction: the $G$ model tested. Limnol. Oceanogr. 29, 236-249.

Wilke, C. (1950) A Viscosity Equation for Gas Mixtures. J. Chem. Phys. 18, 517-519.

Wordsworth, R., \& R. Pierrehumbert (2014) Abiotic oxygen-dominated atmospheres on terrestrial habitable zone planets. Ap. J. Lett. 785, 1-4.

Yung, Y., J. Wen, J. Moses, B. Landry, M. Allen, \& K. Hsu (1989) Hydrogen and deuterium loss from the terrestrial atmosphere: A quantitative assessment of nonthermal escape fluxes. J. Geophys. Res. Atmos. 94, 14871-14989.

Zeebe, R., \& D. Wolf-Gladrow (2001) $\mathrm{CO}_{2}$ in Seawater: Equilibrium, Kinetics, Isotopes. Elsevier, Amsterdam. 